\title{
WestVirginiaUniversity
}

THE RESEARCH REPOSITORY @ WVU

Graduate Theses, Dissertations, and Problem Reports

2010

\section{Wireless Sensing System for Load Testing and Rating of Highway Bridges}

Yan Luo

West Virginia University

Follow this and additional works at: https://researchrepository.wvu.edu/etd

\section{Recommended Citation}

Luo, Yan, "Wireless Sensing System for Load Testing and Rating of Highway Bridges" (2010). Graduate Theses, Dissertations, and Problem Reports. 3007.

https://researchrepository.wvu.edu/etd/3007

This Dissertation is protected by copyright and/or related rights. It has been brought to you by the The Research Repository @ WVU with permission from the rights-holder(s). You are free to use this Dissertation in any way that is permitted by the copyright and related rights legislation that applies to your use. For other uses you must obtain permission from the rights-holder(s) directly, unless additional rights are indicated by a Creative Commons license in the record and/ or on the work itself. This Dissertation has been accepted for inclusion in WVU Graduate Theses, Dissertations, and Problem Reports collection by an authorized administrator of The Research Repository @ WVU.

For more information, please contact researchrepository@mail.wvu.edu. 


\title{
Wireless Sensing System for Load Testing and Rating of Highway Bridges
}

\author{
Yan Luo \\ Dissertation submitted to \\ the College of Engineering and Mineral Resources \\ at West Virginia University \\ in partial fulfillment of the requirements \\ for the degree of \\ Doctor of Philosophy \\ in \\ Mechanical Engineering
}

\author{
Samir N. Shoukry, Ph.D., Chair \\ Kenneth H. Means, Ph.D. \\ Jacky C. Prucz, Ph.D. \\ Mourad Riad, Ph.D. \\ Gergis W. William, Ph.D.
}

\section{Department of Mechanical and Aerospace Engineering \\ Morgantown, WV \\ 2010}

Keywords: Wireless Sensor Networks, System Development, Finite Element Analysis, Bridge Load Testing and Rating 


\title{
ABSTRACT \\ Wireless Sensing System for Load Testing and Rating of Highway Bridges
}

\author{
Yan Luo
}

Structural capacity evaluation of bridges is an increasingly important topic in the effort to deal with the deteriorating infrastructure. Most bridges are evaluated through subjective visual inspection and conservative theoretical rating. Diagnostic load test has been recognized as an effective method to accurately assess the carrying capacity of bridges. Traditional wired sensors and data acquisition (DAQ) systems suffer drawbacks of being labor intensive, high cost, and time consumption in installation and maintenance. For those reasons, very few load tests have been conducted on bridges.

This study aims at developing a low-cost wireless bridge load testing \& rating system that can be rapidly deployed on bridges for structural evaluation and load rating. Commercially available wireless hardware is integrated with traditional analogue sensors and the appropriate rating software is developed. The wireless DAQ system can work with traditional strain gages, accelerometers as well as other voltage producing sensors. A wireless truck position indicator (WVPI) is developed and used for measuring the truck position during load testing. The software is capable of calculating the theoretical rating factors based on AASHTO Load Resistance Factor Rating (LRFR) codes, and automatically produces the adjustment factor through load testing data. A simplified finite element model was used to calculate deflection \& moment distribution factors in order to reduce the amount of instrumentation used in field tests. The system was used to evaluate the structural capacity of Evansville Bridge in Preston County, WV. The results show that the wireless bridge load testing \& rating system can effectively be implemented to evaluate the real capacity of bridges with remarkable advantages: low-cost, fast deployment and smaller crew. 


\section{ACKNOWLEDGEMENTS}

It is almost impossible to complete this long journey without the support from my family and friends. First, I would like to thank my parents for their encouragement and support over the years, and my wife for her understanding and love during the hardest period in my life.

I would like to express my deepest gratitude and respect for my advisor, Professor Samir Shoukry, for supporting my research and helping me find an area of intellectual pursuit that fit my abilities and interests well. His endless contribution of ideas and insights resulted in bettering my efforts to design the wireless bridge load testing \& rating system. Having learned under his tutelage helped me to grow both intellectually and as a person.

Many thanks are owed to Dr. Mourad Riad and Dr. Gergis William, who provided me with lots of selfless help and precious experiences in civil engineering and bridges. I would like to thank Professor Michael Palmer for unselfishly sharing with me his encyclopedic knowledge of printed circuit board.

My thanks also go to Mr. Hermman Alcazar and Mr. Joseph Greenfeder for helping me with the field tests. I recall the great fun and experience that I gained when working with Mr. Musat Crihalmeanu. Especial thanks to my friend Joe Watring for some of the best experiences of daily life in Morgantown, WV.

Lastly, I would like to thank the committee members for this research. Each of you has provided me with your valuable time and precious advices and for that I am indebted to you. 


\section{TABLE OF CONTENTS}

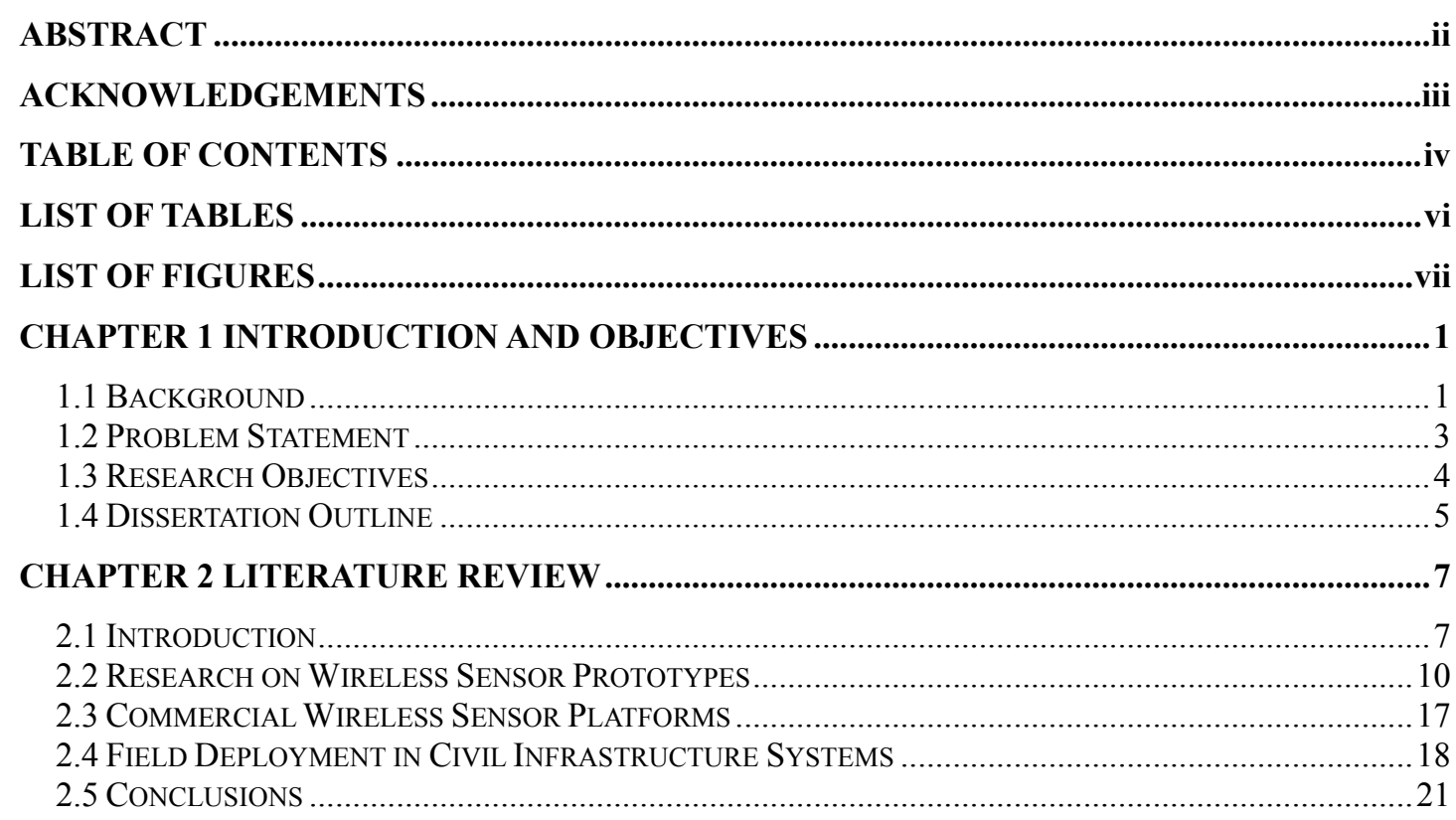

CHAPTER 3 WIRELESS SENSORS AND INSTRUMENTATION .................................................22

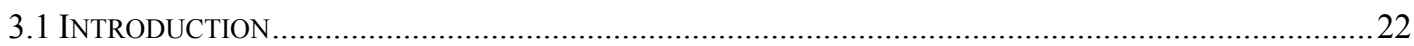

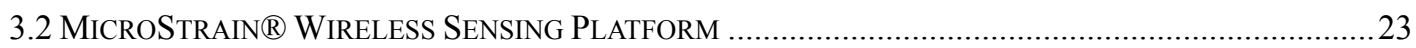

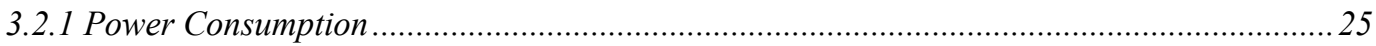

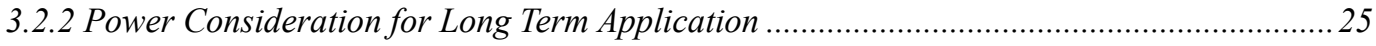

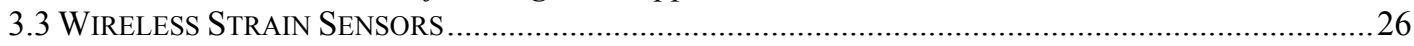

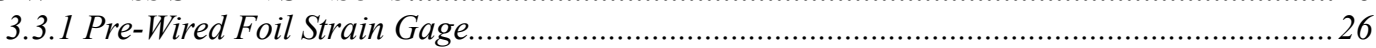

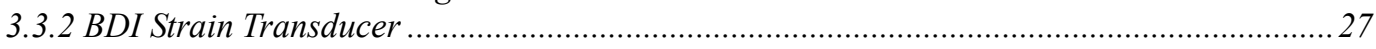

3.3.3 Circuit and Construction of Wireless Strain Sensors.........................................................2 29

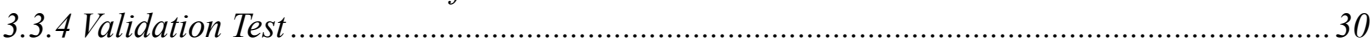



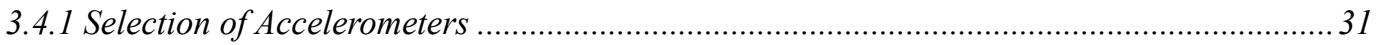

3.4.2 Circuit and Construction of Wireless Accelerometers ........................................................... 33

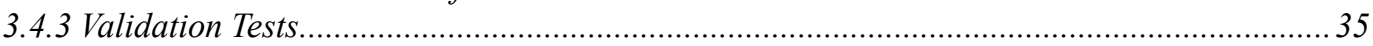

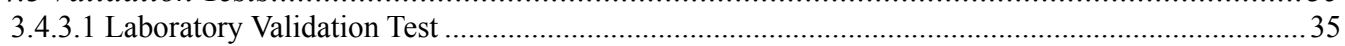

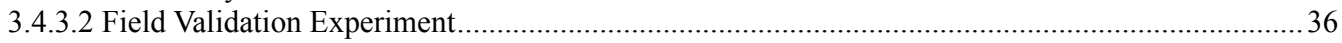



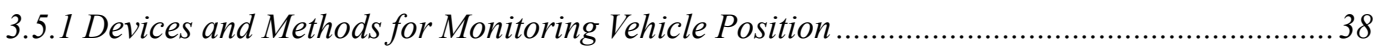

3.5.2 Wireless Vehicle Position Indicator (WVPI) ………...................................................... 40

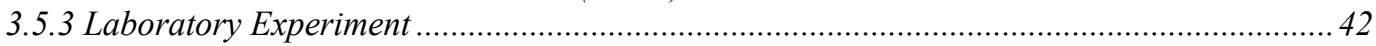

3.5.4 Installation and Calibration in Field Tests................................................................... 44

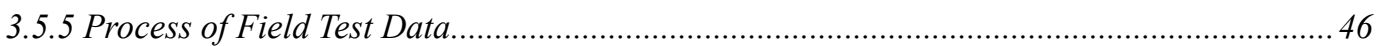

3.5.6 Discussion of Measurement Resolution.......................................................................... 48

CHAPTER 4 SOFTWARE DEVELOPMENT OF WIRELESS BRIDGE LOAD TESTING AND

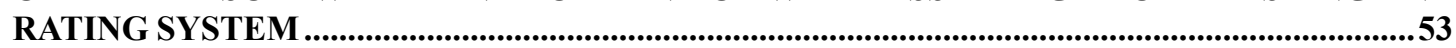

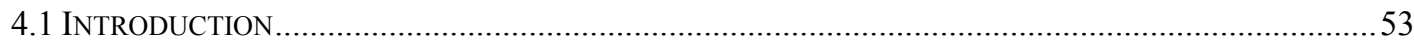

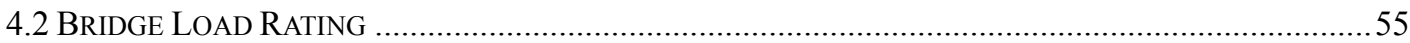

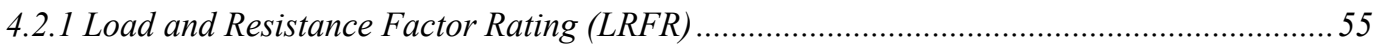

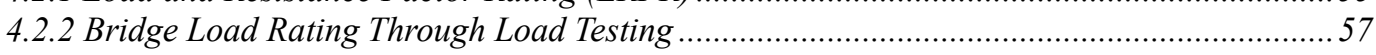

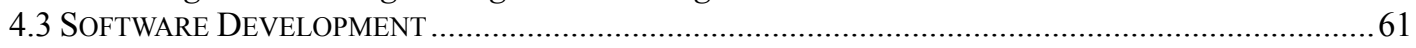

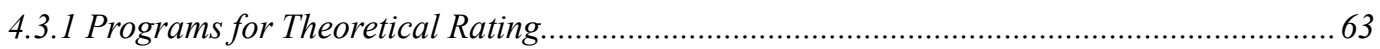




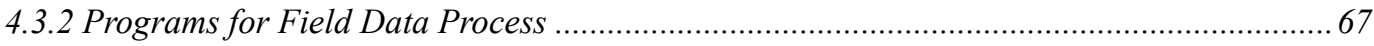

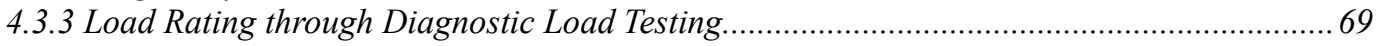

CHAPTER 5 STRUCTURAL MODEL OF EVANSVILLE BRIDGE ............................................71

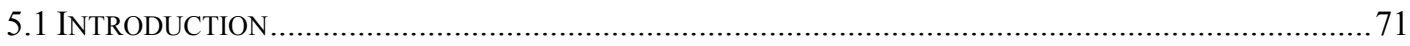

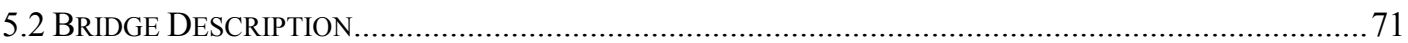

5.3 FINITE ELEMENT MODEL OF EVANSVILLE BRIDGE …............................................................. 72

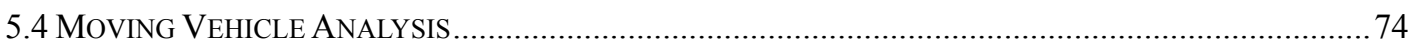

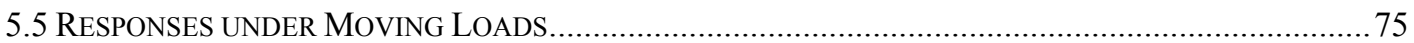

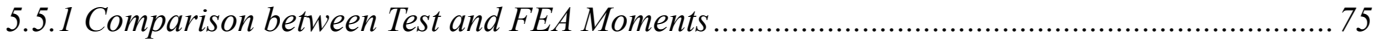

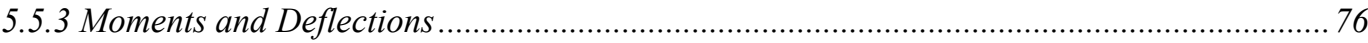

5.6 CALCULATION OF LOAD DiSTRIBUTION FACTORS ................................................................ 79

CHAPTER 6 LOAD TESTING \& RATING OF EVANSVILLE BRIDGE..................................81

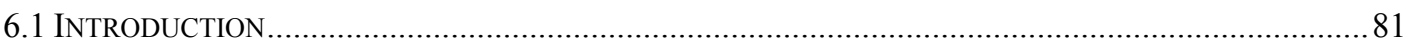

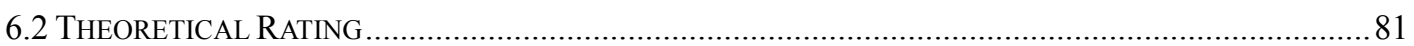

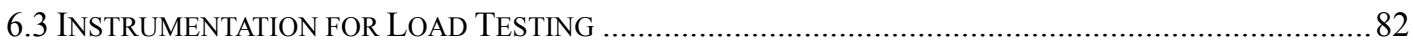

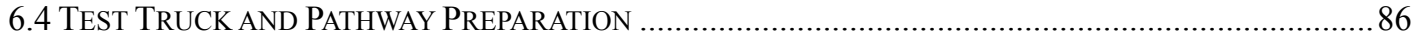



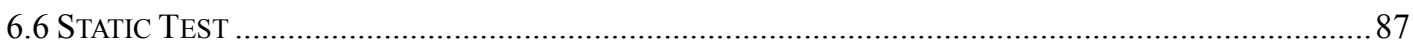

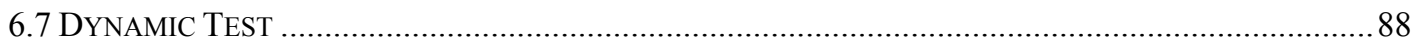

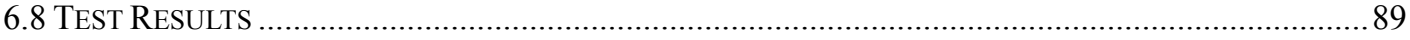

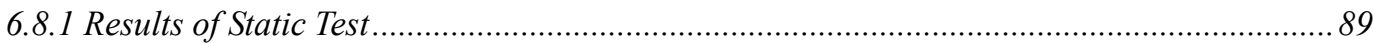



6.10.1.2 Data from Strain Gages and Transducers at Middle Span ........................................................91

6.10.1.3 Data from Strain Gages and Transducers near Pier ................................................................ 97

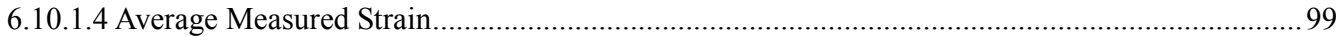

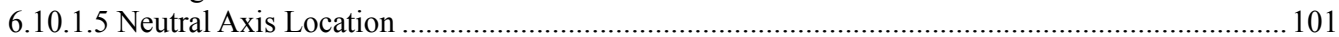

6.10.2 Results of Dynamic Test............................................................................................... 101

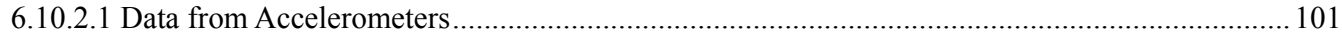

6.10.2.2 Data from Strain Gages and Transducers ............................................................................. 103

6.10.2.3 Deflection through Double Integration of Acceleration ......................................................... 105

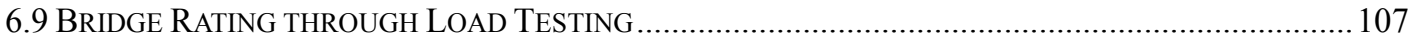

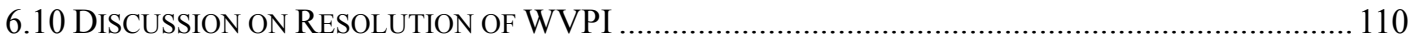

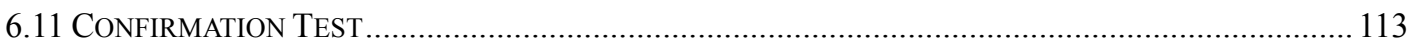

CHAPTER 7 CONCLUSIONS AND RECOMMENDATIONS..................................................... 117

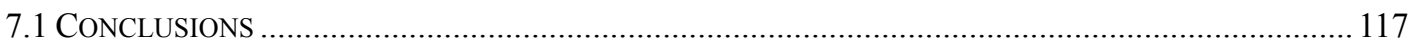

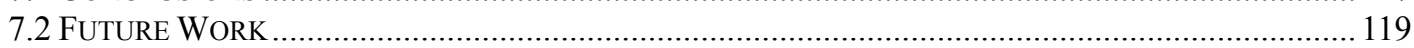

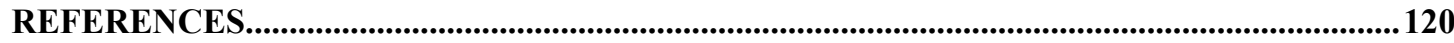

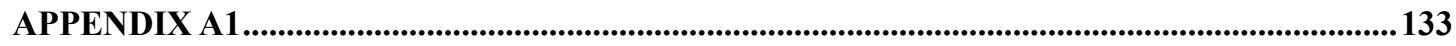

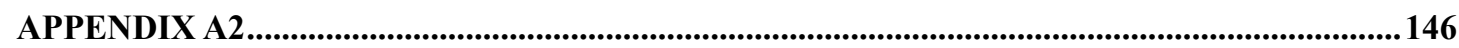



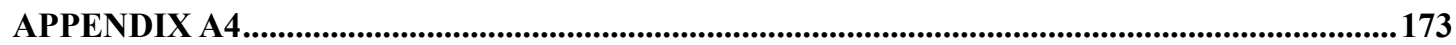

APPENDIX A5 


\section{LIST OF TABLES}

Table 3.1 MicroStrain ${ }^{\circledR} 2.4 \mathrm{GHz}$ wireless nodes (MicroStrain) …..................................................2.

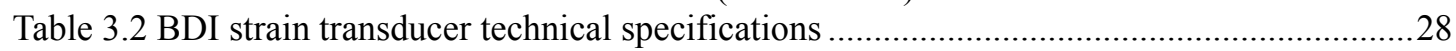

Table 3.3 Comparison of main specifications of the accelerometers ................................................33

Table 3.4 Result comparison of three arrangements of G-Link ${ }^{\circledR}$ nodes .........................................50

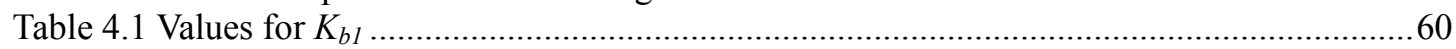

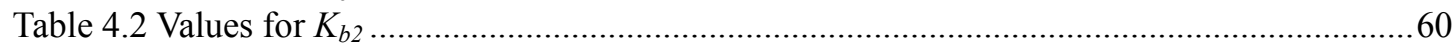

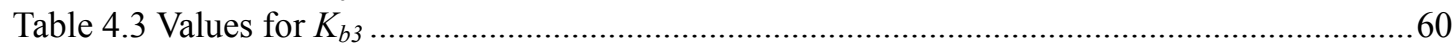

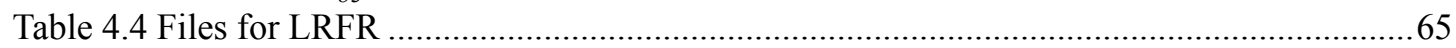



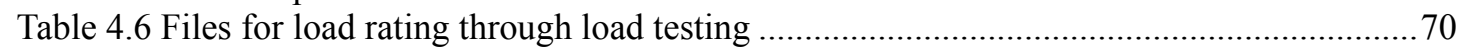

Table 5.1 Material properties of Evansville Bridge (McBride 2005)..............................................73

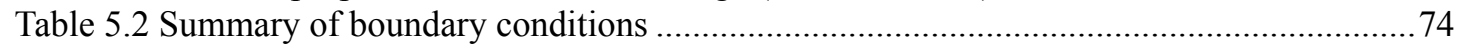

Table 5.3 Distribution factors for moment (one lane loaded) ……..............................................79



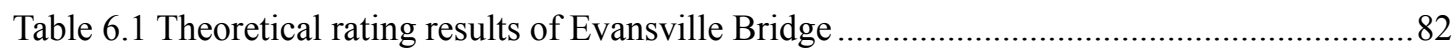

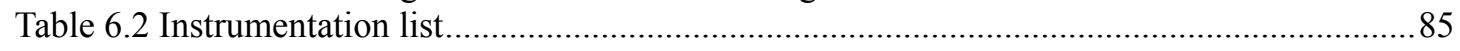

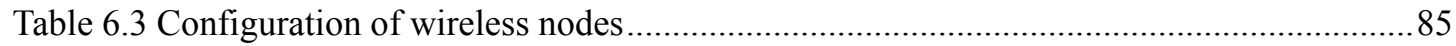

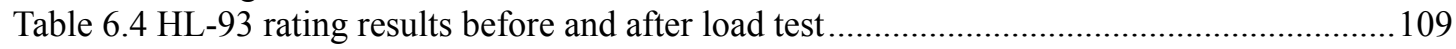

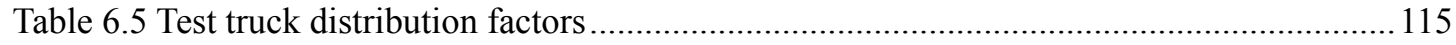

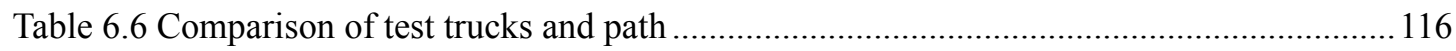

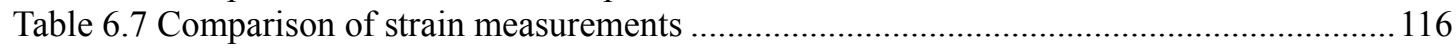

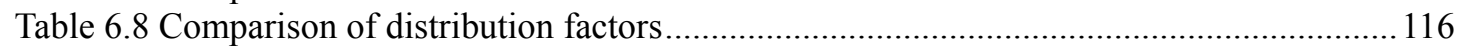

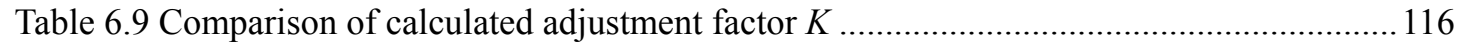




\section{LIST OF FIGURES}

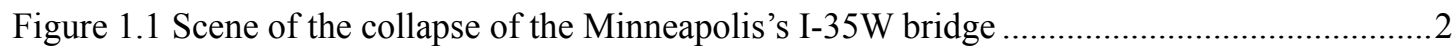

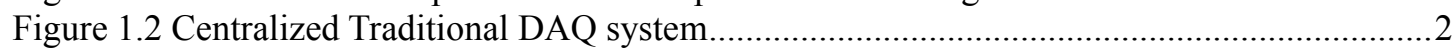

Figure 1.3 Wireless Bridge Load Testing \& Rating System ........................................................

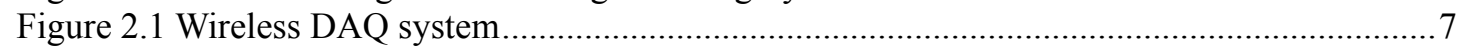

Figure 2.2 Functional subsystems of wireless sensors (Lynch and Loh, 2006) ..............................9

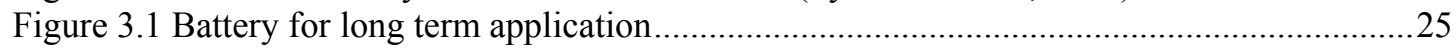

Figure 3.2 Pre-wired strain gage from OMEGA ………......................................................2

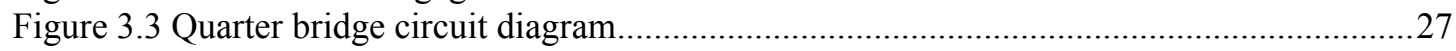

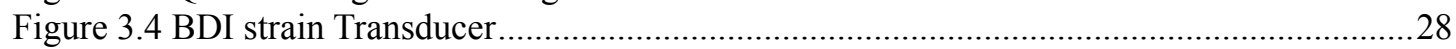

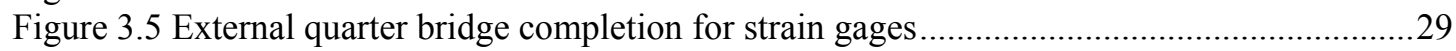

Figure 3.6 Wireless strain sensors and wireless DAQ system ......................................................30

Figure 3.7 Arrangement of strain comparison experiment...........................................................30

Figure 3.8 Comparisons between wired strain and wireless strain ...............................................31

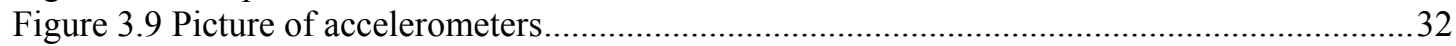

Figure 3.10 Electronic circuitry of the offset device (Kappes and Hauser 1999) ..............................34

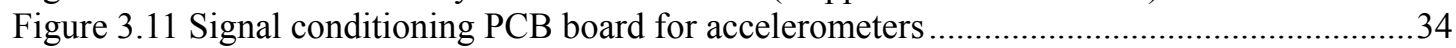

Figure 3.12 Wireless accelerometer and wireless DAQ system.....................................................35

Figure 3.13 Arrangement of acceleration comparison experiment ……………….........................35

Figure 3.14 Comparisons between wired acceleration and wireless acceleration............................36

Figure 3.15 Evansville Bridge steel girder span: (a) side view picture, (b) experiment setup, and (c)

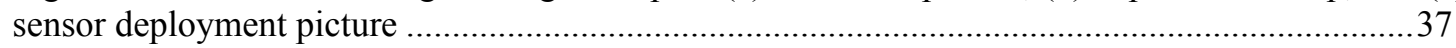

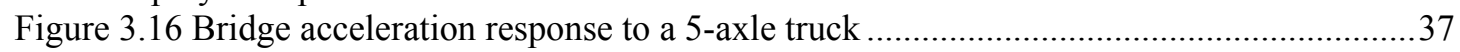

Figure 3.17 Power spectrum corresponding to the acceleration response......................................38

Figure 3.18 Sensitive axes of G-Link ${ }^{\circledR}$ node..............................................................................

Figure 3.19 Using a two-axis accelerometer to measure $360^{\circ}$ of tilt .............................................41

Figure 3.20 Relationship between tile angle and acceleration ....................................................42

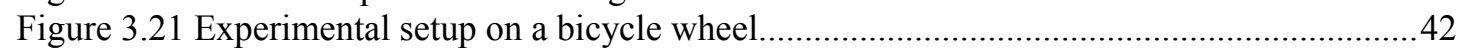

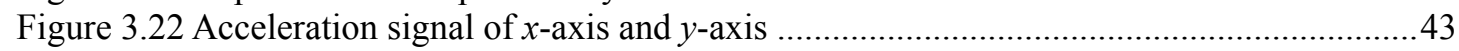

Figure 3.23 Flow chart of measuring the truck position with WVPI ..............................................4

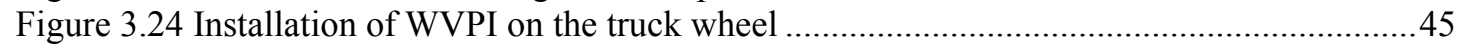

Figure 3.25 Rotation of WVPI and free body diagram ..............................................................45

Figure 3.26 Original data versus denoised data from WVPI .....................................................47

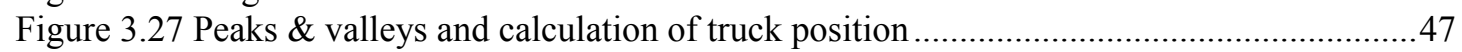

Figure 3.28 Comparison of different arrangements of G-Link nodes ............................................49

Figure 3.29 Division of sub-signal for higher resolution .......................................................50

Figure 3.30 Division of sub-signal into smaller sections ............................................................

Figure 3.31 Modified flow chart of measuring truck positions with WVPI ..................................52

Figure 4.1 Wireless bridge load testing and rating system.........................................................5

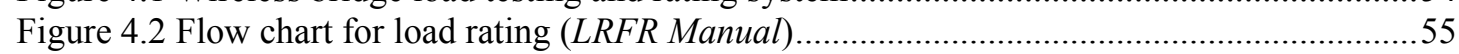

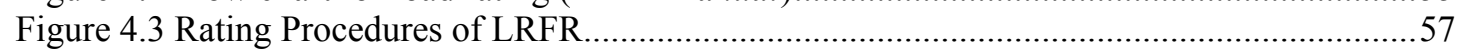

Figure 4.4 Flow chart of bridge load rating through load testing...................................................62



Figure 4.6 Interfaces of bridge rating software using Visual Basic .................................................64

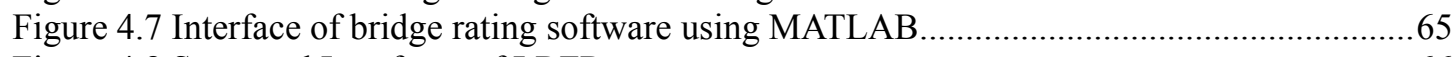

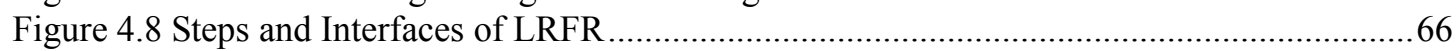

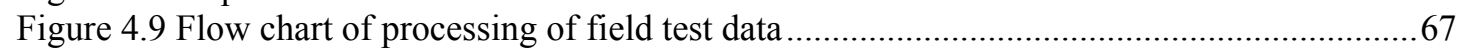

Figure 4.10 Interface of processing of field test data .................................................................6

Figure 4.11 Interface of load rating through load testing results .................................................69

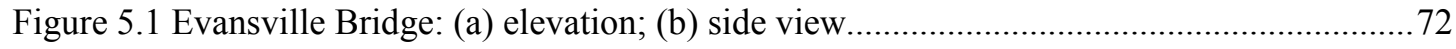

Figure 5.2 SAP2000 model of Evansville Bridge …………....................................................... 


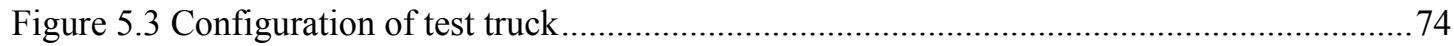



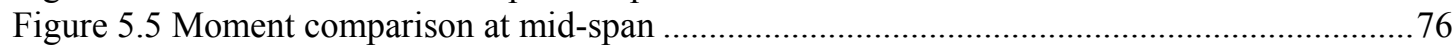

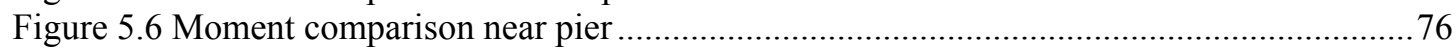

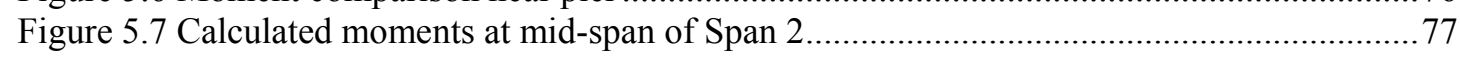

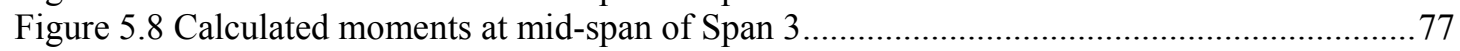

Figure 5.9 Calculated deflections at mid-span of Span 1 ............................................................

Figure 5.10 Calculated deflections at mid-span of Span 2 ……...............................................78

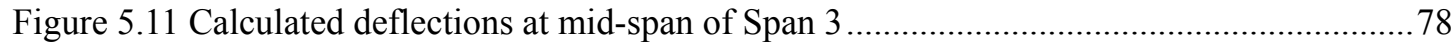

Figure 6.1 Load testing setup of Evansville Bridge: (a) layout (b) side view.................................83

Figure 6.2 Instrumentation for diagnostic load testing on Evansville Bridge.................................. 84

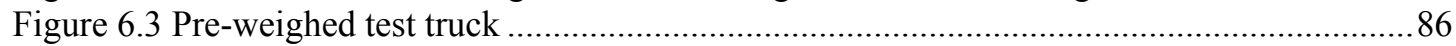

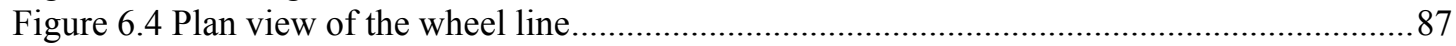

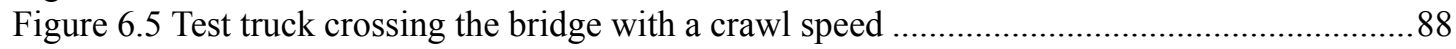

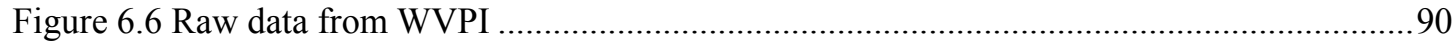

Figure 6.7 Original data versus denoised data from WVPI.............................................................. 90

Figure 6.8 Strain records at $1 / 2$ span of girder 3 (Node 616) .....................................................92

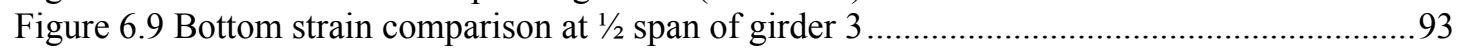

Figure 6.10 Strain records at $1 / 2$ span of girder 3 (truck position domain) ....................................93

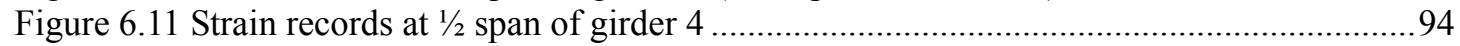

Figure 6.12 Bottom strain comparison at $1 / 2$ span of girder 4 (Node 617).....................................94

Figure 6.13 Strain records at $1 \frac{1}{2}$ span of girder 4 (truck position domain) ...................................95

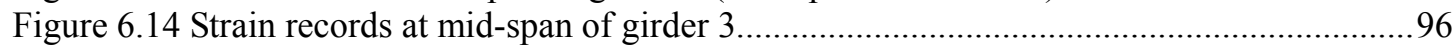

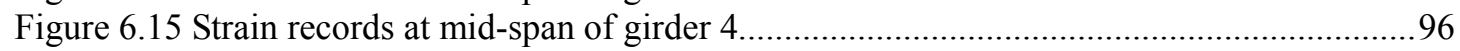

Figure 6.16 Strain records near pier of girder 3 (Node 892) ………………………......................97

Figure 6.17 Strain records near pier of girder 3 (truck position domain)........................................97



Figure 6.19 Strain records near pier of girder 4 (truck position domain)......................................98

Figure 6.20 Average measured strain response ………………………....................................99



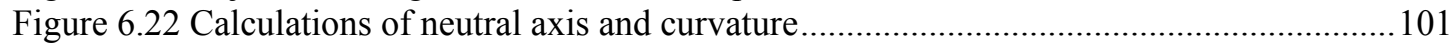

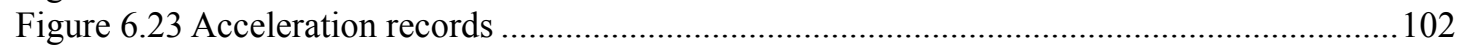

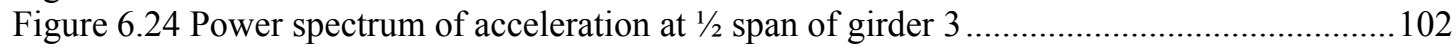

Figure 6.25 Power spectrums of acceleration at different locations .............................................103

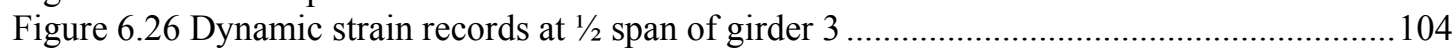

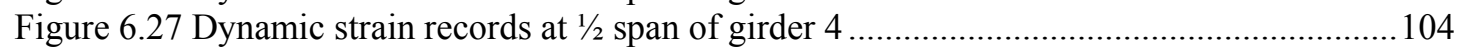



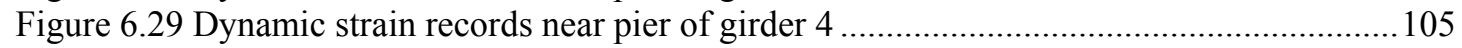

Figure 6.30 Block diagram of double integration of acceleration...................................................106

Figure 6.31 Deflections through double integration of acceleration signals..................................106

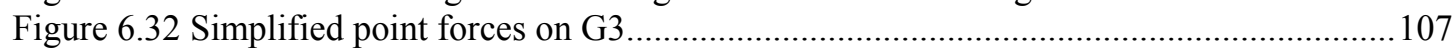

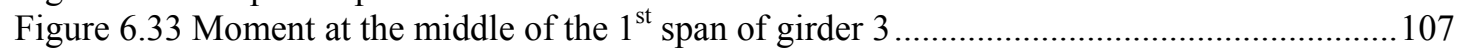

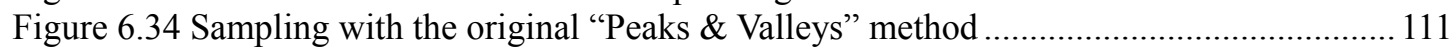

Figure 6.35 Sampling with modified method (interpolation at $30^{\circ}$ ) .............................................. 112

Figure 6.36 Sampling with modified method (interpolation at $10^{\circ}$ ) .............................................112

Figure 6.37 Strain signals in truck position domain with different methods .................................113

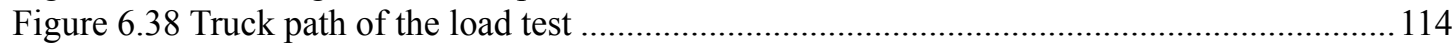

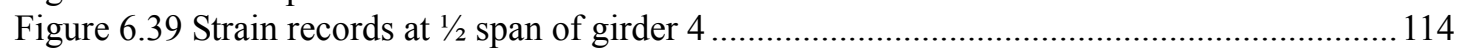

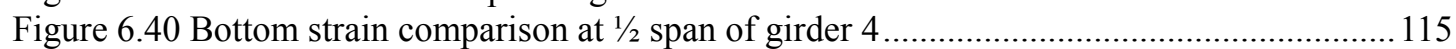




\section{Chapter 1}

\section{Introduction and Objectives}

\subsection{Background}

Civil infrastructure systems, which include bridges and buildings, are of the most expensive assets that countries invest (e.g. estimated at \$20 trillion in the U.S.) (Liu, et al. 2003). Ensuring the safety and reliability of those infrastructure systems is vital for supporting the commerce, economy and social security of a nation. However, because of deteriorating materials, inadequate maintenance, increasing load spectra, environment contamination, or structural damage resulting from different types of natural hazards, conditions of most current civil infrastructures are declining quickly. The deterioration of the civil infrastructure in North America, Europe and Japan has been well documented and publicized. For example, over $50 \%$ of all bridges in the United States were built before 1940, and approximately $42 \%$ of these bridges are reported to be structurally deficient and below established safety standards (Stallings, et al. 2000). In order to protect the public from unsafe bridges, the U.S. federal government requires local transportation authorities to inspect visually the entire inventory of over 590,000 major public bridges at least biannually (Chase 2001 and Memmott 2007). However, there is an inherent drawback for visual inspections: they only consider visible damage on the surface of the structure; damage below the surface is often elusive to the inspectors, therefore bridge inspection can be highly subjective and error-prone. Recently, the U.S. Federal Highway Administration (FHWA) carried out a study on reliability of visual inspection for highway bridges (Moore, et al. 2001). The Minneapolis' I-35W bridge was rated in "poor condition" but still usable before it collapsed on August 1, 2007, killing 13 people and injuring 145 (Webb, 2007). 


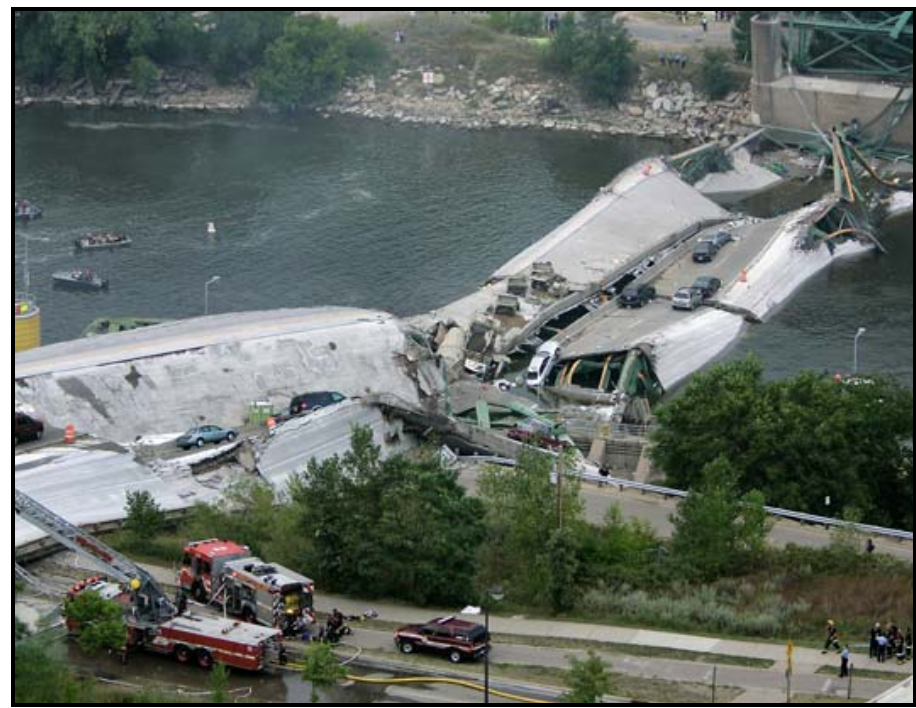

Figure 1.1 Scene of the collapse of the Minneapolis's I-35W bridge

In order to accurately assess safety conditions of existing infrastructure systems, and to identify structural vulnerabilities to extreme events, strong interests in various structural health monitoring technologies have been growing rapidly in recent years (Sohn, et al. 2003). Structural health monitor can provide insights into the real performance of a structure, and offer empirical data for refining structural models and existing building codes. The ability to continuously monitor the integrity and control the response of structures in real time can provide more security for the public, particularly with regard to the aging structures in widespread use today (Spencer, et al. 2004). In order to obtain valuable real-time information about the behavior of a structure or its environmental conditions, various types of sensors, such as accelerometers, displacement transducers, inclinometers, strain gages, thermometers, may be deployed. Traditional structure health monitoring systems are characterized as having instrumentation sensors wire-connected to the centralized data-acquisition (DAQ) system through cables (Figure 1.2).

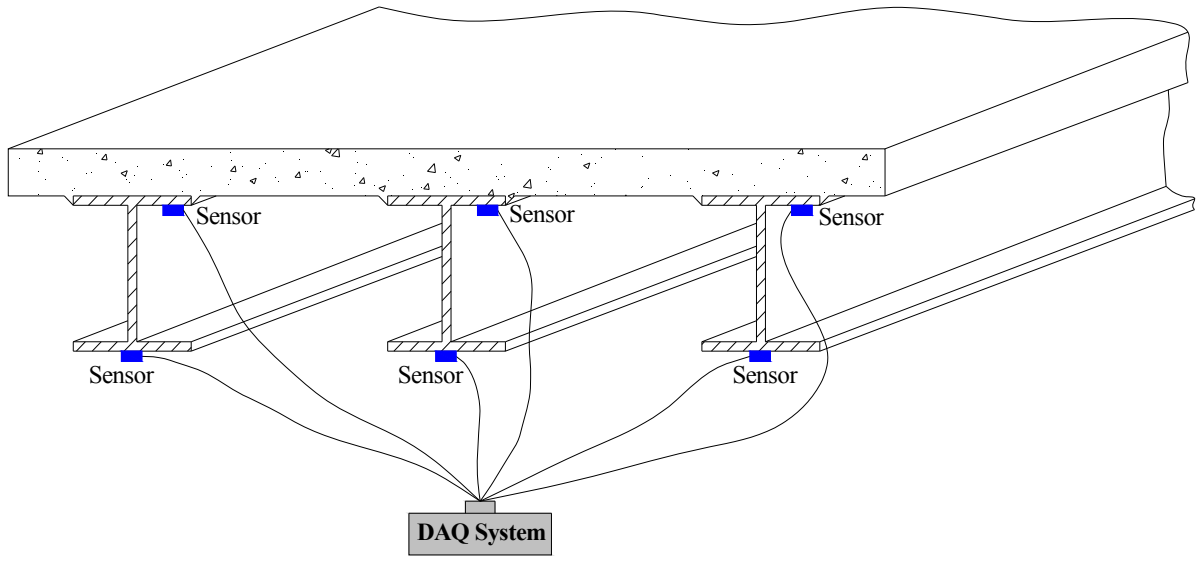

Figure 1.2 Centralized Traditional DAQ system 
Evaluation of bridge is an increasingly important topic in the effort to deal with the deteriorating infrastructure. Major factors causing the present bridge deterioration are age, inadequate maintenance, increasing load spectra, and environmental contamination (Nowak, et al. 1993). As one of the chief causes of bridge fatigue, the heavy truck traffic is growing. It is not only the number of trucks that is increasing, but also their maximum weight. In 1967, the top weight of a truck in the US was 36 tons; today it is 40 tons. There are three and half times as many heavy trucks today as in 1967. Freight traffic on interstate highways is forecast to double over the next 20 years (Webb, 2007). There is a stringent need for accurate and inexpensive methods to determine the actual strength of the bridge, its remaining life, and actual load spectrum.

\subsection{Problem Statement}

The traditional structural monitoring systems make use of conventional sensors, such as strain gages, accelerometers etc., hardwired to data acquisition system or DAQ boards residing in a PC. The drawbacks of such a system include (1) the high cost of installation and disturbance of the normal operation of the structure due to wires having to run all over the structure, (2) the high cost of equipment and (3) high cost of maintenance. By running cables between sensors and the data server, traditional DAQ systems suffer from high installation costs in terms of both time and money. Installing extensive lengths of cables can consume over $75 \%$ of the total structural health monitoring (SHM) system installation time with costs over $25 \%$ of the total system cost (Lynch et al. 2002). Although wired communication provides a reliable dedicated communication link, cable installation can be time consuming and extremely costly (Celebi 2002). As structural monitoring systems grow in size (as defined by the total number of sensors), the cost of the monitoring system can grow faster than at a linear rate. For instance, over 350 sensors have been instrumented on the Tsing Ma suspension bridge in Hong Kong, and the cost of installation is estimated to have exceeded \$8 million. (Farrar 2001). Wired sensors have limited application because they usually need to be installed during construction. The wiring can also be a problem as wires get in the way of the function of the structure and limit the number of sensors that can be deployed (Chang et al. 2003). In addition, vandalism is a potential threat to wired systems. During installation of a cabled 
datalogging system on the Scott Slab Bridge in Shinnston, West Virginia, in March 2009, several cables were stolen. Although this bridge is a short one-span bridge, the installation and cable arrangement were still cumbersome.

A report presented by U.S. Department of Transportation indicated that more than 153,000 bridges in the United States are recorded in the National Bridge Inventory as either structurally deficient or functionally obsolete (Memmott 2007). The key factor contributing to a bridge being classified as structurally deficient is a low load rating. (Load Rating - The determination of the live load carrying capacity of an existing bridge). However, not every structurally deficient bridge is unsafe and needs to be replaced. With proper load posting (Posting - Signing a bridge for load restriction) and enforcement, most structurally deficient bridges can continue to serve traffic safely when restricted to the posted maximum loads. Results from experimental load rating carried by Michael (1997) showed the evaluated bridge has much higher carrying capacity than the posting load levels. The vast majority of bridges are load-rated using theoretical calculations rather than actual testing; therefore, the real load capacity is not known. Theoretical calculations tend to be very conservative, underestimating the capacity of a structure. The objective-based load ratings and their corresponding allowable live loads can greatly exceed the recommended load limit (Lenett et al. 2001). The only way to determine the actual capacity is to perform a load test on the bridge (Washer and Fuchs 1998). Due to the cost involved, very few load tests have been conducted. This lack of actual testing may lead to an inaccurate count of structurally deficient bridges.

\subsection{Research Objectives}

The main objectives of this research are to develop a low-cost wireless bridge load testing and rating system that includes both wireless hardware and software, as shown in Figure 1.3.

The hardware makes use of wireless nodes developed by MicroStrain ${ }^{\circledR}$ (http://www.microstrain.com). The system will include different sensors needed for bridge rating, such as strain gages, accelerometers etc. Development of software interfaces for easy data acquisition \& processing and bridge load rating through testing will be the other important part of this research. The integrated wireless bridge 
load testing and rating system will be validated via laboratory experiments and field tests.
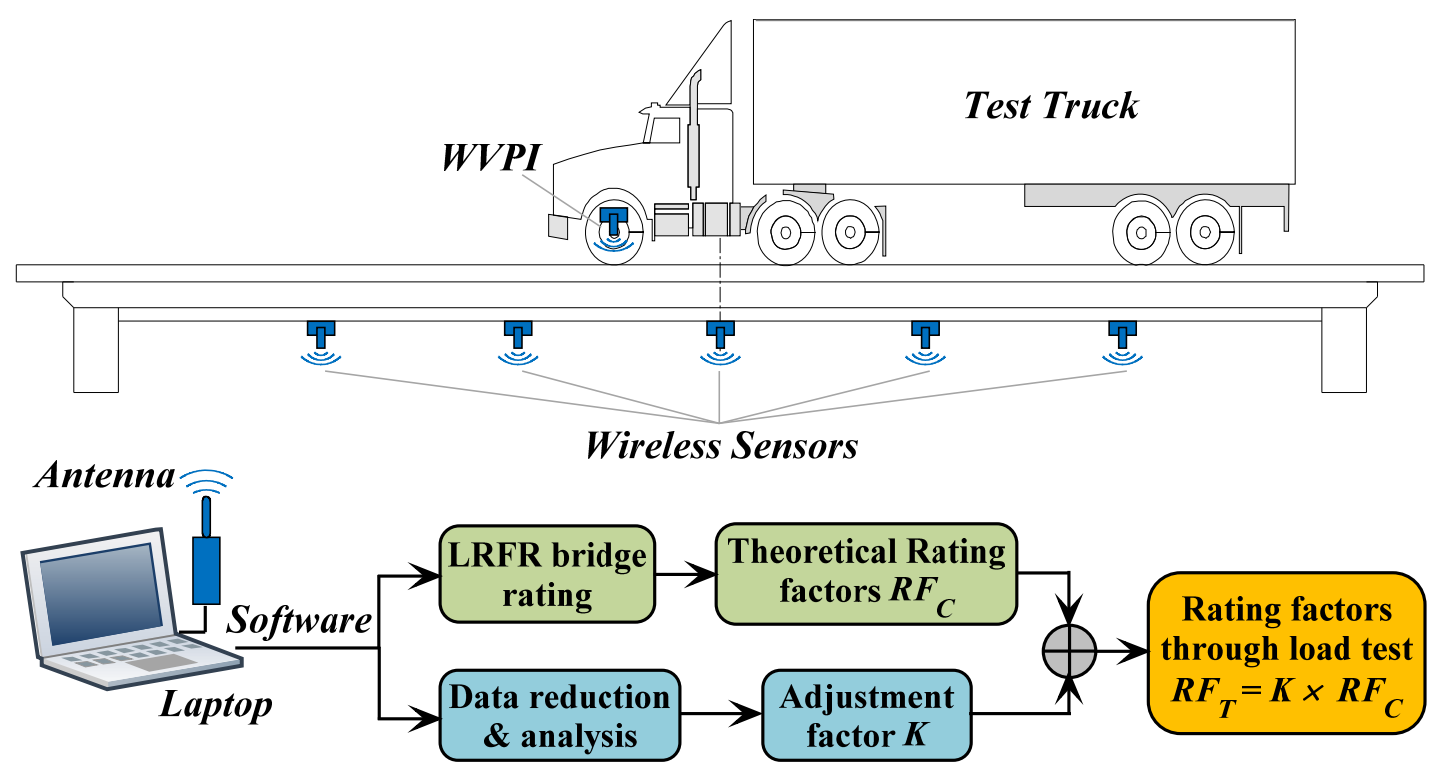

Figure 1.3 Wireless Bridge Load Testing \& Rating System

\subsection{Dissertation Outline}

The methodology followed during this research is described by the work presented in the subsequent chapters and is outlined as follows:

Chapter 2 includes a thorough literature review on the history of wireless monitoring systems developed in the recent decade, including academic wireless sensing prototypes and commercial wireless platforms. Comparison has been made between traditional wired DAQ system and wireless DAQ system. Remarkable advantages of wireless DAQ system have been summarized. Field deployment of wireless monitoring systems in civil infrastructures has also been reviewed.

Chapter 3 provides a detailed description of the development of a wireless data acquisition system for the purpose of bridge load testing and rating. The commercial wireless sensing platform from MicroStrain ${ }^{\circledR}$ has been used to build the wireless system. Architecture and properties of different wireless nodes have been presented. Wireless sensors have been developed by integrating those wireless nodes with sensors, such as strain gages, transducers and accelerometers etc. Corresponding signal conditioners have also been built. An innovative wireless vehicle position 
indicator (WVPI) has been proposed and designed, which will be used to measure vehicle position during the bridge diagnostic load test. Laboratory and field validation tests have been carried out to assess the performance of the wireless sensors and the wireless data acquisition system.

Chapter 4 describes the development of the software for bridge load testing and rating. The software includes three major modules - theoretical rating, field data processing and load rating through load testing. The advanced software makes the cumbersome bridge load rating much easier and faster.

Chapter 5 presents a detailed description of the finite element model of Evansville Bridge for this study. This includes a description of the structural idealization, boundary conditions, material models, loading conditions etc. Moving vehicle analysis have been carried out for the bridge.

Chapter 6 presents the detailed diagnostic load test on Evansville Bridge using the developed wireless bridge load testing \& rating system. The procedures of instrumentation, testing, data processing and interpretation have been described and discussed. Result comparison has been made between finite element analysis and load test. The bridge has been rated through the load testing results. The theoretical rating factors are modified based on the load testing results.

Chapter 7 presents the conclusions and recommendations that are derived from this study. 


\section{Chapter 2}

\section{Literature Review}

\subsection{Introduction}

In recent years, wireless monitoring has become a promising technology that can greatly influence the area of structural health monitoring and infrastructure assessment. For wireless structural monitoring systems, extensive wiring is no longer needed between sensors and the data acquisition system. With the price reduction and rapid developments in the fields of sensors, microelectromechanical systems (MEMS), wireless networks and integrated circuits, the realization of a low cost monitoring system with wireless communication is now possible, which will cut the installation and maintenance cost of DAQ systems for structural health monitoring. (Lynch, et al. 2002, Akyildiz, et al. 2002, Warneke and Pister 2002, Khemapech, et al. 2005). In addition, wireless sensors can play greater roles in the processing of structural response data; this feature can be utilized to screen signs of structural damage. Wireless microsensor networks have been identified as one of the most important technologies for the 21 st century (Chong and Kumar 2003). The structural engineering field has begun to consider wireless monitoring systems as substitutes for traditional wired systems. An architecture view of a wireless DAQ system is shown in Figure 2.1.

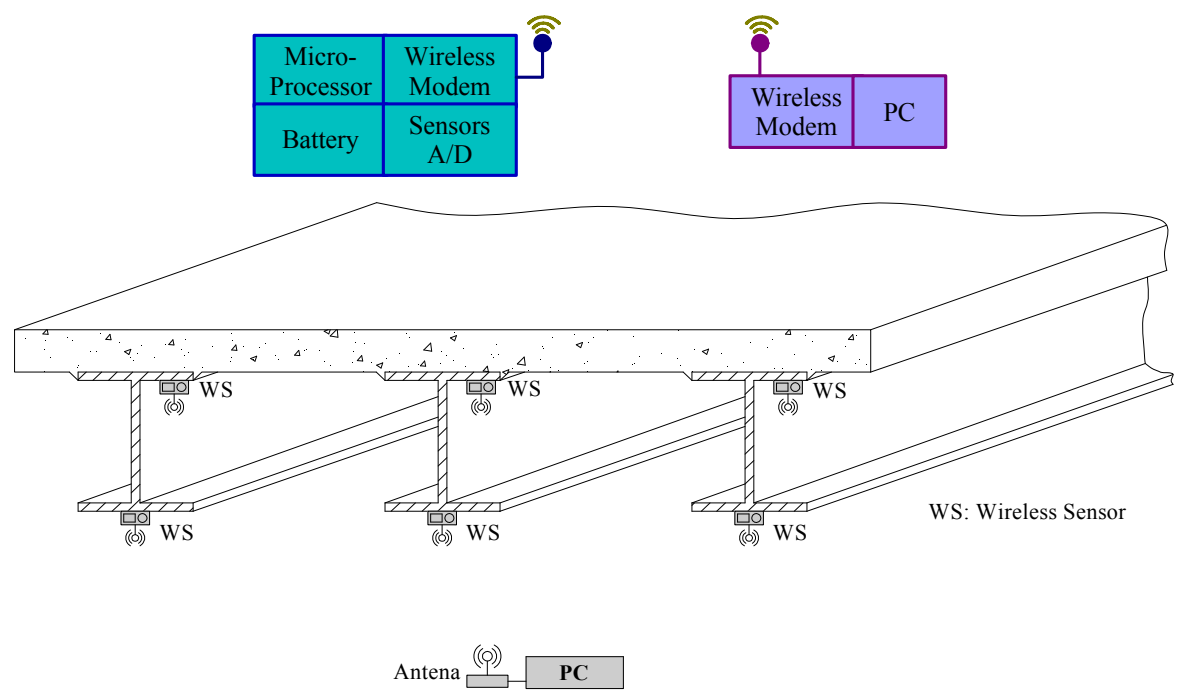

Figure 2.1 Wireless DAQ system 
The wireless monitoring system has remarkable advantages compared to the traditional systems shown in Figure 1.2 (Sohn, et al. 2003):

- Wireless communication can remedy the recurring cabling problem of the traditional monitoring system. Compared to the wired network, installation and maintenance are easy and inexpensive in a wireless sensor network, and the disruption of the operation of the structure is minimal. (Kim, et al. 2007)

- The installation of wireless monitoring system is much faster than the time needed to install the cable-based monitoring system. (Straser and Kiremidjian 1998)

- Embedded microprocessors or microcontrollers can allow the inequity of distributed computational power and data processing.

- MEMS sensors can provide compelling performance with attractive price.

- With the combination of the wireless communication, embedded processors, and MEMS sensors, it is possible to move the data acquisition and a portion of data processing toward the sensors.

In essence, wireless sensors are autonomous data acquisition nodes to which traditional structural sensors (e.g. strain gages, accelerometers, linear voltage displacement transducers, inclinometers, etc.) can be connected. Wireless sensors are best seen as a platform in which mobile computing and wireless communication converge with the sensing transducer (Lynch and Loh 2006). Most of the wireless sensors are passive wireless sensors, which only measure structural response due to static and dynamic loadings as traditional sensors. Some wireless sensors are called active sensors that can interact with or excite a structure when desired (Lynch and Loh 2006).

The fundamental building block of any wireless sensor network is the wireless sensor. All wireless sensors generally have three or four functional subsystems (Lynch and Loh 2006): (1) sensing interface, (2) computational core, (3) wireless transceiver and, for active sensors, (4) an actuation interface. The quality of the sensor interface depends on the conversion resolution, sample rate, and number of channels available on its analog-to-digital converter (ADC). Once measurement data has been collected 
by the sensing interface, the computational core (microcomputer) will take responsibility of the data, where they are stored, processed, and readied for communication. To have the capability to interact with other wireless sensors and to transfer data to remote data repositories, a wireless transceiver is an integral element of the wireless sensor design. Presently in the United Stats, the majority of wireless sensors used in structural monitoring have operated on unlicensed radio frequencies of $900 \mathrm{MHz}, 2.4 \mathrm{GHz}$ and $5.0 \mathrm{GHz}$, which have been designed by the Federal Communications Commission (FCC) as the unlicensed industrial, scientific and medical (ISM) frequency bands. The range of the wireless transceiver is directly correlated to the amount of power the transceiver consumes. For active wireless sensors, there needs an actuation interface built on the digital-to-analog converter (DAC). The DAC converts digital data generated by the microcontroller into a continuous analog voltage output that can be used to excite the structure. One of the major concerns of wireless sensor design is to determine the trade-off between functionality and power consumption, with functionality often coming at the cost of power.



Figure 2.2 Functional subsystems of wireless sensors (Lynch and Loh, 2006)

Lynch and Loh (2006) presented a very detailed summary review of wireless sensors and sensor networks for structural health monitoring. This literature review contains part of the previous review and other research efforts in development of wireless sensors and their implementation in structural health monitoring. 


\subsection{Research on Wireless Sensor Prototypes}

Realizing the high costs associated with wired structural monitoring systems, Straser and Kiremidjian (1998) have proposed the design of a low-cost wireless monitoring system (WiMMS) for civil structures. The wireless sensor approximately $12 \times 21 \times 10 \mathrm{~cm}^{3}$ is made of commercial off-the-shelf components. The Motorola $68 \mathrm{HC} 11$ microprocessor is chosen to control the remote wireless sensing unit because it has many on-chip hardware peripherals and can be programmed using high-level programming languages, e.g. C. The $68 \mathrm{HC} 11$ is mounted upon the New Micros prototyping board NMIT-0022 which features an 8-bit counter, a 16-bit timer, an asynchronous RS-232 serial port, and a $64 \mathrm{~K}$ address space for data and program storage. Additional 32K RAM and 16K ROM are included in order to store embedded firmware for local data processing. A Proxim Proxlink MSU2 wireless modem operating in 902-928 MHz ISM band is used for wireless communication. The wireless modem consumes $135 \mathrm{~mA}$ of current when communicating. It is normally kept in sleep mode where it consumes minimal power (1mA of current). The maximum open space range of the wireless range is approximately $300 \mathrm{~m}$, with a maximum data rate of $19.2 \mathrm{kbps}$. An 8-channel, 16-bit, $240 \mathrm{~Hz}$ Harris H17188IP ADC is used to convert analog signals to digital forms. Their work illustrated both the feasibility and the cost-effectiveness of wireless SHM system. The wireless sensor dose not emphasize power minimization, but it presents the first major step by the structural engineering community towards wireless SHM system.

In order to avoid high costs, pavement damage and unreliable electrical connections cased by installation of cables, Bennett et al. (1999) have proposed the design of a wireless sensing unit intended for embedment in flexible asphalt highway surfaces to record measurement data from two thermometers and two strain gages. In order to accommodate the two strain gages, Wheatstone bridge and amplification circuits are designed. All four analogue signals are fed into an 8-channel analogue multiplexor and then into a 16 bit ADC, ready for processing in real time by the 8-bit Hitachi H8/329 microcontroller, which is programmed via a $\mathrm{C}$-compiler. The radio transmitter is a $418 \mathrm{MHz}$ Radiometrix data link module capable of data rates up to 40 kbps at distances up to $75 \mathrm{~m}$ in-building and $300 \mathrm{~m}$ in open space. For power, a MAX667 voltage regulator is used to regulate $6 \mathrm{~V}$ (four AA $+1.5 \mathrm{~V}$ alkaline batteries) 
to $5 \mathrm{~V}$ voltage for power supply.

Lynch et al. (2001) have proposed a wireless sensor prototype that emphasizes the design of a powerful computational core with minimal power consumption. The 8-bit Atmel AVR AT90S8515 enhanced RISC (reduced instruction set computer) microcontroller is selected because of its low power consumption and high performance characteristics. The AVR microcontroller has a wide variety of on-chip services such as internal oscillators, serial communication transceivers, timers, pulse width modulators (PWM), and four 8-bit input/output ports. The microcontroller also has $8 \mathrm{kB}$ of programmable flash memory, 512 bytes of SRAM (static random access memory), and 512 bytes of EEPROM (electronically erasable programmable read-only memory) to perform local processing and data storage tasks. A low-noise single-channel Texas Instrument 16-bit ADC is used to translate analog signals to a digital format for processing. The high-speed parallel CMOS architecture of the ADC allows the sampling rate to reach $100 \mathrm{kHz}$. Two MEMS (Micro-Electro-Mechanical Systems) accelerometers are used as sensing unit, one is the Analog Device's ADXL210 $\pm 10 \mathrm{~g}$ digital accelerometer and the other is a high performance piezo-resistive planar accelerometer. The Proxim ProxLink MSU2 wireless modem operating on the $902-928 \mathrm{MHz}$ is selected as the wireless communication unit. The wireless sensor approximately $10 \times 10 \times 5 \mathrm{~cm} 3$ consumes $250 \mathrm{~mW}$ when not transmitting data and $900 \mathrm{~mW}$ when using wireless modem.

Mitchell et al. (2002) have proposed a two-tier Web-Controlled Wireless Network Sensors (WCWNS) for SHM. The system is the integration of wireless network sensors and a web interface that allows easy remote access and operation from user-friendly HTML screens. The wireless sensor uses a powerful Cygnal 8051F006 microcontroller which is capable of 25 MIPS and provides $2 \mathrm{~KB}$ of RAM for data storage. An Eriesson Bluetooth wireless transceiver operating on the $2.4 \mathrm{GHz}$ radio band is selected for communication between wireless sensors and wireless data servers. After the wireless sensors collect data, data can then be transferred wirelessly to wireless data servers (cluster nodes). The central server is designed to both store and process the vast amounts of data collected from the cluster's wireless nodes. The cluster node is designed using a single board computer (SBC) running the Microsoft Windows OS. MATLAB is installed in the node for processing measurement data for signs of structural damage. A key characteristic of this wireless system is that 
structural management professionals have the capability to remotely access structural response data, as well as analysis results through World Wide Web.

Kottapalli et al. (2003) have presented a two-tiered wireless sensor network architecture in order to overcome the major challenges associated with time synchronization, data transmitting rates, transmitting range and power efficiency. The lower tier is formed by clusters of sensor units operating on battery power. The upper tier formed by local site masters operating on regular wall power supply with a battery backup. The sensor units transmit data to their respective local site masters and the local site masters route these data to the central monitoring station. The computation core of the wireless sensing unit is an 8-bit Atmel AVR microcontroller with an on-chip 16-bit ADC. Wireless sensing units communicate with their respective local site masters at data rate of $10 \mathrm{Kbps}$ using the BlueChip EVK915 $915 \mathrm{MHz}$ radio transceiver. At the core of the upper tier is an 8-bit Microchip PIC microcontroller that is employed for data storage and local data processing. The Proxim RangeLAN2, used for communication between local site masters, has a data rate of 1.6 Mbps in the 2.4 GHz ISM band and can achieve $300 \mathrm{~m}$ in open range. The RangeLAN2 consumes a large mount of power ( $800 \mathrm{~mW}$ when transmitting or receiving) and requires regular power supply, which limits the applicability of this architecture.

In order to achieve a low-power but computationally rich wireless sensor, Lynch et al. (2003a, 2004a, 2004e) have proposed a dual-processor computation core design based on their earlier wireless sensing unit design (Lynch et al. 2001) by choosing low-power consumption hardware. A low-power 8-bit Atmel AVR AT90S8515 microcontroller is utilized for overall unit operation and real-time data acquisition. When data are ready for local processing, the unit turns on the second microcontroller - the 32-bit Motorola MPC555 PowerPC, which is used for storing and executing the embedded damage detection program. A Texas Instruments ADS7821 16-bit ADC with $10 \mathrm{KHz}$ sampling rate is employed for data collection. For wireless communications, the $2.4 \mathrm{GHz}$ Proxim RangeLAN2 radio modem is selected. A high-energy-density $\mathrm{Li} / \mathrm{FeS}_{2} 7.5 \mathrm{~V}$ battery pack is chosen to supply power to the wireless sensor.

Aoki et al. (2003) have proposed an inexpensive, compact and wireless system, called Remote Intelligent Monitoring System (RIMS). Designed for the purpose of intelligent bridge and infrastructure maintenance, each component is carefully chosen 
to reduce the cost and size while achieving adequate performance. The core microcontroller of RIMS is a Renesas $\mathrm{H} 8 / 4069 \mathrm{~F}$ processor, which is relatively inexpensive and high-speed computing (20 MHz) with an internal 10-bit ADC. In order to enhance the storage capability and perform local computations, an additional 2 MB DRAM (dynamic random access memory) is externally connected. A decent three-axis MEMS piezo-resistance accelerometer (Microstone MA-3) is selected as the sensing unit. The core component of the wireless communication link is the Realtek RTL-8019AS Ethernet controller. Embedded within each wireless sensor is an HTTP manager servelet. The communication range between RIMS and PC/PDA is approximately $50 \mathrm{~m}$. A more recent version of RIMS wireless sensor has been proposed with an improved computational core - the Rabbit 3000 microcontroller offering an internal 12-bit ADC.

Casciati et al. (2003, 2004) present a two-tier design of the wireless structural monitoring system. Intended to collect structural response measurements from accelerometers, the design of the wireless sensing unit is based on the Analog Devices $\mathrm{ADuC} 812$ microsystem. The $\mathrm{ADuC} 812$ is a complete data acquisition system-on-a-chip solution that includes an 8051 microcontroller, $8 \mathrm{kB}$ of flash ROM, an 8-channel 12-bit ADC, and a two-channel 12-bit DAC. The wireless communication subsystem of the wireless sensing unit is based upon the single-channel AUREL XTR-915 RF transceiver operating at $914.5 \mathrm{MHz}$ with a maximum data transmission rate of $100 \mathrm{kbps}$ and low power consumption $(160 \mathrm{~mW}$ maximum). An important component of the wireless sensing unit design is the inclusion of a third-order low-pass anti-aliasing filter whose pass band is adjustable through the ADuC812 microcontroller. The MaxStream 2.4 GHz XStream wireless radio is selected for inter-wireless unit communication. The wireless sensor system can attain a communication range of over $180 \mathrm{~m}$.

Basheer et al. (2003) have proposed the design of a wireless sensor node called the ISC-iBlue to sense strain of the strucutre. The ISC-iBlue has four main components: communication, processing, sensing, and power subsystems. The processing core of the wireless sensor is the ARM7TDMI microcontroller which is low-power with computation capability of 100 MIPS. For wireless communication, the Phillips Blueberry $2.4 \mathrm{GHz}$ Bluetooth wireless radio is chosen for data transmission. 
Wang et al. (2003) have proposed the design of a wireless sensor to record displacement and strain readings from a polyvinylidene fluoride (PVDF) thinfilm sensor. The wireless sensor design is based upon an Analog Devices ADuC832 microsystem. The ADuC832 combines a powerful 8051 microcontroller with a complete data acquisition system on a single integrated circuit chip. To collect data from the PVDF sensor, the ADuC832 provides a 8-channel 12-bit ADC. Also included in the microsystem are two separate 12-bit DACs. Once data are collected, the internal 8-bit 8052 microcontroller is responsible for management of the sensor data. To facilitate the storage and processing of data, the ADuC832 microsystem has $62 \mathrm{~KB}$ of ROM reserved for the storage of executable programs and 256 bytes of SRAM for data storage. For wireless communication, a single-channel half-duplex wireless radio operating on the $916 \mathrm{MHz}$ frequency band is used, which has a range of $150 \mathrm{~m}$ and a data rate of $33.6 \mathrm{kbps}$ (Gu et al., 2004).

Mastroleon et al. (2004) have achieved greater power efficiency by upgrading the original hardware components of the wireless sensor proposed by Kottapalli et al. (2003). In particular, the Microchip PICmicro microcontroller is selected as the computational core because of its low power consumption and high computational performance. Identical to the previous design, the wireless sensor employs the Bluechip RFB915B RF transceiver for wireless communication. For the sensing interface, the 18-bit Maxim MAX1402 ADC is chosen. The MAX1402 is capable of sample rates as high as $480 \mathrm{~Hz}$ and can simultaneously sample sensor data from five channels. Acknowledging the strong dependence upon the ambient temperature of the structure and the accuracy of current damage detection methods, the Maxim DS18S20 digital thermometer is also implemented within the wireless sensing unit design.

Ou et al. (2004) have proposed a new low-power wireless sensor prototype for structural monitoring. Several modules have been constructed using commercial parts, and integrated in to a complete wireless sensor for monitoring temperature and acceleration. The low-power Atmel AVR ATmega8L microcontroller is selected as the computational core. In total, eight sensing channels are provided for the interface of sensors. Six of the channels support the conversion from analog sensor outputs into digital formats with resolutions of 8 and 10 bits. The last two channels are for measuring the output of digital sensors such as the Analog Devices ADXL202E MEMS accelerometer. For wireless communication between wireless sensors, the 
Chipcon CC1000 wireless transceiver is chosen. This radio operates on the $433 \mathrm{MHz}$ radio band and can communicate at a data rate of $76.8 \mathrm{kbps}$.

Shinozuka (2003) and Chung et al. (2004a) have proposed the design of a wireless sensor called DuraNode. The microcontroller subsystem consists of three low-power microcontrollers (two Microchip 8-bit PIC18F8680s and one Freescale HSC12-based 16-bit MC9S12NE64) (Park et al. 2005). The DuraNode contains two accelerometers (Analog Devices ADXL202 and Silicon Design SD1221) for sensing vibrations in the $x, y$, and $z$ axes. A $2.4 \mathrm{GHz} 802.11 \mathrm{~b}$ wireless network interface card is used for wireless communication. The wireless sensor can be powered by a two-cell $4000 \mathrm{mAh}$ Li-Ion battery or an AC adapter. The DuraNode has dimensions of $6 \times 9 \times$ $3.1 \mathrm{~cm}^{3}$.

A new wireless communication standard, IEEE802.15.4, has been developed explicitly for wireless sensor networks (Institute of Electrical and Electronics Engineers, 2003). This wireless standard is intended for use in energy constrained wireless sensor networks because of its extreme power efficiency. Another important aspect of IEEE802.15.4 is that it offers a standardized wireless interface for wireless sensor networks, thereby ensuring compatibility between wireless sensor platforms with different designs and functionalities. Sazonov et al. (2004) have proposed the design of a low-power wireless sensor around the IEEE802.15.4 wireless standard. For wireless communication, their unit employs the Chipcon CC2420 wireless transceiver. IEEE802.15.4-compliant, the radio operates on the $2.4 \mathrm{GHz}$ radio spectrum with a data rate of $250 \mathrm{kbps}$. The radio has a range of 10-75 $\mathrm{m}$ and only consumes $60 \mathrm{~mW}$ when receiving and $52 \mathrm{~mW}$ when transmitting. An ultra-low-power microcontroller MSP430F1611 from Texas Instruments is selected for the computational core. The MSP430F1611 provides the wireless sensing unit with a 6-channel 12-bit ADC and a 2-channel 12-bit DAC. With $2 \mathrm{MB}$ of non-volatile EEPROM, the MSP430F1611 is capable of storing sophisticated data interrogation algorithms. When fully assembled, the proposed low-power wireless sensor is intended to serve as the building block of a wireless intelligent sensor and actuator network (WISAN).

Allen (2004) and Farrar et al. (2004) have described a wireless sensor platform called Husky. Instead of power efficiency, their design emphasizes on ample computational power to perform a broad array of damage detection algorithms within 
the wireless SHM system. The wireless sensor platform uses a standard PC-104 SBC with a $133 \mathrm{MHz}$ Pentium process, $256 \mathrm{MB}$ of RAM, and a $512 \mathrm{MB}$ Compact Flash (CF) card serving as a hard drive. A separate sensing board is designed for interfacing with sensors. On the sensing board, a Motorola DSP56858 digital signal processor (DSP) is used to sample data from six single-channel Maxim ADCs. The maximum rate from simultaneously sampling the six ADCs is $200 \mathrm{~Hz}$. The Motorola neuRFon ${ }^{\mathrm{TM}}$ board utilizing the IEEE 802.15.4 wireless standard is selected for communication. The receiver operates on the $2.4 \mathrm{GHz}$ ISM radio band with a data rate of $230 \mathrm{kbps}$ and an indoor range of $10 \mathrm{~m}$.

Using the latest on-the-shelf components, Wang et al. (2005) have proposed a new design of a low-power wireless sensor that can sample measurement data simultaneously and wirelessly transmit data. A 4-channel 16-bit Texas Instrument ADS8341 is selected as the sensing interface for its low-power consumption and high sample rates $(100 \mathrm{KHz}$ maximum). The computational core is a low-power 8-bit Atmel ATmega128 AVR microcontroller. The microcontroller have $128 \mathrm{~KB}$ of ROM and $4 \mathrm{~KB}$ of SRAM. An additional $128 \mathrm{~KB}$ of SRAM (Cypress CY62128B) is interfaced with the microcontroller for data storage. The MaxStream 9XCite wireless modem is chosen for wireless communication. The modem operates on the $900 \mathrm{MHz}$ radio band and is capable of data rates of $40 \mathrm{kbps}$. The outdoor line-of-sight communication range is up to $300 \mathrm{~m}$. The 9XCite modem only consumes a current of about $50 \mathrm{~mA}$ when transmitting data, or a current of about $30 \mathrm{~mA}$ when receiving data. The wireless sensor is $10 \times 6.5 \times 4 \mathrm{~cm}^{3}$ and powered by five AA batteries.

In order to examine how various hardware design choices and operating conditions would affect the quality of the wireless sensing data, Pei et al. (2005) have designed a highly modular wireless sensor architecture, in which different hardware components can be readily interchanged. The wireless sensor architecture is based on the Motorola 68HC11 microcontroller. The other hardware components, such as interfaced sensors (accelerometers), ADC, and wireless transceivers, can be interchanged for evaluation tests. Two MEMS accelerometers, respectively Analog Devices ADXL105EM-1 and Silicon Design SD2012-005, are integrated. Texas Instruments ADCs with 10-, 12- and 16-bit resolutions are selected. For wireless transmission, MaxStream radios that operate on the $900 \mathrm{MHz}$ and $2.4 \mathrm{MHz}$ frequency bands are chosen. 
Realizing the technical challenges for a wireless sensor network, such as power supply, installation, maintenance, data collection etc., Mascarenas et al. (2008) have proposed a novel "mobile host" wireless sensor network system. The wireless sensor nodes are capable of being powered solely on RF power transmitted to them wirelessly by a mobile host (a commercially available radio-controlled helicopter). After the wireless nodes make peak displacement measurements, the data will be wirelessly transmitted back to the helicopter. The wireless sensor node is called THINNER which is made up of an ATmega128L microcontroller, and AD7745 capacitance-to-digital converter and an XBee radio. The THINNER is unique and specially suited to peak displacement measurement in the absence of a power supply.

\subsection{Commercial Wireless Sensor Platforms}

In recent years, a number of commercial wireless sensor platforms have become available that are well suit for use in SHM applications. By employing a commercial wireless sensor system, there comes immediate out-of-the-box operation, availability of technical support from the platform manufacture, and low unit costs. For this reason, many academic and industrial research teams have begun to explore these generic wireless sensors for use within SHM systems.

One of the popular platforms is the Mote wireless sensor platform initially developed at the University of California-Berkeley and finally commercialized by Crossbow (http://www.xbow.com/) (Zhao and Guibas, 2004). A major reason for the Motes' popularity is that it is an open source wireless sensor platform with both its hardware and software design available to the public. In addition, the Tmote Sky wireless platform marketed by the MoteIV Corporation (http://www.moteiv.com/) is also open source (Whelan et al. 2007).

A number of other commercial wireless sensor platforms have been used for structural monitoring in addition to the Motes, including platforms from Ember (http://www.ember.com/), MicroStrain (http://www.microstrain.com/) and Sensametrics (http://www.sensametrics.com/). In contrast to the Motes, these wireless sensor platforms are proprietary and not open source. 


\subsection{Field Deployment in Civil Infrastructure Systems}

Because bridges and buildings provide complex environments in which wireless sensors can be thoroughly tested, the deployment of wireless sensors in actual civil structures is perhaps the best way to evaluate 000000 the advantages and limitations of this new technology. The researchers have been to assess the performance of a variety of wireless sensor platforms for the accurate measurement of structural acceleration and strain responses. A number of researchers have validated the sensitivity and accuracy of the wireless monitoring systems by comparing the outputs of wireless sensors to that of traditional wired sensor installed alongside their wireless counterparts.

After completing the design of their academic wireless sensor prototype, Straser and Kiremidjian (1998) installed five wireless nodes with MEMS accelerometers along one of the spans on the Alamosa Canyon Bridge. A traditional wired structural monitoring system was parallelly installed to serve as a performance counterpart. It was reported that the installation of the wireless monitoring system is almost five times faster than the time needed to install the cable-based monitoring system. Test and analysis results indicated that the time-history response records from wireless and wired systems are in strong agreement and the calculated modal frequencies of the bridge are identical.

Bennett et al. (1999) have reported a series of field experiments of their wireless device embedded in an asphalt highway surface. Two strain gages are interfaced to the wireless node to measure the tensile strain of the asphalt lower surface, and two thermometers are used to measure the asphalt temperature. The system records the asphalt temperature with an accuracy of $0.2{ }^{\circ} \mathrm{C}$ and strains with resolutions of 5-10 $\mu \varepsilon$.

In order to validate the performance of the wireless sensing prototype, Lynch et al. (2003a) deployed seven wireless sensing units upon an interior span of the Alamosa Canyon Bridge to measure the bridge dynamic response subjected to forced excitations. It was reported that the installation of the wireless monitoring system only takes half the time of the installation of the traditional wired monitoring system. There is strong agreement for time-history signal. For the wireless system, the frequency 
response function (FRF) is calculated by the wireless sensing units using an embedded FFT algorithm.

In order to validate the continuous real-time streaming performance of the wireless sensor platform and assess the capability of the sensors to simultaneously record $2 \mathrm{MB}$ of sensor data in the wireless sensor data bank, Galbreath et al. (2003) demonstrate the use of the MicroStrain SG-Link wireless sensor platform to monitor the performance of a steel girder composite deck highway bridge spanning the LaPlatte River in Shelburne, Vermont. To accurately measure strain, high-resolution differential variable reluctance transducers (DVRTs) are used. The study finds that the effective resolution of the DVRT strain sensor, when interfaced to the wireless sensors, is approximately $1.5 \mu \varepsilon$. When sampled at $2 \mathrm{kHz}$, the resolution of the DVRT sensors is sufficient to identify the passing of trucks over the bridge when viewing the strain time-history records collected.

Aoki et al. (2003) have described the validation of their Remote Intelligent Monitoring System (RIMS) wireless sensor platform by using a flexible light instrumented pole mounted to the surface of the Tokyo Rainbow Bridge, Japan. With fatigue failure common in light poles subjected to frequent excitation, the study is intended to illustrate the potential of the RIMS wireless monitoring system to monitor the long-term health of non-structural components on bridges.

Chung et al. (2004a, 2004b) use two different MEMS accelerometers interfaced to their DuraNode wireless sensing unit to record the ambient and forced response of a $30 \mathrm{~m}$ long steel truss bridge upon the campus of the University of California-Irvine. Results from the field study show very strong agreement in the acceleration time histories recorded by both the wireless and parallel cable-based monitoring systems. Subsequently, a theoretical computer model is created using SAP 2000 in order to compare the theoretical modal frequencies to those obtained from the actual bridge response data.

Binns (2004) has presented a wireless sensor system, WISE (Wireless InfraStructure Evaluation System), developed by researchers at the University of Dayton, Ohio for bridge monitoring. The advantage of WISE, besides the compatibility with any off-the-shelf sensors, is its ability to incorporate an unlimited number of sensor channels in the global monitoring system (Farhey, 2003). 
Time-history records from 16 LVDTs show that the WISE system can accurately measure bridge responses induced by trucks.

Ou et al. (2005) have outlined a series of field experiments using MICA Motes installed in the Di Wang Tower in Guangdong, China. Considering potential susceptibility to vibrations during typhoons, the building is instrumented to investigate its wind response behavior. Acceleration response data collected by the wireless monitoring system matches well with those recorded by a cable-based monitoring system.

Lynch et al. (2005) have installed 14 wireless sensing units to monitor the forced vibration response of the Geumdang Bridge in Korea. The stated goals of the field validation study are to assess the measurement accuracy of the wireless sensing units, to determine the ability of a central data repository to time synchronize the wireless sensor network, and to use the wireless sensors to calculate the Fourier amplitude spectra from the recorded acceleration records.

Kim et al. (2007) employed 64 Crossbow MicaZ Mote wireless sensors over the main span and southern tower of the Golden Gate Bridge. This is the largest wireless sensor network ever installed for structural health monitoring purposes. The goal is to determine the response of the structure to both ambient and extreme conditions and compare actual behavior to design predictions. The wireless sensor network measures ambient structural accelerations from wind load at closely spaced locations, as well as strong shaking from a possible earthquake, all at low cost and without interfering with the operation of the bridge. Except obtaining reliable and calibrated data for analysis, the authors solve a myriad of problems encountered in a real structural deployment in difficult conditions.

Whelan et al. (2007) deployed a large-scale network consisting of 40 channels of sensor measurements acquired through 20 remote wireless transceiver nodes (Tmote Sky wireless platform, MoteIV Corporation) on an integral abutment, single-span bridge in St. Lawrence County, NY. Both quasi-static, similar to load-rating protocol, and dynamic monitoring of the bridge was conducted using a total of 29 MEMS accelerometers and 11 BDI strain transducers. Field deployments have verified the performance of the wireless acquisition system and demonstrated the ability of the system to capture natural frequencies, construct clear modes shapes, and measure 
small amplitude strain responses even for a relatively stiff bridge.

\subsection{Conclusions}

From above summarization of the chronological development of wireless sensor networks, it can be seen that, since the mid-1990s, a number of research teams in both academia and industry have proposed an impressive array of wireless sensor prototypes featuring a wide offering of functionalities. The hardware architecture is a critical element in the design of wireless sensors optimized for monitoring the performance and health of structures. Equally important is the design of embedded software that operates each wireless sensor. Wireless sensor networks are sufficiently mature that many field validation studies have been undertaken. A wide assortment of structures, ranging from aircrafts to bridges, has been utilized to display the means of wireless structural monitoring. However, in many respects, wireless sensor networks are still in their infancy. A remaining limitation of current wireless sensors is the finite energy sources used to power devices in the field. As the field of wireless sensors and sensor networks matures, the technology must continuously be installed in real structures to fully validate performance in the complex field environment.

While the number of unique wireless sensor platforms has continued to rapidly expand, there has been limited success in replicating previous cable-based bridge assessment test programs in regards to the number of deployed sensors and data rates. The sensor networks have generally relied on either local data logging and post-sampling transmission of sensor data or on low sampling rates and/or limited numbers of sensors to achieve real-time transmission (Whelan et al. 2007). Low sampling rates do not matter for collecting data from strain gages, but may encounter problems when acquiring acceleration. Reduced sampling rates may be acceptable for some bridges where there are many low natural frequencies, however, moderately stiff bridges, such as integral abutment and shot-span bridges, necessitate higher sampling rates to capture a sufficient number of modes for analysis.

As the objective-based bridge load rating is getting more important and necessary for assessment of bridge capacity and health, the wireless sensing technology has an enormous potential in this area. None of previous researchers integrated wireless transducer system with LRFR structural capacity evaluation for highway bridges. 


\section{Chapter 3}

\section{Wireless Sensors and Instrumentation}

\subsection{Introduction}

Realizing the need to reduce the costs associated with wired structural monitoring system, Straser and Kiremidjian (1998) have proposed the design of a low-cost wireless modular monitoring system (WiMMS) for civil structures. After that, many other researchers have begun to develop wireless sensing platforms for structural health monitoring applications (Lynch and Loh 2006, Wang 2007). Except academic wireless sensing unit prototypes, a number of commercial wireless sensor platforms (Crossbow: www.xbow.com, Ember: www.ember.com, MicroStrain: www.microstrain.com, Sensametrics: sensametrics.com, MoteIV: www.moteiv.com) have emerged in recent years that are well suited for use in SHM applications. The advantages associated with employing a commercial wireless sensor system include immediate out-of-the-box operation, availability of technical support from the platform manufacturer, and low unit cost. For those reasons, many academic and industrial research teams have begun to explore these generic wireless sensors for use in structural health monitoring (SHM) systems.

For structural health monitoring, the typical measurements include strain, displacement and acceleration. In some cases, the measurements of temperatures, humidity and wind are required in order to quantify the environmental conditions. According to the physical properties of the structures to be monitored, the type and number of sensors, instrumentation plan and others are subsequently decided.

Especially for bridge load testing, the following responses of the bridge are required for monitoring: 1) strain (stresses) in bridge components, 2) relative or absolute displacement of bridge components, 3) relative or absolute rotation of bridge components, and 4) dynamic characteristics of the bridge (Lichtenstein 1998). However, for bridge rating through load testing, the strain records in bridge components are the essential measurements and other measurements do not directly influence the rating factors. 
This chapter describes the hardware development of the wireless DAQ system for bridge load testing based on the MicroStrain ${ }^{\circledR}$ wireless sensing platform. The wireless DAQ system includes wireless strain sensors, wireless accelerometers and wireless vehicle position indicator which is used to monitor the truck position during load testing. Laboratory and filed validation experiments have been conducted in order to evaluation the wireless DAQ system.

\subsection{MicroStrain ${ }^{\circledR}$ Wireless Sensing Platform}

With the capability of wireless, simultaneous, high-speed data acquisition from multiple wireless sensors (strain gages, accelerometers, thermometers, voltage inputs), the MicroStrain wireless sensing platform mainly includes USB Base Station, wireless nodes for different purposes (G-Link ${ }^{\circledR}$, SG-Link ${ }^{\circledR}$, V-Link ${ }^{\circledR}$, TC-Link ${ }^{\circledR}$, shown in Table 3.1), software and Software Development Kit (SDK).

The wireless nodes utilize worldwide IEEE 802.15.4 Direct Sequence Spread Spectrum (DSSS) and work at $2.4 \mathrm{GHz}$ radio frequency. With a 12 -bit A/D convector and a $2 \mathrm{MB}$ on-board memory capable of storing 1,000,000 measurements, the nodes can stream at $4 \mathrm{KHz}$ and datalog at $2048 \mathrm{~Hz}$. There are up to 4 differential channels and 3 single ended inputs $(0-3.0 \mathrm{~V})$ with excitation and signal conditioning. The wireless communication range is line-of-sight $70 \mathrm{~m}$ with the standard antenna and can be extended to $300 \mathrm{~m}$ with a high-gain antenna. With the characteristics of small size, lightweight and low power consumption, the wireless nodes are suitable for applications of short-term testing or long-term monitoring.

Only power consumption and battery choice for long-term application are discussed in the following sections. More information about the MicroStrain $\mathbb{}$ wireless sensing system can be found in Appendix A1. 
Table 3.1 MicroStrain ${ }^{\circledR}$ 2.4GHz wireless nodes (MicroStrain)

\begin{tabular}{|c|c|c|c|c|}
\hline $\begin{array}{l}\text { Node } \\
\text { Type }\end{array}$ & Specifications & Input channels & Dimension & Weight \\
\hline V-Link® & & $\begin{array}{l}4 \text { full differential, } 350 \Omega \text { or higher } \\
\text { (optional bridge completion), } 3 \text { single } \\
\text { ended inputs ( } 0-3 \text { volts) and internal } \\
\text { temperature sensor }\end{array}$ & $\begin{array}{l}88 \mathrm{~mm} \times 72 \mathrm{~mm} \times 26 \mathrm{~mm} \\
72 \mathrm{~mm} \times 65 \mathrm{~mm} \times 24 \mathrm{~mm} \\
\text { (board only) }\end{array}$ & $97 \mathrm{~g}$ \\
\hline SG-Link ${ }^{\circledR}$ & & $\begin{array}{l}1 \text { full differential, } 350 \Omega \text { or higher } \\
\text { (optional bridge completion), } 1 \text { single } \\
\text { ended input }(0-3 \text { volts }) \text { and internal } \\
\text { temperature sensor }\end{array}$ & $\begin{array}{l}58 \mathrm{~mm} \times 49 \mathrm{~mm} \times 26 \mathrm{~mm} \\
47 \mathrm{~mm} \times 36 \mathrm{~mm} \times 24 \mathrm{~mm} \\
\text { (board only) }\end{array}$ & $46 \mathrm{~g}$ \\
\hline G-Link ${ }^{\circledR}$ & & $\begin{array}{l}\text { triaxial MEMS accelerometers } \pm 2 \mathrm{~g} \text { or } \\
\pm 10 \mathrm{~g} \text {, and internal temperature sensor }\end{array}$ & $\begin{array}{l}58 \mathrm{~mm} \times 43 \mathrm{~mm} \times 26 \mathrm{~mm} \\
36 \mathrm{~mm} \times 36 \mathrm{~mm} \times 24 \mathrm{~mm} \\
\text { (board only) }\end{array}$ & $46 \mathrm{~g}$ \\
\hline TC-Link ${ }^{\circledR}$ & 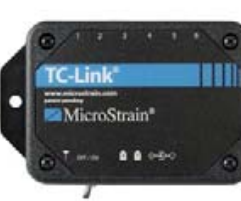 & $\begin{array}{l}\text { six thermocouple inputs, type J, K, R, S, T, } \\
\text { E, B and one CJC channel. Optional relative } \\
\text { humidity sensor. Single channel unit on } \\
\text { request }\end{array}$ & $\begin{array}{l}110 \mathrm{~mm} \times 62 \mathrm{~mm} \times 28 \mathrm{~mm} \\
72 \mathrm{~mm} \times 58 \mathrm{~mm} \times 23 \mathrm{~mm} \\
\text { (board only) }\end{array}$ & $116 \mathrm{~g}$ \\
\hline
\end{tabular}




\subsubsection{Power Consumption}

The MicroStrain ${ }^{\circledR}$ node is normally powered by its internal rechargeable Lithium Ion battery and may also be powered by an external source through changing an internal 2-position power switch. Properties of the internal batteries (Ultralife $\mathbb{R}$ brand 3.7-volt Lithium Ion battery) for different wireless nodes are listed in Appendix A1 Table 1. For example, the internal battery in V-Link ${ }^{\circledR}$ node has a power capacity of $600 \mathrm{mAh}$.

Power consumption on the wireless node is influenced by a wide range of variables including operating mode (sleep, idle, streaming, data logging, low duty cycle), sampling rate $(0.1 \mathrm{~Hz}-2048 \mathrm{~Hz})$ and number of active channels $(1-8$ channels). For instance, when the V-Link ${ }^{\circledR}$ node has one active channel and is in streaming mode, the power consumption rate (indicated by average current) is about $30 \mathrm{~mA}$. It means that the full charged V-Link ${ }^{\circledR}$ node can continuously keeping streaming for about 2 hours (600 mAh / $30 \mathrm{~mA}=2$ hours). The complete power profiles that outline power consumption are documented in tables in Appendix A1.

\subsubsection{Power Consideration for Long Term Application}

As for long term monitoring application, capacity of the internal battery is limited. In this case, external batteries with high capacity are needed. The Tadiran Lithium battery is a good choice for this application. The model TL-5930 has a capacity of 19 Ahr, as shown in Figure 3.1.



Figure 3.1 Battery for long term application

Assumed that a V-Link ${ }^{\circledR}$ node will be used for 5 hours daily under the highest power consumption (average current $30 \mathrm{~mA}$ ), and be kept sleeping (average current $0.20 \mathrm{~mA}$ ) in the rest of time in order to save power. Considering outdoor battery life is 
$3 / 5$ of indoor life (MicroStrain ${ }^{\circledR}$ Application Note, 2007), it can be easily calculated that, the Tadiran TL-5930 battery can last about 2 years indoor and 1.2 years outdoor.

\subsection{Wireless Strain Sensors}

Measuring the strains in structural members is the most direct way to quantify the live-load stresses in a structure. Since strain measurements on bridges are performed under varying environmental conditions, the selection and installation of strain sensors may affect the quality and data reliability.

There are four common types of strain sensors: 1) bondable gages, 2) weldable gages, 3) strain transducers, and 4) vibrating wire gages. All of them have pros and cons, users need to choose based on strain magnitude, strain gradient, environmental conditions, accuracy, filed noise and so on (Lichtenstein 1998).

Considering the instrumentation conditions and easy installation, pre-wired strain gages and BDI strain transducers are used in this research.

\subsubsection{Pre-Wired Foil Strain Gage}

The most widely used strain gage is the bonded metallic strain gage, which consists of a very fine wire and commonly arranged in a grid pattern. Strain gages are available commercially with nominal resistance values from 30 to $3000 \Omega$. Especially, strain gages with 120,350 and $1000 \Omega$ are the most common. In the bridge load testing, the strain levels in components are normally low, in the range of only $50 \mu \varepsilon$ to $150 \mu \varepsilon$, corresponding to 2 to $4 \mathrm{ksi}$ in the steel (Lichtenstein 1998). In this case, strain gages with high resistance $(1000 \Omega$ or $350 \Omega$ versus $120 \Omega)$ is preferable. For these strain gages, careful surface preparation is needed and installation is time consuming. Sometimes, it gets very difficult to solder the wires to the gage tabs.

For easy installation, pre-wired quarter-bridge strain gages from OMEGA with resistance $350 \Omega \pm 2.4 \Omega$ are used. The strain gage has a gage factor $(G F)$ of $2.10 \pm$ $1.0 \%$ with a length of $5 \mathrm{~mm}$. A picture of the strain gage is shown in Figure 3.2. 


\section{Figure 3.2 Pre-wired strain gage from OMEGA}

As for the quarter-bridge completion, as shown in Figure 3.3, there are three dummy resistances, and the voltage output is determined as:

$$
V_{0}=\frac{G F}{4}(\varepsilon) V_{e x}+\frac{G F}{4}\left(\varepsilon^{T}\right) V_{e x}
$$

where, $V_{e x}$ is excitation voltage, $V_{0}$ is output voltage, $\varepsilon$ is the strain value of the gage caused by deformation, $\varepsilon^{T}$ is the additional strain caused by effects of temperature and other factors, and $G F$ is the gage factor. In normal environment, the $\varepsilon^{T}$ can be ignored. Then, the strain value can be obtained as:

$$
\varepsilon=\frac{4 V_{0}}{G F \times V_{e x}}
$$

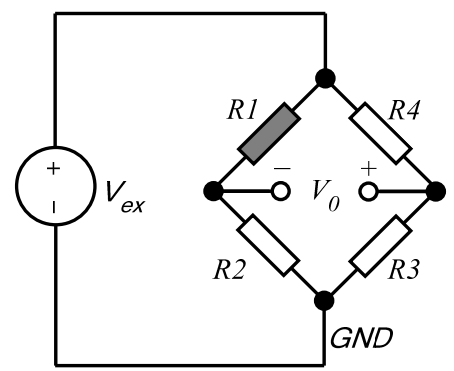

Figure 3.3 Quarter bridge circuit diagram

\subsubsection{BDI Strain Transducer}

Comparing to installation of foil strain gages, which normally needs tedious work such as careful surface preparation and soldering, instrumentation of strain transducers is much easier and faster. Strain transducers are assembled and calibrated in the laboratory, which are sealed for environmental protection with lead wires. The strain transducers are rugged and can be installed in any weather. Normally there is a full-bridge completion in the strain transducer. Figure 3.4 shows a strain transducer from Bridge Diagnostics Inc (http://www.bridgetest.com), which is claimed with the following key features: 
- Easy Installation: Attaches to all types of structural members in about five minutes each.

- High Output: Because of the full-bridge completion, it provides approximately 4 times the output as a typical quarter-arm foil gage installation, which improved signal-to-noise ration.

- Excellent Compatibility: The stain transducers can be used with most data acquisition systems that support full-bridge type sensors.

- Very Cost-Effective: Due to their complete re-usability and the extensive reduction in installation time, the transducers will pay for themselves with just a few uses.

- Field Proven: These sensors have been used over the last two decades for recording millions of strain measurements on all types of structures, often in harsh conditions.



Figure 3.4 BDI strain Transducer

The strain transducer's technical specifications are list in Table 3.2. The sensor can be installed with C-clamps or adhesives, by drilling, or by setting one or more anchors.

Table 3.2 BDI strain transducer technical specifications

\begin{tabular}{l|l}
\hline & \multicolumn{1}{c}{ Technical Specifications } \\
\hline Effective gage length & $76.2 \mathrm{~mm}$ \\
\hline Overall Size & $111 \mathrm{~mm} \times 32 \mathrm{~mm} \times 13 \mathrm{~mm}$ \\
\hline Material & Aluminum \\
\hline Circuit & Full Wheatstone bridge with 4 active $350 \Omega$ foil gages, 4-wire hookup \\
\hline Accuracy & $\pm 2 \%$, individually calibrated to NIST standards \\
\hline Strain Range & Aluminum: $\pm 4000 \mu \varepsilon$ \\
\hline Sensitivity & Approximately $500 \mu \varepsilon / \mathrm{mV} / \mathrm{V}$ \\
\hline Weight & Approximately $85 \mathrm{~g}$ \\
\hline Environmental & Built-in protective cover, also water resistant \\
\hline Temperature Range & $-50{ }^{\circ} \mathrm{C}$ to $120^{\circ} \mathrm{C}$ \\
\hline Attachment Methods & Mounting tabs \& adhesive, C-Clamps, masonry or wood screws \\
\hline
\end{tabular}




\subsubsection{Circuit and Construction of Wireless Strain Sensors}

The V-Link ${ }^{\circledR}$ and SG-Link ${ }^{\circledR}$ nodes can be hooked up with quarter, half and full bridge strain gages. However, for the quarter and half bridge strain gages, the nodes should be ordered with optional on-board bridge resistors. Otherwise, the completion of the bridge must be completed externally.

In order to compare the signal quality, two out of four $\mathrm{V}$-Link ${ }^{\circledR}$ nodes were equipped with on-board quarter-bridge completion. For the other two nodes, the external bridge completion circuits were built, as shown in Figure 3.5 Because of the use of metal foil strain gages with a nominal resistance of $350 \Omega$, the strain gage circuit proposed in this research was designed with $350 \Omega 0.1 \%$ resistors on three sides of the bridge circuit. There are two circuits for two gages in one box, because normally there are two strain gages respectively installed on the top and bottom flanges of the target bridge at the same location.

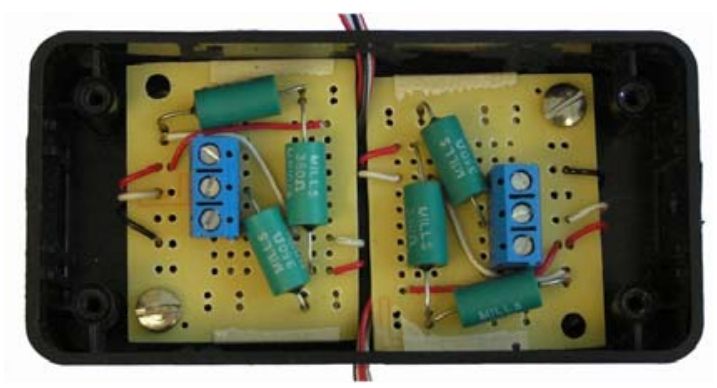

Figure 3.5 External quarter bridge completion for strain gages

As for the full bridge sensor, such as the BDI strain transducer, it can be connected directly with the wireless node. The configuration and connection between strain gages and wireless nodes are described in Appendix A1.

The wireless strain sensors are formed as the strain sensors are connected to the wireless nodes, as shown in Figure 3.6. Through the antenna hooked up with the laptop, control commands are wirelessly transmitted to the sensors for configuration, data acquisition, and data downloading and so on. 

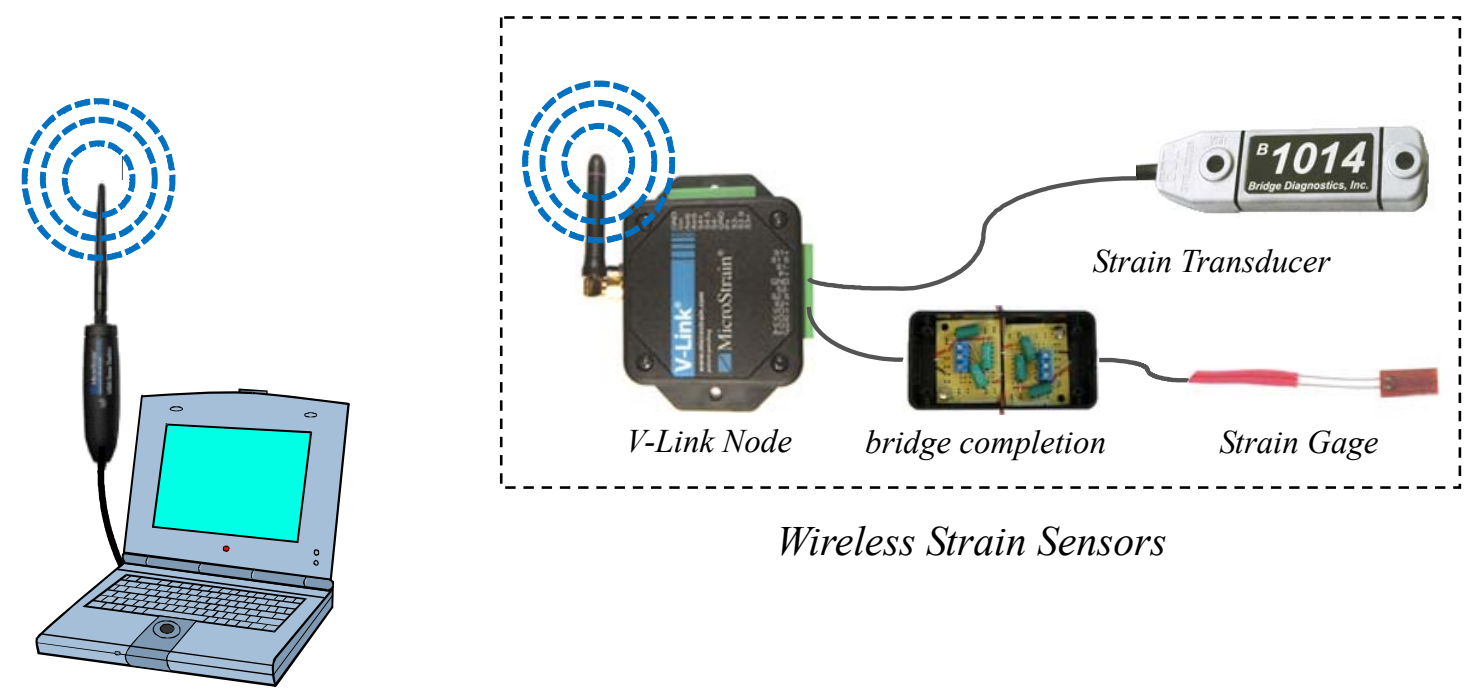

Wireless Strain Sensors

Figure 3.6 Wireless strain sensors and wireless DAQ system

\subsubsection{Validation Test}

Several validation tests have been carried out in order to assess the performance of the wireless sensors and data acquisition system. Wireless sensors are installation alongside their wired counterparts, the sensitivity and accuracy of the wireless DAQ system can be assessed from comparison of these results.

Two strain gages, with nominal resistances of $350 \Omega$ and gage factor of 2.1 , were attached parallelly at the same location on a cantilever beam, as shown in Figure 3.7. One strain gage was connected to the MicroStrain ${ }^{\circledR}$ V-Link ${ }^{\circledR}$ node through an external quarter-bridge completion. The other one was connected to the Strain Indicator and Recorder from Vishay Micro-Measurements ${ }^{\circledR}$, which can record the strain with the highest frequency at $1 \mathrm{~Hz}$. If only bending moment is applied to the beam, the outputs from the two strain gages should have the same value.

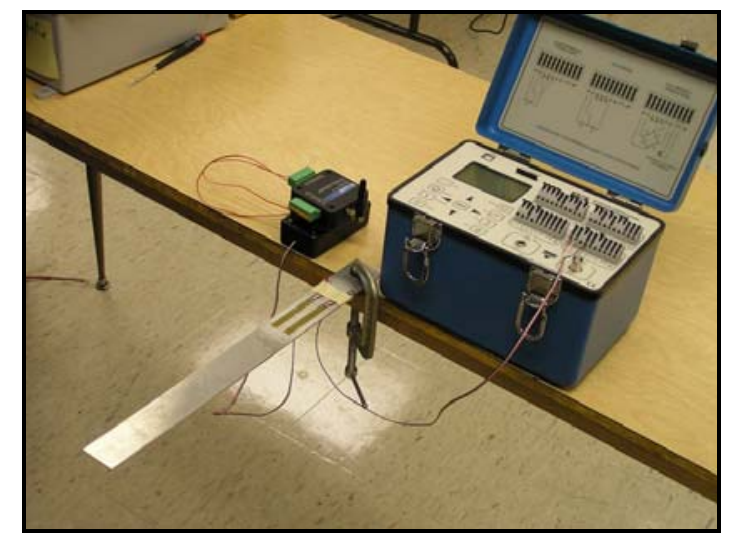

Figure 3.7 Arrangement of strain comparison experiment

The beam was excited at the free end with a very low frequency (around 4 cycles per minute). Strains were recorded through wired system and wireless system. The 
strain recorder recorded the strain at $1 \mathrm{~Hz}$. The wireless system recorded the data at $256 \mathrm{~Hz}$. The synchronized records acquired by wired and wireless DAQ systems are shown in Figure 3.8. As it can be seen, the time history response measured by the wireless acquisition system matches well with that measured independently by the cable-based acquisition system.
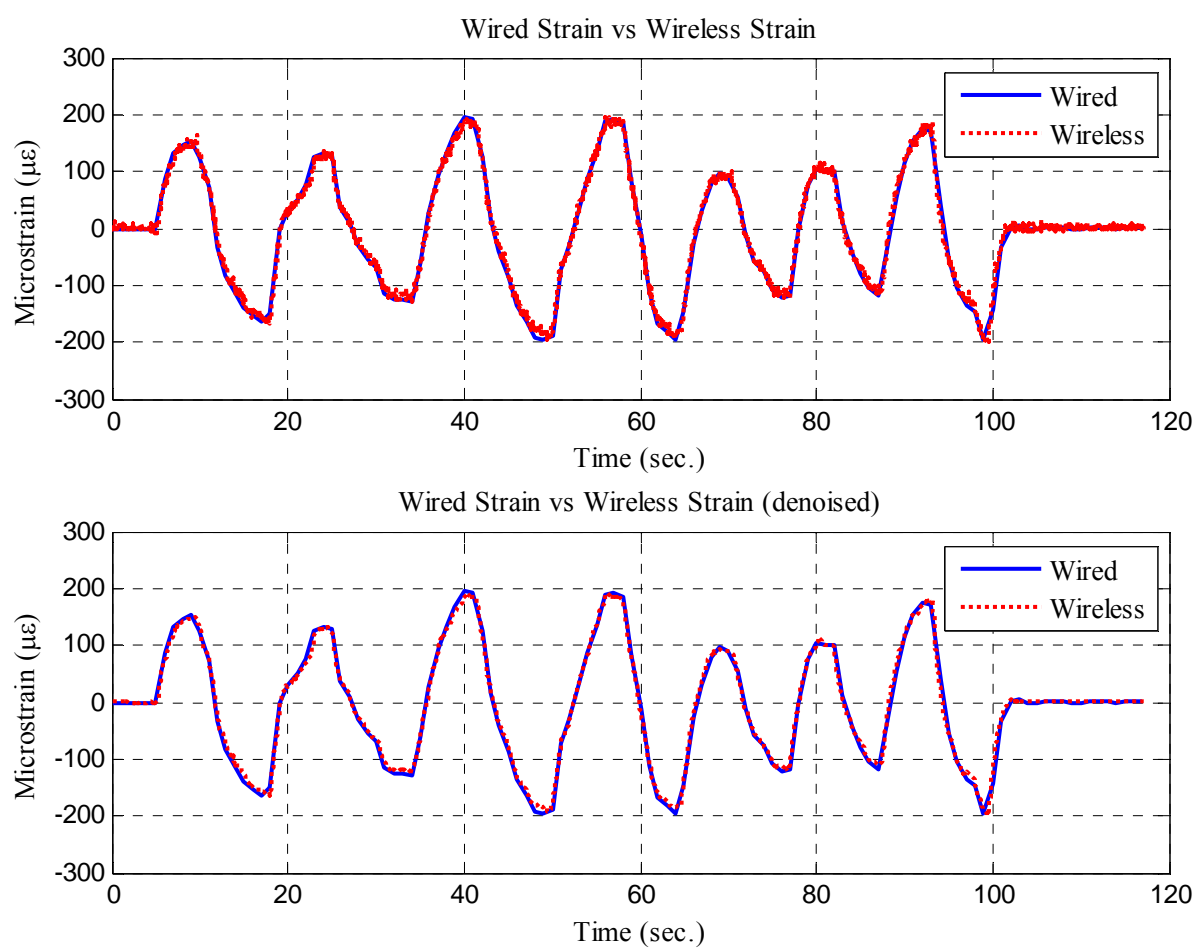

Figure 3.8 Comparisons between wired strain and wireless strain

\subsection{Wireless Accelerometers}

Normally, accelerometers are used to measure the dynamic response of structures. There are several types of accelerometers including piezoelectric, capacitive or force-balanced (servo). Compared with other kinds of accelerometers, such as piezoelectric, MEMS sensors, force-balanced (servo) accelerometers provide high accuracy and a high-level output at a relatively high cost, and can be used for very low measuring ranges (well below $1 \mathrm{mG}$ ). Force-balanced accelerometers are very suitable for dynamic testing of large structures, such as bridges, building, dams, whose natural frequencies are very small.

\subsubsection{Selection of Accelerometers}

There accelerometers have been evaluated. They are PCB seismic accelerometer 
(Model\# 393B31), ENDEVCO seismic accelerometer (Model\# 86), and force balance accelerometer from Columbia Research Laboratories (Model\# SA-107LN).

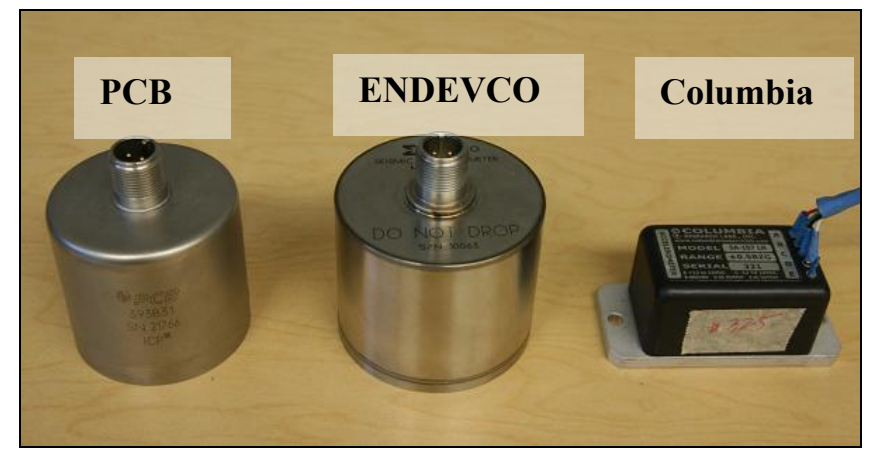

Figure 3.9 Picture of accelerometers

$\mathrm{PCB}$ and ENDEVCO accelerometers are piezoelectric and feature a $10 \mathrm{~V} / \mathrm{g}$ sensitivity and near-DC frequency response. Columbia accelerometer is force-balanced and features a $10 \mathrm{~V} / \mathrm{g}$ sensitivity and DC-100 Hz frequency range. The Columbia accelerometer has better capacity than the other two in very low frequency events $(0-1 \mathrm{~Hz})$. Especially for big structures, such as long bridges, where the vibration frequencies are very low, the force-balanced accelerometers are widely used (Cunha and Caetano, 2006). The major specifications of the three accelerometers are compared in Table 3.3. Because of the better performance in low-frequency applications, the Columbia accelerometers are chosen for this research.

The accelerometers from Columbia Research Laboratories are force-balanced with customary configurations. This accelerometer is a high-sensitivity and low noise sensor designed for use in seismic and low level, low frequency motion studies, which is common in the bridge dynamic response. The Columbia Model SA-107LN accelerometer is self-contained and provides a high level, low impedance output. No signal conditioning is required in most applications. 
Table 3.3 Comparison of main specifications of the accelerometers

\begin{tabular}{|c|c|c|c|}
\hline $\begin{array}{c}\text { Technical } \\
\text { Specifications }\end{array}$ & Columbia & PCB & ENDEVCO \\
\hline Excitation & $\begin{array}{c} \pm 12 \text { to } \pm 15 \text { VDC }, 10 \\
m A \max \end{array}$ & $\begin{array}{c}\text { No need for power } \\
\text { supply }\end{array}$ & $\begin{array}{c}\text { No need for power } \\
\text { supply }\end{array}$ \\
\hline $\begin{array}{l}\text { Signal } \\
\text { Conditioning }\end{array}$ & No need & Need & Need \\
\hline Range & $\pm 0.5 \mathrm{G}$ & $\pm 0.5 \mathrm{G}$ & $\pm 0.5 \mathrm{G}$ \\
\hline Details & $\begin{array}{l}\text { Ultra low noise } \\
\text { (Seismic) }\end{array}$ & $\begin{array}{l}\text { Ultra low noise } \\
\text { (Seismic) }\end{array}$ & $\begin{array}{l}\text { Ultra low noise } \\
\text { (Seismic) }\end{array}$ \\
\hline Overall Accuracy & $\pm 0.15 \%$ & & \\
\hline Output & $\pm 5 \mathrm{~V}$ & $\pm 5 \mathrm{~V}$ & $\pm 5 \mathrm{~V}$ \\
\hline Scale Factor & $10 \mathrm{~V} / \mathrm{G}$ & $10 \mathrm{~V} / \mathrm{G}$ & $10 \mathrm{~V} / \mathrm{G}$ \\
\hline $\begin{array}{l}\text { Response } \\
\text { Frequency Range }\end{array}$ & $\mathrm{DC}$ to $100 \mathrm{~Hz}$ & $0.1-200 \mathrm{~Hz}$ & $0.01-200 \mathrm{~Hz}$ \\
\hline Natural Frequency & $150 \mathrm{~Hz}$ & $700 \mathrm{~Hz}$ & $370 \mathrm{~Hz}$ \\
\hline Output Noise & $\begin{array}{c}<2.5 \mu \mathrm{V} \text { RMS from } \\
0 \text { to } 50 \mathrm{~Hz}\end{array}$ & $\begin{array}{cc}0.06 \mu \mathrm{g} / \sqrt{ } \mathrm{Hz} & (1 \mathrm{~Hz}) \\
0.01 \mu \mathrm{g} / \sqrt{ } \mathrm{Hz} & (10 \mathrm{~Hz}) \\
0.004 \mu \mathrm{g} / \sqrt{ } \mathrm{Hz} & (100 \mathrm{~Hz})\end{array}$ & $\begin{array}{c}0.03 \mu \mathrm{g} / \sqrt{ } \mathrm{Hz} \quad(0.5 \mathrm{~Hz}) \\
0.02 \mu \mathrm{g} / \sqrt{ } \mathrm{Hz} \quad(1 \mathrm{~Hz}) \\
0.0035 \mu \mathrm{g} / \sqrt{\mathrm{Hz}}(10 \mathrm{~Hz}) \\
0.0025 \mu \mathrm{g} / \sqrt{ } \mathrm{Hz} \quad(100 \mathrm{~Hz})\end{array}$ \\
\hline Temperature Range & $-40^{\circ} \mathrm{C}$ to $80^{\circ} \mathrm{C}$ & $-18^{\circ} \mathrm{C}$ to $65^{\circ} \mathrm{C}$ & $-10^{\circ} \mathrm{C}$ to $80^{\circ} \mathrm{C}$ \\
\hline Size & $\begin{array}{c}78.5 \mathrm{~mm} \times 35.1 \mathrm{~mm} \\
\times 34.1 \mathrm{~mm}\end{array}$ & $\begin{array}{l}57.2 \mathrm{~mm} \times 71.1 \mathrm{~mm} \\
(\text { Diameter } \times \text { Height })\end{array}$ & $\begin{array}{l}64.8 \mathrm{~mm} \times 72.4 \mathrm{~mm} \\
(\text { Diameter } \times \text { Height })\end{array}$ \\
\hline Weight & $113 \mathrm{~g}$ & $635 \mathrm{~g}$ & $771 \mathrm{~g}$ \\
\hline
\end{tabular}

\subsubsection{Circuit and Construction of Wireless Accelerometers}

The majority of structural sensors for using with the wireless node modulate their sensor reading upon a voltage signal. Some sensors, such as accelerometers, output positive and negative voltage signals with a zero mean. However, the MicroStrain ${ }^{\circledR}$ nodes can only take $0-3$ volt input. It requires a voltage offset device to shift the accelerometer signal in order to fully utilize the small input range and avoid damaging the unit. The offset device adds to the measured voltage a positive or negative offset voltage. As shown in the diagram in Figure 3.10 (Kappes and Hauser 1999), the circuitry comprises a voltage divider and two operational amplifiers. The offset voltage is adjusted manually by means of a potentiometer (P1). The ratio of R1 and $\mathrm{R} 2$ to $\mathrm{P} 1$ determines the offset range and sensitivity. By choosing P1 $=10 \mathrm{k} \Omega$ and $\mathrm{R} 1$ $=\mathrm{R} 2=33 \mathrm{k} \Omega$, an adjustable range of $\pm 1.6 \mathrm{~V}$ can be obtained. 


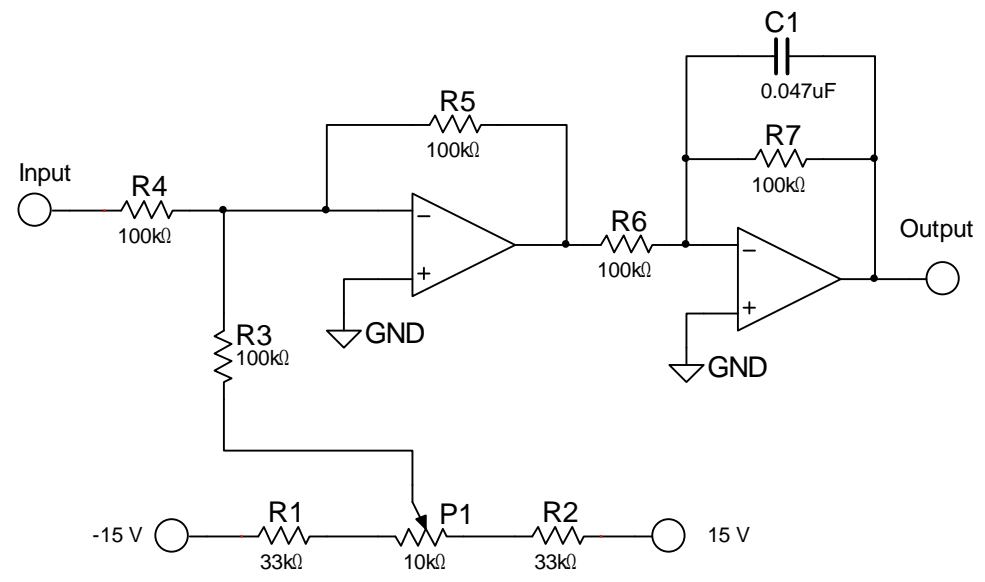

Figure 3.10 Electronic circuitry of the offset device (Kappes and Hauser 1999)

A power supply capable of providing regulated voltages of $\pm 15 \mathrm{~V}$ completes the circuitry. Alternatively, the device can be operated with $9 \mathrm{~V}$ batteries by using a DC-DC voltage converter. Since the Columbia servo accelerometer also needs $\pm 15 \mathrm{~V}$ as excitation, the $\pm 15 \mathrm{~V}$ voltage are also used as the power supply of the accelerometer. The final signal conditioning PCB board for the accelerometer is shown in Figure 3.11. By adjusting the potentiometer P1, the signal from the accelerometer can be shifted about +1.5 volts after going through the conditioning board. Then the adjusted signal can be input into the wireless node. The conditioning board makes the wireless nodes be able to measure signal in a range of $\pm 1.5 \mathrm{~V}$, which is enough for vibration test on bridges.

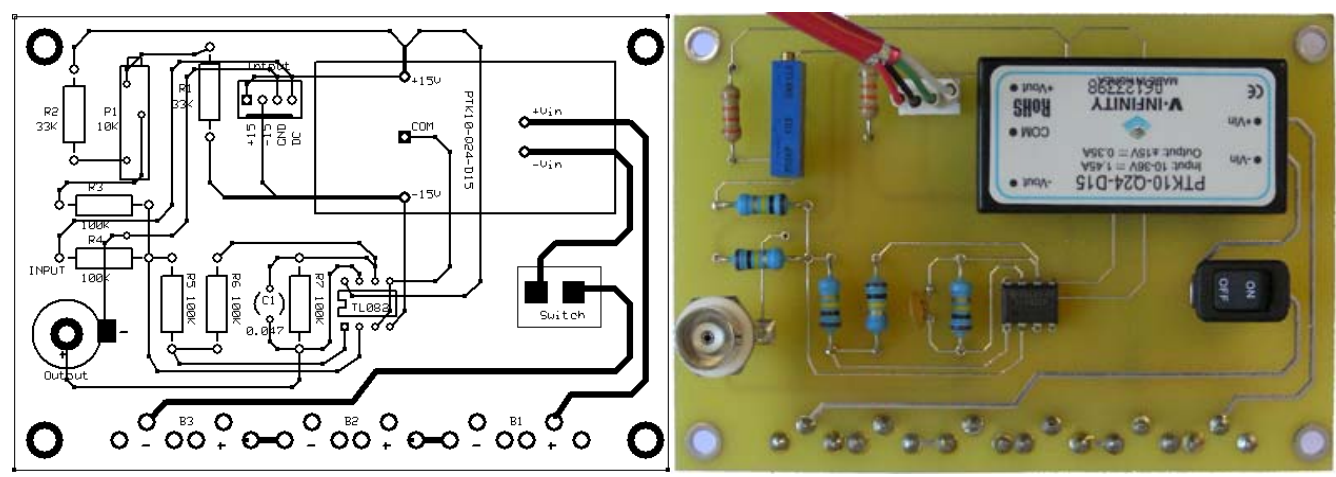

Figure 3.11 Signal conditioning PCB board for accelerometers

The wireless strain accelerometer is formed as the sensor is connected to the wireless nodes through the conditioning circuits, as shown in Figure 3.12. 

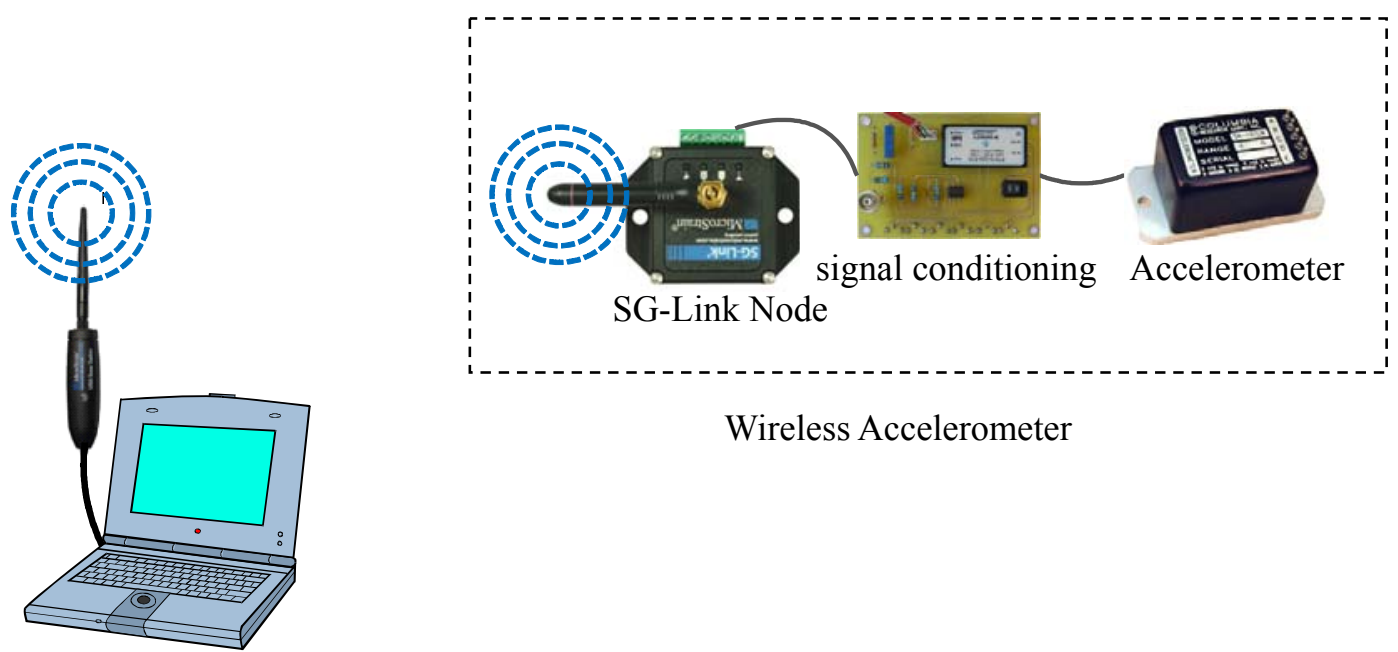

Wireless Accelerometer

Figure 3.12 Wireless accelerometer and wireless DAQ system

\subsubsection{Validation Tests}

A number of laboratory and field validation tests have been carried out in order to assess the performance of the wireless sensors and data acquisition system.

\subsubsection{Laboratory Validation Test}

Two accelerometers (Columbia Model SA-107LN) were clamped parallelly at the same location on a simple-supported I beam, as shown in Figure 3.13. One accelerometer was connected to the MicroStrain ${ }^{\circledR}$ SG-Link ${ }^{\circledR}$ node through a signal conditioning circuit (see Figure 3.11). The other one was connected to the Tektronix ${ }^{\circledR}$ TPS2014 oscilloscope through another conditioning circuit. By exciting the support base (floor), the two data acquisition systems were triggered and acceleration signals were recorded. The oscilloscope can work as a recorder and the sampling frequency was set to $1 \mathrm{KHz}$. For the wireless node, the sampling frequency was configured to $1024 \mathrm{KHz}$.



Figure 3.13 Arrangement of acceleration comparison experiment 
Figure 3.14 presents the acceleration response of the beam at the demonstrated location. The wireless acceleration signal matches very well with the wired acceleration signal.
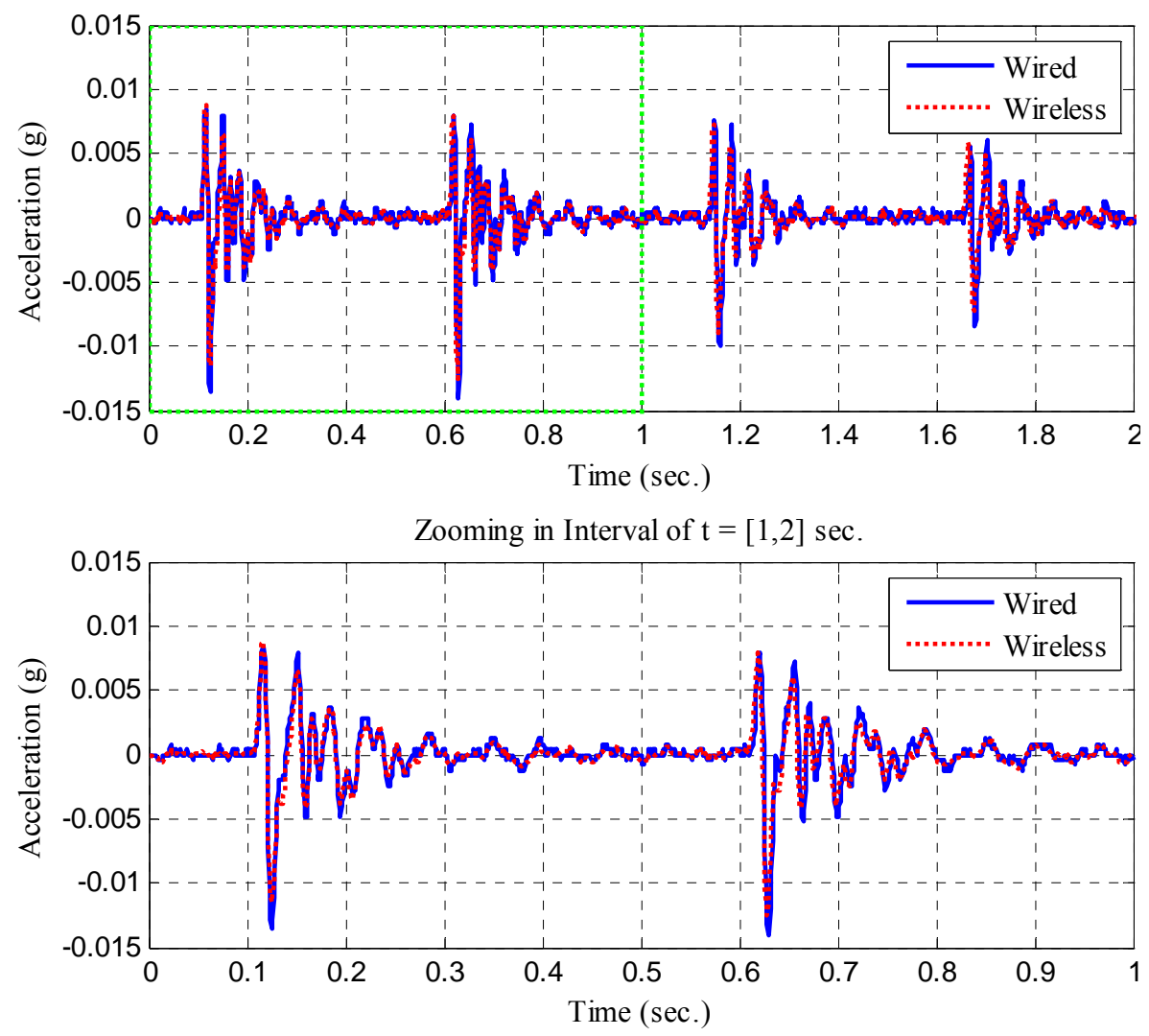

Figure 3.14 Comparisons between wired acceleration and wireless acceleration

\subsubsection{Field Validation Experiment}

The deployment of wireless sensors and sensor networks in actual civil structures is perhaps the best approach to evaluate the merits and limitations of this new technology (Lynch and Loh, 2006).

Evansville Bridge, a three-span bridge with seven steel girders carrying WV Route 92 over the Little Sandy Creek as shown in Figure 3.15 (a), was utilized to validate the performance of the wireless DAQ system. Two force-balanced accelerometers (from Columbia Research Laboratories) were installed parallelly at the middle of the first span of the third girder. One of the accelerometers was connected with a SG-Link ${ }^{\circledR}$ wireless node via a conditioner, and the other one was hooked with a cable-based USB DAQ device called NI USB-9233 with 24-bit ADCs from National Instruments, as shown in Figure 3.15. 


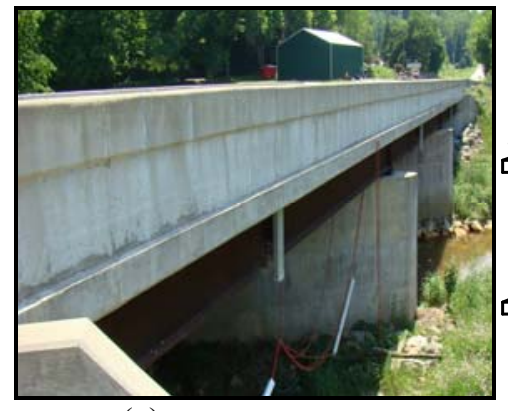

(a)

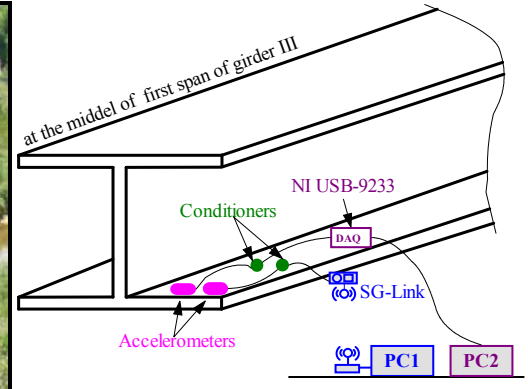

(b)



(c)

Figure 3.15 Evansville Bridge steel girder span: (a) side view picture, (b) experiment setup, and (c) sensor deployment picture

The field validation experiments were conducted in June 2009. The sampling frequency for the wireless DAQ system was set to $1024 \mathrm{~Hz}$, and for the wired DAQ system was $10 \mathrm{k} \mathrm{Hz}$. Acceleration signal was recorded while normal traffic was crossing. As shown in Figure 3.16, the maximum acceleration recorded is approximately $70 \mathrm{mg}$ when a 5-axle truck crossed over. By comparing the two identical time-history responses from the wired and the wireless system, it can be seen that the wireless DAQ system is capable of accurately measuring the response of the bridge when the truck dynamically loads the bridge.

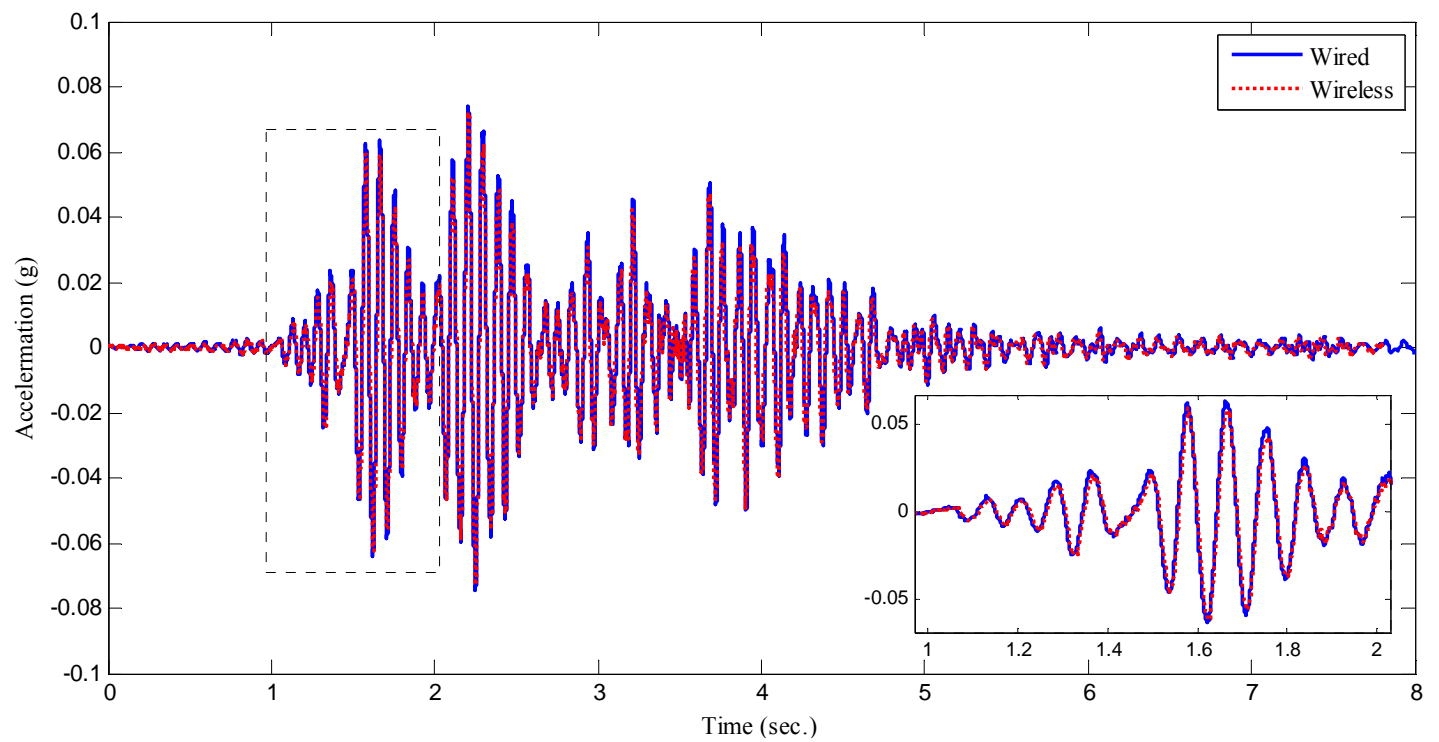

Figure 3.16 Bridge acceleration response to a 5-axle truck 
To identify the primary modal frequencies of the instrumented bridge span, the acceleration response time histories were transformed to the frequency domain using the FFT algorithm. The power spectrums of the time-history records presented in Figure 3.16 are shown in Figure 3.17. It can also be seen that the FFT spectrums from wired and wireless signal match with each other very well.

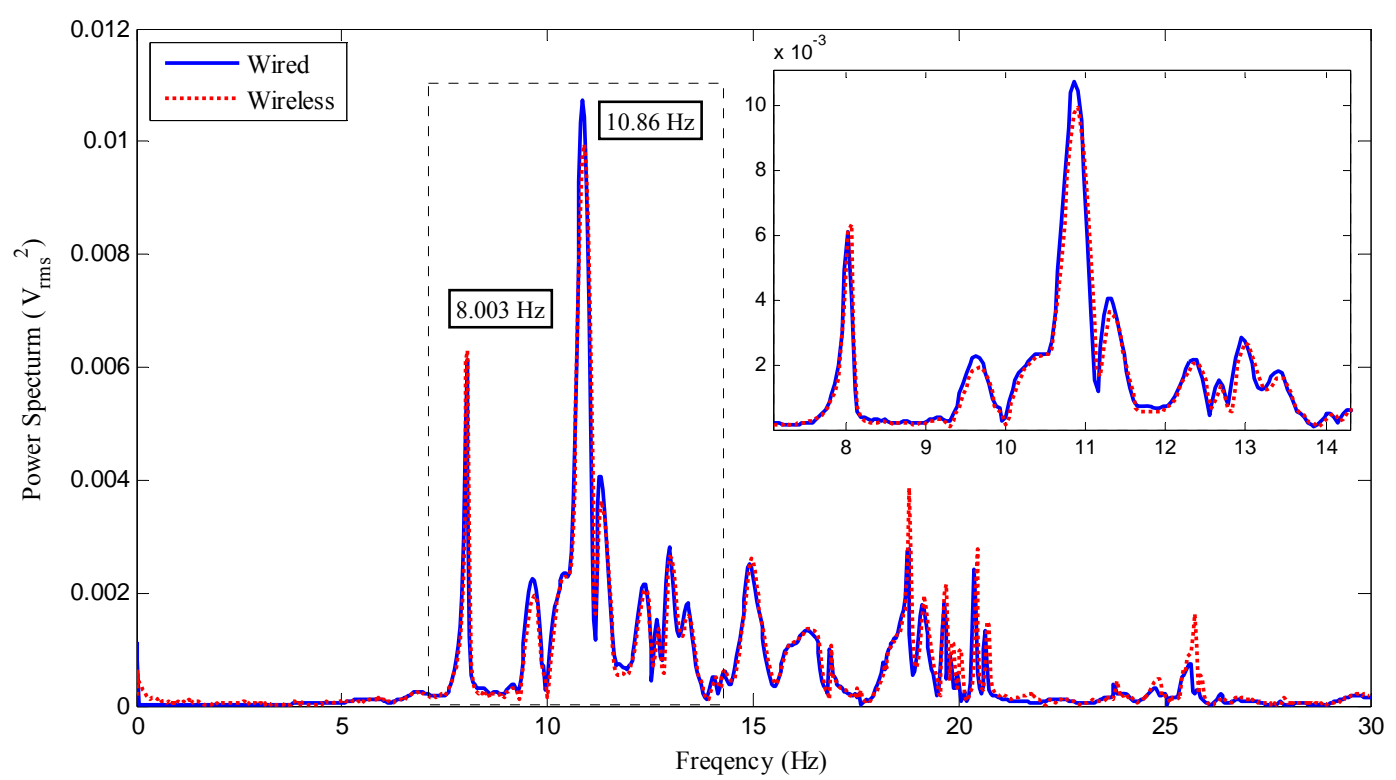

Figure 3.17 Power spectrum corresponding to the acceleration response

\subsection{Wireless Vehicle Position Indicator}

A critical component of bridge diagnostic load testing is to monitor the longitudinal position of the loading vehicle as it crosses the deck at crawl speed. Correct interpretation of the results of load tests requires precise measurement of the relative position between sensors and the path followed by a test truck (Phares, et al. 2003). Comparison between field test results and finite element analysis results also counts on the knowing of vehicle position (Chajes, et al. 1997, Jauregui et al. 2004). A wireless vehicle position indicator (WVPI) is proposed by using the MicroStrain ${ }^{\circledR}$ wireless G-Link ${ }^{\circledR}$ node.

\subsubsection{Devices and Methods for Monitoring Vehicle Position}

Several different methods and devices have been used by researchers for monitoring vehicle position in bridge load testing.

In the research of Shahawy (1995), Laflamme et al. (2006) and Huang (2008), 
critical load positions were predetermined through theoretical calculation. During the load testing, the truck was driven and stopped at those predefined positions on the bridges. Then strain and deflection readings were recorded for each loading case. Because the records only contain bridge responses from several load positions, the whole response spectrum is unknown. Normally, this method needs traffic control, more crews and longer testing time.

Paultre et al. (1995) used two pressure tubes connected to the data acquisition system at both ends of the instrumented span. A voltage pulse was generated from the tube when a vehicle axle crossed. Then the pulses were used to compute the average speed and approximate position of the test vehicle on the deck. Similarly, Nassif et al. (2003) and Ingersoll et al. (2003) used tape switches pasted to the pavement to determine speed, configuration and longitudinal location of the test truck. Those two methods need longer setup time and the accuracy is limited because the vehicle position is calculated based on average speed.

A switch was used by Schonwetter (1999) to record the longitudinal truck position in the test data. The switch was connected to data acquisition system and was operated by a person standing on the deck of the bridge. The truck's position was recorded by interrupting the signal every time the truck's front axle crossed a bearing. A similar position indicator was employed by Chajes et al. (1997) to correlate strain readings with the truck position with a resolution around 6 meters. This approach requires more crews and more time for path preparation and the resolution of truck position is low.

The BDI AutoClicker was utilized by Phares at al. (2003) and Commander et al. (2009) to measure and transmit the load vehicle position through using an electronic eye and hand-held radio transmitters. The BDI AutoCliker was temporarily mounted to the front fender of the vehicle directly over the center of the front axle. A retroreflective target was clamped on the front rim, allowing wheel rotation to be counted by creating a "click" in the data, which can be used to convert data collected in the time domain to the truck position domain. If used properly, the AutoClicker can enhance the accuracy of the known truck position (up to one wheel circumference). However, this device can only be used at crawl speed during a diagnostic load test, and the installation is relatively complex and time-consuming. 
Jackson et al. (2006) proposed a cost efficient solution to tracking test vehicles, which uses accelerometers to capture acceleration data of the vehicle and then integrates to get the position. However, the method has several problems. The serial accelerometer produces a variable offset error. Using raw accelerometer data to derive position is also subject to cumulative error. Other calibration accessories are needed for this approach.

Global Positioning System (GPS) is another choice for positioning vehicles. In the application of bridge testing, which requires accuracy to several centimeters, GPS does not present the ideal solution. Although greater accuracy can be achieved through techniques such as Differential GPS, with some companies claiming sub-1m accuracy, the equipment costs and setup time can be excessive (Jackson et al. 2007). With a goal of developing a reliable automated system that can accurately determine the vehicle position in load tests using primarily real-time RTK-GPS data, a research project sponsored by Minnesota Department of Transportation is undergoing (http://www.cts.umn.edu/Research/ProjectDetail.html?id=2009038).

\subsubsection{Wireless Vehicle Position Indicator (WVPI)}

Among these vehicle positioning devices, BDI AutoClicker has reliable performance and relatively high resolution of one wheel circumference $(W C)$. A radio transmitter wirelessly sends the "click" signal for marking truck positions. However, this device is expensive (around 5,000 dollars) and needs BDI data acquisition system to work with for best performance.

In order to equip with a low-price, high-performance device for vehicle positioning, a wireless vehicle position indicator (WVPI) is designed to operate as part of the Wireless Bridge Load Testing \& Rating System. The WVPI is actually a G-Link ${ }^{\circledR}$ node from MicrosStrain ${ }^{\circledR}$, namely a wireless accelerometer node with $a \pm 2 g$ range, as shown in Table 3.1. The wireless node is powered by an internal rechargeable battery $(180 \mathrm{mAhr})$ with very low power consumption $(0.18 \mathrm{~mA}$ for sleep mode, $15 \mathrm{~mA}$ for datalogging mode). It works on $2.4 \mathrm{GHz}$ radio frequency with $70 \mathrm{~m}$ line-of-sight communication range, featuring up to $2 \mathrm{kHz}$ sampling rates, combined with $2 \mathrm{MB}$ onboard flash memory for storage. The node integrates two orthogonally, dual-axis MEMS capacitive accelerometers from Analog Devices (Model ADXL202). Triaxial accelerometer output is presented on G-Link® channels 
1, 2 and 3, being $x, y$ and $z$, as shown in Figure 3.18. The wireless node is relatively low-cost (500 dollars), very light and compact $(46 \mathrm{~g}, 58 \mathrm{~mm} \times 43 \mathrm{~mm} \times 26 \mathrm{~mm}$ in size $)$.

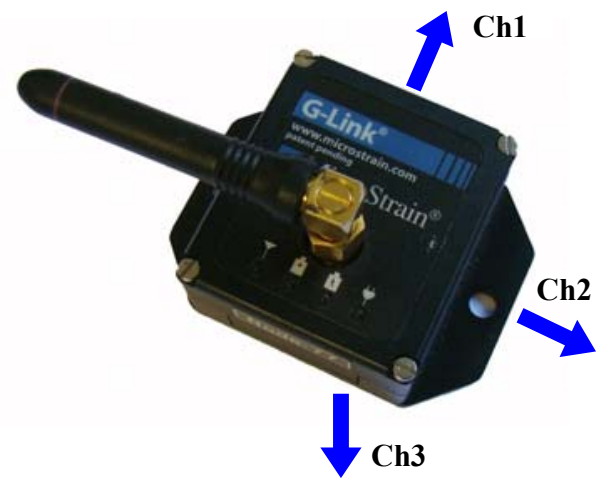

Figure 3.18 Sensitive axes of G-Link ${ }^{\circledR}$ node

The ADXL202 can measure dynamic acceleration and as well as static acceleration forces such as gravity, allowing it to be used as a tilt sensor to measure a full $360^{\circ}$ of orientation through gravity by using two accelerometers oriented perpendicular to one another, as shown in Figure 3.19.

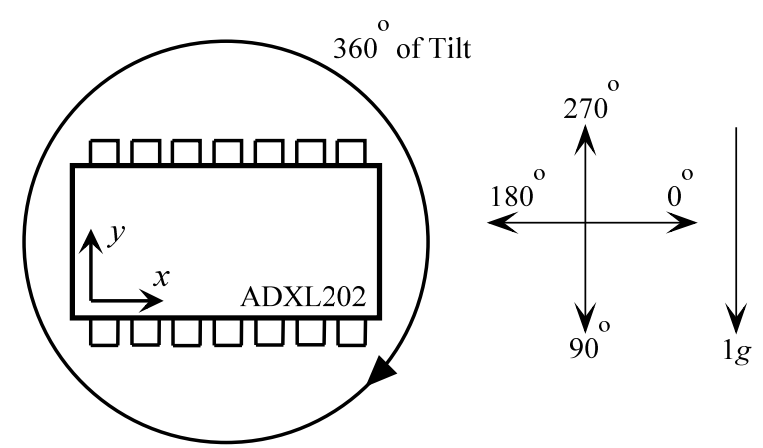

Figure 3.19 Using a two-axis accelerometer to measure $360^{\circ}$ of tilt

The accelerometer is most sensitive to tilt when its sensitive axis is perpendicular to the force of gravity. At this orientation, its sensitivity to changes in tilt is highest. When the accelerometer is oriented on axis to gravity, the change in output acceleration per degree of tilt is negligible. When one sensor is reading a maximum change in output per degree, the other is at its minimum. Namely, the two channels have a $90^{\circ}$ phase difference. The output tilts in degrees of $x$ - and $y$-axis are calculated as follows (ADXL202 data sheet):

$$
A x=-\sin \theta \times 1 g, \quad A y=\cos \theta \times 1 g
$$




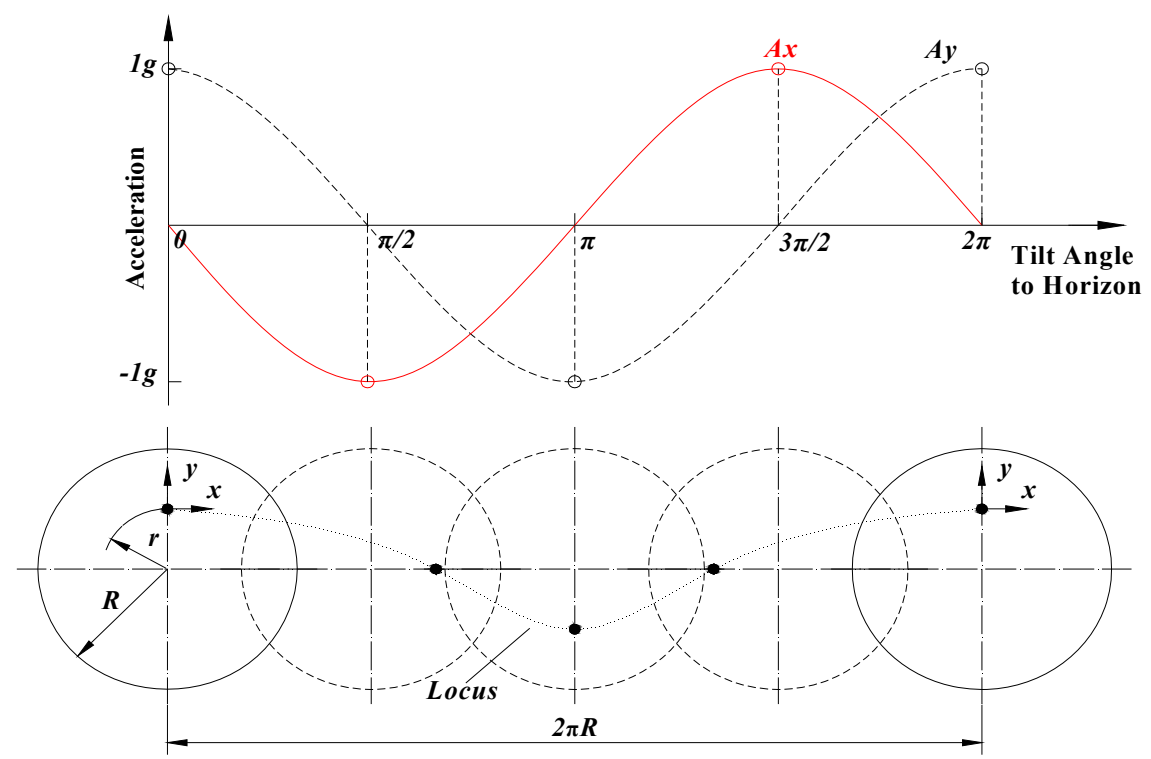

Figure 3.20 Relationship between tile angle and acceleration

Since the accelerometer can measure the tilt angle, if it is installed on a rolling wheel, the rotation angle of the wheel can be computed using the method discussed above. The rotation of wheel is related to the traveling distance of the wheel. Therefore, the position of the wheel can be calculated.

Combined the special properties of the embedded MEMS accelerometers with the remarkable advantages of wireless transmission, the G-Link node becomes an ideal device to monitor the positions of the moving vehicle with a high resolution.

\subsubsection{Laboratory Experiment}

The G-Link ${ }^{\circledR}$ node was fixed with screws to an aluminum plate, which was firmly bonded to a worm-drive clamp with $J \& B$ Weld. The clamp was tightened on the axle of a bicycle. As a result, the $x-y$ plane of the node was parallel to the face of the wheel. The G-Link ${ }^{\circledR}$ node rotates as the wheel dose with two sensitive axes $x$ and y, as shown in Figure 3.21.

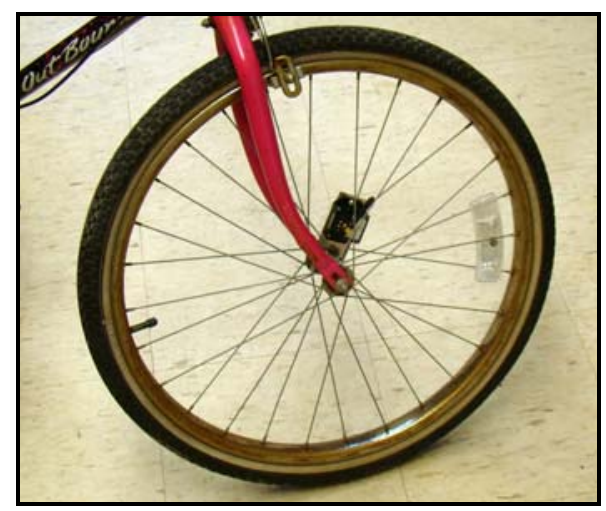

Figure 3.21 Experimental setup on a bicycle wheel 
When the wheel turns, the accelerometer generates acceleration signals. Figure 3.22 shows the outputs when the wheel starts to turn with G-Link ${ }^{\circledR}$ node at the highest position. Since the exact value of the acceleration is not what we concern, the acceleration is directly presented as voltage $(V)$ instead of $\mathrm{m}^{2} / \mathrm{s}$ without offset zeroing. It is obvious that the acceleration signal is sinusoidal, whose period is depended on the rotational speed of the wheel. Outputs of $x$-axis and $y$-axis have a $90^{\circ}$ phase difference. The denoised signal is generated by the action of rotation (tilt), and the 'noise' represents the dynamic signal.
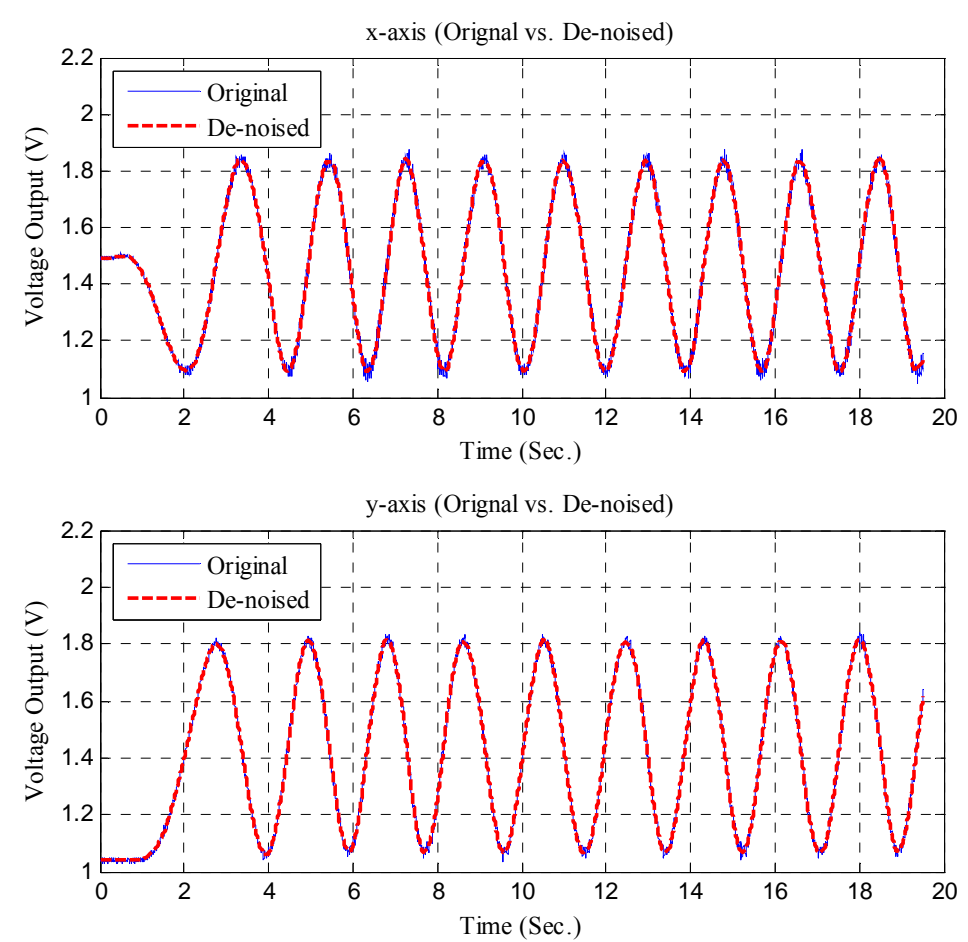

Figure 3.22 Acceleration signal of $x$-axis and $y$-axis

Obviously, from equation (3.3), Figure 3.20 and Figure 3.22, it can be seen that every cycle of $x, y$ signals represents one cycle of wheel rotation and the peaks $\&$ valleys are corresponding to $90^{\circ}$ wheel rotations (namely $1 / 4$ wheel circumference). Therefore, by combining the time coordinates of peaks \& valleys with the wheel circumference that can be easily measured, the longitudinal position of the wheel can be calculated. The resolution of the method will be $1 / 4 W C$ compared with $1 W C$ by using the BDI AutoClicker.

Assuming the value array of peaks \& valleys obtained from the WVPI signals is $P V=\left\{p v_{1}, p v_{2}, \cdots, p v_{n}\right\}$, and the corresponding time array is $T=\left\{t_{1}, t_{2}, \cdots, t_{n}\right\}$. The initial angle $\alpha$ of the first peak or valley can be calculated from the ratio of its magnitude to peak-to-peak value: 


$$
\alpha=\sin ^{-1}\left(\frac{\left|p v_{1}\right|}{\left|p v_{2}-p v_{1}\right| / 2}\right)
$$

Then, the array of vehicle positions $P O S=\left\{\operatorname{pos}_{1}, \operatorname{pos}_{2}, \cdots, \operatorname{pos}_{n}\right\}$ corresponding to $T=\left\{t_{1}, t_{2}, \cdots, t_{n}\right\}$ can be presented as:

$$
\operatorname{pos}_{i}=\frac{\alpha \times W C}{2 \pi}+\frac{W C}{4} \times(i-1), \quad(i=1,2, \cdots, n)
$$

The flow chart of measuring the truck position with the proposed WVPI is shown in Figure 3.23. Appendix A3 describes the detailed procedures on how to install and use the WVPI.
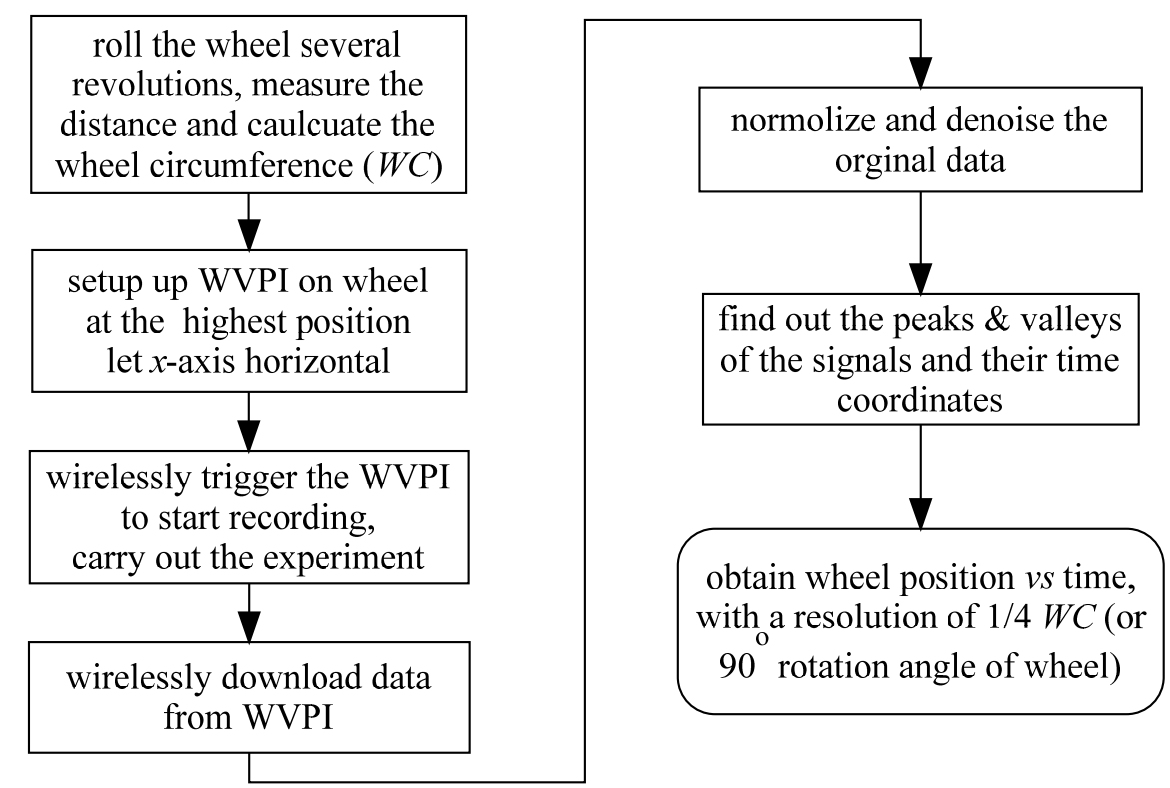

Figure 3.23 Flow chart of measuring the truck position with WVPI

\subsubsection{Installation and Calibration in Field Tests}

In the bridge diagnostic load test, the WVPI was mounted on the front wheel hub using strong fasteners. Before installation, the surface of the wheel hub was cleaned with degreaser. Figure 3.24 shows the installation of WVPI on the front wheel.

In order to measure the wheel circumference of the test truck, a white mark was made at the side of the tire and on the pavement directly below the center of the front axle. Then, the truck was rolled forward exactly four wheel revolutions, and another mark was placed on the pavement that lines up with the mark on the tire. The wheel circumference is calculated via dividing the distance between the two marks by four. This method of measuring produces a good "averaged" value for the wheel 
circumference. Appendix A4 provides detailed procedures of installation and calibration.

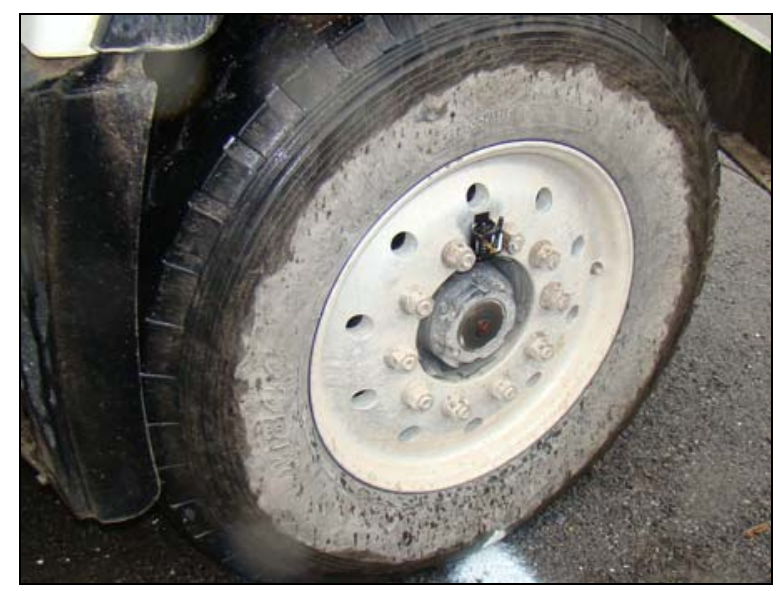

Figure 3.24 Installation of WVPI on the truck wheel

After the wheel rolled four turns, the distance between these two marks was measured as $13.18 \mathrm{~m}$ (43'3'). The wheel circumference $(W C)$ can be calculated as follows:

$$
W C=\frac{\text { Distance between Marks }}{\text { Number of Turns }}=\frac{13.18}{4}=3.30 \mathrm{~m}
$$

As it is discussed above, the resolution of this method is up to $1 / 4 W C=0.82 \mathrm{~m}$. In this case, the resolution of BDI AutoClicker is $1 W C=3.30 \mathrm{~m}$.

The connection strength of the fastener can reach $4 \mathrm{lb} / \mathrm{in}^{2}$ in tensile and sheer at $72^{\circ} \mathrm{F}\left(22^{\circ} \mathrm{C}\right)$. The contact area of the two fasteners is $1 \mathrm{in} \times 2 \mathrm{in}=2 \mathrm{in}^{2}$, therefore, the maximum shear force can reach $F_{S \max }=8 \mathrm{lb}=35.6 \mathrm{~N}$. Besides the gravity, Force $(F)$ applied on the node can be calculated using equation (3.7) based on the free body diagram in Figure 3.25:

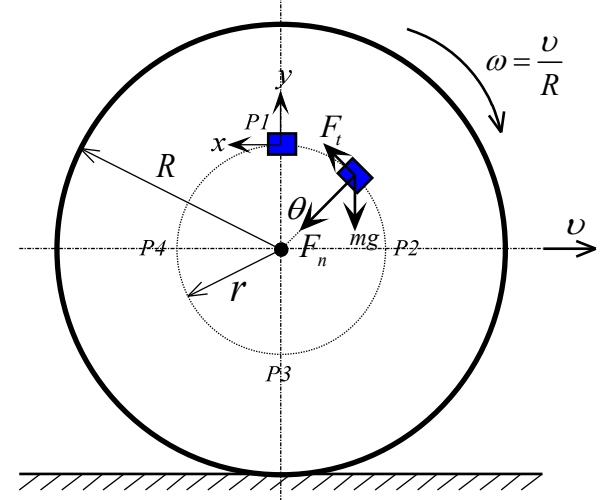

Figure 3.25 Rotation of WVPI and free body diagram 


$$
F=\sqrt{F_{n}^{2}+F_{t}^{2}}=\sqrt{\left(m \omega^{2} r-m g \cos \theta\right)^{2}+(m g \sin \theta)^{2}}
$$

When $\theta=90^{\circ}$ or $270^{\circ}, F$ reaches maximum value as:

$$
F_{\max }=m \sqrt{\left(\omega^{2} r\right)^{2}+g^{2}}=m \sqrt{\left(r v^{2} / R^{2}\right)^{2}+g^{2}}
$$

Here:

$g$ : the gravity constant $\left(g=9.81 \mathrm{~m}^{2} / \mathrm{s}\right)$

$m$ : Mass of WVPI $(m=0.046 \mathrm{~kg})$

$\omega$ : Angler speed of wheel $(\omega=v / R)$

$v$ : Speed of the test vehicle $(v=5 \mathrm{mph}=2.24 \mathrm{~m} / \mathrm{s})$

$R$ : Radius of the wheel $(R=W C / 2 \pi=0.525 \mathrm{~m})$

$r$ : Distance from WVPI to center of the wheel $(r=0.25 \mathrm{~m}$, measured $)$

For diagnostic load test, normally, the test vehicle travels at a craw speed around $5 \mathrm{mph}(v=2.24 \mathrm{~m} / \mathrm{s})$, then we can obtain:

$$
F_{\text {max }}=0.5 N \ll F_{S \max }
$$

If we assume $F_{\text {max }}=F_{S \max }$, then the maximum safe speed that the test vehicle can travel without failing the connection is:

$$
v_{\max }=\sqrt{\frac{R^{2}}{r} \sqrt{\left(\frac{F_{S_{\text {max }}}}{m}\right)^{2}-g^{2}}}=29.2 \mathrm{~m} / \mathrm{s}=65.3 \mathrm{mph}
$$

From equations (3.9) \& (3.10), it can be seen that the connection between the WVPI and the wheel is strong enough for the diagnostic load testing. Installation of WVPI only needs to find out a small area of flat surface on the wheel hub. The whole installation is straightforward and easy, and only takes 1-2 minutes. Meanwhile, it is not only suit for crawl speed in diagnostic load test, but also for some higher speed cases.

\subsubsection{Process of Field Test Data}

The field WVPI measurements are noisy because of the vibration of engine and rough road. Data denoising is necessary in order to accurately locate peaks \& valley for calculating vehicle positions. Figure 3.26 shows the trimmed and converted 
original data versus denoised data.
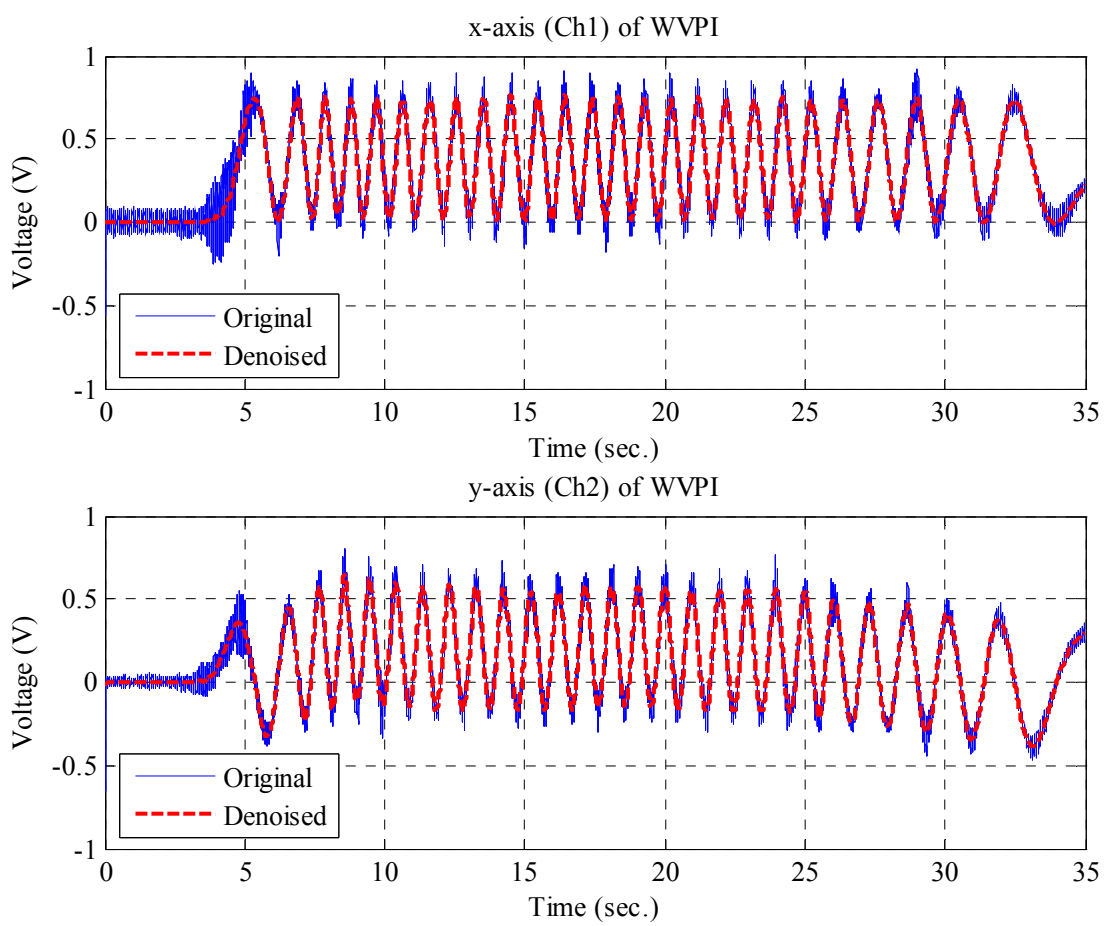

Figure 3.26 Original data versus denoised data from WVPI

It became much easier to work on the denoised data for locating peaks \& valleys. By following the method discussed in previous section and using the measured wheel circumference $(W C)$, the relationship between the truck position and time can be obtained, as shown in Figure 3.27.


Figure 3.27 Peaks \& valleys and calculation of truck position 
The wireless accelerometer was directly attached to the wheel hub, which is inclined. The inclination caused that the sensitive $x$-y plane of the accelerometer was not parallel with the direction of gravity. This setup distorted the $y$-axis acceleration signal, as shown in Figure 3.27. Although the signal is not perfectly sinusoidal, the peaks $\&$ valleys still comply with the relationship to wheel rotations.

\subsubsection{Discussion of Measurement Resolution}

With the approach discussed above, the WVPI can measure the vehicle position with a resolution of $1 / 4$ wheel circumference (or a resolution of $90^{\circ}$ rotation angle of wheel). Higher resolution can be achieved if more G-Link ${ }^{\circledR}$ nodes are used. Figure 3.28 shows the comparison of different arrangements of G-Link ${ }^{\circledR}$ nodes. When two nodes are used and arranged at a $45^{\circ}$ interval, it can be obviously seen that a resolution of $1 / 8$ wheel circumference can be obtained by using the same principle of locating peaks and valleys. When three nodes are installed at a $120^{\circ}$ interval, a resolution of $1 / 12$ wheel circumference is achieved. The resolution is three times higher than that of the original one-node design. A result comparison of these three arrangements using the discussed method is listed in Table 3.4. If more nodes are used, there needs more time for installation with increased cost. Moreover, possibility of deployment of more nodes also counts on the configuration of the wheel hub. 
One G-Link Node
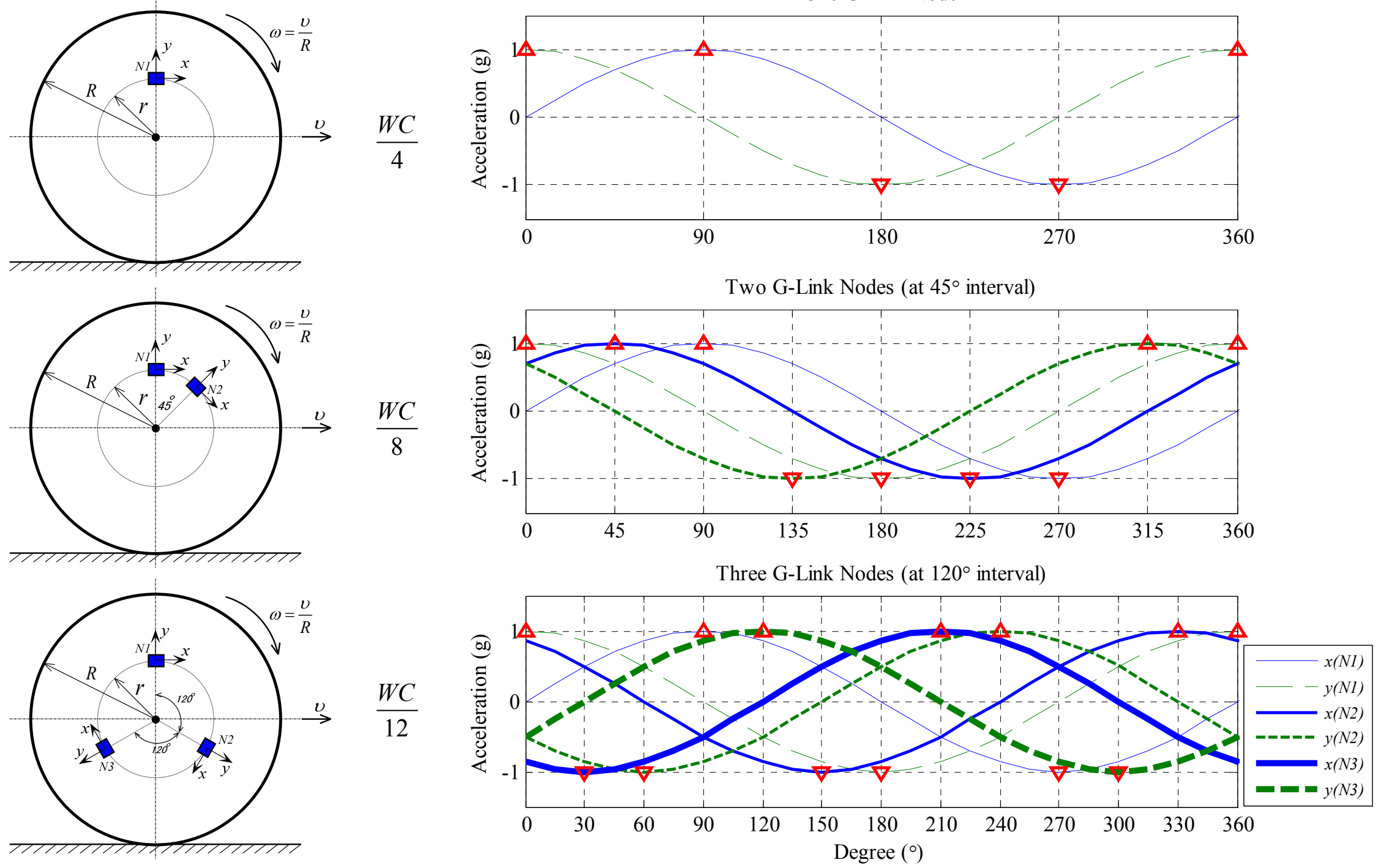

Figure 3.28 Comparison of different arrangements of G-Link nodes 
Table 3.4 Result comparison of three arrangements of G-Link ${ }^{\circledR}$ nodes

\begin{tabular}{c|c|c|c|c}
\hline No. & $\begin{array}{c}\text { Num. of } \\
\text { Nodes }\end{array}$ & Setup & Resolution & Cost \& Installation \\
\hline$\# 1$ & 1 & Attached to wheel & $\begin{array}{c}1 / 4 \text { wheel circumference } \\
\left(90^{\circ} \text { rotation angle of wheel }\right)\end{array}$ & $\begin{array}{c}\text { Least cost } \\
\text { Fastest installation }\end{array}$ \\
\hline$\# 2$ & 2 & $\begin{array}{c}\text { Attached to wheel at a } \\
45^{\circ} \text { interval }\end{array}$ & $\begin{array}{c}1 / 8 \text { wheel circumference } \\
\left(45^{\circ} \text { rotation angle of wheel }\right)\end{array}$ & $\begin{array}{c}\text { Double cost } \\
\text { More installation time }\end{array}$ \\
\hline$\# 3$ & 3 & $\begin{array}{c}\text { Attached to wheel at a } \\
120^{\circ} \text { interval }\end{array}$ & $\begin{array}{c}1 / 12 \text { wheel circumference } \\
\left(30^{\circ} \text { rotation angle of wheel }\right)\end{array}$ & $\begin{array}{c}\text { Triple cost } \\
\text { Longest installation time }\end{array}$ \\
\hline
\end{tabular}

Theoretically, by deploying only one G-Link ${ }^{\circledR}$ node, any rotation angle of the vehicle wheel can be calculated by using equation (3.3). However, in practice, the acceleration signals may be distorted and hardly be perfectly sinusoidal, which can influence the calculation accuracy by using the equation (3.3).

Although the whole signal is not perfectly sinusoidal, the signal can be divided into multiple sub-signals at an interval of $90^{\circ}$ rotation. Each sub-signal can be seen as a sinusoidal signal. With this assumption, each sub-signal can be divided into smaller sections by using the sinusoidal equation. In this way, the whole signal can be divided into small sections at a smaller interval of rotation angle, for example $30^{\circ}$. In consequence, the measurement resolution will be improved.

After the signal has been divided into $90^{\circ}$ sections, with the sinusoidal assumption, each sub-signal is divided again at an interval of $30^{\circ}$ angle by finding out the locations where the corresponding sinusoidal equations are satisfied, as shown in Figure 3.29.

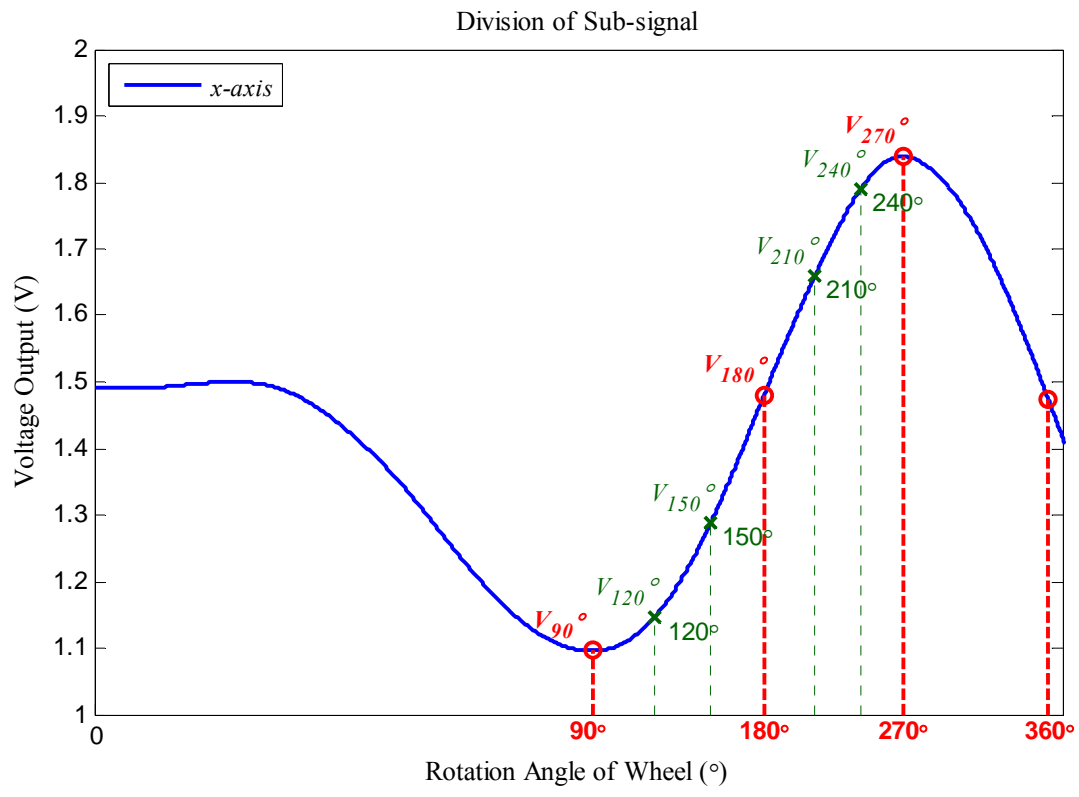

Figure 3.29 Division of sub-signal for higher resolution 
For example, the sub-signal between $90^{\circ}$ and $180^{\circ}$ rotation angle range is taken out for further division at a smaller interval of $30^{\circ}$ rotation angle, see Figure 3.29. Let the amplitudes at $90^{\circ}$ and $180^{\circ}$ as $V_{90^{\circ}}$ and $V_{180^{\circ}}$ respectively. With the assumption that the sub-signal can be considered as a sinusoidal signal, the amplitudes $V_{120^{\circ}}$ and $V_{150^{\circ}}$ at $120^{\circ}$ and $150^{\circ}$ can be calculated or interpolated by simply using the sinusoidal equations.

$$
\begin{aligned}
& V_{120^{\circ}}=V_{180^{\circ}}-\sin \left(60^{\circ}\right) \times\left(V_{180^{\circ}}-V_{90^{\circ}}\right) \\
& V_{150^{\circ}}=V_{180^{\circ}}-\sin \left(30^{\circ}\right) \times\left(V_{180^{\circ}}-V_{90^{\circ}}\right)
\end{aligned}
$$

Similarly, the interpolation can be applied for other sub-signals. For instance, the amplitudes $V_{210^{\circ}}$ and $V_{240^{\circ}}$ at $210^{\circ}$ and $240^{\circ}$ can be calculated as

$$
\begin{aligned}
& V_{210^{\circ}}=V_{180^{\circ}}-\sin \left(30^{\circ}\right) \times\left(V_{180^{\circ}}-V_{270^{\circ}}\right) \\
& V_{240^{\circ}}=V_{180^{\circ}}-\sin \left(60^{\circ}\right) \times\left(V_{180^{\circ}}-V_{270^{\circ}}\right)
\end{aligned}
$$

After obtaining these interpolation values, the corresponding coordinates in the signal can be found out reversely. Therefore, a resolution of $1 / 12$ wheel circumference, namely a resolution of $30^{\circ}$ rotation angle, can be obtained by only using one G-Link ${ }^{\circledR}$ node, illustrated in Figure 3.30.

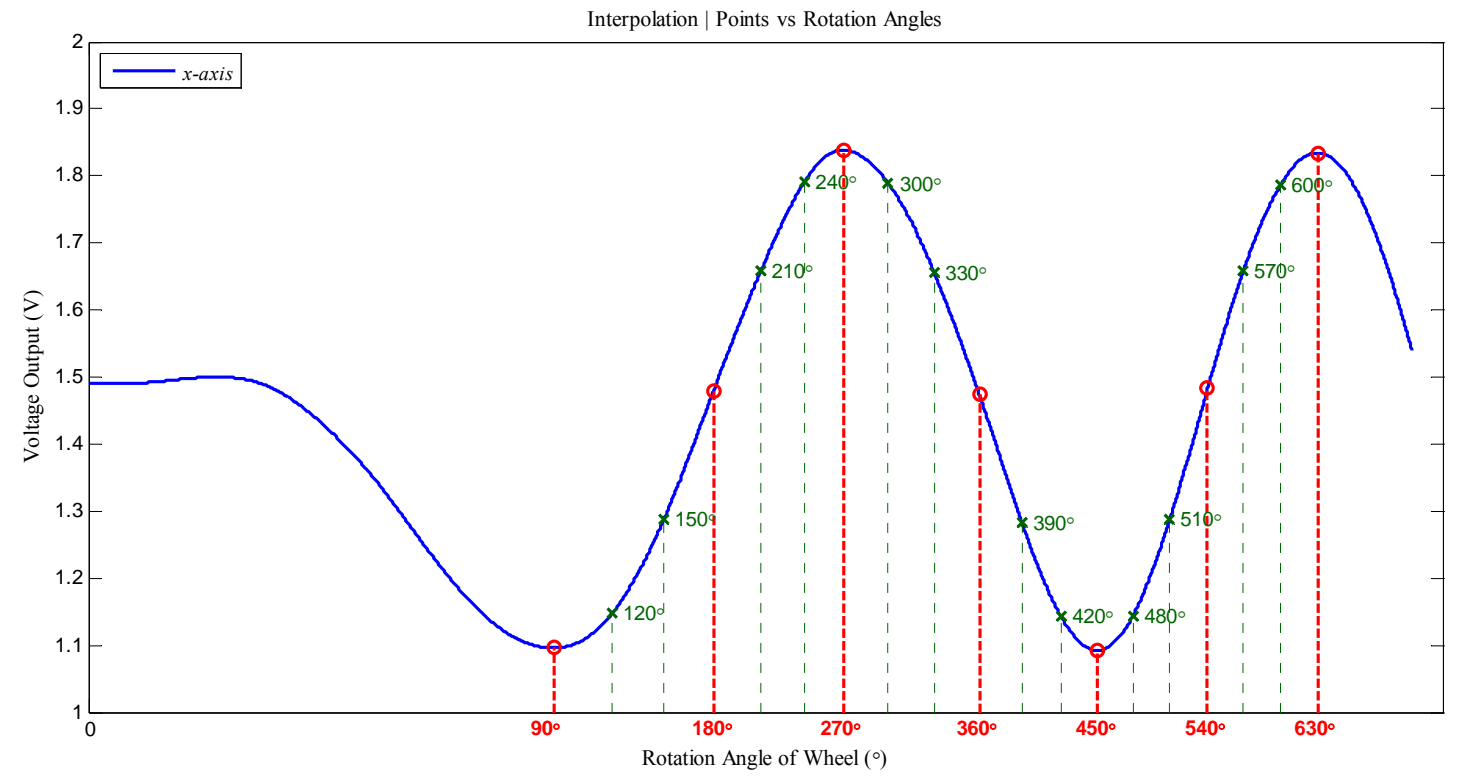

Figure 3.30 Division of sub-signal into smaller sections

Assuming that a smaller interval of $\theta$ rotation angle is required and $90^{\circ}$ is dividable by $\theta$, the interpolation in any sub-section can be expressed as equation (3.13). 


$$
V_{180^{\circ} \times i-\theta \times j}=V_{180^{\circ} \times i}+\sin (\theta \times j) \times\left|V_{180^{\circ} \times i}-V_{180^{\circ} \times i \pm 90^{\circ}}\right|, \quad\left(\begin{array}{l}
i=1,2, \cdots, n \\
m=90^{\circ} / \theta \\
j=[1-m, m-1], j \neq 0
\end{array}\right)
$$

The corresponding measurement resolution can be calculated by equation

$$
\text { Measurement Resolution }=\frac{\theta}{360^{\circ}} \times W C
$$

Higher measurement resolution may be achieved if the signal is divided at a smaller rotation angle, such as at an interval of $15^{\circ}$ or $10^{\circ}$. However, when the signal is divided into smaller sections, eccentric calculation results may occur because the signal from field test may contain some singularities. The modified calculation flow chart is shown in Figure 3.31.
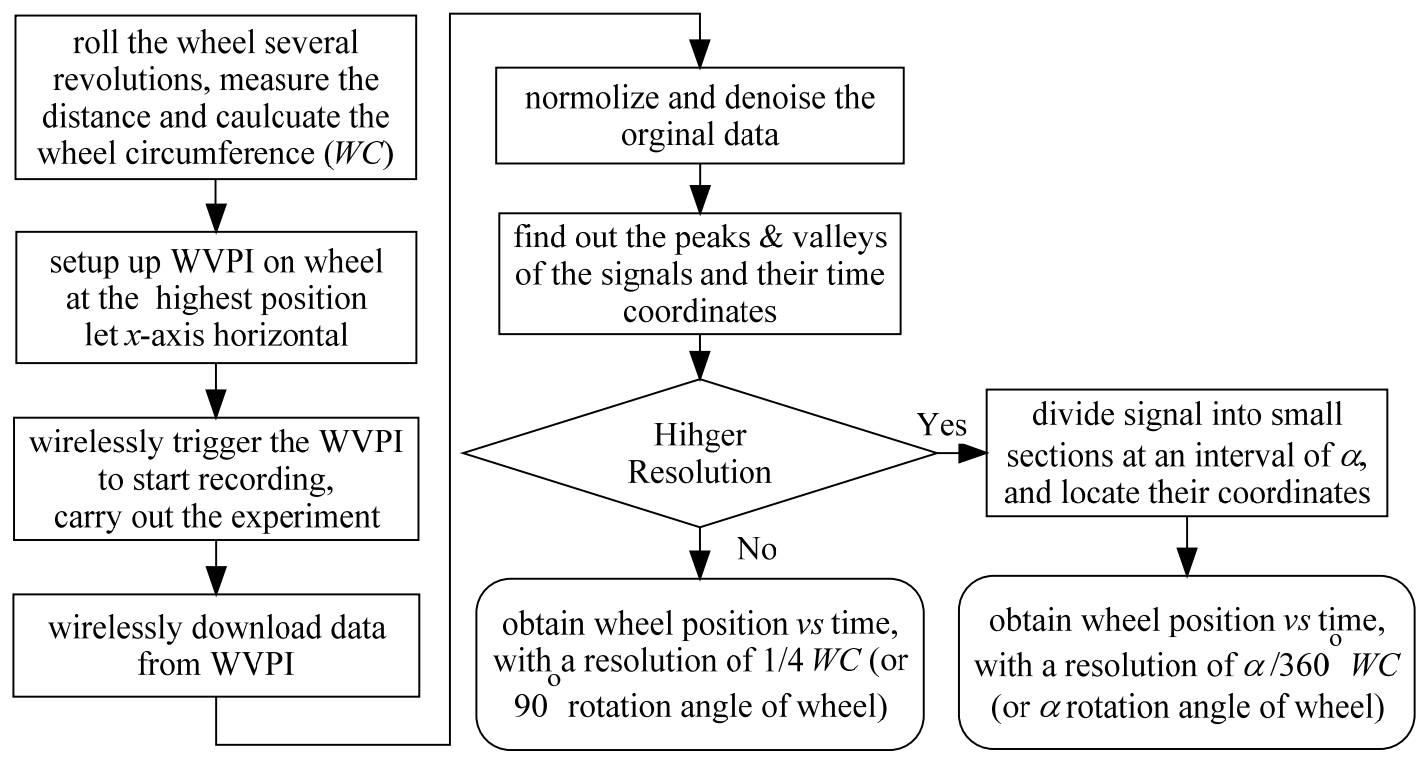

Figure 3.31 Modified flow chart of measuring truck positions with WVPI 


\section{Chapter 4}

\section{Software Development of Wireless Bridge Load Testing and Rating System}

\subsection{Introduction}

The software Agile-Link ${ }^{\mathrm{TM}}$ with the MicroStrain ${ }^{\circledR}$ wireless sensing platform allows user to wirelessly configure and communicate with the G-Link ${ }^{\circledR}, V-\operatorname{Link}{ }^{\circledR}$ and SG-Link ${ }^{\circledR}$ nodes. Among other functionality, Agile-Link ${ }^{\mathrm{TM}}$ incorporates power management options, simple quality of service tests, remote, channel independent auto balancing, and node information. Each wireless channel is completely configurable to monitor real-time and logged data. Data monitoring becomes easier as graph configurability provides robust options for viewing real-time data. Moreover, integration with popular graphing applications such as Microsoft Excel and OpenOffice increases the overall speed and productivity. However, the Agile-Link ${ }^{\mathrm{TM}}$ cannot satisfy the requirement of post signal processing in this research. Therefore, a signal processing software was developed. The software can automatically perform theoretical rating based on the properties and dimension parameters of the target bridge. Critical values can swiftly be obtained from the load testing data and combined with theoretical rating factors to produce accurate rating factors.

A block diagram illustrating the wireless bridge load testing and rating system is shown in Figure 4.1. Wireless sensors automatically collect and save signals, including strain records, accelerations and vehicle position signal. Recorded data are wirelessly downloaded to the laptop and are later processed in the lab or on site using the developed software. 


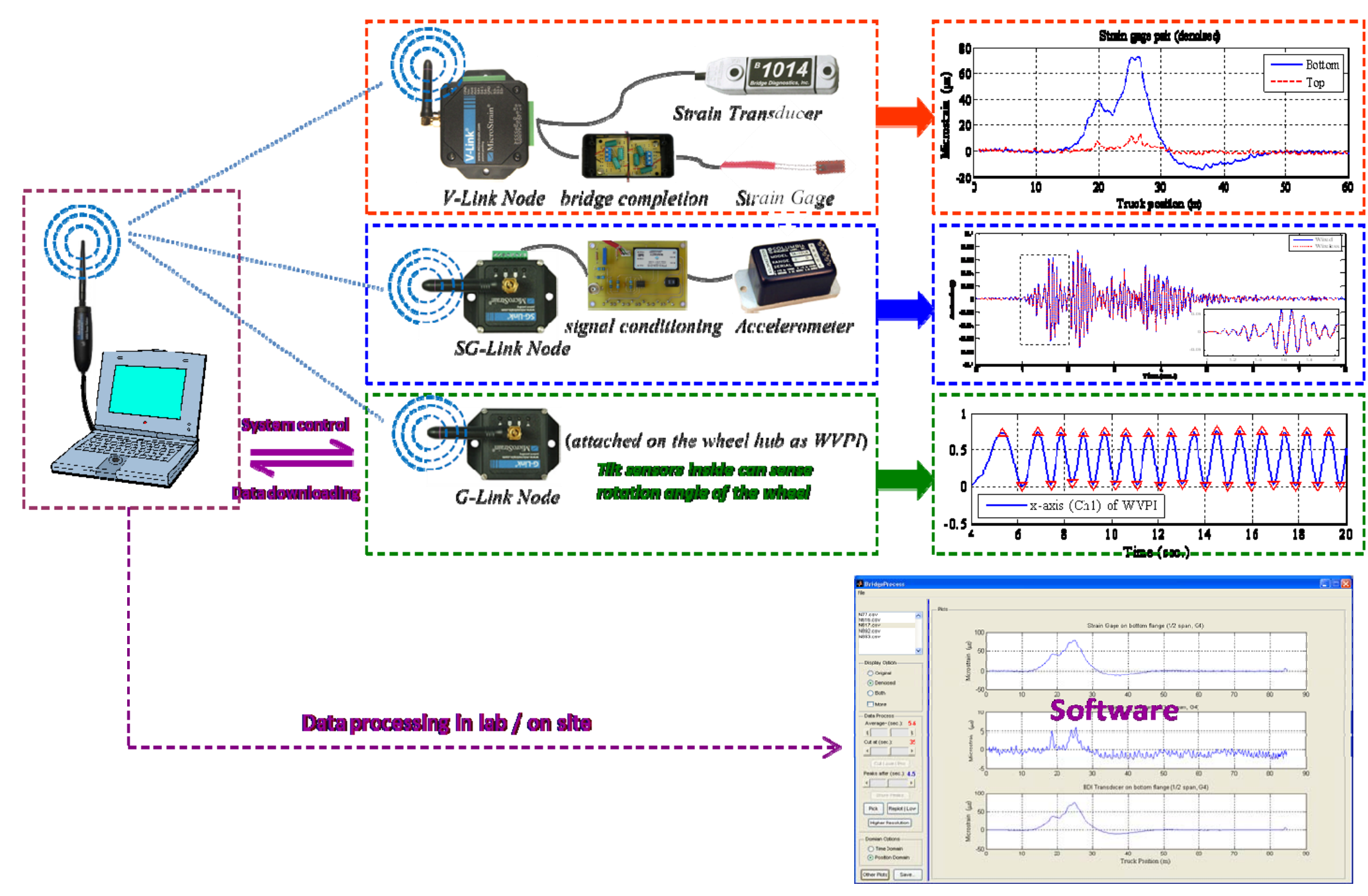

Figure 4.1 Wireless bridge load testing and rating system 


\subsection{Bridge Load Rating}

\subsubsection{Load and Resistance Factor Rating (LRFR)}

In 2001 AASHTO developed a new bridge rating method - the load and resistance factor rating (LRFR) method. The LRFR manual (Manual for Condition Evaluation and Load and Resistance Factor Rating (LRFR) of Highway Bridges) reflects the latest technologies on the structural reliability approach inherent in specifications for load and resistance factor design (LRFD) (Jaramilla and Huo 2005).

The methodology for LRFR of bridges contains three procedures: 1) design load rating, 2) legal load rating, and 3) permit load rating. Design load rating is the first level of bridge assessment based on the HL-93 load and LRFD design standards, using dimensions and properties of the bridge in its present as-inspected condition. Legal load rating is a second-level evaluation that provides a single safe load capacity (for a given truck configuration) applicable to AASHTO standards and State legal Loads. Permit load rating is a third-level rating that checks the safety and serviceability for the passage of trucks beyond the legally established weight limits. This rating process should be applied only to bridges having sufficient capacity for AASHTO legal loads. A flow chart outlining this approach is shown in Figure 4.2.

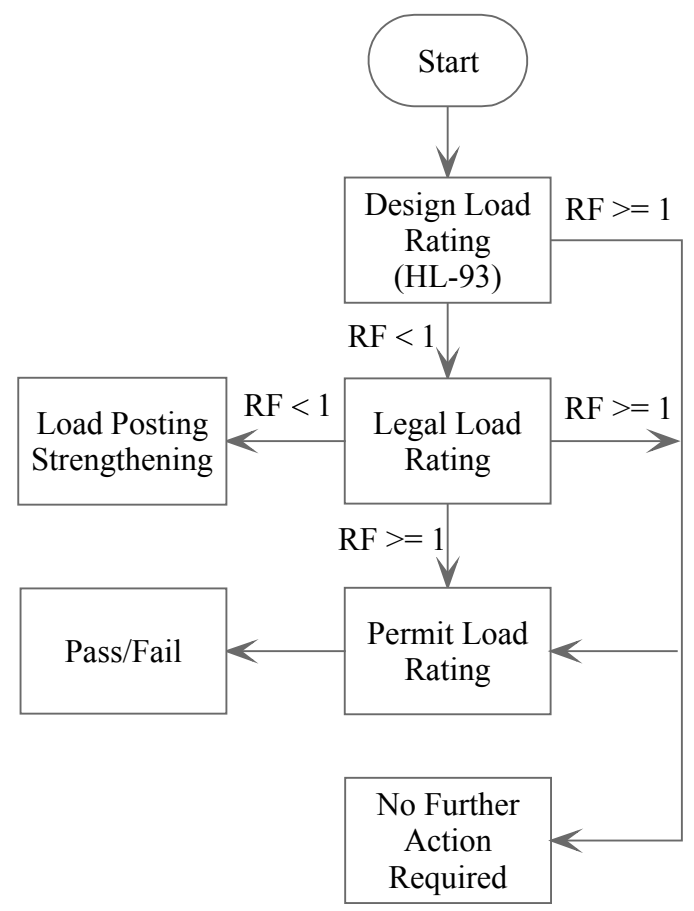

Figure 4.2 Flow chart for load rating (LRFR Manual) 
The following general expression is used in LRFR manual to calculate the load rating of each component and connection subjected to a force effect (i.e., axial force, flexure, or shear):

$$
R F=\frac{C-\left(\gamma_{D C}\right)(D C)-\left(\gamma_{D W}\right)(D W) \pm\left(\gamma_{P}\right)(P)}{\left(\gamma_{L}\right)(L L+I M)}
$$

For the Strength Limit States: $C=\varphi_{c} \varphi_{s} \varphi R_{n}$, where the following lower limit shall apply: $\varphi_{c} \varphi_{s} \geq 0.85$. For the Service Limit States: $C=f_{R}$, where:

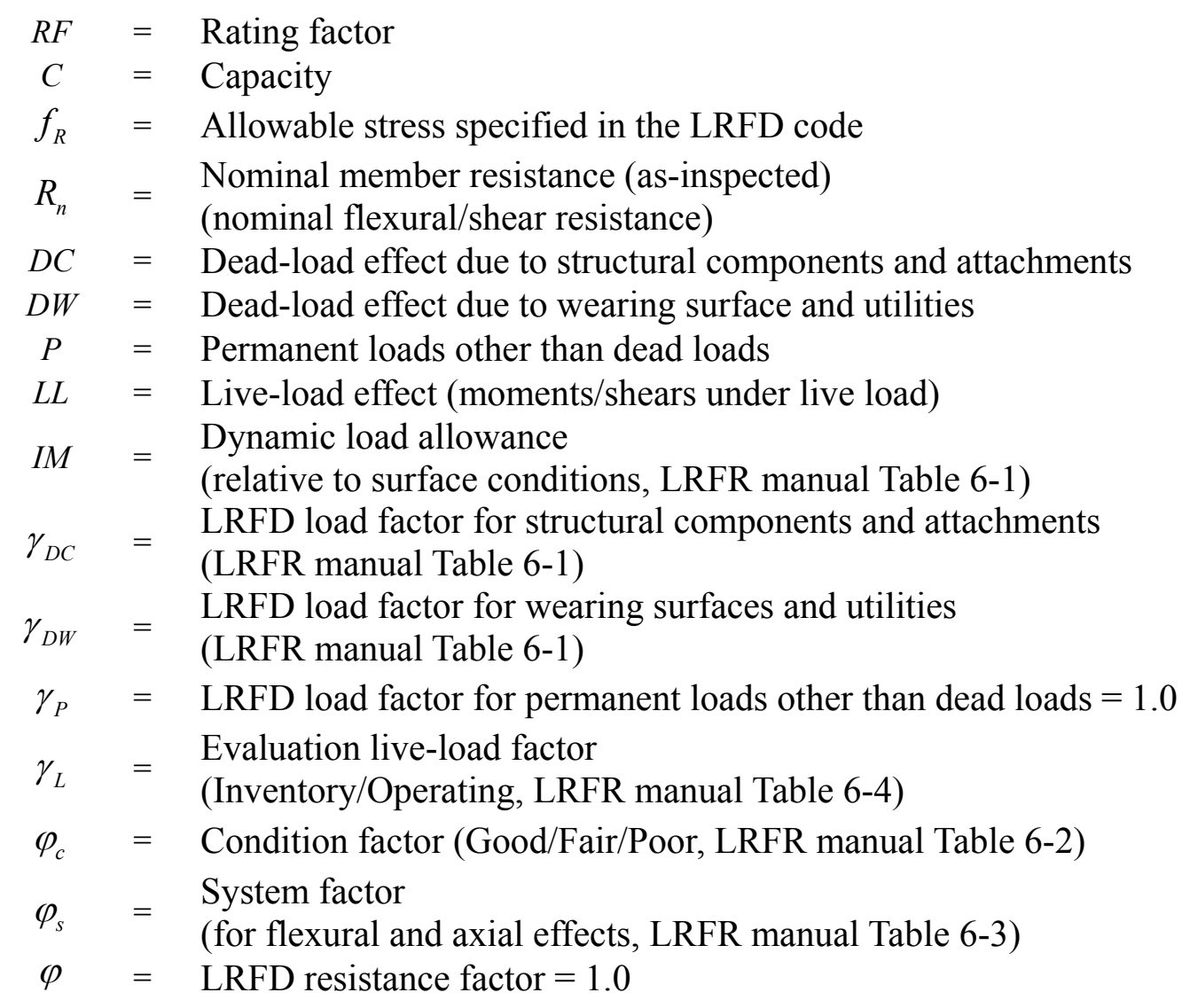

The procedures of the theoretical load rating can be summarized as shown in Figure 4.3. For detail rating process and rating example, refer to the LRFR manual. The detail rating procedures of Evansville Bridge are described in Appendix A2. 


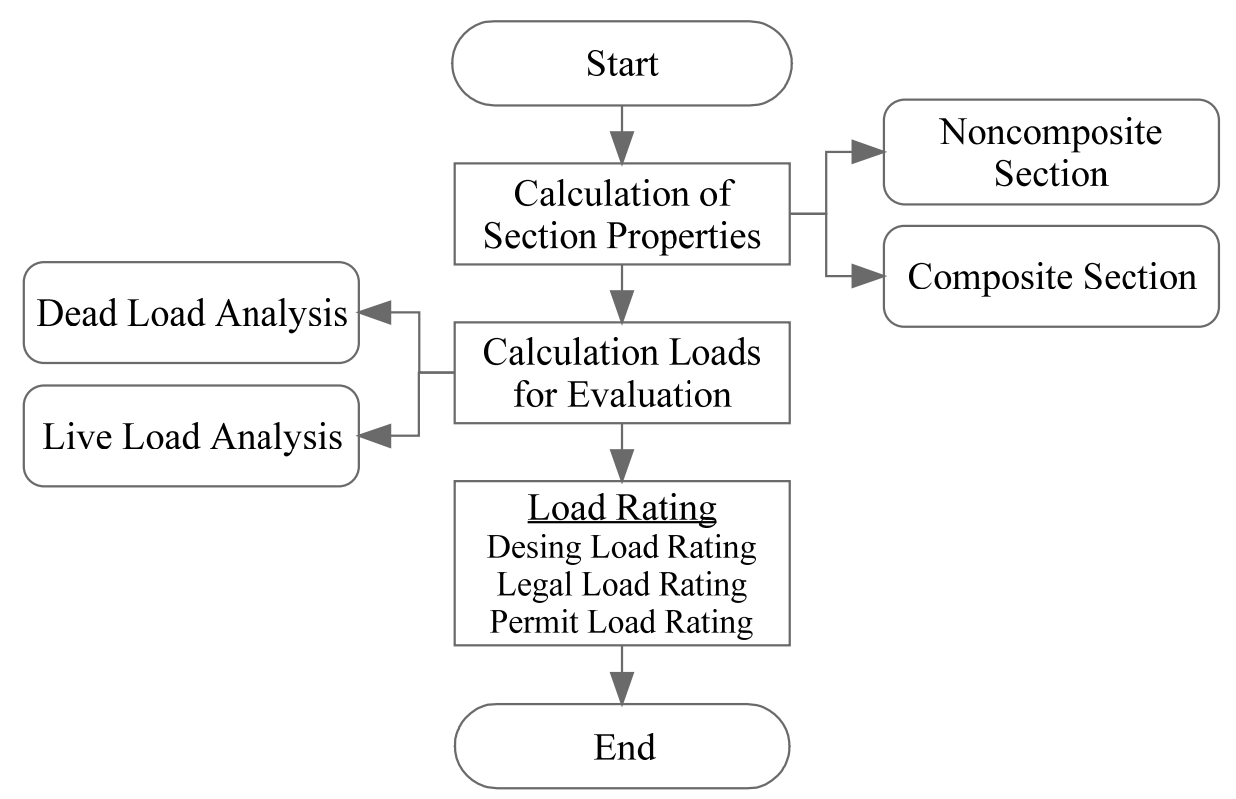

Figure 4.3 Rating Procedures of LRFR

\subsubsection{Bridge Load Rating Through Load Testing}

Bridge load testing is to observe and measure the response of a bridge under controlled and predetermined loadings without causing elastic response changes in the structure. Load tests can be carried out to verify the structure performance under known loads and provide an alternative evaluation method to theoretical load rating of a bridge (LRFR Manual). It is recognized as the only way to determine the real capacity of bridges (Washer and Fuchs 1998).

Load tests can be classified into two major types: diagnostic tests and proof tests. In a diagnostic test, the bridge is subjected to a pre-weighed load below its elastic load limit. Strain and/or deflection measurements are recorded at predetermined locations in order to determine the load distribution factor and stiffness of the bridge. Diagnostic tests are normally used to determine certain response characteristics of the bridge, or to validate analytical procedures or mathematical models. In a proof test, loads applied to the bridge are increased gradually until a certain load is reached or nonlinear behavior happens. Proof tests are performed to establish the maximum safe load capacity of a bridge, where the bridge behavior is within the linear-elastic range (Lichtenstein 1998).

Bridge load rating through load testing is conducted to determine the live load capacity that the bridge can safely carry. Both of diagnostic and proof tests can be employed to provide better understanding of the behavior of the bridge, and the 
measurements can be used to adjust or refine the theoretical load rating factors. In this study, only diagnostic tests were employed because it can be completed in less time than a proof test and the design plans of the target bridge are available to create a reprehensive analytical model.

Prior to initiating a diagnostic load test, the bridge should be rated analytically using the procedures outlined in the LRFR manual. The theoretical values are then re-examined and adjusted to reflect the actual performance of the bridge obtained from the diagnostic test results.

A major part of diagnostic testing is to assess the differences between predicted and measured responses that will be used in determining the load rating of the bridge. The following equation should be used to modify the calculated load rating following a diagnostic load test (Lichtenstein 1998):

$$
R F_{T}=R F_{c} \times K
$$

where:

$R F_{T}=$ the load-rating factor for the live-load capacity based on the load test results.

$R F_{c}=$ the rating factor based on calculations prior to incorporating test results.

$K=$ adjustment factor resulting from the comparison of measured test behavior with the analytical model (represents the benefits of the field load test, if any)

The adjustment factor $(K)$ is given by

$$
K=1+K_{a} \times K_{b}
$$

where:

$K_{a}=$ Accounts for both the benefit derived from the load test, if any, and consideration of the section factor (area, section modulus, etc.) resisting the applied test load.

$K_{b}=$ Accounts for the understanding of the load test results when compared with those predicted by theory

Without a load test, $K=1$. If the load test results agree exactly with theory, then $K$ $=1$ also. Generally, after a load test $K$ is not equal to one. If $K>1$, then response of the bridge is more favorable than predicted by theory and the bridge load capacity 
may be enhanced. On the other hand, if $K<1$, then actual response of the bridge is more severe than that predicted and the theoretical bridge load capacity may have to be reduced.

The following general expression are used in determining $K_{a}$ :

$$
K_{a}=\frac{\varepsilon_{C}}{\varepsilon_{T}}-1
$$

where:

$\varepsilon_{T}=$ Maximum member strain measured during load test.

$\varepsilon_{C}=$ Corresponding calculated strain due to the test vehicle, at its position on the bridge which produced $\varepsilon_{T}$.

In general:

$$
\varepsilon_{C}=\frac{L_{T}}{(S F) E}
$$

$L_{T}=$ Calculated theoretical load effect in member corresponding to the measured strain $\varepsilon_{T}$.

$S F=$ Member appropriate section factor (area, section modulus, etc.).

$E=$ Member modulus of elasticity.

The factor $K_{b}$ is defined as follows:

$$
K_{b}=K_{b 1} \times K_{b 2} \times K_{b 3}
$$

$K_{b 1}$ takes into account the analysis performed by the load test team and their understanding and explanations of the possible enhancements to the load capacity observed during the test. Table 4.1 provides guidance based on the anticipated behavior of the bridge members at the rating load level, and the relationship between the unfactored test vehicle effect $(T)$ and the unfactored gross rating load effect $(W)$. 
Table 4.1 Values for $K_{b 1}$

\begin{tabular}{c|c|c|c|c|c}
\hline \multicolumn{2}{c}{$\begin{array}{c}\text { Can member behavior be } \\
\text { extrapolated to 1.33 } \boldsymbol{W} \text { ? }\end{array}$} & \multicolumn{3}{c|}{ Magnitude of test load } & \multirow{2}{*}{$\boldsymbol{K}_{\boldsymbol{b} \boldsymbol{1}}$} \\
\hline YES & NO & $T / W<0.4$ & $0.4 \leq T / W \leq 0.7$ & $T / W>0.7$ & \\
\hline$\sqrt{ }$ & & $\sqrt{ }$ & & & 0 \\
\hline$\sqrt{ }$ & & & $\sqrt{ }$ & & 0.8 \\
\hline$\sqrt{ }$ & $\sqrt{ }$ & $\sqrt{ }$ & & $\sqrt{ }$ & 1.0 \\
\hline & $\sqrt{ }$ & & $\sqrt{n}$ & 0 \\
\hline & $\sqrt{ }$ & & & $\sqrt{ }$ & 0.5 \\
\hline
\end{tabular}

$K_{b 2}$ takes into account the ability of the inspection team to find problems in time to prevent any changes of bridge condition from invalidating the test results, and will depend on the type and frequency of inspection. Values for $K_{b 2}$ are given in Table 4.2.

Table 4.2 Values for $K_{b 2}$

\begin{tabular}{c|c|c}
\hline \multicolumn{2}{c|}{ Inspection } & \multirow{2}{*}{$\boldsymbol{K}_{\boldsymbol{b} \mathbf{2}}$} \\
\hline Type & Frequency & 0.8 \\
\hline Routine & Between 1 \& 2 years & 0.9 \\
\hline Routine & Less than 1 year & 0.9 \\
\hline In-Depth & Between 1 \& 2 years & 1.0 \\
\hline In-Depth & Less than 1 year & \\
\hline
\end{tabular}

$K_{b 3}$ takes into account the presence of critical structural features which cannot be determined in a diagnostic test and which could contribute to the sudden fatigue, fracture or instability failure. Typical values for $K_{b 3}$ are given in Table 4.3.

Table 4.3 Values for $K_{b 3}$

\begin{tabular}{c|c|c|c|c}
\hline \multicolumn{2}{c|}{ Fatigue Controls } & \multicolumn{2}{c|}{ Redundancy } & \multirow{2}{*}{$\boldsymbol{K}_{\boldsymbol{b} 3}$} \\
\hline NO & YES & NO & YES & 0.7 \\
\hline & $\sqrt{ }$ & $\sqrt{ }$ & & 0.8 \\
\hline$\sqrt{ }$ & $\sqrt{ }$ & $\sqrt{ }$ & $\sqrt{ }$ & 0.9 \\
\hline$\sqrt{ }$ & & & $\sqrt{ }$ & 1.0 \\
\hline
\end{tabular}

Engineering judgment based on observation made during the diagnostic load test must be used in establishing values for $K_{b 1}, K_{b 2}, K_{b 3}$. The values recommended for these parameters are based on experience and have been selected to provide a "level of comfort" in extrapolating the diagnostic test results to a realistic rating load. They should be considered as maximum values. Engineers may select smaller values as an appropriate consideration.

Following the diagnostic test, the theoretical rating vehicle effects are modified by the term $K$ (4.3) which includes both the benefits of the test results as well as the adjustment factor. 


\subsection{Software Development}

The procedures and processes of bridge load rating through load testing is summarized in the flow chart shown in Figure 4.4. From the geometrical \& material properties of the bridge, visual inspection results, load configurations (design load, legal load and permit load) and others, the bridge is theoretically rated according to the AASHTO LRFR tables \& procedures. This produces the theoretical rating factors $R F_{C}$. From the geometrical \& material properties of the bridge, boundary conditions, moving loads and dimension of lanes, finite element model may be developed to calculate the moments under moving loads and decide the critical positions on the bridge. Instrumentation plan for diagnostic load test may be worked out according to these critical positions. Strain responses under moving loads at crawl speeds are measured in the diagnostic load test. Comparison between measured strain and calculated strain will produce an adjustment factor $K$. Then the rating factors $R F_{T}$ through load test can be calculated as $R F_{T}=K \times R F_{C}$. 


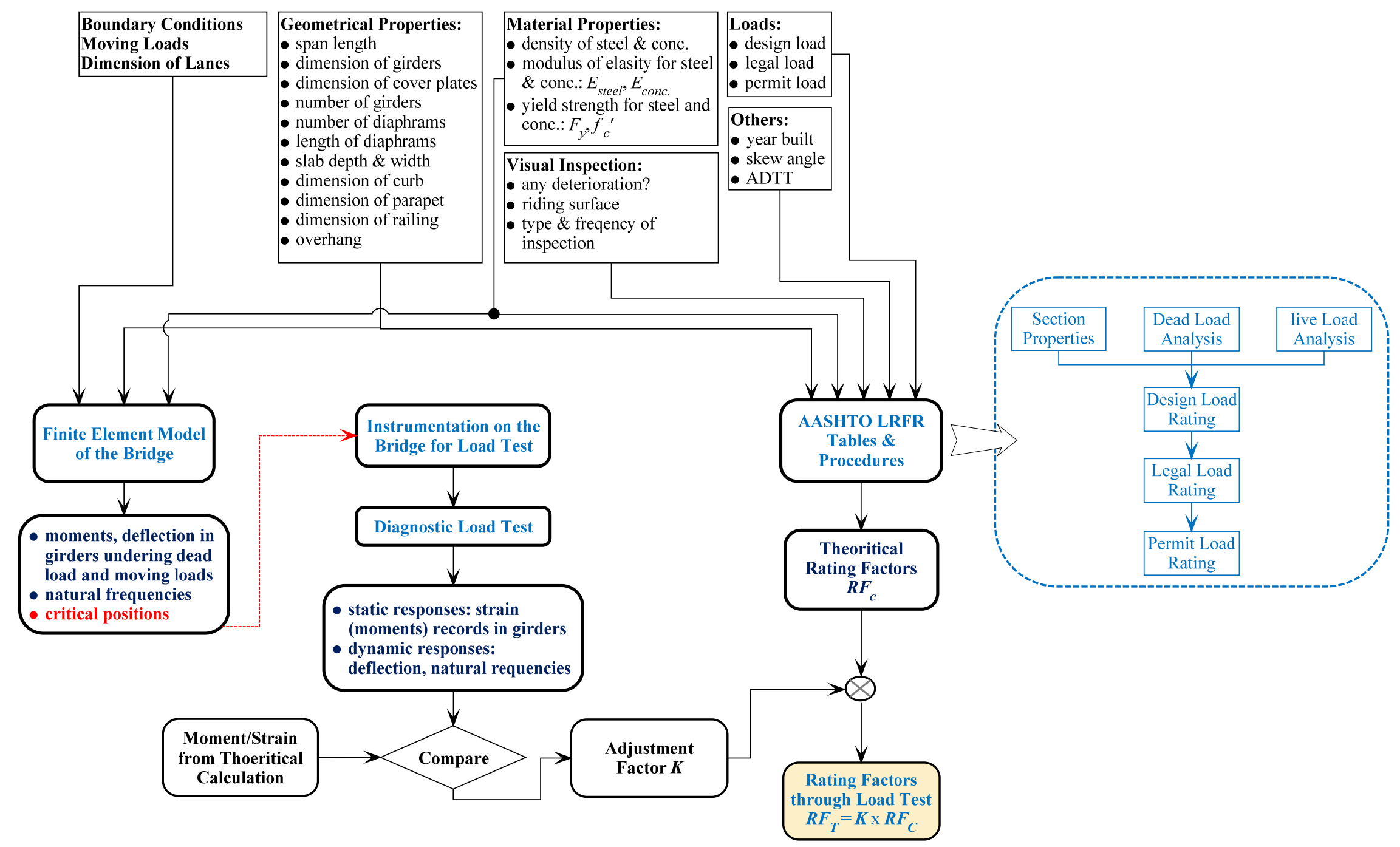

Figure 4.4 Flow chart of bridge load rating through load testing 


\subsubsection{Programs for Theoretical Rating}

Prior to initiating a diagnostic load test, the bridge should be rated theoretically using procedures contained in Manual for Condition Evaluation and Load and Resistance Factor Rating (LRFR) of Highway Bridges (2003). The key rating procedures of Evansville Bridge is shown in Appendix A2.

Actually, three different programs for theoretical rating have been developed during this study. For all of them, the rating factors can be automatically obtained by just inputting the values of the bridge properties and choosing proper values based on the AASHTO LRFR specifications.

The first version was developed using Microsoft Excel, shown in Figure 4.5. According to the rating procedures of LRFR (Figure 4.3), a series of sheets have been created to calculate different values, and rating factors are obtained at the end. The procedures strictly follow the LRFR codes and examples.

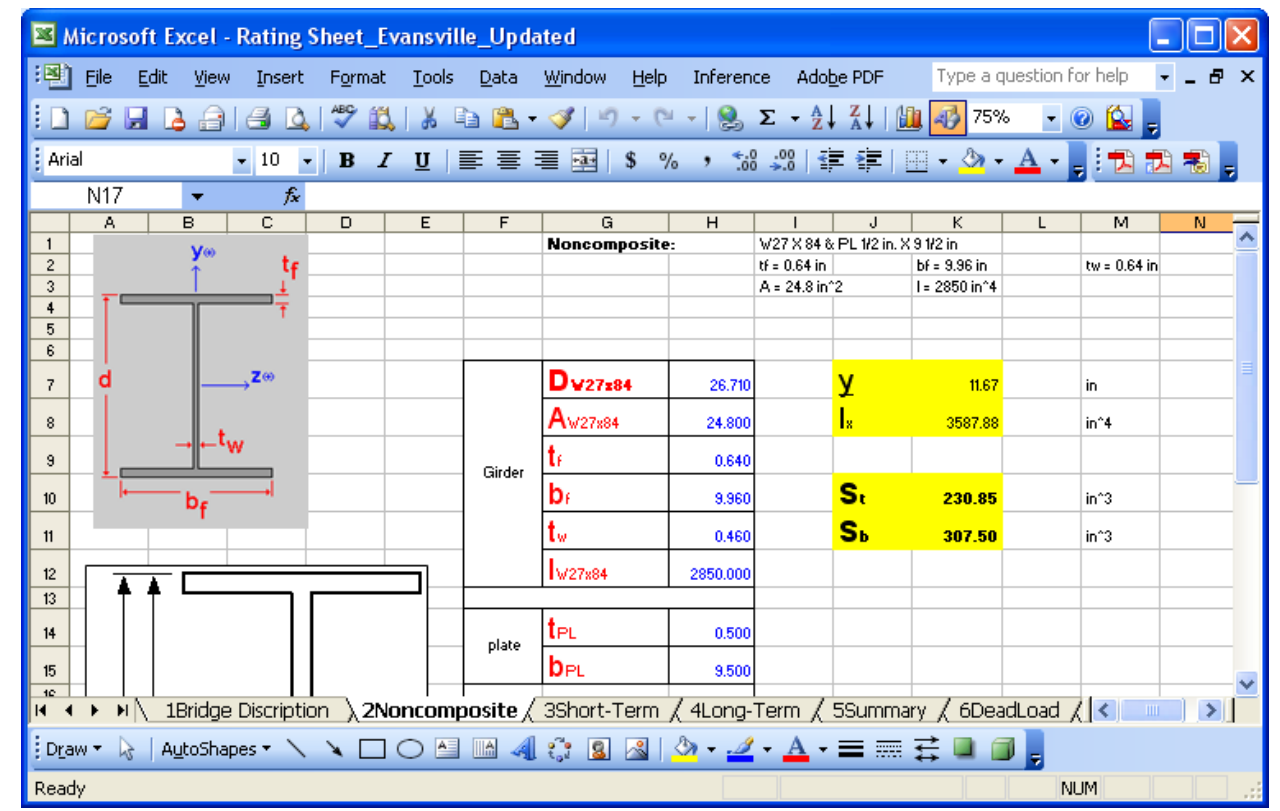

Figure 4.5 Excel LRFR load rating program

In order to make it more convenient for users, a graphic user interface (GUI) was developed using Visual Basic 2005. All of the confusing LRFR codes and cumbersome calculations are invisible to users. Users just need to input the properties and parameters through the friendly interface and the software will do the rating very quickly. The interfaces of the Visual Basic program are shown in Figure 4.6. 


\begin{tabular}{|c|c|c|}
\hline \multicolumn{3}{|c|}{ Given Properties } \\
\hline Span (ft.): & 48.5 & \\
\hline Year Built: & 2003 & \\
\hline Material (Type): & & A36 Steel \\
\hline Material (Fv. ksi): & 50 & \\
\hline Material (fc'. ksi): & 3 & \\
\hline Conditioin: & & No deterioration \\
\hline Rating Surface: & & Minor surface deviations \\
\hline ADTT (one dir.): & 1000 & \\
\hline Skew (Deqree): & 55 & \\
\hline
\end{tabular}

Skew (Deqree):

\section{Noncomposite Properties}

\begin{tabular}{|c|c|c|}
\hline \multicolumn{3}{|c|}{ Noncomposite } \\
\hline \multirow{6}{*}{ Girder: } & $d$ (in.): & 26 \\
\hline & tf (in.): & \\
\hline & bf (in.): & \\
\hline & tw (in.): & \\
\hline & $A($ in 2$):$ & \\
\hline & I (in. 4): & \\
\hline \multirow{3}{*}{ Plate: } & tPL (in.): & \\
\hline & $b P L$ (in.): & \\
\hline & IPL (ft.): & \\
\hline
\end{tabular}

\section{Parameters of the Bridge}

Slab Depth. ts (in ) Slab Width. ws (ft.)

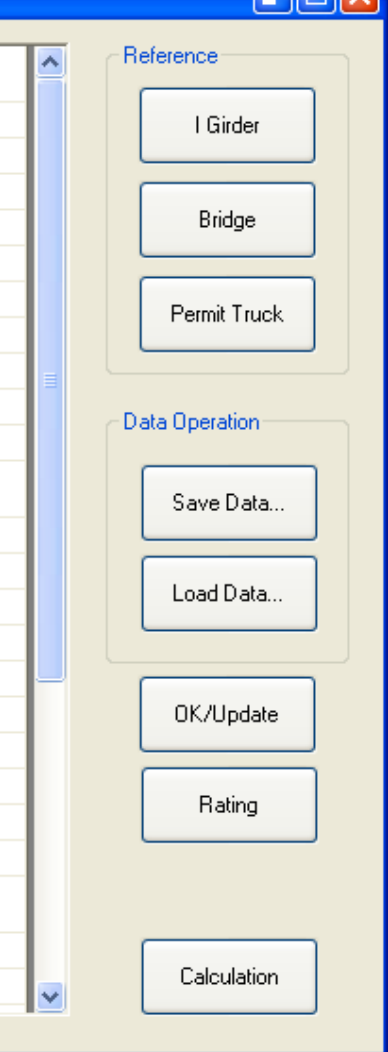

\begin{tabular}{|c|c|c|c|c|c|c|c|}
\hline \multicolumn{8}{|c|}{ Rating Results of Interior Girder } \\
\hline \multicolumn{2}{|c|}{ Limit State } & \multicolumn{2}{|c|}{ Design Load Rating } & \multicolumn{3}{|c|}{ Legal Load Rating } & \multirow[t]{2}{*}{ Permit Load Rating } \\
\hline & & Inventory & Operating & T3 & $\mathrm{T} 3 \mathrm{~S} 2$ & T3-3 & \\
\hline \multirow{2}{*}{ Strength I } & Flexure & 2.13 & 2.76 & 3.91 & 4.31 & 4.6 & \\
\hline & Shear & 2.3 & 2.98 & 4.38 & 4.06 & 4.3 & \\
\hline \multirow{2}{*}{ Strength II } & Flexure & & & & & & 3.41 \\
\hline & Shear & & & & & & 2.9 \\
\hline Service II & & 1.91 & 2.48 & 3.31 & 3.65 & 3.89 & 2.61 \\
\hline \multicolumn{2}{|c|}{ Safe Load Capacity (tons) } & & & 82.6 & 131.4 & 156 & \\
\hline \multicolumn{8}{|c|}{ Rating Results of Exterior Girder } \\
\hline \multicolumn{2}{|c|}{ Limit State } & \multicolumn{2}{|c|}{ Design Load Rating } & \multicolumn{3}{|c|}{ Legal Load Rating } & Permit Load Rating \\
\hline & & Inventory & Operating & $\mathrm{T} 3$ & $\mathrm{~T} 3 \mathrm{~S} 2$ & T3.3 & \\
\hline \multirow{2}{*}{ Strength I } & Flexure & 2.41 & 3.12 & 4.56 & 5.04 & 5.38 & \\
\hline & Shear & 3.65 & 4.73 & & & & \\
\hline \multirow{2}{*}{ Strength II } & Flexure & & & & & & 2.93 \\
\hline & Shear & & & & & & 4.01 \\
\hline Service II & & 2.42 & 3.15 & 4.2 & 4.63 & 4.94 & 2.52 \\
\hline \multicolumn{2}{|c|}{ Safe Load Capacity (tons) } & & & 104.9 & 166.7 & 198 & \\
\hline
\end{tabular}

Figure 4.6 Interfaces of bridge rating software using Visual Basic 
For integrating the theoretical rating results with load testing results to obtain accurate rating factors, the third version program has been developed. In the new version, theoretical rating is part of the software. The software also contains the functions of field data process and rating through load test. MATLAB platform has been adopted because of its strong ability of data analysis and process.

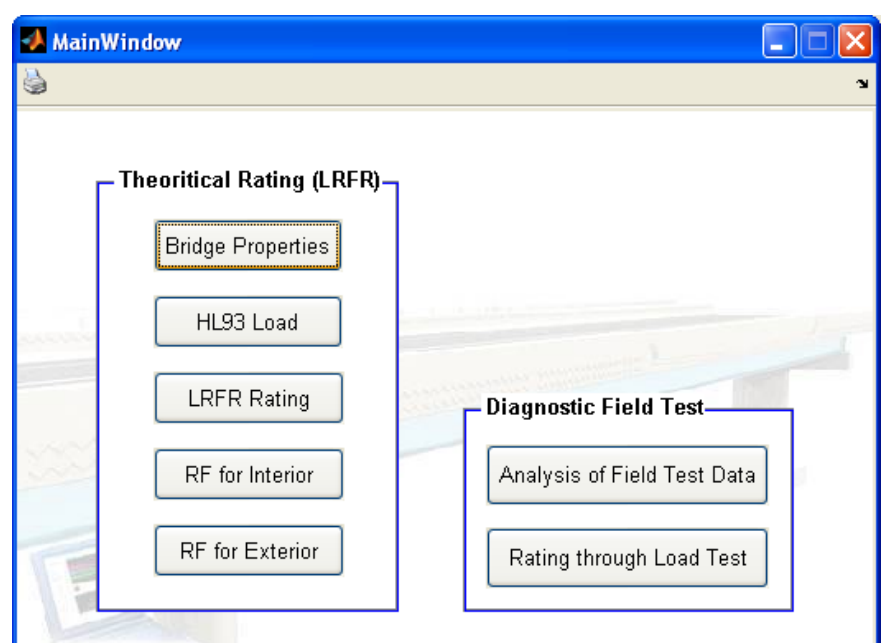

\section{Figure 4.7 Interface of bridge rating software using MATLAB}

The theoretical rating strictly follows the rating procedures of LRFR, as shown in Figure 4.3. The cumbersome hand-calculating rating procedures are also presented in Appendix A2. The list of files and their functions are shown in Table 4.4.

Table 4.4 Files for $\mathbf{L R F R}$

\begin{tabular}{l|l}
\hline \multicolumn{1}{c}{ Files } & \multicolumn{1}{c}{ Functions } \\
\hline $\begin{array}{l}\text { MainWindow.fig } \\
\text { MainWindow.m }\end{array}$ & Create the main window of the software \\
\hline $\begin{array}{l}\text { frmProperties.fig } \\
\text { frmProperties.m }\end{array}$ & $\begin{array}{l}\text { Create interface of "Bridge Properties" and allow users to } \\
\text { input parameters of the bridge }\end{array}$ \\
\hline properties.mat & Contains the bridge properties \\
\hline CalMoment.m & $\begin{array}{l}\text { Calculates moments \& shears of continues beam using } \\
\text { three-moment method }\end{array}$ \\
\hline HL93Load.m & Calculates moments \& shears of the bridge under HL93 Load \\
\hline LegalLoad.m & Calculates moments \& shears of the bridge under Legal Load \\
\hline LoadResults.mat & Contains moment \& shear values of HL93 design load \\
\hline LegalPermimtLoad.mat & Contains moment \& shear values of legal load and permit load \\
\hline $\begin{array}{l}\text { frmRatingResults_Exterior.fig } \\
\text { frmRatingResults_Exterior.m }\end{array}$ & $\begin{array}{l}\text { Creates interface of displaying rating factors of exterior } \\
\text { girders }\end{array}$ \\
\hline $\begin{array}{l}\text { frmRatingResults_Interior.fig } \\
\text { frmRatingResults_Interior.m }\end{array}$ & Creates interface of displaying rating factors of interior girders \\
\hline Rating_Interior.mat & Contains rating factors of interior girders \\
\hline Rating_Exterior.mat & Contains rating factors of exterior girders \\
\hline
\end{tabular}

After the use input the bridge properties, moments and shears under design HL93 load are calculated. The bridge is rated according to the AASHTO LRFR codes and rating factors can be obtained. Figure 4.8 illustrated the steps and interfaces. 




Figure 4.8 Steps and Interfaces of LRFR 


\subsubsection{Programs for Field Data Process}

The data of the diagnostic test includes data from strain gages, accelerometers and wireless vehicle position indicator. After the field test, data is downloaded to the computer for post-process. The raw data is saved as voltage code and needs to be converted to physical values, such as microstrain for strain and $g$ for acceleration. The original signals are normally noisy and desnoing is necessary.

The initial value of the raw signal from each channel is not zero. The signals need to be normalized (balanced) and converted to voltage values. Based on the gage factors of the wireless sensors, the corresponding signals are transformed into their physical values.

Considering the raw data is noisy and denoising is necessary, the signal denoising method called 1-D double-density complex DWT denoising method (http://taco.poly.edu/selesi/DoubleSoftware/signal.html) is applied to clean the data. This method is very effective and the denoising results can be found in Chapter 6 .

In order to obtain the truck positions from the signal of WVPI, all peaks and valleys of the WVPI signal are located. The users are allowed to erase the redundant local peaks \& valleys to insure the right calculation. By coordinating the peaks \& valleys with the time, the truck positions in time domain can be identified.

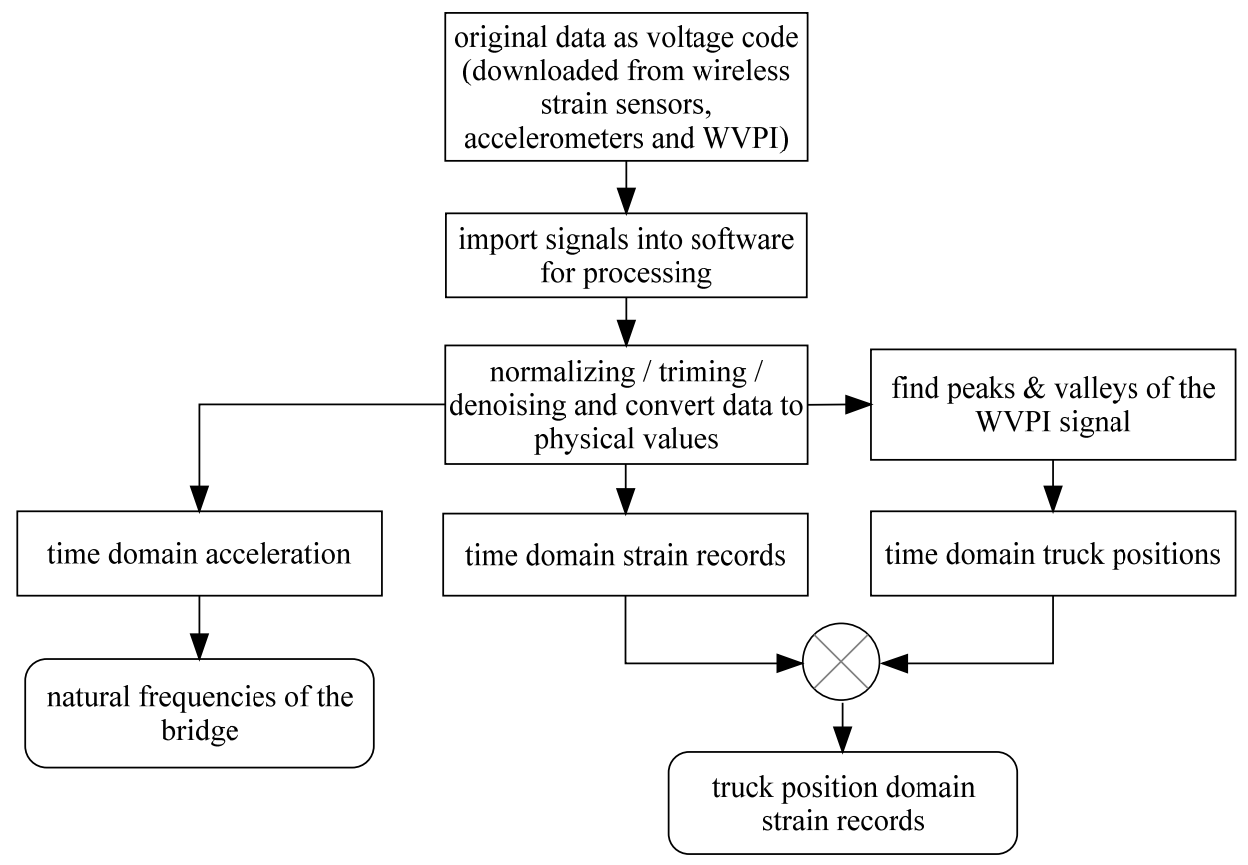

Figure 4.9 Flow chart of processing of field test data 
Following the steps discussed above, the time domain signals (acceleration, strain, truck positions) can be obtained. The natural frequencies of the bridge can be calculated with the acceleration signals. By combining the time domain strain signals and truck positions, truck position domain strain records can be achieved. The flow chart of the data-processing procedures is shown in Figure 4.9, and the MATLAB interface for data processing is shown in Figure 4.10. Files for process of field test data are listed in Table 4.5.

Table 4.5 Files for process of load test data

\begin{tabular}{|c|c|}
\hline Files & Functions \\
\hline $\begin{array}{l}\text { BridgeProcess.fig } \\
\text { BridgeProcess.m }\end{array}$ & Create interface and process data of diagnostic load test \\
\hline $\begin{array}{l}\text { afb3.m } \\
\text { cshift.m } \\
\text { doubledual_S1D.m } \\
\text { doubledualfilt.m } \\
\text { doubledualtree_f1D.m } \\
\text { doubledualtree_i1D.m } \\
\text { FSdoubledualfilt.m } \\
\text { sfb3.m } \\
\text { Soft.m }\end{array}$ & $\begin{array}{l}\text { Denosing package for 1-D signal. } \\
\text { (http://taco.poly.edu/WaveletSoftware/dt1D.html) } \\
\text { Key function for denoising: } \\
\text { de_signal = doubledual_S1D (noise_signal, threshold) }\end{array}$ \\
\hline WVPI.mat & Contains processed data of WVPI signals \\
\hline
\end{tabular}

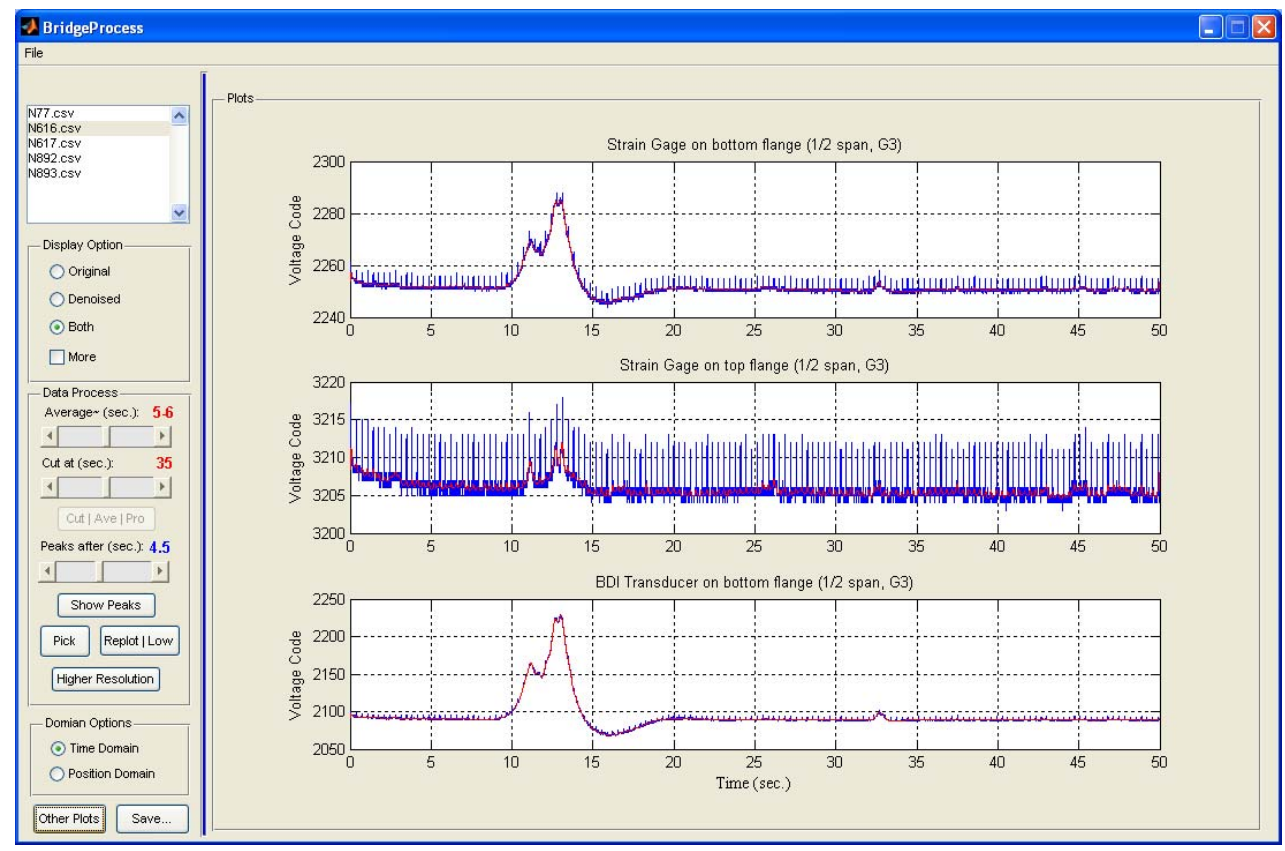

Figure 4.10 Interface of processing of field test data

The key functions and subroutines for data processing are following and they are also available in the attached CD.

$\%$ open files and import recorded data for processing function fileopen_Callback(hobject, eventdata, handles) 
$\%$ data denoising using the 1-D double-density complex DWT

function DData $=$ DenoisedData $($ data $)$

$\%$ convert signal from codes to volt, then to physical values (ue,g...)

function AveData $=$ AverageData(Range, Data, strName)

$\%$ average $\&$ cut data based on user definition

function AvecutData(indexCut, AveRange, TestType)

$\%$ find peaks \& valleys and their locations of WVPI signals

function $[\mathrm{P} 1, \mathrm{~L} 1, \mathrm{P} 2, \mathrm{~L} 2]$ = FindPeakValley (data, Peakstart)

$\%$ modified interpolation method for high resolution of truck positions

function [Ind_all, Pos_all, X_all] = InterPeaksValleys(dN77, L11, L12, L21, L22, DA, WC)

$\%$ plot figures according to users' choice

function WPlot(data, ddata, pmode, node, xDomain, MoreorNot, ProorNot)

\subsubsection{Load Rating through Diagnostic Load Testing}

After the theoretical rating and field data process, more accurate rating factors can be obtained by combining the theoretical rating factors with the field-testing results. Based on the axle weights and dimension of the test truck, theoretical maximum strain value at the instrumentation position is calculated. Through comparing the difference between the measured and calculated maximum strain value, an adjustment factor $K$ can be calculated according to the procedures discussed in Section 4.2.2. Multiplying the theoretical rating factors with the adjustment factor $K$, the more accurate factors through field-testing can be obtained. Figure 4.11 shows the interface of load rating through load testing results. Table 4.6 lists the corresponding files.

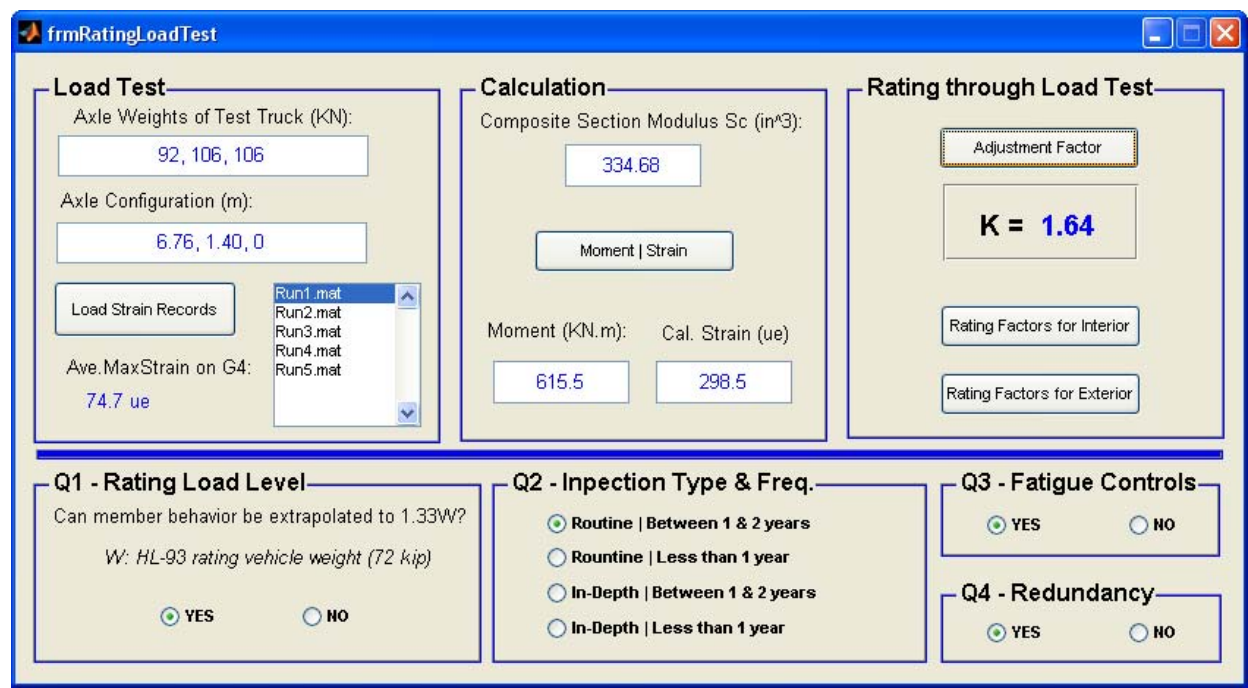

Figure 4.11 Interface of load rating through load testing results 
Table 4.6 Files for load rating through load testing

\begin{tabular}{|c|c|}
\hline Files & Functions \\
\hline $\begin{array}{l}\text { frmRatingLoadTest.fig } \\
\text { frmRatingLoadTest.m }\end{array}$ & $\begin{array}{l}\text { Create interface of rating through load testing and } \\
\text { calculate adjustment factor } K\end{array}$ \\
\hline MovingLoad.m & Calculates maximum moment under test truck loads \\
\hline $\begin{array}{l}\text { frmRatingResults_Exterior_LoadTest.fig } \\
\text { frmRatingResults_Exterior_LoadTest.m }\end{array}$ & $\begin{array}{l}\text { Creates interface of displaying rating factors of } \\
\text { exterior girders }\end{array}$ \\
\hline $\begin{array}{l}\text { frmRatingResults_Interior_LoadTest.fig } \\
\text { frmRatingResults_Interior_LoadTest.m }\end{array}$ & $\begin{array}{l}\text { Creates interface of displaying rating factors of } \\
\text { interior girders }\end{array}$ \\
\hline
\end{tabular}

With the advanced software, the cumbersome theoretical rating becomes much easier. The field test data can be processed very quickly in the lab or even on site. Rating factors through load testing can be calculated automatically. The software greatly saves the time for analysis and processing and makes the bridge load rating much easier to carry out. User manual of this software can be found in Appendix A5. 


\section{Chapter 5 \\ Structural Model of Evansville Bridge}

\subsection{Introduction}

The performance of the wireless bridge load testing \& rating system is to be evaluated through tests conducted on Evansville Bridge. In this chapter, a simplified finite element model of Evansville Bridge is created using SAP2000. The model is used to determine the bridge's theoretical responses under moving loads and allow for direct comparison with the measurements from the live load tests. Because only two of seven girders are instrumented, the lateral load distribution factors cannot be obtained through the load testing results. Therefore, the model is used to calculate the approximate distribution factors, which are important variables for bridge rating through load testing. The model is also utilized to predict the deflections of girders under moving load, because no displacement sensors were installed on the bridge.

\subsection{Bridge Description}

Evansville Bridge is located near the intersection of WV Route 92 with Route 50 over the Little Sandy Creek in Preston County, West Virginia. The bridge was completed in 2003. It is a typical three-span continuous steel girder bridge and has a $55^{\circ}$ skewed angle. The total length of the bridge is $44.8 \mathrm{~m}(147 \mathrm{ft})$, in which the lengths of the edge spans are $14.78 \mathrm{~m}(48.5 \mathrm{ft})$ and the central span is $15.24 \mathrm{~m}(50 \mathrm{ft})$ long. The bridge is supported over two piers and two integral abutments as shown in Figure 5.1 (a). Over the piers, the bottom flange of the girder was fillet-welded to 25 $\mathrm{mm}$ thick bearing plate with $6 \mathrm{~mm}$ weld size on both sides. Each bearing plate is placed over $0.12 \mathrm{~m}$ thick elastomeric bearings and anchored to the pier with four 32 $\mathrm{mm}$ diameter and $0.6 \mathrm{~m}$ long anchor bolts. At the abutment ends, the girders are placed on $6 \mathrm{~mm}$ thick elastomeric pads set on top of the bridge abutments. The abutments are $0.9 \mathrm{~m}$ thick, $1.82 \mathrm{~m}$ high and $162 \mathrm{~m}$ wide. The total bridge width is

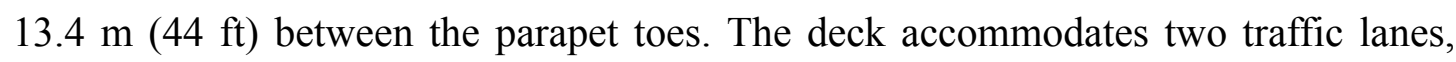
each $3.65 \mathrm{~m}$ (12 ft) wide, and two shoulders of widths 2.6 and $2.9 \mathrm{~m}$ as shown in 
Figure 5.1 (b). The bridge superstructure and abutments were designed in accordance with the AASHTO LRFD Specifications for HL-93 live load model (AASHTO 1999).

Shoukry et al. (2005) instrumented the bridge during its construction in order to monitor the bridge behavior due to temperature effects and traffic loads. McBride (2005) developed a detailed finite element model of this bridge using ADINA and compared the results with the measured data from the sensors installed in the bridge.

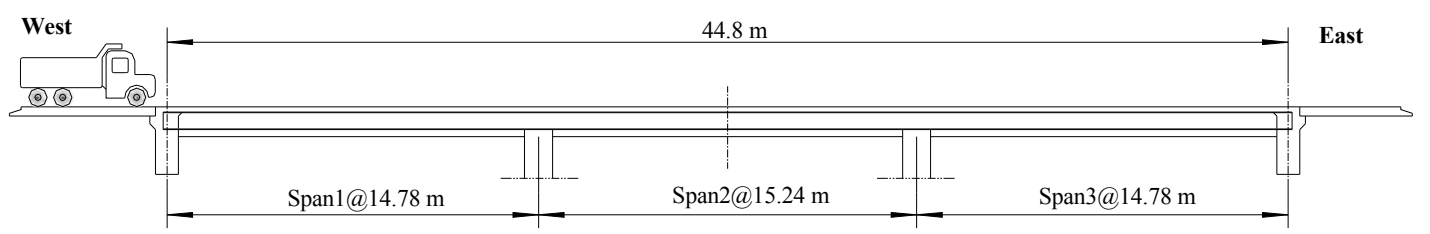

(a)

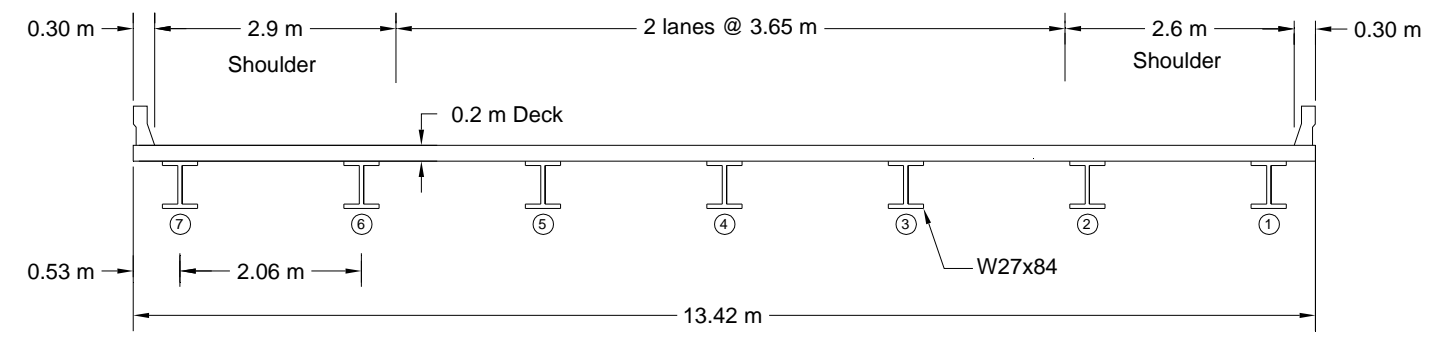

(b)

Figure 5.1 Evansville Bridge: (a) elevation; (b) side view

\subsection{Finite Element Model of Evansville Bridge}

In this study, the FEM was created with SAP2000. The analysis of dynamic responses under moving loads was carried out. The output of the software presents results including moments, axial loads and displacements. Figure 5.2 shows the SAP2000 model of Evansville Bridge.

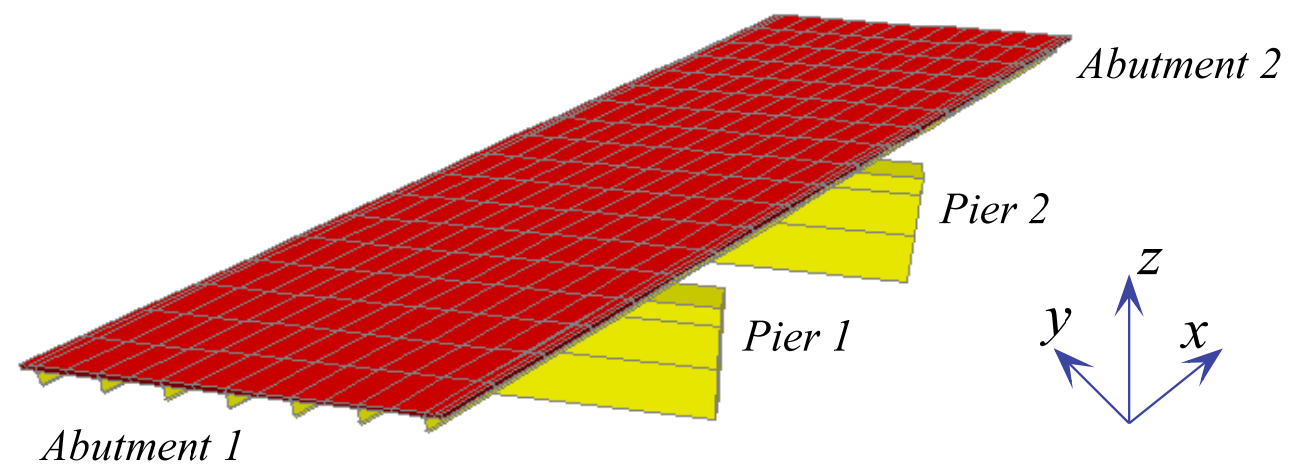

Figure 5.2 SAP2000 model of Evansville Bridge

The following material parameters were used (McBride, 2005): 
Table 5.1 Material properties of Evansville Bridge (McBride 2005)

\begin{tabular}{c|c|c}
\hline Properties & Steel & Concrete \\
\hline Modulus of Elasticity $(\mathrm{GPa})$ & 199.995 & 30.23 \\
\hline Poisson's Ratio & 0.3 & 0.24 \\
\hline Density $\left(\mathrm{Kg} / \mathrm{m}^{3}\right)$ & 7750.4 & 2395.7 \\
\hline Coefficient of Thermal Expansion $\left(/{ }^{\circ} \mathrm{C}\right)$ & $1.22 \times 10^{-5}$ & $1.126 \times 10^{-5}$ \\
\hline
\end{tabular}

At pier 1, the girders are connected to the concrete pier by a pinned support. The girders are only allowed to rotate about the transverse axis. The $y$-rotation degrees of freedom is set free with others fixed. At pier 2, the girders are able to translate slightly in the longitudinal direction and rotate about the transverse axis. Therefore, the $x$-translation and $y$-rotation degrees of freedom are left free while all others are fixed.

At the integral abutments, passive pressure $p_{p}$ caused by the surrounding sand can be expressed as following (McBride, 2005):

$$
p_{p}=K_{p} \gamma h
$$

where $K_{p}$ is earth pressure coefficient, $K_{p}=3.852$ when $\Delta / H=0.02$ or maximum passive earth pressures (McBride, 2005). Respectively, $\Delta$ and $H$ are wall displacement and wall height, $H=2.75 \mathrm{~m} . \gamma$ is the unit weight of soil, $\gamma=17.62 \mathrm{KN} / \mathrm{m}^{3}$ for medium dense sand. $h$ is the depth below the soil surface.

Then, the effective force apply on the abutment wall can be expressed as:

$$
F_{p}=\frac{1}{2} K_{p} \gamma H^{2} L_{b}
$$

where $L_{b}$ is the length of the abutment wall, $L_{b}=16.4 \mathrm{~m}$.

The soil pressure can be simplified as spring force with stiffness $k$ :

$$
k=F_{p} / \Delta
$$

Since $\Delta=0.02 H$, combining with equation $(5.2), k$ is obtained as:

$$
k=25 K_{p} \gamma H L_{b}
$$

Considering the skew angle of the bridge, the stiffness in $x$ - and $y$-direction can be calculated:

$$
\begin{aligned}
& k_{x}=k \sin \left(55^{\circ}\right)=62686 \mathrm{KN} / \mathrm{m} \\
& k_{y}=k \cos \left(55^{\circ}\right)=43893 \mathrm{KN} / \mathrm{m}
\end{aligned}
$$

The boundary conditions are summarized in Table 5.2. 
Table 5.2 Summary of boundary conditions

\begin{tabular}{c|c|c|c|c|c|c}
\hline & $\boldsymbol{x}$ & $\boldsymbol{y}$ & $\boldsymbol{z}$ & $\boldsymbol{R} \boldsymbol{R}$ & $\boldsymbol{R} \boldsymbol{R}$ & \multirow{2}{*}{} \\
\hline \multirow{2}{*}{ Abutment 1 } & $\begin{array}{c}\text { Spring } \\
(62686 \mathrm{KN} / \mathrm{m})\end{array}$ & $\begin{array}{c}\text { Spring } \\
(43893 \mathrm{KN} / \mathrm{m})\end{array}$ & $\times$ & $\times$ & $\sqrt{ }$ & $\sqrt{ }$ \\
\hline Pier 1 & $\times$ & $\times$ & $\times$ & $\times$ & $\sqrt{ }$ & $\times$ \\
\hline Pier 2 & $\sqrt{ }$ & $\times$ & $\times$ & $\times$ & $\sqrt{ }$ & $\times$ \\
\hline Abutment 2 & $\begin{array}{c}\text { Spring } \\
(62686 \mathrm{KN} / \mathrm{m})\end{array}$ & $\begin{array}{c}\text { Spring } \\
(43893 \mathrm{KN} / \mathrm{m})\end{array}$ & $\times$ & $\times$ & $\sqrt{ }$ & $\sqrt{ }$ \\
\hline
\end{tabular}

$x$ - fixed, $\sqrt{ }$ - free

Based on the information of bridge definitions, model of Evansville Bridge was created with shell elements. Because the moving truck paths are needed for dynamic response analysis, two lanes of the bridge were defined. The position of the moving truck on the bridge is determined by the properties of lanes and truck speed. Therefore, the bridge responses under moving loads can be calculated by automatically moving the truck loads step by step.

\subsection{Moving Vehicle Analysis}

The SAP2000 allows users to define the properties of the moving vehicles (loads), such as axle weights, distances between axles, distance between wheels, speed, starting point, wheel lines, directions and vehicle sequences etc. Two major concerns of bridge load analysis and test - moment \& deflection under moving loads at critical locations in girders can be calculated.

Figure 5.3 shows the dimensions and weights of the test truck used in the diagnostic load test on Evansville Bridge. The test truck crossed at crawl speed $(5 \mathrm{~m} / \mathrm{h})$ from west to east, and the starting position is $10 \mathrm{~m}$ away from the bridge. The distance between bridge centerline and drive-side wheel path is $0.45 \mathrm{~m}$.

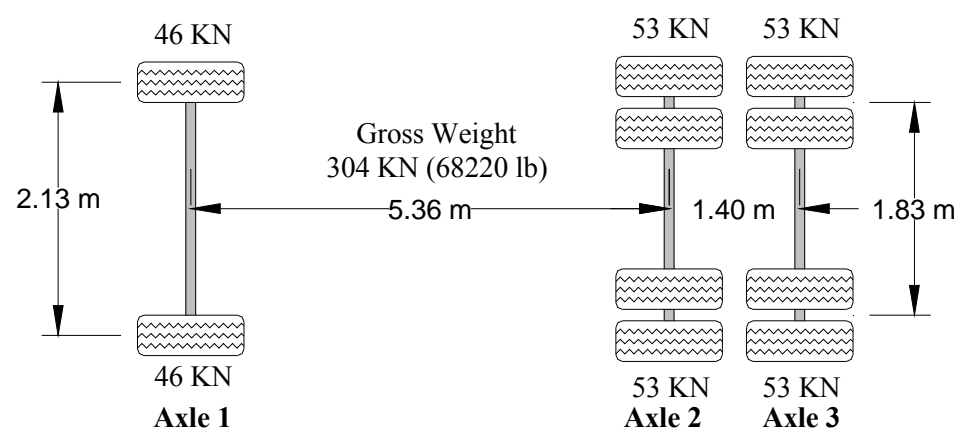

Figure 5.3 Configuration of test truck 


\subsection{Responses under Moving Loads}

The structural model was updated according to the configuration of test truck and preset truck path. Calculated moments at the middle of Span 1 in each girder are shown in Figure 5.4. Because the bridge has a $55^{\circ}$ skew angle, the maximum moments in each girder respectively appear at different truck positions. Since the truck started moving at $10 \mathrm{~m}$ away from the bridge, the moments corresponding to the first $10 \mathrm{~m}$ are zeros. When the truck is on Span 1, positive moments are produced. When the truck moves on Span 2, small negative moments appear. The moments are almost zeros after the truck moves on Span 3.

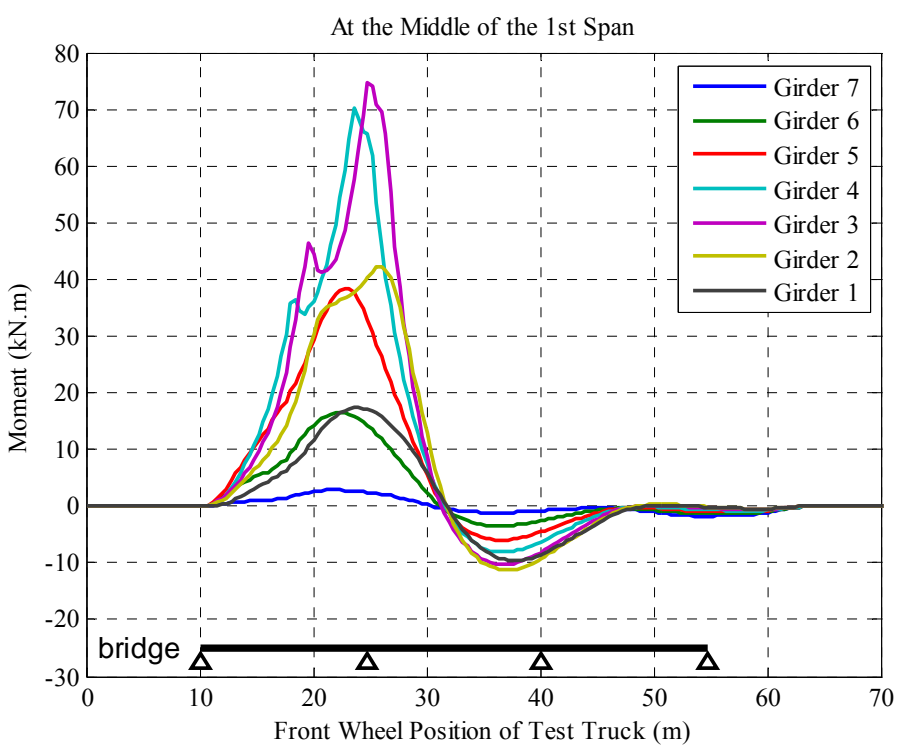

Figure 5.4 FEA moments at mid-span of Span 1

\subsubsection{Comparison between Test and FEA Moments}

The field test data can be used as a basis for modifying the parameters of the bridge model in order that the model behaves very similar to the actual structure. Moments calculated from finite element analysis were compared with test moments in girders. The latter can be computed by multiplying measured strain records and non-composite section modulus to bottom of girder $S_{B O T}\left(S_{B O T}=213.40 \mathrm{in}^{3}\right.$, Appendix A2).

Comparisons between test and modified FEA moments are shown in Figure 5.5 5.6. At mid-span, the maximum positive moment differences between FEA and load test were $0.3 \%$ in girder 3 and $4.4 \%$ in girder 4 respectively. The finite element model 
provided an acceptable approach to predict moments at the mid-span under moving loads.


Figure 5.5 Moment comparison at mid-span
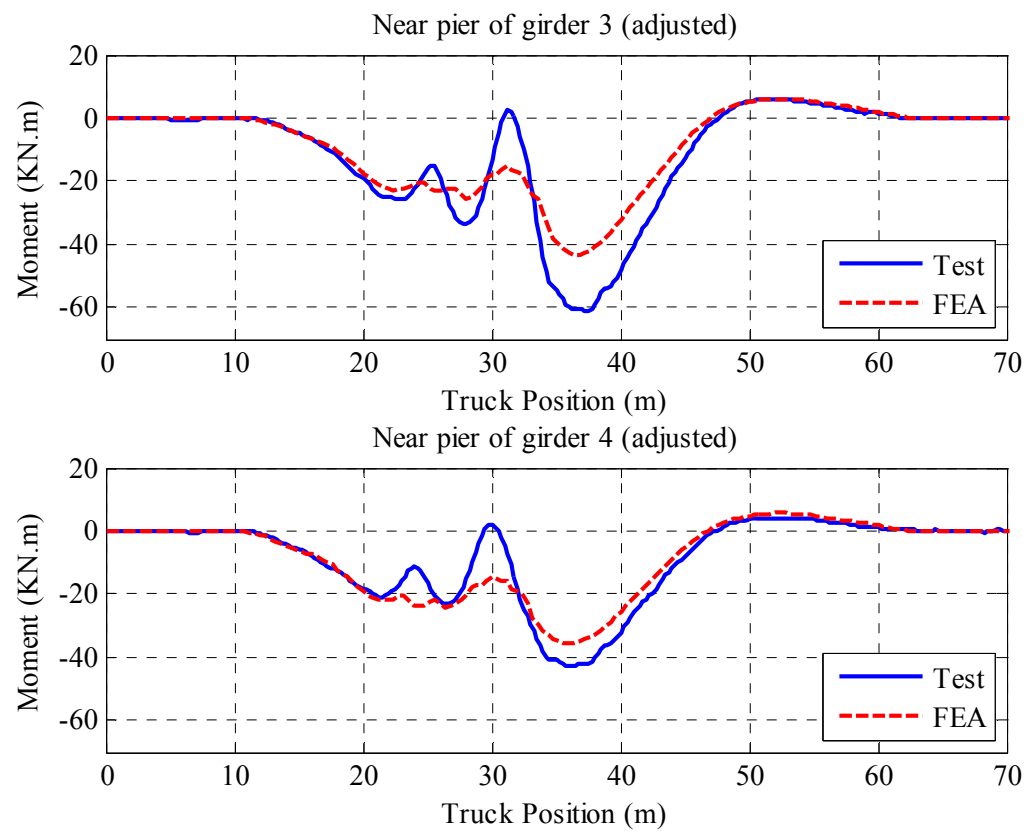

Figure 5.6 Moment comparison near pier

\subsubsection{Moments and Deflections}

For bridge load testing, instrumentation plan including locations and sensors may be influenced by accessibility and budget, responses at some locations may not be available. For example, in this study, only two of seven girders were instrumented on the first span and no displacement sensors were installed for deflection measurements. 
After the FE model has been calibrated by the test data, it can be considered as a relatively accurate model and is capable of predicting bridge responses under moving loads. Figure $5.7-5.8$ show the moments at the middle of other two spans. Figure 5.9 -5.11 show the deflections at the middle of each span. In the case that there are no measured responses, the calculated responses can be used as approximate predictions.

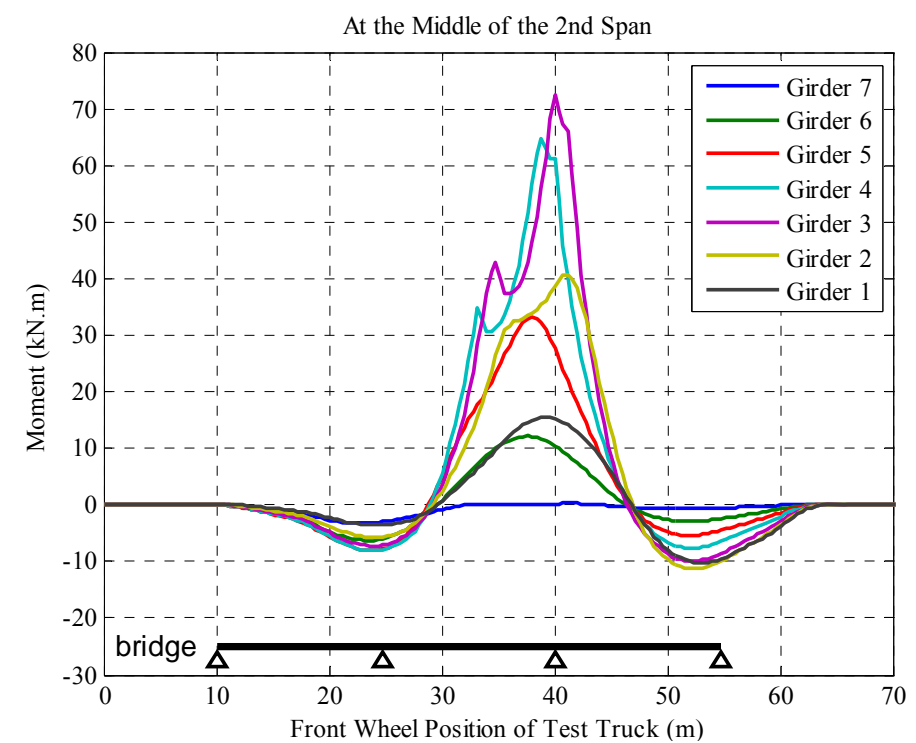

Figure 5.7 Calculated moments at mid-span of Span 2

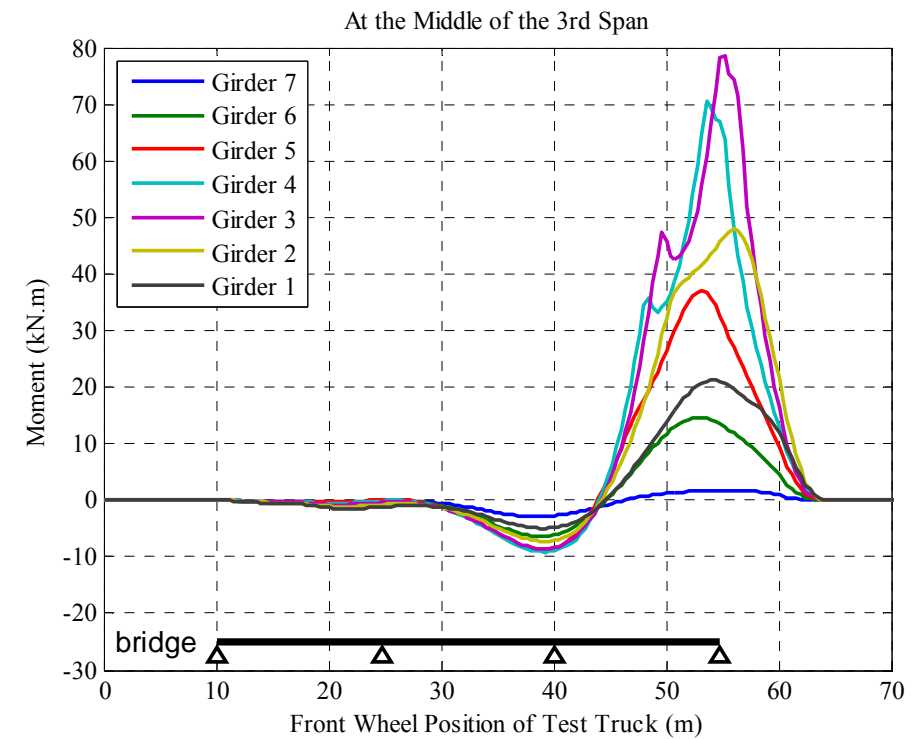

Figure 5.8 Calculated moments at mid-span of Span 3 




Figure 5.9 Calculated deflections at mid-span of Span 1

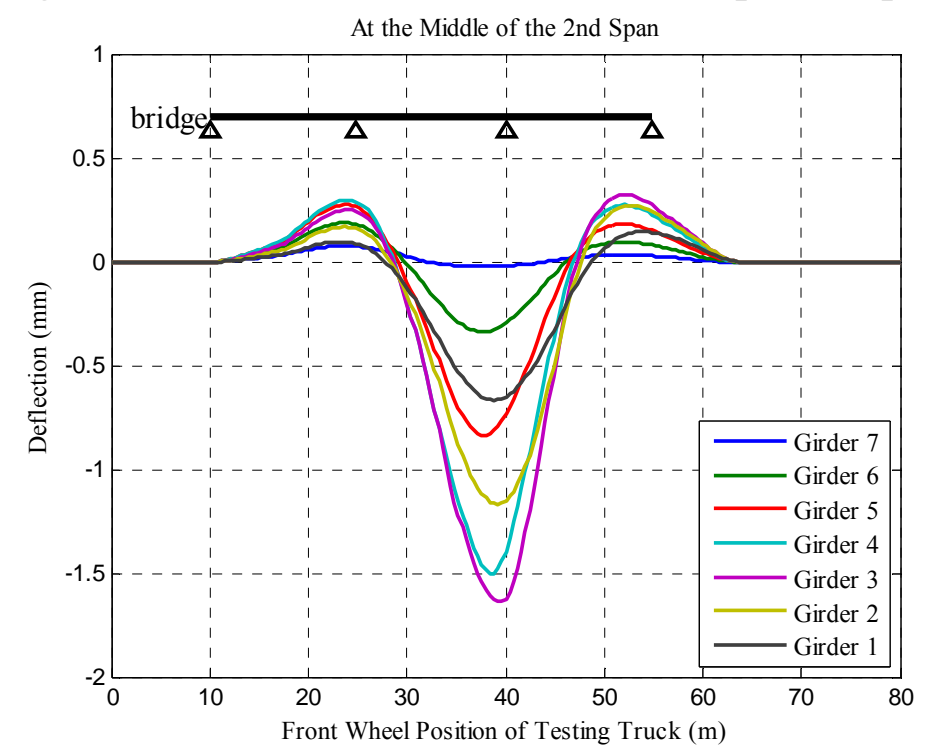

Figure 5.10 Calculated deflections at mid-span of Span 2

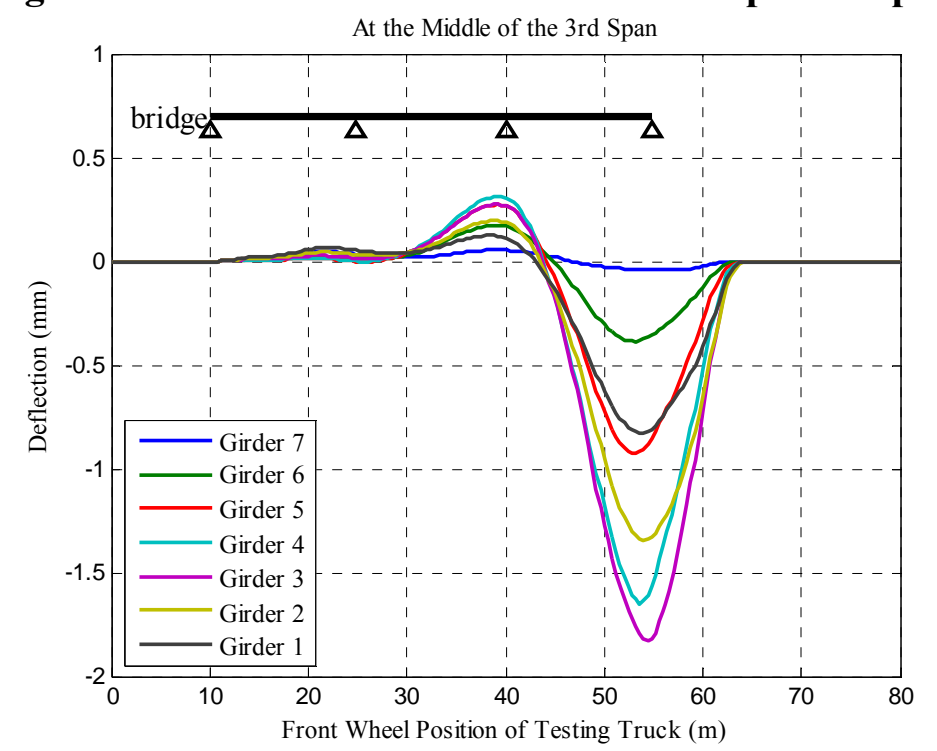

Figure 5.11 Calculated deflections at mid-span of Span 3 


\subsection{Calculation of Load Distribution Factors}

The transverse load distributions can be calculated with the ratio of that girder moment to the total bending moment at mid-span of the girders as following:

$$
T D F_{j}=\frac{M_{j}}{\sum_{i=1}^{n} M_{i}} \times 100 \%
$$

where: TDF: Transverse Distribution Factor, $M$ : Moment in girder, $j$ : Girder being evaluated, $n$ : Total number of girders, $i: i^{\text {th }}$ girder.

If all the girders have the same section properties, the transverse load distributions can be expressed as the ratio of that girder strain to the total bending strain at mid-span of the girders:

$$
T D F_{j}=\frac{\varepsilon_{j}}{\sum_{i=1}^{n} \varepsilon_{i}} \times 100 \%
$$

where: $T D F$ : Transverse Distribution Factor, $\varepsilon$ : Strain in girder, $j$ : Girder being evaluated, $n$ : Total number of girders, $i: i^{\text {th }}$ girder.

In this study, only two out of seven girders were instrumented during the field test on Evansville Bridge, the distribution factors can not be calculated from the measured strain values. However, the FE model has been calibrated with the test data and behaves similar to the actual bridge. Approximate load distribution factors can be determined from the FEA moments according to the equation (5.6), as shown in Table 5.2.

Table 5.3 Distribution factors for moment (one lane loaded)

\begin{tabular}{c|c|c|c|c|c|c|c|c}
\hline Girder No. & G1 & G2 & G3 & G4 & G5 & G6 & G7 & Total \\
\hline Dist. (\%) & 6.9 & 16.3 & $\mathbf{3 0 . 2}$ & 26.6 & 13.3 & 5.7 & 1.0 & 100 \\
\hline
\end{tabular}

The distribution factors in Table 5.2 are for the situation when one test truck is loaded on one lane (south lane). For this case, G3 is the critical member and carries $30.2 \%$ of the truck moment. Because of the symmetry, the distribution factor for G3 during a north lane pass is equal to that of G5 during a south lane pass, also $13.3 \%$. Then the distribution factors when two lanes are loaded can be obtained. Table 5.3 shows the complete list of distribution factors. 
Table 5.4 Test truck distribution factors

\begin{tabular}{c|c|c|c}
\hline Girder No. & Lane 1 Loaded (\%) & Lane 2 Loaded (\%) & 2 Lanes Loaded (\%) \\
\hline G1 & 6.9 & 1.0 & 7.9 \\
\hline G2 & 16.3 & 5.7 & 22 \\
\hline G3 & 30.2 & 13.3 & 43.5 \\
\hline G4 & 26.6 & 26.6 & $\mathbf{5 3 . 2}$ \\
\hline G5 & 13.3 & 30.2 & 43.5 \\
\hline G6 & 5.7 & 16.3 & 22 \\
\hline G7 & 1.0 & 6.9 & 7.9 \\
\hline Total & 100 & 100 & 200 \\
\hline
\end{tabular}

As can be seen from the table, when two lanes are loaded, the critical girder becomes G4 instead of G3, which carries $53.2 \%$ of the truck moment. 


\section{Chapter 6 \\ Load Testing \& Rating of Evansville Bridge}

\subsection{Introduction}

Compared to proof tests, diagnostic tests have several practical advantages including a lower cost, a shorter testing time, and less disruption to traffic. In addition, the design plans of the bridge is available to create a representative analytical model. Because of these advantages, diagnostic tests were employed in this study.

In order to evaluate the abilities of the wireless bridge load testing \& rating system, a diagnostic load test was carried out on Evansville Bridge. Before the field test, theoretical rating was performed. The bridge was instrumented and vehicle pathway was prepared according to the plan. A pre-weighed dump truck was using as the moving loads. Static and dynamic tests were executed and collected data was analyzed. A validation test was performed to assess the effectiveness and repeatability of the system.

\subsection{Theoretical Rating}

Before the diagnostic load test, Evansville Bridge was theoretically rated using the developed rating software. All three rating programs produced the same rating results. The rating factors are shown in Table 6.1. Detailed rating procedures can be found in Appendix A2.

During theoretical rating, the following section properties at midspan were obtained, which will also be used for bridge rating through load testing later on.

Non-composite section modulus to bottom of steel at maximum moment section

$$
S_{N C}=213.40 \mathrm{in}^{3}
$$

Composite section modulus to bottom of steel at maximum moment section

$$
S_{C}=334.68 \mathrm{in}^{3}
$$


Table 6.1 Theoretical rating results of Evansville Bridge

\begin{tabular}{|c|c|c|c|c|c|c|c|}
\hline \multicolumn{8}{|c|}{ Rating Results of Interior Girder } \\
\hline \multirow{2}{*}{\multicolumn{2}{|c|}{ Limit State }} & \multicolumn{2}{|c|}{ Design Load Rating } & \multicolumn{3}{|c|}{ Legal Load Rating } & \multirow{2}{*}{$\begin{array}{c}\text { Permit Load } \\
\text { Rating }\end{array}$} \\
\hline & & Inventory & Operating & T3 & T3S2 & T3-3 & \\
\hline \multirow{2}{*}{ Strength I } & Flexure & 2.13 & 2.76 & 3.91 & 4.31 & 4.60 & \\
\hline & Shear & 2.30 & 2.98 & 4.38 & 4.06 & 4.30 & \\
\hline \multirow{2}{*}{ Strength II } & Flexure & & & & & & 3.41 \\
\hline & Shear & & & & & & 2.90 \\
\hline Service II & & 1.91 & 2.48 & 3.31 & 3.65 & 3.89 & 2.61 \\
\hline \multicolumn{2}{|c|}{ Safe Load Capacity (tons) } & & & 82.6 & 131.4 & 156.0 & \\
\hline \multicolumn{8}{|c|}{ Rating Results of Exterior Girder } \\
\hline \multirow{2}{*}{\multicolumn{2}{|c|}{ Limit State }} & \multicolumn{2}{|c|}{ Design Load Rating } & \multicolumn{3}{|c|}{ Legal Load Rating } & \multirow{2}{*}{$\begin{array}{c}\text { Permit Load } \\
\text { Rating }\end{array}$} \\
\hline & & Inventory & Operating & T3 & T3S2 & T3-3 & \\
\hline Strength I & Flexure & 2.41 & 3.12 & 4.56 & 5.04 & 5.38 & \\
\hline Strength I & Shear & 3.65 & 4.73 & & & & \\
\hline Strength II & Flexure & & & & & & 2.93 \\
\hline Strength II & Shear & & & & & & 4.01 \\
\hline Service II & & 2.42 & 3.15 & 4.20 & 4.63 & 4.94 & 2.52 \\
\hline \multicolumn{2}{|c|}{ Safe Load Capacity (tons) } & & & 104.9 & 166.7 & 198.0 & \\
\hline
\end{tabular}

\subsection{Instrumentation for Load Testing}

In consideration of accessibility during instrumentation, strain gages and transducers were installed on two of seven girders along the first span: 1) close to the interior support or negative moment region (1 meter from the pier bearing), and 2) at the $1 / 2$ span or positive moment region (marked as NEG and POS, respectively, in Figure 6.1 (a)). At both locations, two strain gages were installed on the bottom of the girder and below the top flange as shown in Figure 6.2 (a). This instrumentation layout results in a total eight strain measurements (4 at each instrumented section), as shown in Figure 6.2 (a). Meanwhile, two BDI strain transducers were clamped on the bottom flanges at the $1 / 2$ span on these two girders, parallel with these two strain pairs for result comparison.

Four accelerometers were installed on girder (3) and (4) (three on girder (3) and one on girder (4)) at four locations: $1 / 4$ span, middle sections and $3 / 4$ span, shown in Figure $6.2(\mathrm{a})$. 
Four SG-Link ${ }^{\circledR}$ nodes were connected to the four accelerometers respectively through conditioning boards. Since each V-Link ${ }^{\circledR}$ node have four input channels, each of them can be connected with four strain gages or transducers. Four V-Link ${ }^{\circledR}$ nodes were connected with strain gage pairs and BDI transducers at four locations shown in Figure 6.2 (a).

One G-Link ${ }^{\circledR}$ node (WVPI) was attached to the wheel hub for measuring truck positions. Section 3.5.4 described the procedures of installation and calibration. The wheel circumference $(W C)$ of the test truck was measured as $3.30 \mathrm{~m}$. Appendix A4 also summarizes the usage of WVPI for truck position monitoring.

It took a crew of two people about three hours to instrument all sensors. The sensors and wireless nodes instrumented for the load testing are listed in Table 6.2. Configurations of the wireless nodes for different tests are listed in Table 6.3.

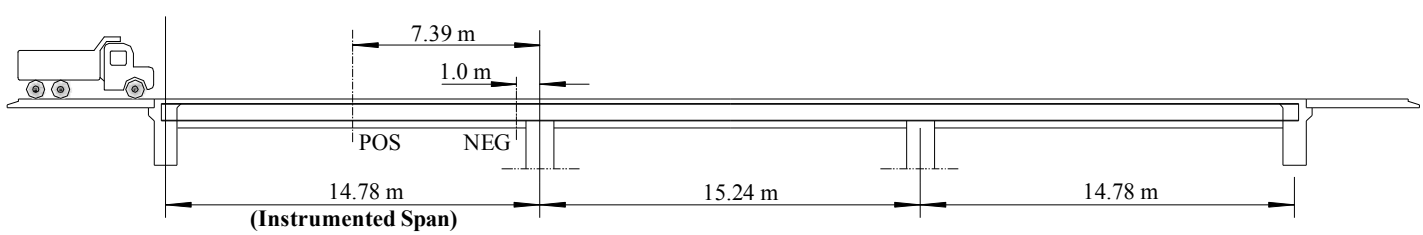

(a)

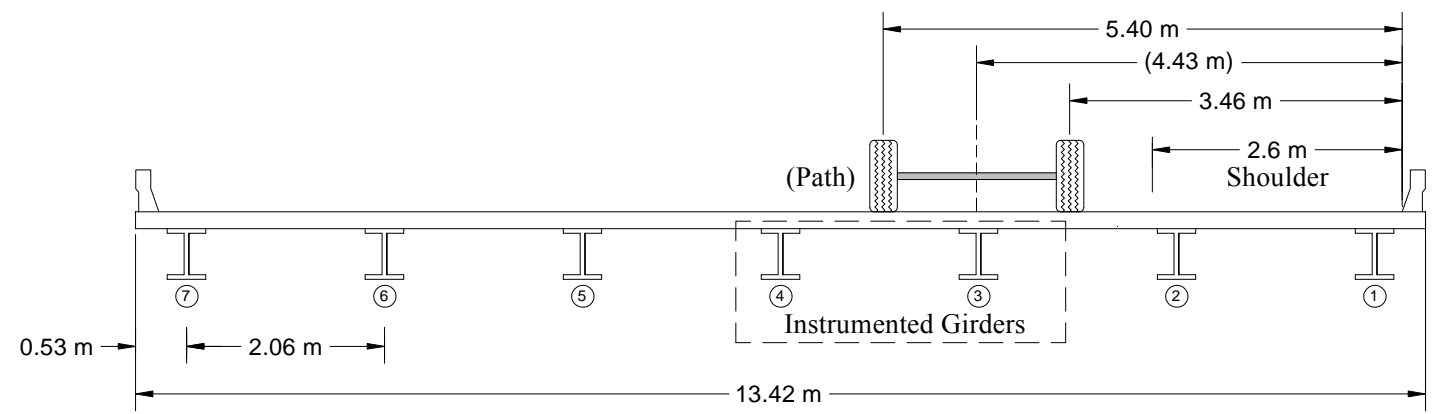

(b)

Figure 6.1 Load testing setup of Evansville Bridge: (a) layout (b) side view 


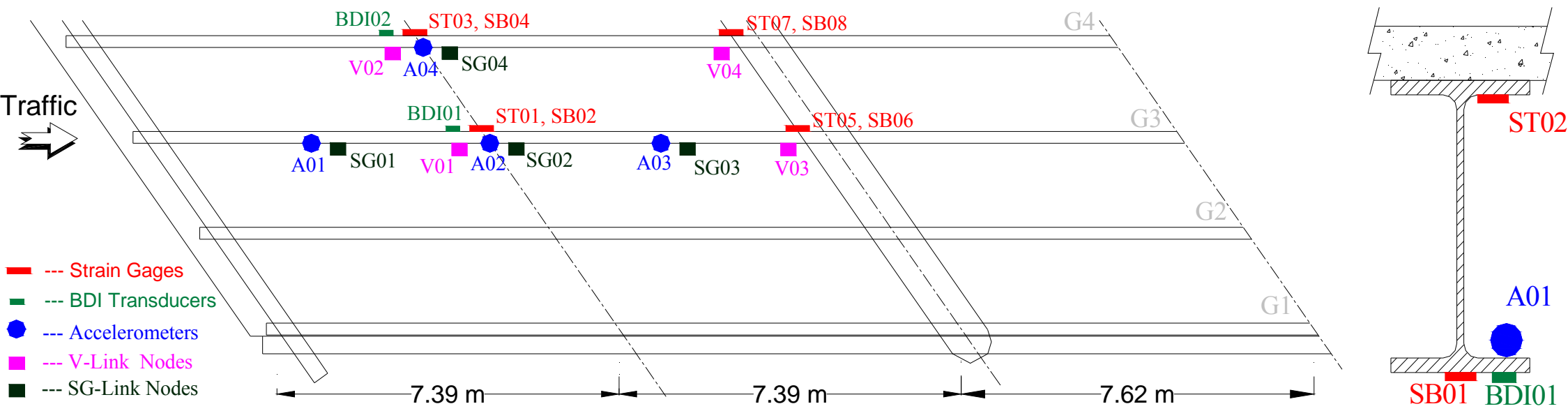

(a) instrumentation plan for load testing

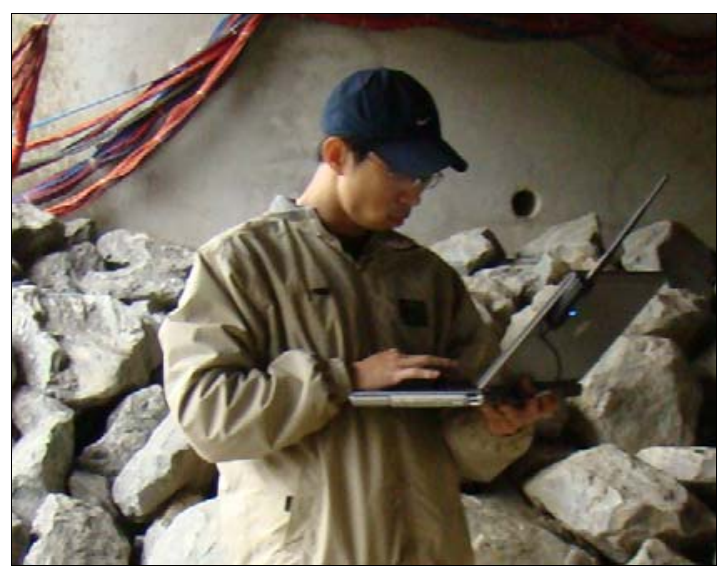

(b) checking wireless communication

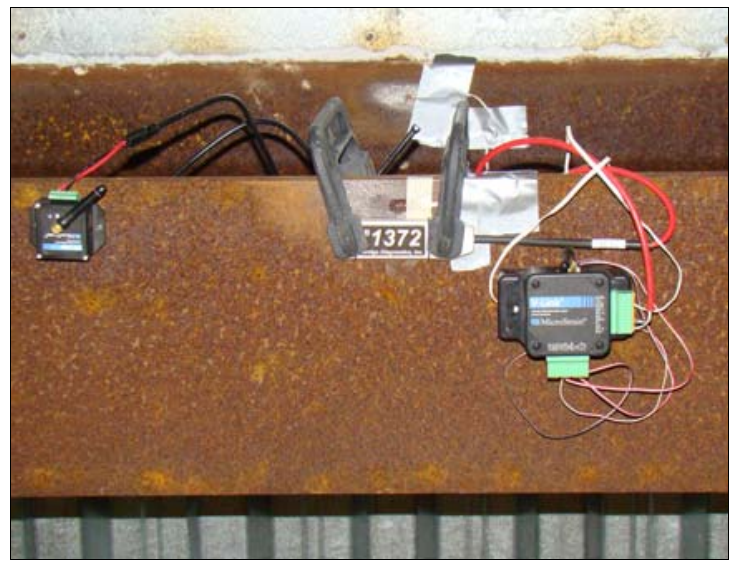

(c) on girder

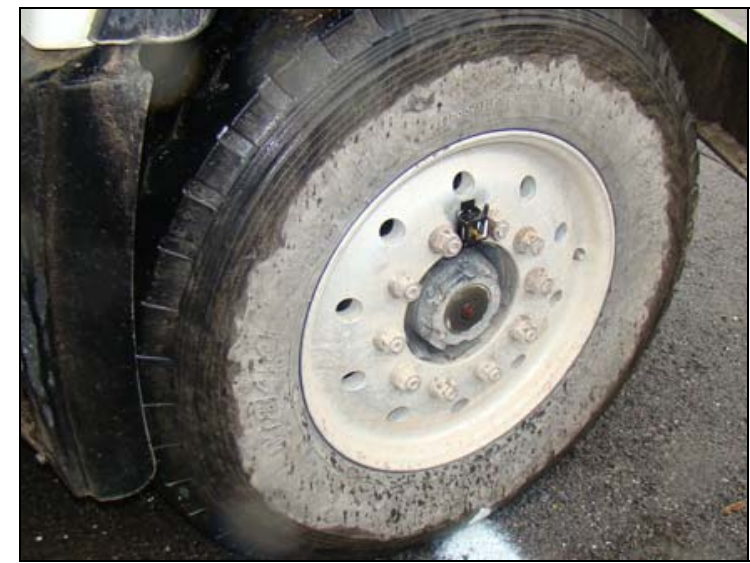

(d) installation of WVPI

Figure 6.2 Instrumentation for diagnostic load testing on Evansville Bridge 
Table 6.2 Instrumentation list

\begin{tabular}{|c|c|c|c|c|c|c|c|c|}
\hline Sensor Type & Total Num. & Position & Sensor No. & Serial No. & Gage Factor & Wireless Nodes (ID) & Channel No. & Conditioner \\
\hline \multirow{4}{*}{ Strain Gage } & \multirow{4}{*}{8} & S1 & ST01, SB02 & I & 2.10 & V-Link (616) & 1,2 & External \\
\hline & & $\mathrm{S} 2$ & ST03, SB04 & 1 & 2.10 & V-Link (617) & 1,2 & External \\
\hline & & S3 & ST05, SB06 & 1 & 2.10 & V-Link (892) & 1,3 & Internal \\
\hline & & S4 & ST07, SB08 & 1 & 2.10 & V-Link (893) & 1,3 & Internal \\
\hline \multirow{2}{*}{$\begin{array}{c}\text { BDI } \\
\text { Transducer }\end{array}$} & \multirow{2}{*}{2} & $\mathrm{~S} 1$ & BDI01 & 1360 & $492.0 \mu \varepsilon / \mathrm{mV} / \mathrm{V}$ & V-Link (616) & 3 & 1 \\
\hline & & $\mathrm{S} 2$ & BDI02 & 1372 & $493.4 \mu \varepsilon / \mathrm{mV} / \mathrm{V}$ & V-Link (617) & 3 & 1 \\
\hline \multirow{4}{*}{ Accelerometer } & \multirow{4}{*}{4} & A1 & A01 & 317 & $10005(\mathrm{mV} / \mathrm{g})$ & SG-Link (81) & 4 & External \\
\hline & & A2 & A02 & 320 & $10000(\mathrm{mV} / \mathrm{g})$ & SG-Link (82) & 4 & External \\
\hline & & A3 & A03 & 321 & $10030(\mathrm{mV} / \mathrm{g})$ & SG-Link (325) & 4 & External \\
\hline & & A4 & A04 & 322 & $10010(\mathrm{mV} / \mathrm{g})$ & SG-Link (326) & 4 & External \\
\hline Position Indicator & 1 & On Truck & WVPI & 77 & 1 & G-Link (77) & 1,2 & 1 \\
\hline \multirow{4}{*}{$\begin{array}{l}\text { Temperature } \\
\text { Sensor } \\
\text { (internal) }\end{array}$} & \multirow{4}{*}{4} & A1 & $\mathrm{A} 01$ & 1 & 1 & SG-Link (81) & 3 & 1 \\
\hline & & $\mathrm{A} 2$ & A02 & 1 & 1 & SG-Link (82) & 3 & 1 \\
\hline & & A3 & A03 & 1 & 1 & SG-Link (325) & 3 & 1 \\
\hline & & A4 & A04 & 1 & I & SG-Link (326) & 3 & 1 \\
\hline
\end{tabular}

Table 6.3 Configuration of wireless nodes

\begin{tabular}{|c|c|c|c|c|c|c|c|c|c|c|}
\hline \multirow{3}{*}{$\begin{array}{l}\text { Antenna } \\
\text { ID }\end{array}$} & \multirow{3}{*}{$\begin{array}{l}\text { Node } \\
\text { Type }\end{array}$} & \multirow{3}{*}{ Num. } & \multirow{3}{*}{$\begin{array}{l}\text { Node } \\
\text { ID }\end{array}$} & \multirow{3}{*}{$\begin{array}{l}\text { Engaged } \\
\text { Channels }\end{array}$} & \multirow{2}{*}{\multicolumn{3}{|c|}{$\begin{array}{c}\text { Static Test } \\
\text { Vehicle Speed: } 3 \sim 5 \mathrm{mph}\end{array}$}} & \multirow{2}{*}{\multicolumn{3}{|c|}{$\begin{array}{c}\text { Dynamic Test } \\
\text { Vehicle Speed: } 35 \text { mph }\end{array}$}} \\
\hline & & & & & & & & & & \\
\hline & & & & & $\begin{array}{c}\text { Sampling Freq. } \\
(\mathrm{Hz})\end{array}$ & $\begin{array}{c}\text { Data } \\
\text { Length }\end{array}$ & $\begin{array}{c}\text { Duration } \\
\text { (Sec.) }\end{array}$ & $\begin{array}{c}\text { Sampling Freq. } \\
\text { (Hz) }\end{array}$ & $\begin{array}{c}\text { Data } \\
\text { Length }\end{array}$ & $\begin{array}{l}\text { Duration } \\
\text { (Sec.) }\end{array}$ \\
\hline \multirow{7}{*}{$\# 1$} & \multirow{4}{*}{ V-Link } & \multirow{4}{*}{4} & 616 & $1,2,3$ & 256 & 12800 & 50 & 512 & 12800 & 25 \\
\hline & & & 617 & $1,2,3$ & 256 & 12800 & 50 & 512 & 12800 & 25 \\
\hline & & & 892 & 1,3 & 256 & 12800 & 50 & 512 & 12800 & 25 \\
\hline & & & 893 & 1,3 & 256 & 12800 & 50 & 512 & 12800 & 25 \\
\hline & \multirow{3}{*}{ SG-Link } & \multirow{3}{*}{4} & 81 & 3,4 & 256 & 12800 & 50 & 512 & 12800 & 25 \\
\hline & & & 325 & 3,4 & 256 & 12800 & 50 & 512 & 12800 & 25 \\
\hline & & & 326 & 3,4 & 256 & 12800 & 50 & 512 & 12800 & 25 \\
\hline$\# 2$ & G-Link & 1 & 77 & 1,2 & 256 & 12800 & 50 & / & / & 1 \\
\hline
\end{tabular}




\subsection{Test Truck and Pathway Preparation}

A dump truck loaded with gravel from the J.F. Allen Company was used to load test the bridge. Figure 6.3 shows the loaded dump truck, which has four rear axles. However, only two rear axles were engaged during the load test.



Figure 6.3 Pre-weighed test truck

Before the field test, the truck was weighted and the dimension was measured. The actual gross weight of the test truck was $304 \mathrm{KN}$ (68.22 kips). Respectively, weights of three axles are: front $92 \mathrm{KN}$ (20.68 kips), rear one $106 \mathrm{KN}$ (23.77 kips) and rear two $106 \mathrm{KN}$ (23.77 kips). Distances between axles are $5.36 \mathrm{~m}, 1.40 \mathrm{~m}$. Front wheel distance is $2.13 \mathrm{~m}$ and rear wheel distance is $1.83 \mathrm{~m}$. These parameters were used in theoretical moment calculation and finite element analysis. The configuration of the test truck can be seen in Figure 5.3.

Based on the geometric properties of the bridge and the instrumentation plan, the test truck only moved across the bridge following one pathway. The wheel line was painted on the bridge deck. As the test truck crossed the bridge, the driver followed the line to maintain the same lateral position. From the driver's view, the easiest line to follow was a line drawn underneath the centerline of the front left wheel. The test truck started moving at a starting line which was marked on the ground and is about $9.64 \mathrm{~m}$ away from the geometric original point of the bridge. Plan view of the wheel line and starting line were prepared as shown in Figure 6.4. 


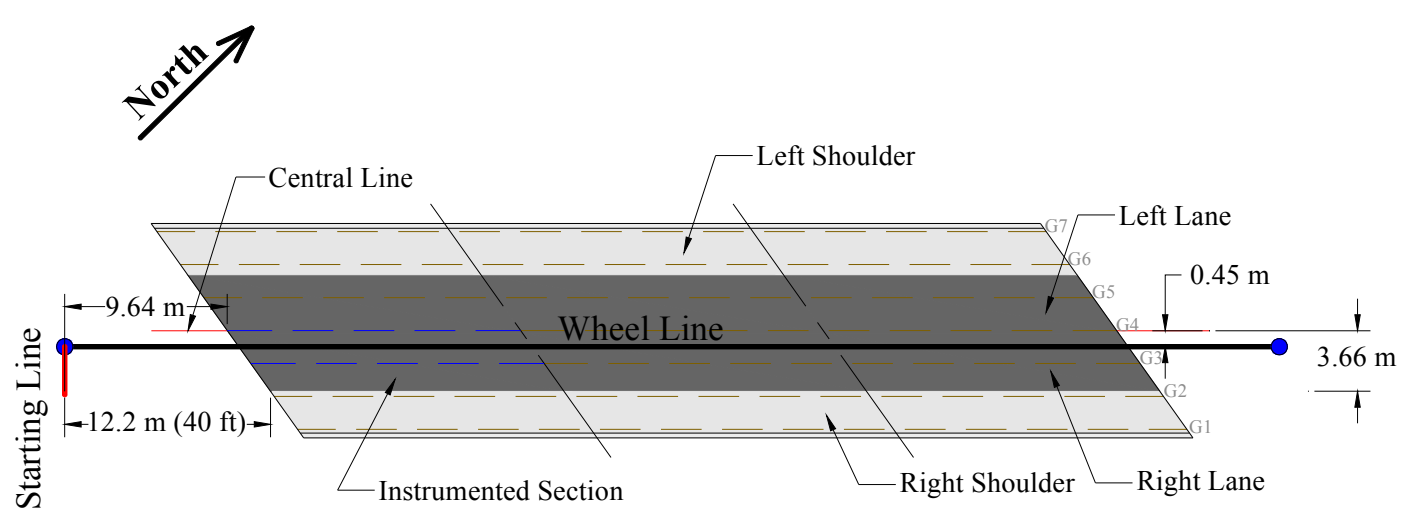

Figure 6.4 Plan view of the wheel line

\subsection{Wireless Communication and Triggering}

After the instrumentation of wireless sensors and installation of WVPI, the wireless communication needs to be set up and checked between all wireless nodes and antenna/laptop. Since the WVPI is located above the bridge (on the wheel hub) and other wireless nodes are underneath the bridge, two antennas were used. Both two antennas were connected with laptop through USB cables. The laptop was placed above the bridge and beside the parapet wall. In this way, the operator can observe the test truck and the coming traffic. One antenna was fixed higher in order to have a direct sight to WVPI and get good communication with it. The other antenna was placed under the bridge with extended cable for good communication with sensors on the girders. Communication was checked and confirmed before the load test.

\subsection{Static Test}

The static test was conducted on the bridge using the 3-axle (10 wheels) dump truck fully loaded with gravel. The truck crossed the bridge from the starting line on the prescribed route (see Figure 6.4) at a crawl speed (5mph or less), and the structural response was monitored continuously.

Because there is not too much traffic on this bridge, the bridge was left open to the normal traffic. The test was only carried out when there was no other vehicle passing. Before the test, the wireless nodes were configured wirelessly according to Table 6.3. The sampling rate was set to $256 \mathrm{~Hz}$ and time duration was 50 seconds, which lead totally 12,800 samples.

When there was not traffic passing by, the test truck was moved from the 
shoulder to the starting line (around $10 \mathrm{~m}$ away from the geometric origin of the bridge) to wait for signal. Then the operator triggered the wireless data acquisition system for recording, and gave a sign to the driver. The truck crossed the bridge on the eastbound lane with a crawl speed to the other end of the bridge. That finished one run for static test. After the wireless system finished data collection, the truck was pulled back on the shoulder or at the starting line to wait for another run.

Totally six runs were carried out and responses were recorded for the static test. Five out of six records were completed and valid.

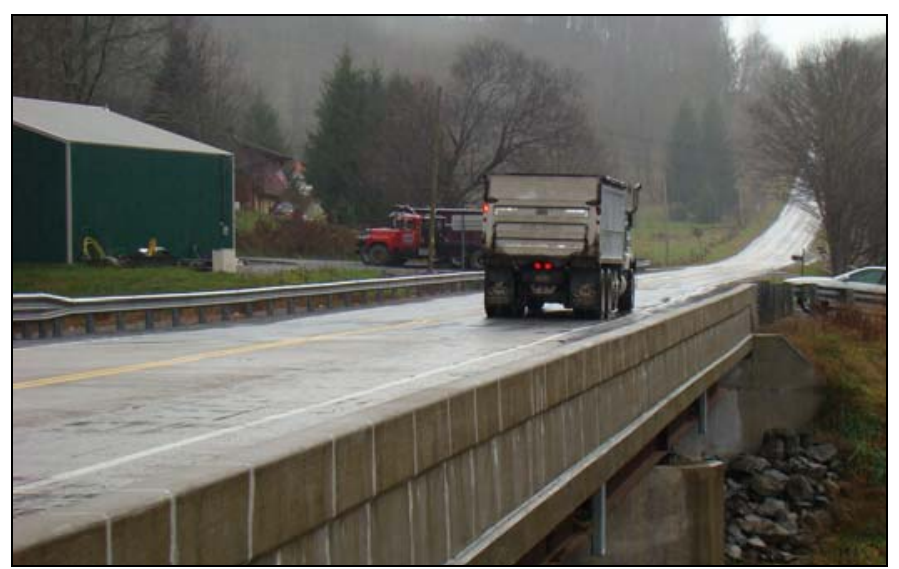

Figure 6.5 Test truck crossing the bridge with a crawl speed

\subsection{Dynamic Test}

Dynamic test can be performed to obtain realistic estimates of dynamic load allowance and live-load stress ranges, and to determine bridge dynamic characteristics such as frequencies of vibration, mode shapes, and damping.

Before the dynamic test, the WVPI was removed. The wireless nodes were re-configured (see Table 6.3). The sampling rate was $512 \mathrm{~Hz}$ and the whole data collection time was 25 seconds, which lead totally 12,800 samples. The truck crossed the bridge with regular speed (35mph in that area) following the same wheel path as the static test. The wireless data acquisition system was triggered before the test truck moved on the bridge.

Totally eight runs were carried on and recorded for the dynamic test, including two westbound runs on the left lane when the truck was driving back. Four out of eight records were completed and valid, including three eastbound run on pre-define path and one westbound run on the other lane. 


\subsection{Test Results}

It took a crew of three people about 1.5 hours to carry out the diagnostic load test. All collected data were saved in the wireless nodes respectively. Data were only downloaded once on the site when the first test run finished, in order to check the data and to make sure everything was working well. After the tests were finished, wireless nodes were brought back to laboratory, and data were downloaded for review and analysis. GUI data processing software was developed with MATLAB for quick process, the software was discussed in Chapter 4.

\subsubsection{Results of Static Test}

For static test, data from WVPI and strain gages/transducers were downloaded and analyzed. The collected data were denoised before processing.

\subsubsection{Data from WVPI}

WVPI was used to measure the position of the test truck. A record of the raw data from WVPI is shown in Figure 6.6. Respectively, $x$-axis and y-axis represents the two sensitive axes to tilt of the device. During this static test run, the test truck started to move from the starting line after around three seconds the wireless system was triggered. The truck passed the other end of the bridge and stopped after around 35 seconds. Then it was backed up toward the starting line, and the WVPI kept recording data up to 50 seconds. 

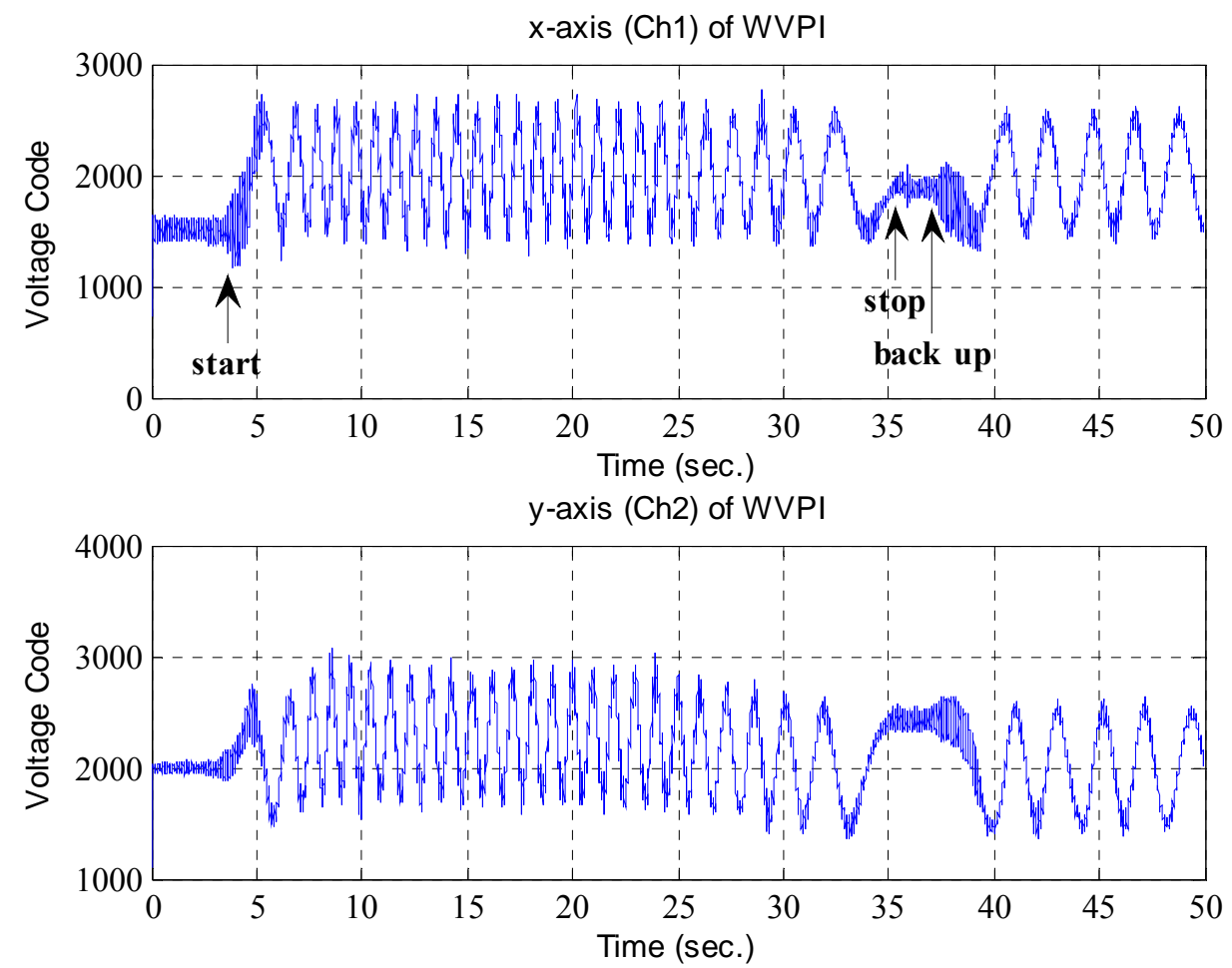

Figure 6.6 Raw data from WVPI

In order to accurately locate peaks \& valleys of WVPI data for calculating truck positions, data denoising and trimming are necessary. By following the method discussed in section 3.5.2 and using the wheel circumference measured, the relationship between the truck position and time can be obtained, as shown in Figure 6.7 .

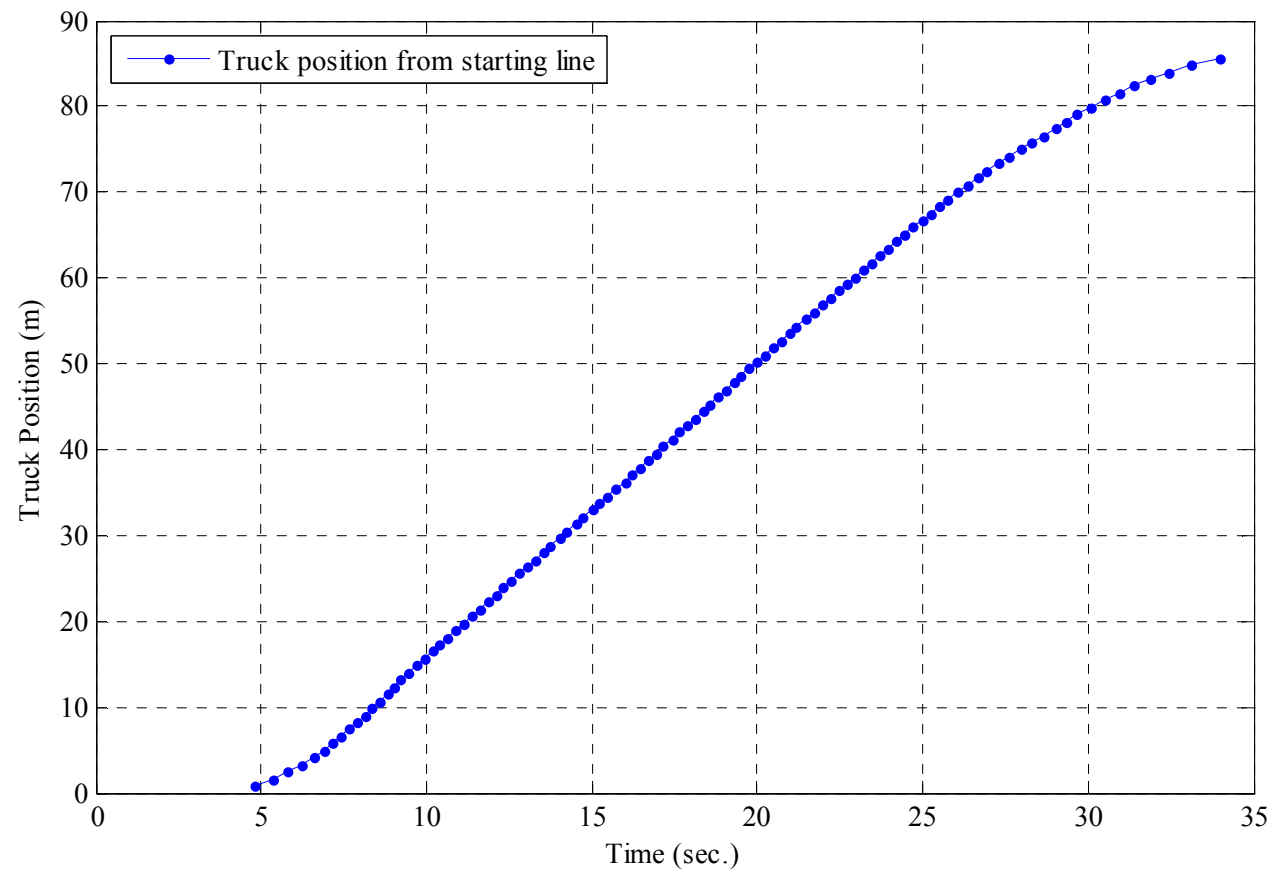

Figure 6.7 Original data versus denoised data from WVPI 


\subsubsection{Data from Strain Gages and Transducers at Middle Span}

By using the same methods for signal denoising and trimming, the strain signals were obtained with relevant conversion factors.

If the temperature effect is minimum and can be ignored for the quarter bridge completion, the relationship between voltage output $\left(V_{0}\right)$ and the strain value $\left(\varepsilon_{S}\right)$ can be induced as:

$$
V_{0}=\frac{G F \times \varepsilon_{S} \times V_{e x}}{4}
$$

where, $G F$ is the gage factor of the strain gage, $G F=2.1 ; V_{e x}$ is the excitation voltage of the quarter-bridge completion, $V_{e x}=3 \mathrm{~V}$.

The voltage output $V_{0}$ from the quarter bridge can be calculated as:

$$
V_{0}=\frac{\left(V_{\text {code }}-V_{\text {code_ref }}\right) \times V_{\text {range }}}{2^{n} \times G_{\text {Soffware }}}
$$

where, $V_{\text {code }}$ is the raw signal (voltage code) downloaded from the wireless node; $V_{\text {code_ref }}$ is the reference value and used to zero the raw signal $V_{\text {code }} ; V_{\text {range }}$ is the voltage measurement range of the wireless node and $V_{\text {range }}=3 \mathbf{V} ; n$ is the resolution of ADC of the wireless node, $n=12$ since the node is equipped with a 12-bit ADC; $G_{\text {Soffwre }}$ is the gain set in the node, $G_{\text {Software }}=210$ in this case.

Then, strain value $\varepsilon_{S}$ of the strain gage can be calculated:

$$
\varepsilon_{S}=\frac{4 \times\left(V_{\text {code }}-V_{\text {code_ref }}\right) \times V_{\text {range }}}{G F \times V_{e x} \times 2^{n} \times G_{\text {Software }}} \times 10^{6} \quad(\mu \varepsilon)
$$

For the strain transducer, the strain value $\varepsilon_{T}$ can be expressed as:

$$
\varepsilon_{T}=\frac{T_{\text {Factor }} \times 1000 \times\left(V_{\text {code }}-V_{\text {code_ref }}\right) \times V_{\text {range }}}{V_{e x} \times 2^{n} \times G_{\text {Software }}} \quad(\mu \varepsilon)
$$

where, $T_{\text {Factor }}$ is the factor of the transducer in unit of $(\mu \varepsilon / \mathrm{mV} / \mathrm{V})$, the factor values can be found in Table 6.2 .

Figure 6.8 shows the strain records at $1 / 2$ span of girder 3 . At this location, two 
strain gages (strain pair) were installed respectively on the top and bottom flanges, one BDI strain transducer was clamped beside the strain gage on the bottom flange.
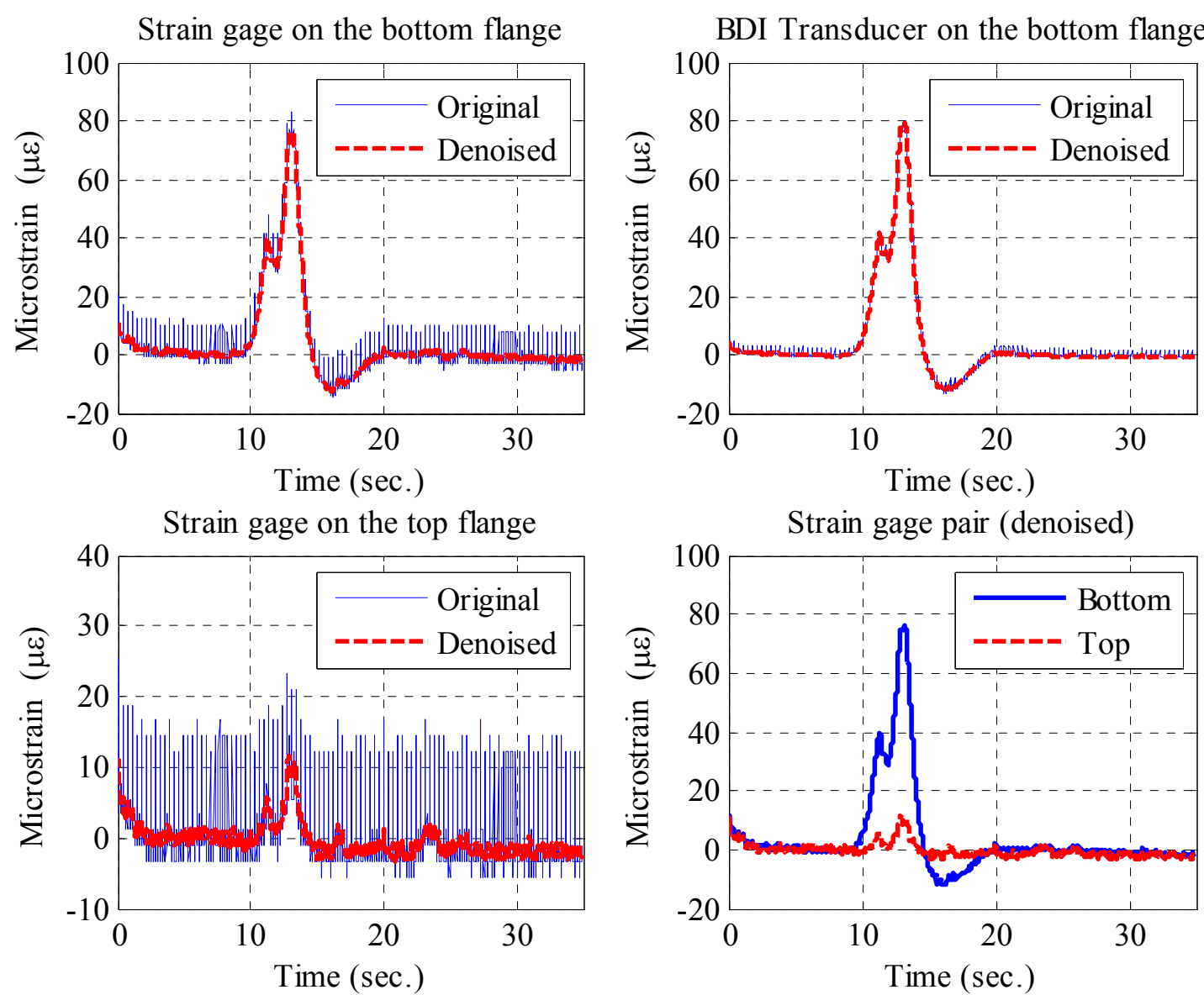

Figure 6.8 Strain records at $1 / 2$ span of girder 3 (Node 616)

As discussed in section 3.3.2, BDI transducer can provide approximately 4 times the output as a quarter-arm strain gage, which leads improved signal-to-noise ratio and higher-resolution measurements. The difference in noise level can be observed in Figure 6.8 (upper left and upper right). With the signal-denoising method discussed above, the strain comparison between the strain gage and BDI transducer is shown in Figure 6.9. These two denoised outputs matched with each other pretty well although the signal-to-noise ratios were different. 


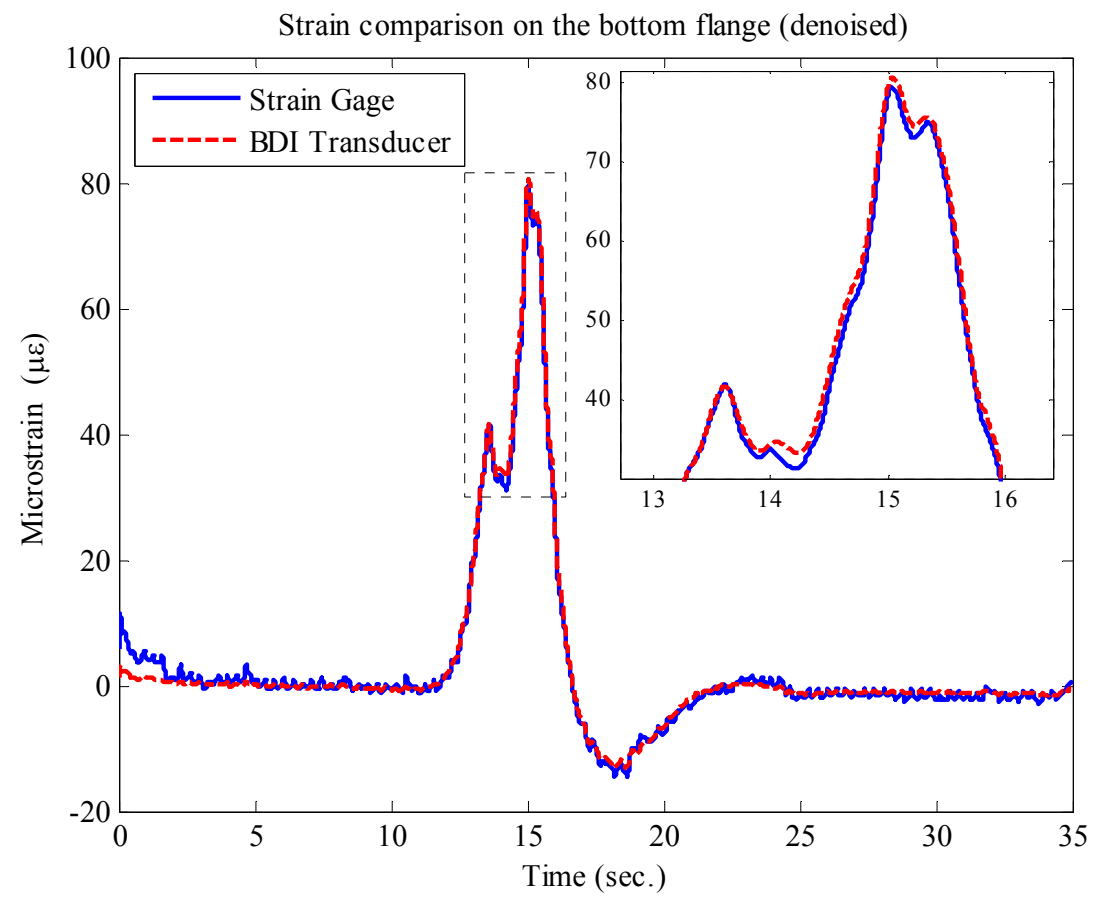

Figure 6.9 Bottom strain comparison at $1 / 2$ span of girder 3

Based on the corresponding truck position computed in the previous section, the strain records versus truck position can be plotted, as shown in Figure 6.10. Then the time domain strain signals are transformed to truck-position domain signals.



Strain gage pair (denoised)

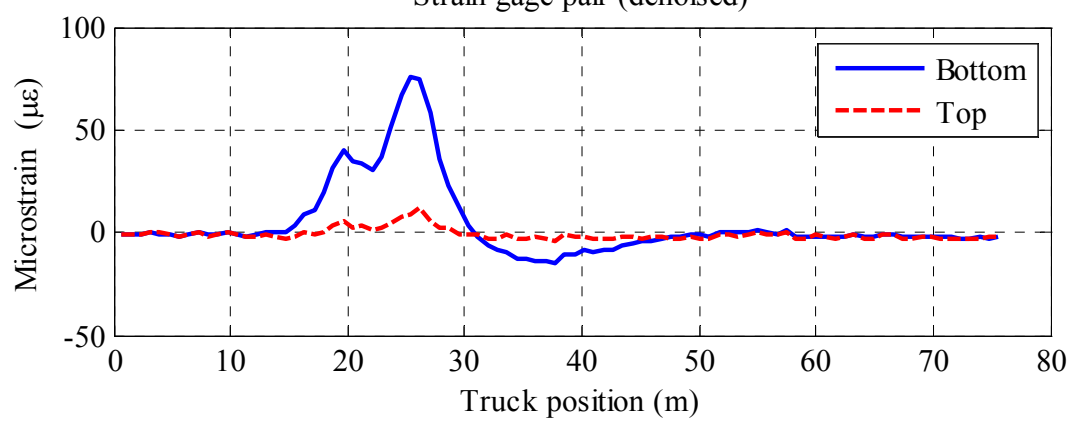

Figure 6.10 Strain records at $1 / 2$ span of girder 3 (truck position domain)

The truck started moving from the starting line, which is about $10 \mathrm{~m}$ away from the geometric origin of the bridge and corresponding to the "zero" truck position in the $\mathrm{x}$-axis of Figure 6.10. After the truck moved forward about 10 meters, the wheel weight started to be applied on the bridge and the strain gages started to sense the 
strain responses of the girders.

Figure $6.11-6.13$ show the same plots for strain records at $1 / 2$ span of girder 4 .


Figure 6.11 Strain records at $1 / 2$ span of girder 4

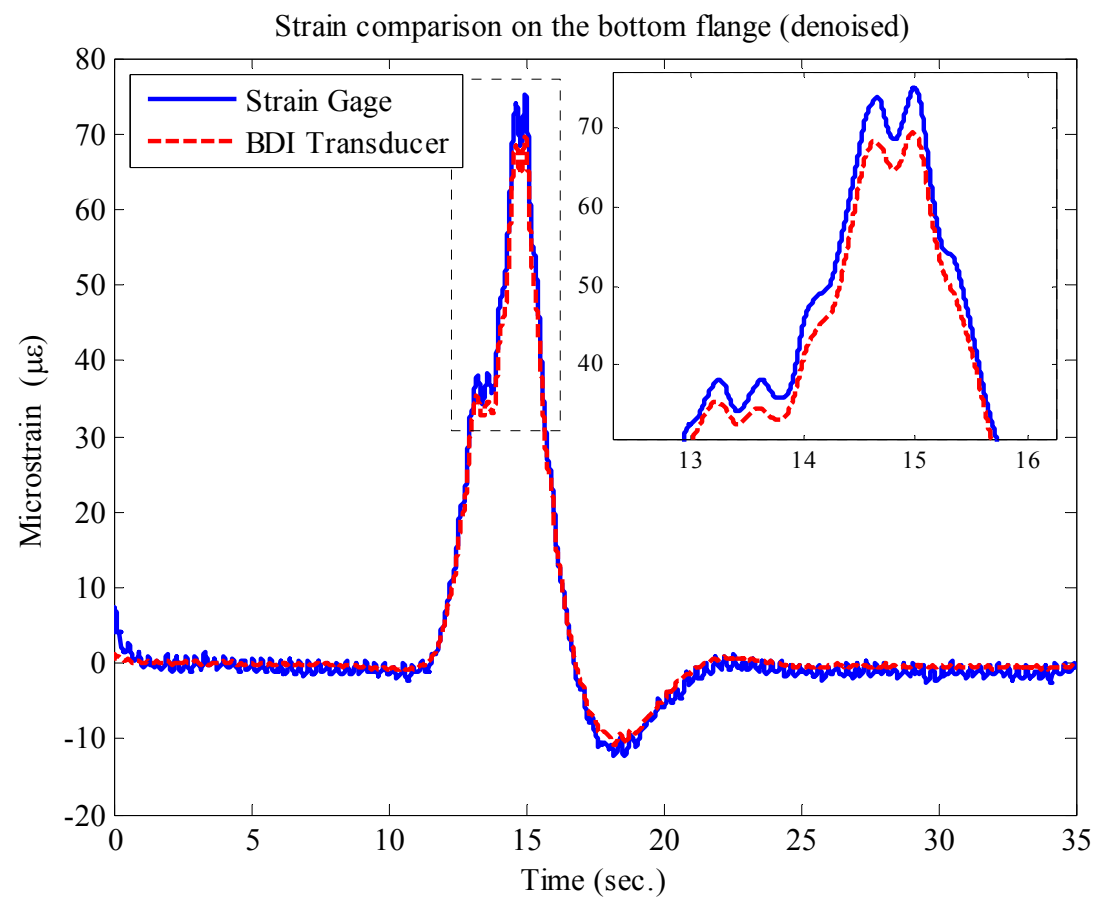

Figure 6.12 Bottom strain comparison at $1 / 2$ span of girder 4 (Node 617) 

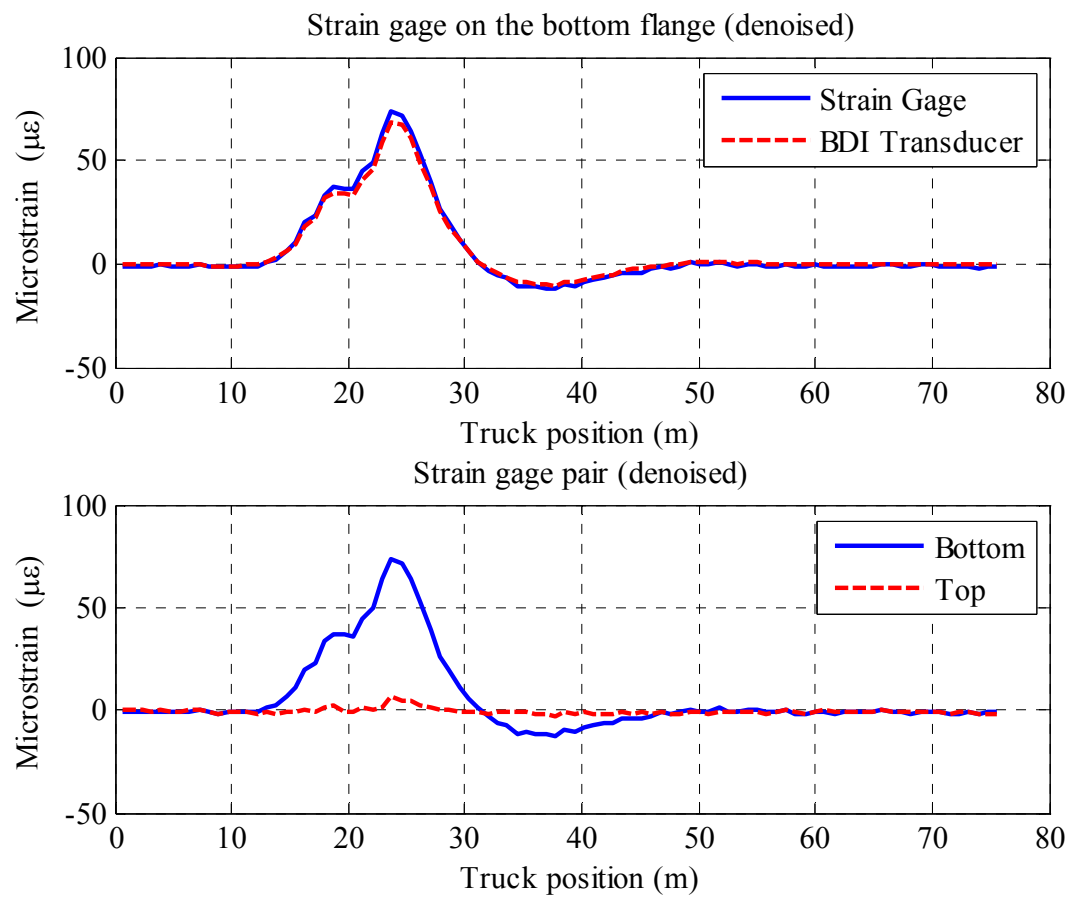

Figure 6.13 Strain records at $1 / 2$ span of girder 4 (truck position domain)

From the strain records in truck position domain, it can be seen that there are two peaks, as shown in the following Figure 6.14 and Figure 6.15. The pass of front axle of the test truck produces the "Peak1" with a value of around $40 \mu \varepsilon$. The pass of rear axles causes the "Peak2" with a value around $80 \mu \varepsilon$. In fact, the weight of rear axles $(212 \mathrm{KN})$ is approximately two times of that of front axle $(92 \mathrm{KN})$, which explains the ratio of the two peak values.

By comparing the two strain records at mid-span of girder 3 and girder 4 (Figure $6.14-6.15)$, it can be found that the peaks occur at different truck positions. The reason for this difference is that the bridge is skewed at a 55 angle. With the geometric parameter (girder spacing is $2.06 \mathrm{~m}$ ), a value of $1.44 \mathrm{~m}$ is computed as the horizontal distance between the mid-spans of girder 3 and girder $4\left(2.06 \mathrm{~m} / \tan \left(55^{\circ}\right)=1.44 \mathrm{~m}\right)$. From the measurement, the difference of truck positions when strain peaks happen at mid-spans on girder 3 and girder 4 is calculated at an approximate value of $1.64 \mathrm{~m}$. This explains the difference of the coordinates of the peak strain values. 




Figure 6.14 Strain records at mid-span of girder 3

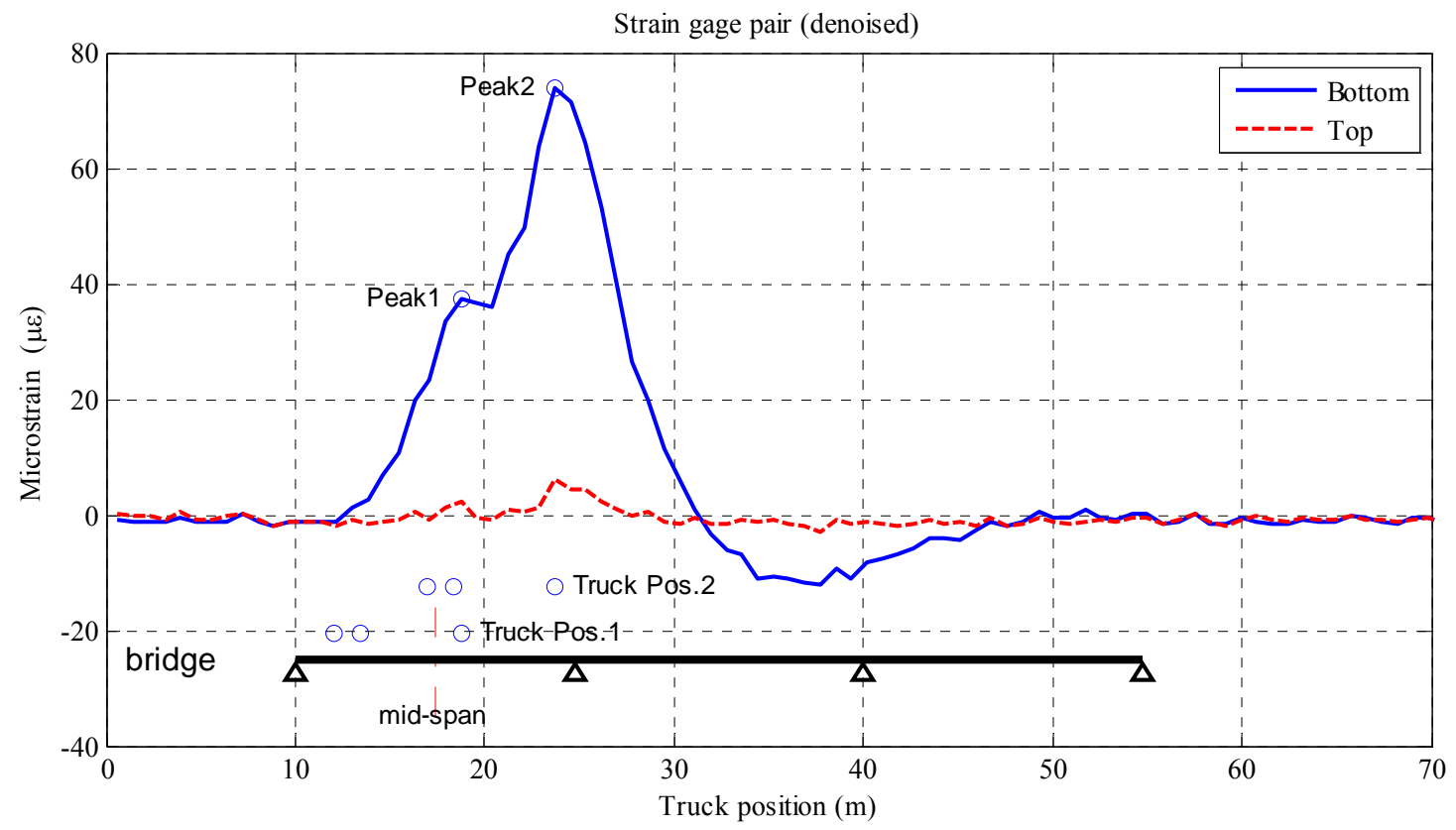

Figure 6.15 Strain records at mid-span of girder 4 


\subsubsection{Data from Strain Gages and Transducers near Pier}

Figure $6.16,6.17$ show the strain records near pier of girder 3 .

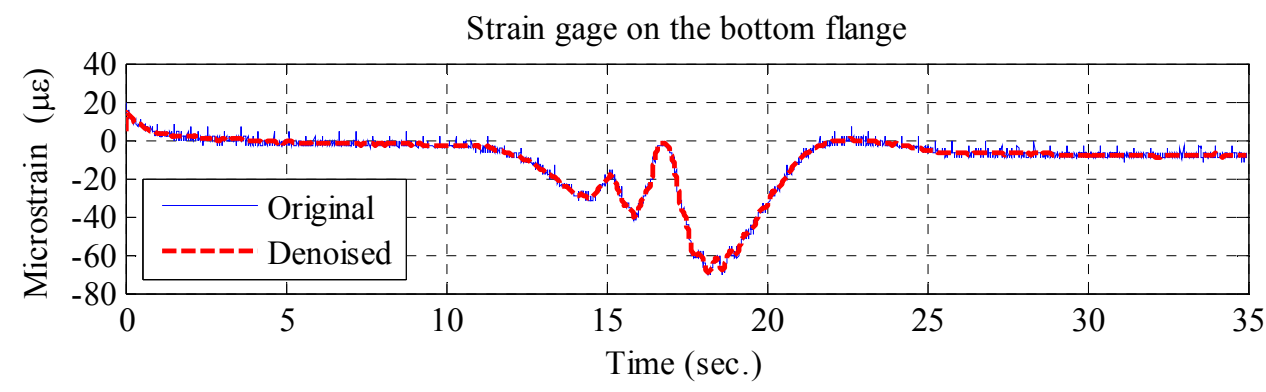

Strain gage on the Top flange

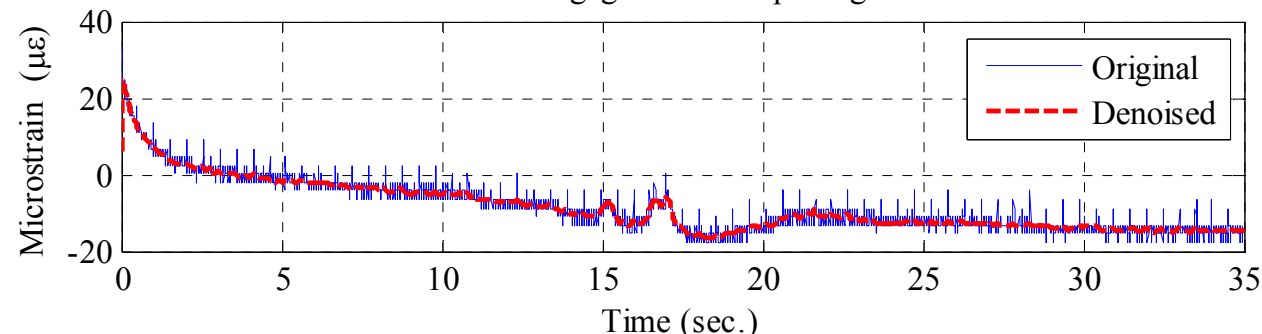

Strain gage pair (denoised)

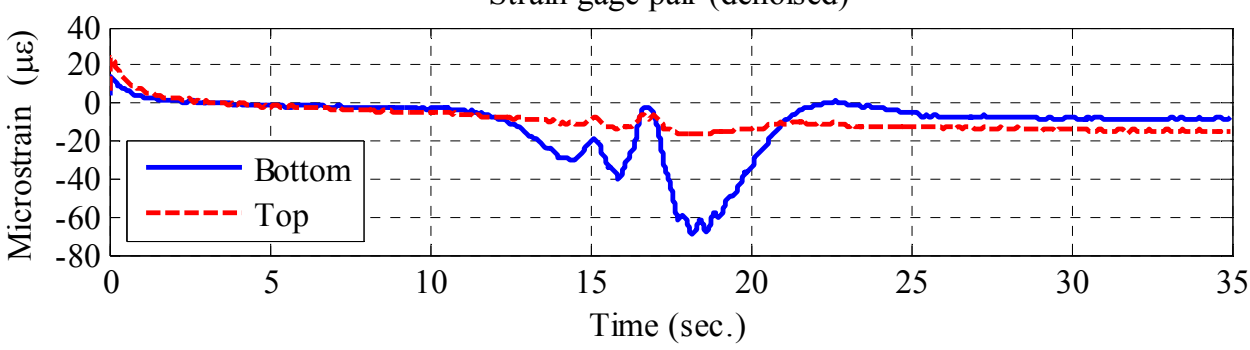

Figure 6.16 Strain records near pier of girder 3 (Node 892)

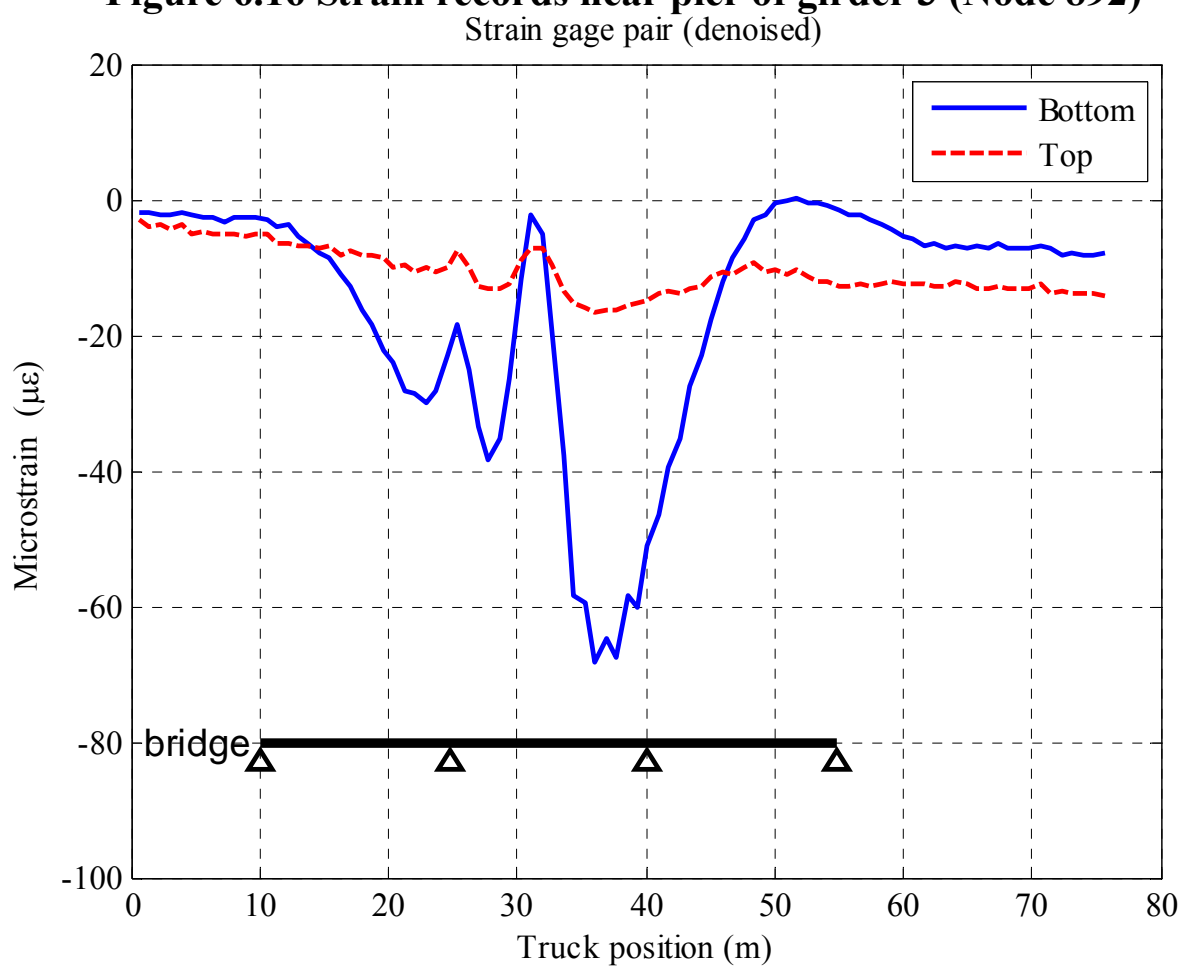

Figure 6.17 Strain records near pier of girder 3 (truck position domain) 
Figure $6.22,6.23$ show the strain records near pier of girder 4 .

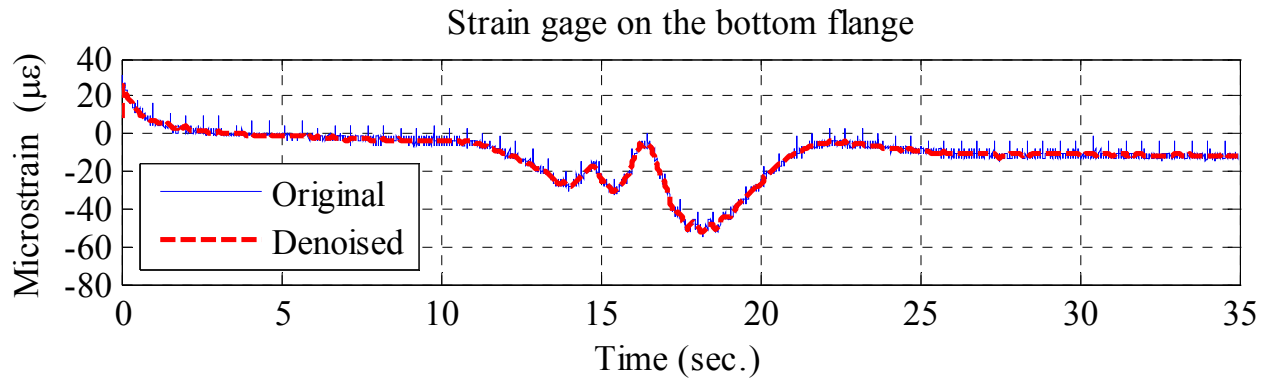

Strain gage on the Top flange

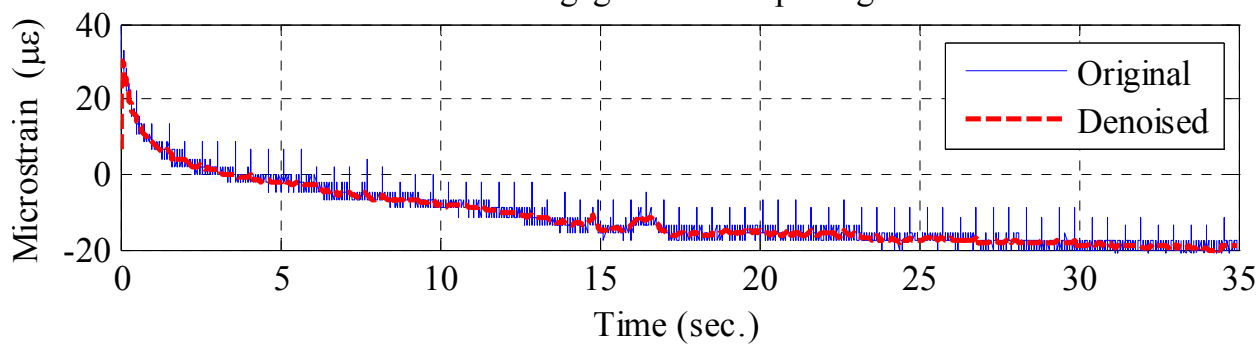

Strain gage pair (denoised)

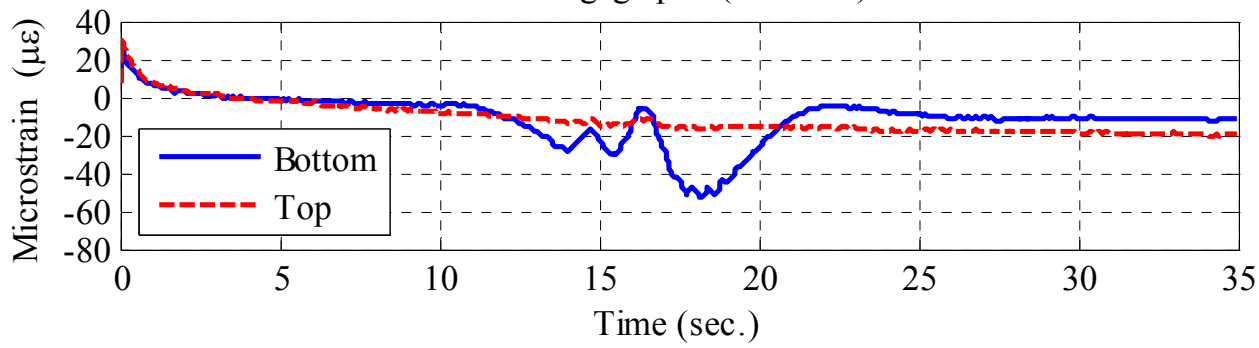

Figure 6.18 Strain records near pier of girder 4

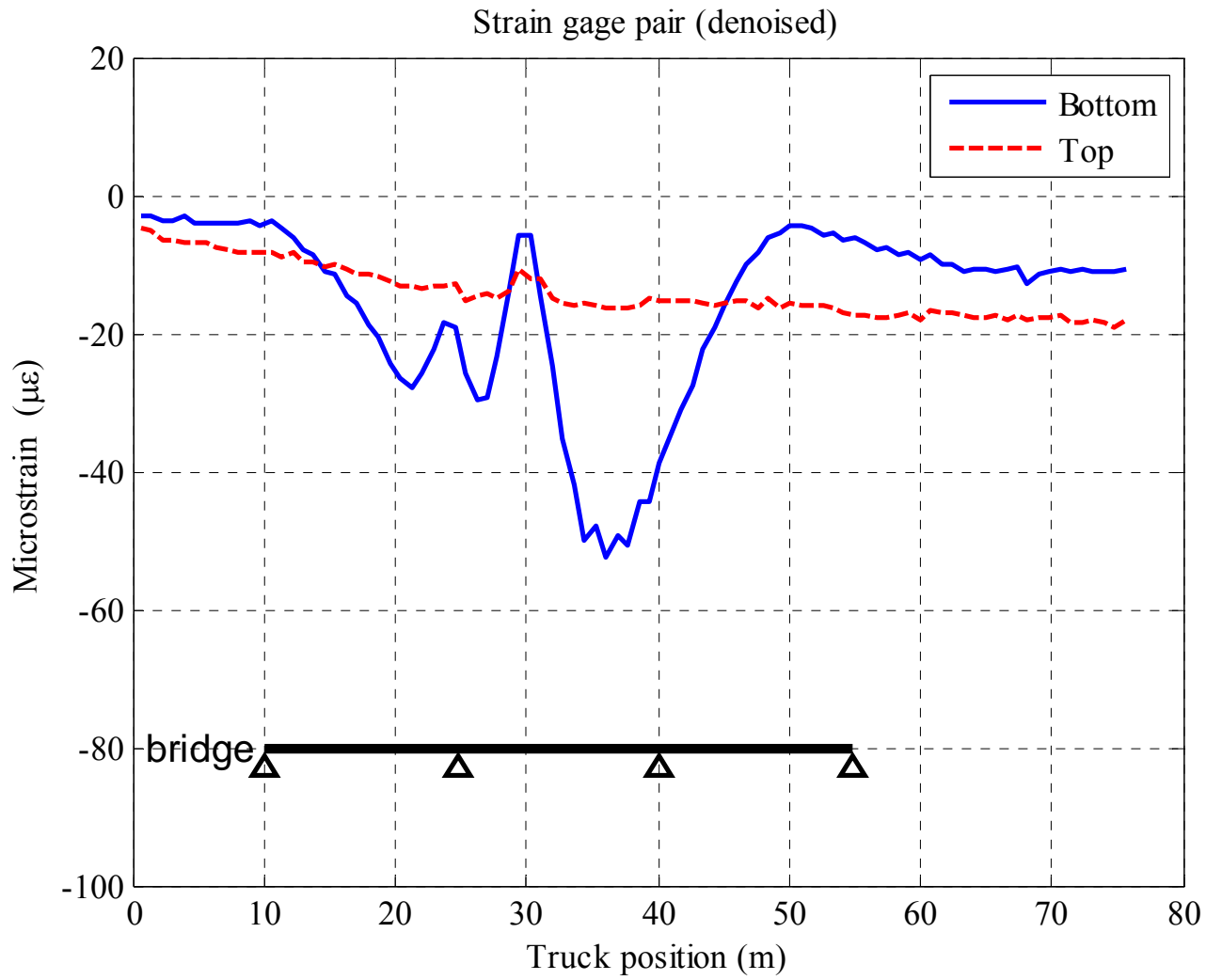

Figure 6.19 Strain records near pier of girder 4 (truck position domain) 


\subsubsection{Average Measured Strain}

By applying spline interpolation method, strain records of all five runs were resampled at same truck position interval. Then strain records were averaged according to the new truck position coordinates. Figure 6.20 shows the average measured strain records.
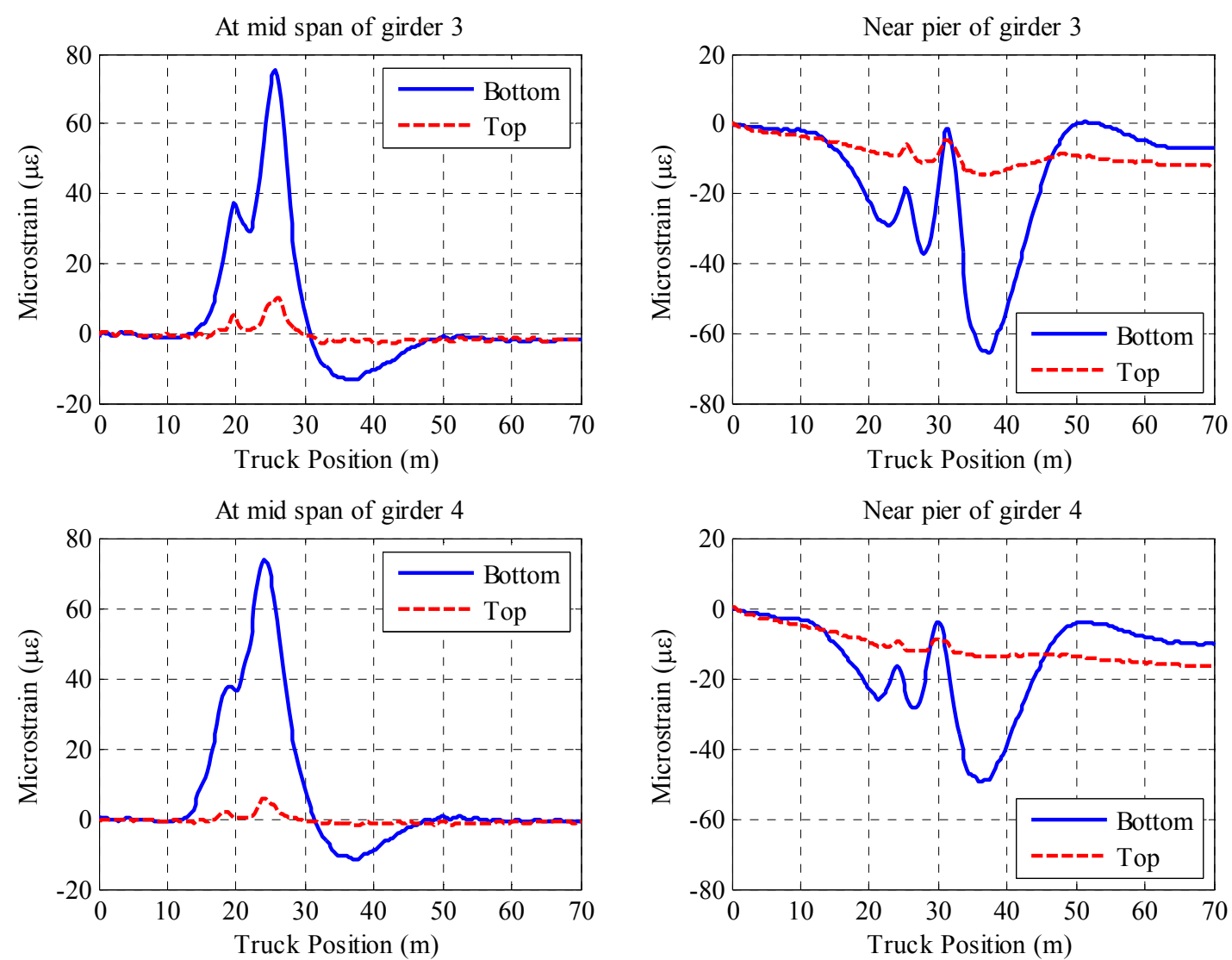

Figure 6.20 Average measured strain response

From Figure 6.20, it can be notice that, after the truck passed the bridge, the strain records near pier (Node 892 and Node 893) did not return to zero level as those at mid span (Node 616 and Node 617). This shifting should not be caused by temperature change. Since the testing duration for each run was very short, actual valid time duration was only about 30 seconds although the recording duration was set to 50 seconds for static test. If the temperature change did have a great influence, all of the records should shift in the same magnitude. In fact, the signal from Node 892 and Node 893 started to shift right after the nodes were triggered.

This phenomenon can only be explained from the hardware configurations (refer to Table 6.2.). Wireless nodes 892 and 893 have internal quarter-bridge completion, which was ordered from the manufacture. However, Wireless nodes 616 and 617 have self-made external quarter-bridge completion. The quality of the resistors used for 
bridge completion may influence the quality of the conditioned signals.

Adjustment was made to strain records from Node 892 and Node 893, in order to shift the signal back to zero level with an assumption that the shifting value was proportional to time. The adjusted average measured strain response is shown in Figure 6.26. The calculation of adjustment was carried out based on equation (6.5).

$$
S V_{i_{-} a d j}=S V_{i}+\frac{\left|S V_{n}-S V_{1}\right|}{n} \times(i-1), \quad(i=1,2,3, \cdots, n)
$$

where, $n$ is the sample number of the strain record, $S V_{i}(i=1,2,3, \cdots, n)$ represents the strain value without adjustment, $S V_{i_{-} \text {adj }}$ is the strain value after adjustment.
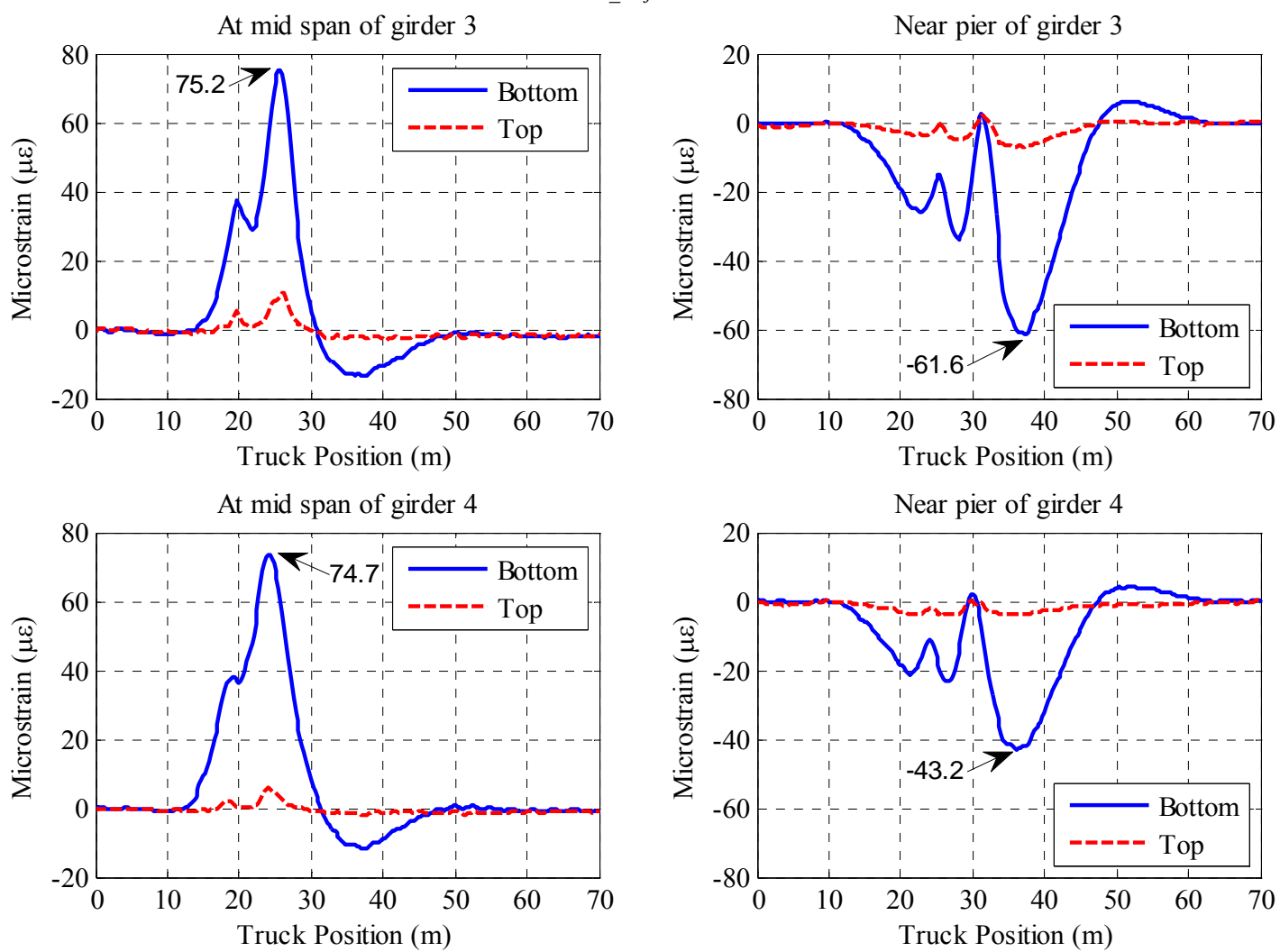

Figure 6.21 Adjusted average measured strain response

At middle span, the maximum average measured strain (Positive) is $75.2 \pm 3.8 \mu \varepsilon$ in girder 3, and $74.7 \pm 3.6 \mu \varepsilon$ in girder 4 . Near pier, the maximum averaged strain (Negative) $-61.6 \pm 3.1 \mu \varepsilon$ in girder 3, and $-43.2 \pm 2.9 \mu \varepsilon$ in girder 4 .

The experimental errors are inherent in the measurement process and cannot be eliminated by repeating the experiment. There are two types of experimental errors: systematic errors and random errors. Systematic errors affect the accuracy of a measurement and cannot be improved by repeating. In this case, sources of systematic errors may come from hardware, such as wireless nodes, strain gages, and bridge 
completion for strain gages. Random errors affect the precision of a measurement and can be improved by repeating process. In this application, random errors may be caused by temperature variation, variation of truck pathway, dynamic effect of truck.

\subsubsection{Neutral Axis Location}

Strain records from the strain pairs can be used to calculate the neutral axis locations $(\bar{y})$ with equation (6.6). Figure 6.22 illustrates the computation of neutral axis from two strain measurements.

$$
\bar{y}=\frac{\varepsilon_{S B} d}{\varepsilon_{S B}-\varepsilon_{S T}}
$$

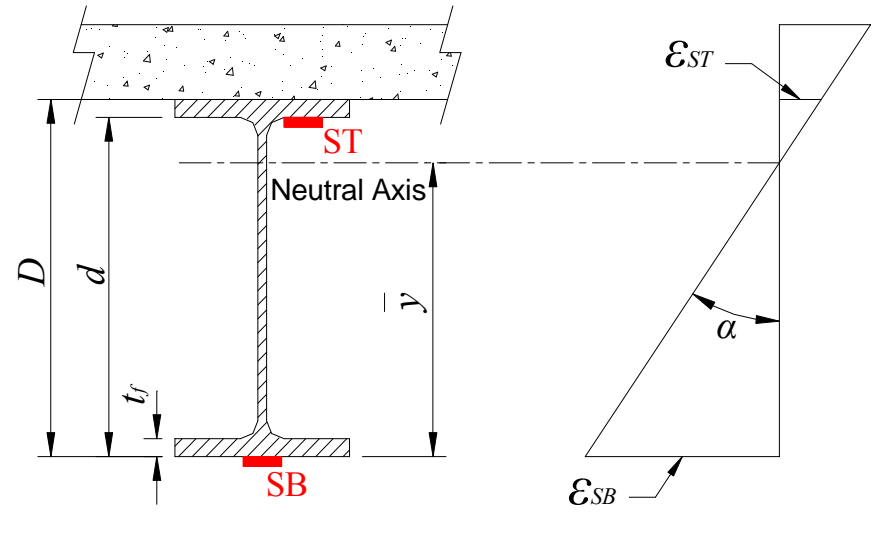

Figure 6.22 Calculations of neutral axis and curvature

The steel girders are $\mathrm{W} 27 \times 84$ beams. The geometric parameters of the beam are: $D=26.71 \mathrm{in}, t_{f}=0.64 \mathrm{in}, d=D-t_{f}=26.07 \mathrm{in}$. Use maximum strain values recorded at the mid-span of girder $3\left(\varepsilon_{S B}=75.2 \mu \varepsilon, \varepsilon_{S T}=9.7 \mu \varepsilon\right)$, the location of neutral axis is computed: $\bar{y}=29.9 \mathrm{in}$. Since $\bar{y}>D$, the neutral axis of the beam locates in the concrete slab, which indicates that the girder is acting as a composite beam.

\subsubsection{Results of Dynamic Test}

For dynamic test, WVPI were removed and data from accelerometers and strain gages/transducers was downloaded and analyzed. Same denoising method were used to clean the strain records, and all records were normalized to their physical units.

\subsubsection{Data from Accelerometers}

Figure 6.23 shows the acceleration signal from each accelerometer. The sampling rate was $512 \mathrm{~Hz}$, and there were totally 12800 samples for 25 seconds. 

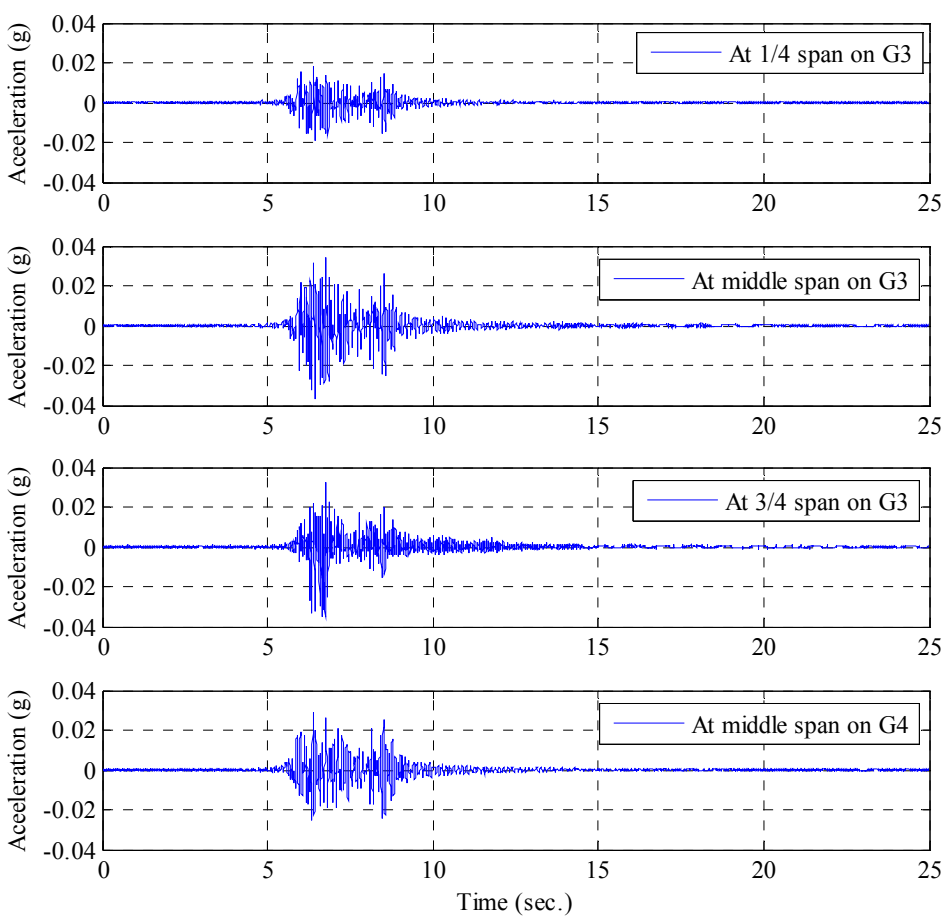

Figure 6.23 Acceleration records

In order to obtain the frequency characteristics of the bridge, a LabVIEW program was created for power spectrum analysis of the acceleration signals. The LabVIEW contains a power spectrum block, which make it very easy to carry out frequency analysis of the acceleration signal.

Power spectrum of acceleration signal was calculated and display in Figure 6.24 and Figure 6.25. There are two obvious peaks at $8.00 \mathrm{~Hz}$ and $10.84 \mathrm{~Hz}$, which are two major natural frequencies of the bridge. Compared with section 3.4.3.2 and the ambient vibration response in Figure 3.17, the same peaks are found at $8.033 \mathrm{~Hz}$ and $10.86 \mathrm{~Hz}$, which validates the test results.

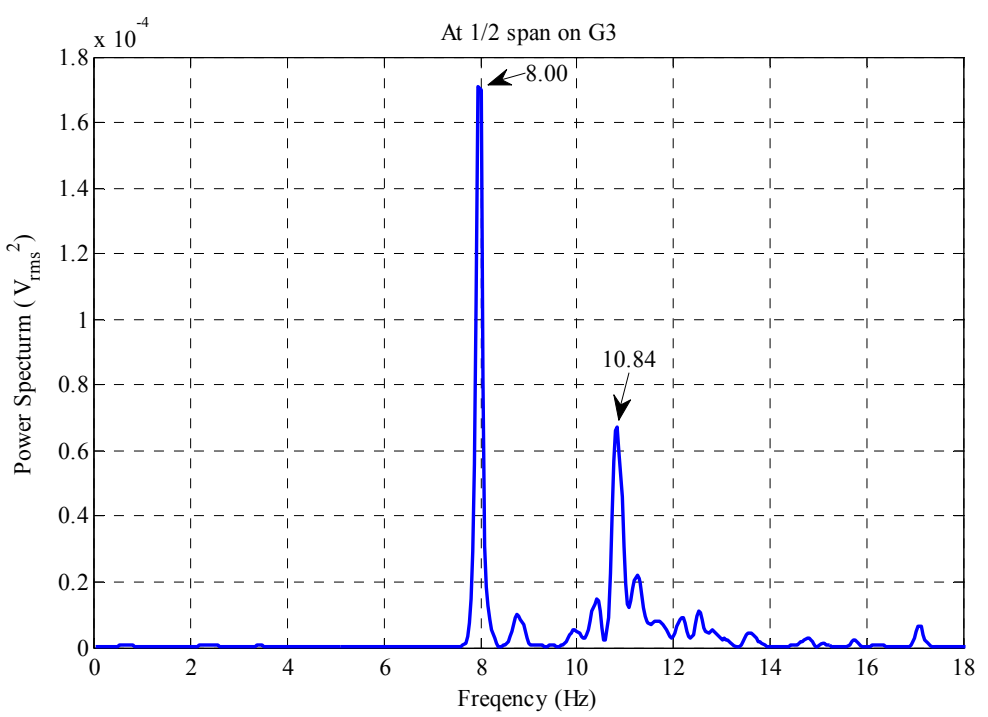

Figure 6.24 Power spectrum of acceleration at $1 / 2$ span of girder 3 
Figure 6.25 shows the power spectrums of acceleration at different locations. There is a good coherence of frequency response among all accelerometers. The different spectrum magnitude indicates the different vibration power.


Figure 6.25 Power spectrums of acceleration at different locations

\subsubsection{Data from Strain Gages and Transducers}

Figure 6.26 - Figure 6.29 show the dynamic strain records from the strain gages and transducers when the test truck crossed at $35 \mathrm{mph}$. The difference between dynamic strain value and static strain value is small, and the maximum difference is about $10 \%$ at mid span of girder 4 . That means the dynamic factor is relatively small due to the good condition of road surface. From filed observation, there are no obvious cracks and uneven pavements found on the bridge deck. 



Figure 6.26 Dynamic strain records at $1 / 2$ span of girder 3
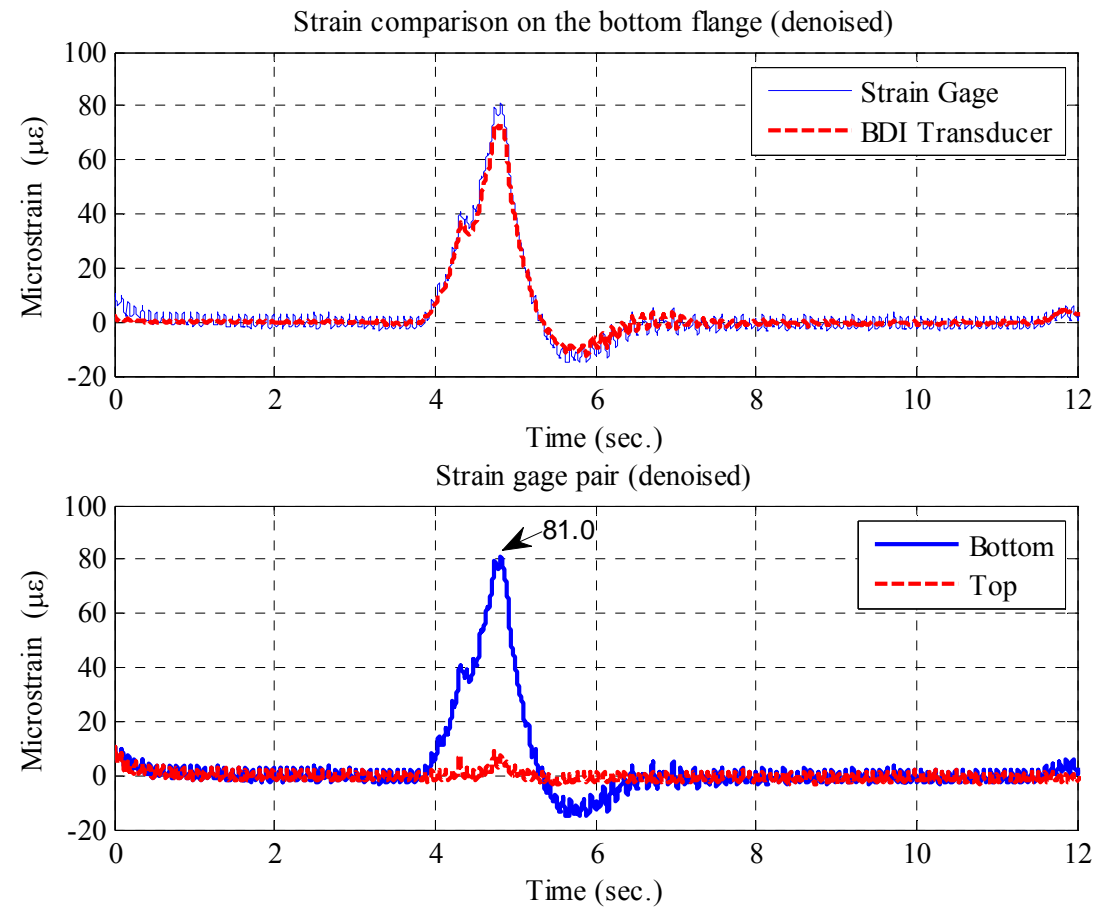

Figure 6.27 Dynamic strain records at $1 / 2$ span of girder 4 


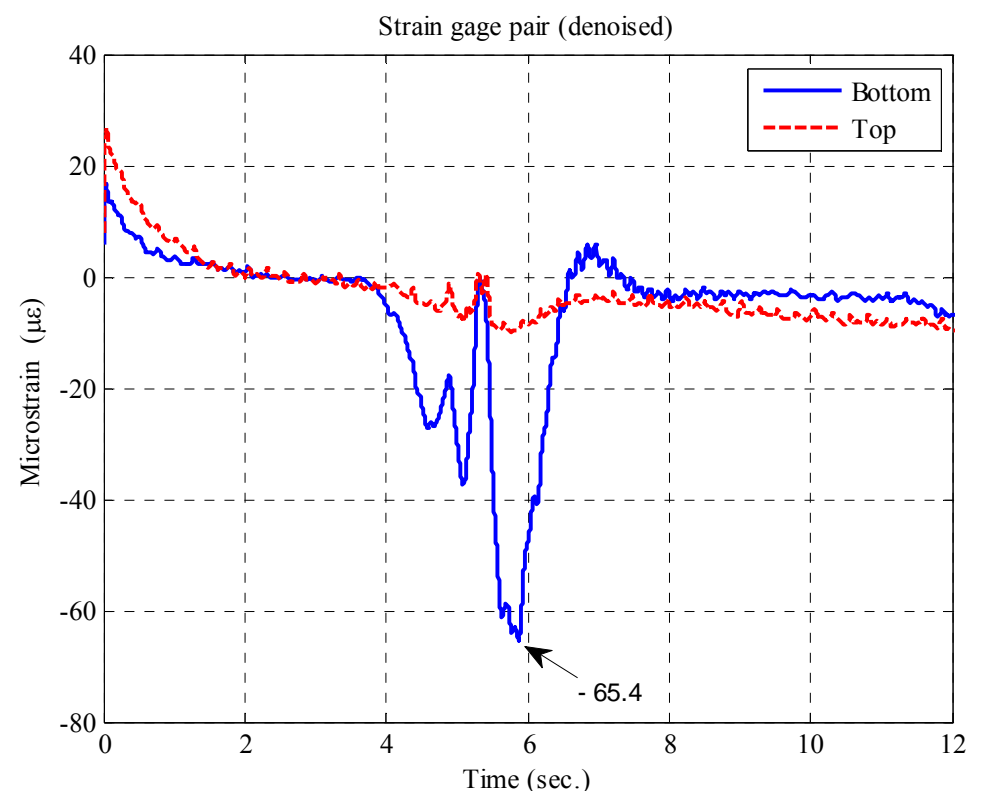

Figure 6.28 Dynamic strain records near pier of girder 3

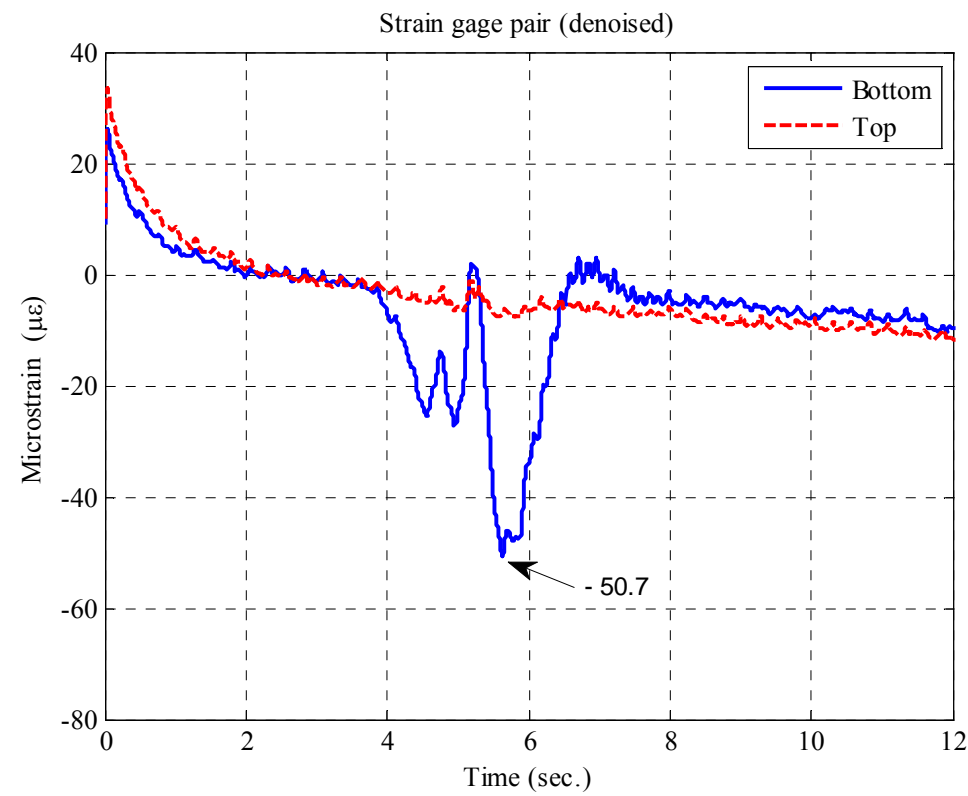

Figure 6.29 Dynamic strain records near pier of girder 4

\subsubsection{Deflection through Double Integration of Acceleration}

As one of the required measurements, deflection represents the characteristics of the bridge's behavior. LVDT is generally used as the method for displacement measurements. Because the LVDT requires stationary platform as the measurement reference, this method cannot be applied effectively if the bridge height is so high that it is difficult to install the sensor and the measured results are not as reliable and accurate.

Estimation of bridge displacement using measured acceleration has been carried 
out by several researchers. Acceleration data can be integrated to obtain a reliable estimate of the displacement (Paultre etc. 1995, Nassif, etc. 2003, Park etc. 2005).

By using the Integration VI in the Sound and Vibration Toolkit in LabVIEW, the time-domain acceleration data can be converted to velocity data (single integration) and displacement data (double integration). The LabVIEW block diagram is shown in Figure 6.30 .

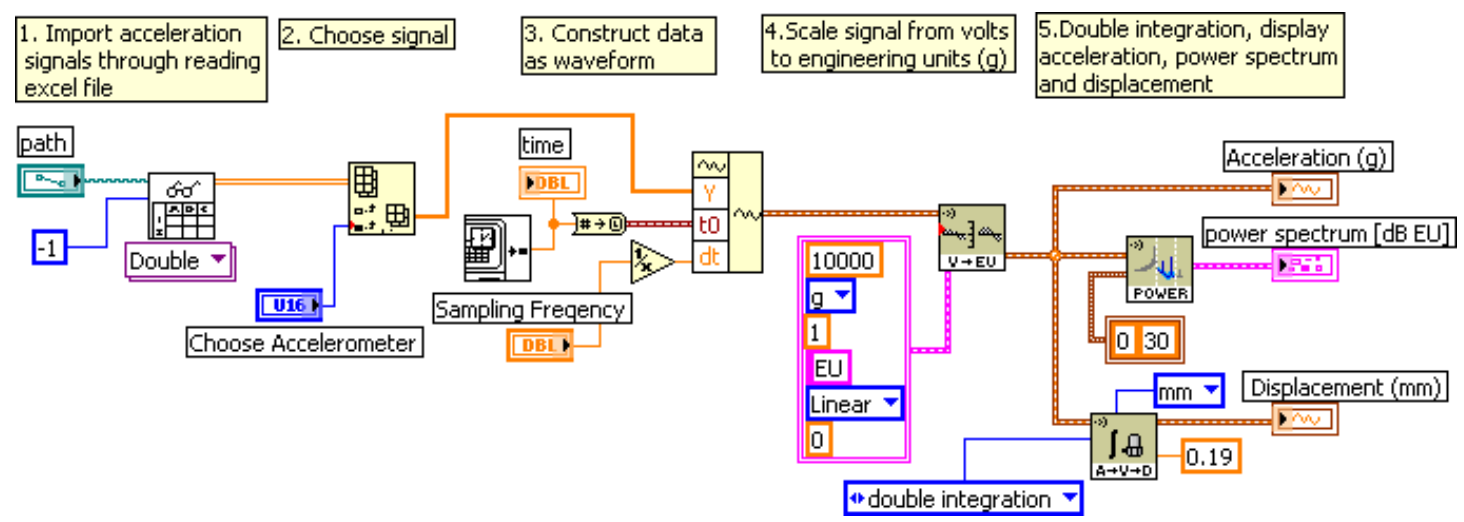

Figure 6.30 Block diagram of double integration of acceleration

In this research, the force-balanced accelerometers were used, which can measure DC $-100 \mathrm{~Hz}$ signal. The DC components were eliminated by zeroing before double-integration processing. Figure 6.31 shows the deflection plots at three different locations through double-integration of acceleration data. Since no LVDT was instrumented because of the field condition, the calculated deflection had no reference to compare with.
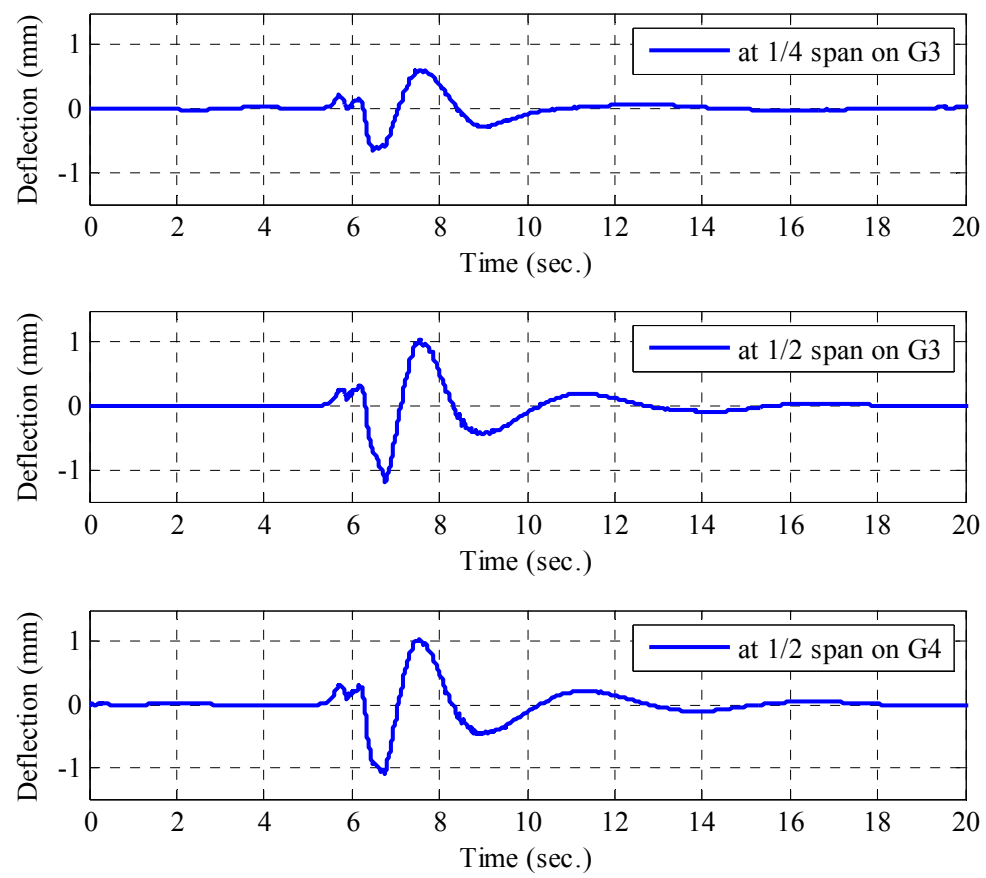

Figure 6.31 Deflections through double integration of acceleration signals 


\subsection{Bridge Rating through Load Testing}

The bridge was idealized as a continuous beam and basic statics were used to find maximum moments due to live loads. The stresses produced by these moments may be found by applying the appropriate section modulus. The composite section modulus to bottom of steel at maximum moment section $\left(S_{C}=334.68 \mathrm{in}^{3}\right)$ is pertinent to this diagnostic test.

Load distribution factors (LDF) obtained from FEA are used in bridge rating through load testing. The factors can be found in Table 5.3.

By creating a simple model of a typical beam using the structural model program, such as RISA 2D, the maximum theoretical moment produced by the test truck on the bridge was determined: $M=616.0 \mathrm{KN} . \mathrm{m}$ when the front axle is located at $23.75 \mathrm{~m}$ (from the starting line which is $10 \mathrm{~m}$ away from one end of the bridge), see Figure 6.32 and Figure 6.33.

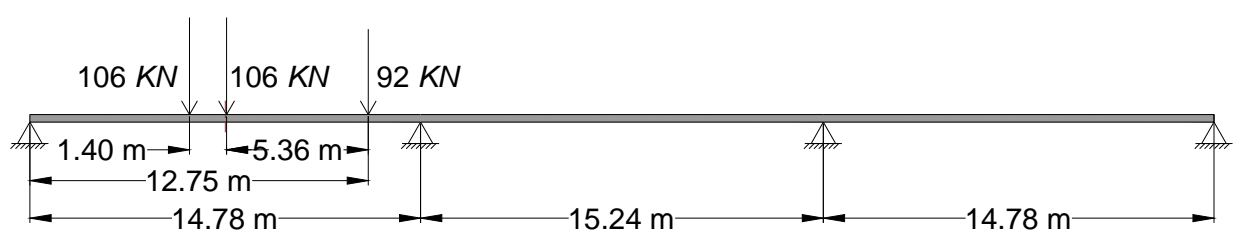

Figure 6.32 Simplified point forces on G3

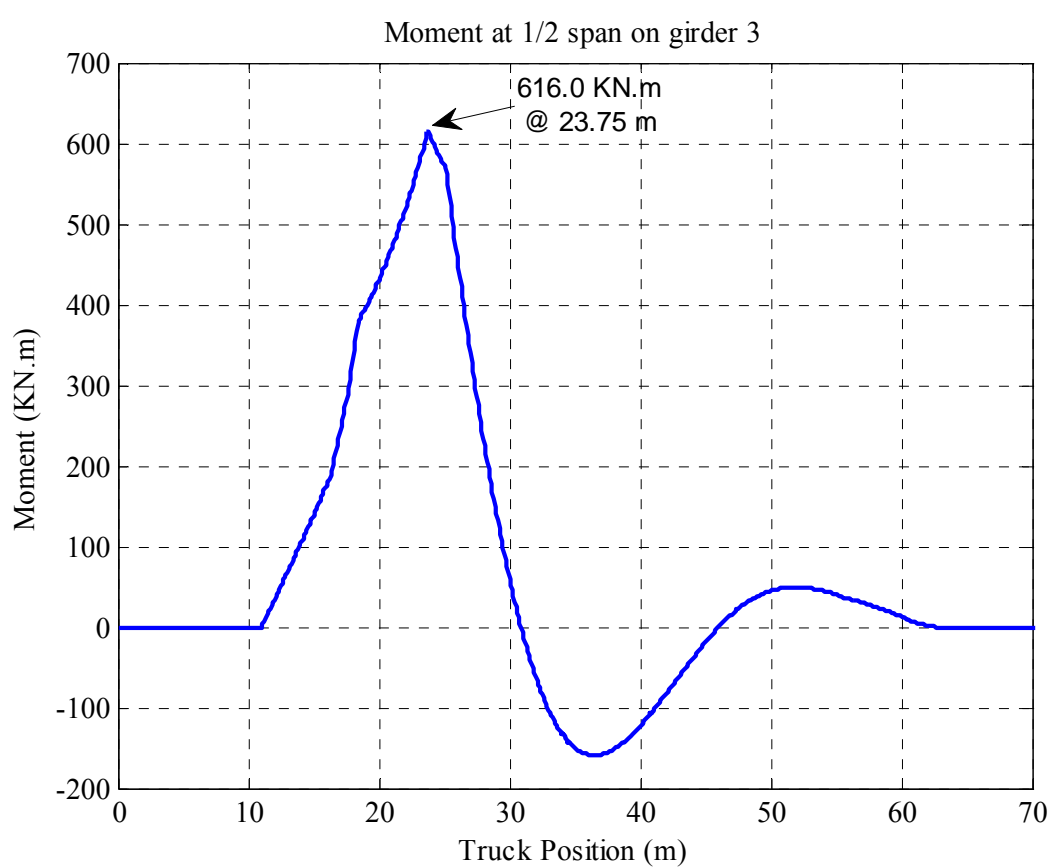

Figure 6.33 Moment at the middle of the $1^{\text {st }}$ span of girder 3 
Because the load test was semi-static test, the impact moment was not counted in. Then the bending moment in G4, when two trucks loaded on both lanes, can be calculated :

$$
M_{m}=M \times L D F=616.0 \times 53.2 \%=327.7 \mathrm{KN} . \mathrm{m}
$$

According to equation (4.5), the theoretical bottom-flange maximum strain resulting is the maximum moment dividend by the composite section modulus:

$\varepsilon_{C}=\frac{L_{T}}{(S F) E}=\frac{M_{m}}{S_{C} E}=\frac{327.7 \mathrm{KN} \cdot \mathrm{m}}{334.68 \mathrm{in}^{3} \times(0.0254)^{3} \mathrm{~m}^{3} / \mathrm{in}^{3} \times 200 \mathrm{GPa}}=298.5 \mu \varepsilon$

The measured maximum strain recorded in girder 4 was $74.7 \pm 3.6 \mu \varepsilon$ when the truck's front wheel was about $24 \mathrm{~m}$ away from the starting line. This strain value is for the case of one lane loaded. When both of lanes were loaded, the adjusted strain value of $146.6 \mu \varepsilon$ was calculated as shown in equation (6.9).

$$
\varepsilon_{T}=74.7 \mu \varepsilon\left(\frac{53.2 \%}{26.6 \%}\right)=149.4 \mu \varepsilon
$$

An apparent section modulus $S_{C A}$ can be calculated by using the adjusted strain and the corresponding moment results:

$$
S_{C A}=\frac{M_{m}}{\varepsilon_{T} E}=\frac{327.7 \mathrm{KN} \cdot \mathrm{m}}{149.4 \times(0.0254)^{3} \mathrm{~m}^{3} / \mathrm{in}^{3} \times 200 \mathrm{GPa}}=669.3 \mathrm{in}^{3}
$$

The reason for the difference between the AASHTO composite section modulus and the apparent section modulus are related to differences between the actual and assumed transverse and longitudinal distributions, as well as additional composite action beyond that specified by AASHTO.

According to the discussion in section 4.2.2, the analytical rating factor $R F_{C}$ was adjusted by a factor $K$ to obtain a new rating factor $R F_{T}$ based on the diagnostic test results. The adjustment coefficient includes two factors $K_{a}$ and $K_{b}$ which must be evaluated.

$$
\begin{gathered}
K_{a}=\frac{\varepsilon_{C}}{\varepsilon_{T}}-1=\frac{298.5}{149.4}-1=0.998 \\
K_{b}=K_{b 1} \times K_{b 2} \times K_{b 3}
\end{gathered}
$$


$K_{b 1}$ can be determined based on Table 4.1. Before that, the $T / W$ ratio needs to be calculated. " $T$ " was gross weight of the test truck, and " $W$ " was HL-93 rating vehicle weight. For the vehicles used for Evansville Bridge the ratio was $T / W 68.22 \mathrm{kips} / 72 \mathrm{kips}=0.95>0.7$, From Table 4.1 , the resulting value of $K_{b 1}=1.0$.

A value of 0.8 was chosen from Table 4.2 for $K_{b 2}$ as a result of the routine inspections that occurred between 1 and 2 years.

From Table 4.3, the value of $K_{b 3}$ was chosen as 0.8 because the bridge was fatigue sensitive, and redundancy was established.

Thus:

$$
K_{b}=1.0 \times 0.8 \times 0.8=0.64
$$

Then using equation (4.3), the adjustment factor $K$ was calculated:

$$
K=1+K_{a} K_{b}=1+0.998 \times 0.64=1.64
$$

The diagnostic test has resulted in an adjustment factor of 1.64 which could be applied to any rating level. The HL-93 ratings for this bridge before and after the load test are summarized in Table 6.8. The rating factors through load test are obtained by multiplying the theoretical rating factors by 1.64 .

\begin{tabular}{|c|c|c|c|c|c|c|c|}
\hline \multicolumn{8}{|c|}{ Rating Results of Interior Girder } \\
\hline \multirow{2}{*}{\multicolumn{2}{|c|}{ Limit State }} & \multicolumn{2}{|c|}{ Design Load Rating } & \multicolumn{3}{|c|}{ Legal Load Rating } & \multirow{3}{*}{$\begin{array}{c}\text { Permit Load } \\
\text { Rating }\end{array}$} \\
\hline & & Inventory & Operating & T3 & T3S2 & T3-3 & \\
\hline \multirow{2}{*}{ Strength I } & Flexure & $\begin{array}{c}2.13 \\
(3.49)\end{array}$ & $\begin{array}{c}2.76 \\
(4.52)\end{array}$ & $\begin{array}{c}3.91 \\
(6.41)\end{array}$ & $\begin{array}{c}4.31 \\
(7.08)\end{array}$ & $\begin{array}{c}4.60 \\
(7.55)\end{array}$ & \\
\hline & Shear & $\begin{array}{c}2.30 \\
(3.77)\end{array}$ & $\begin{array}{c}2.98 \\
(4.88)\end{array}$ & $\begin{array}{c}4.38 \\
(7.19)\end{array}$ & $\begin{array}{c}4.06 \\
(6.66)\end{array}$ & $\begin{array}{c}4.30 \\
(7.05)\end{array}$ & \\
\hline \multirow{2}{*}{ Strength II } & Flexure & & & & & & $\begin{array}{c}3.41 \\
(5.59)\end{array}$ \\
\hline & Shear & & & & & & $\begin{array}{c}2.90 \\
(4.76)\end{array}$ \\
\hline Service II & & $\begin{array}{c}1.91 \\
(3.13)\end{array}$ & $\begin{array}{c}2.48 \\
(4.07)\end{array}$ & $\begin{array}{c}3.31 \\
(5.42)\end{array}$ & $\begin{array}{c}3.65 \\
(5.98)\end{array}$ & $\begin{array}{c}3.89 \\
(6.38)\end{array}$ & $\begin{array}{c}2.61 \\
(4.43)\end{array}$ \\
\hline \multicolumn{2}{|c|}{ Safe Load Capacity (tons) } & & & $\begin{array}{c}82.6 \\
(135.5)\end{array}$ & $\begin{array}{c}131.4 \\
(215.4)\end{array}$ & $\begin{array}{c}155.7 \\
(255.4)\end{array}$ & \\
\hline
\end{tabular}

Table 6.4 HL-93 rating results before and after load test 


\subsection{Discussion on Resolution of WVPI}

As discussed in Section 3.5.2, by using the wireless vehicle position indicator (WVPI), a resolution of one-quarter wheel-circumference $(W C / 4)$ can be achieved through locating the peaks \& valleys of the acceleration signals of the WVPI recorded with the rotation of the wheel. This resolution is 4 times higher than that of the widely used BDI AutoCliker, which has a resolution of one wheel-circumference ( $1 \mathrm{WC})$.

In the load test, the wheel circumference of the test truck is measured as $3.30 \mathrm{~m}$. If the BDI AutoCliker is used in the test, the resolution of truck position can only reach $3.30 \mathrm{~m}$. This resolution may be enough for those bridges with long spans. However, for bridges with short spans, such as Evansville Bridge which has a span with $14.78 \mathrm{~m}$ in length, the resolution is relative low and not enough to coordinate critical points with truck positions. By using WVPI, the resolution of truck position can be improved to $0.825 \mathrm{~m}$. With much higher resolution, the WVPI is suitable for identification of truck positions in load tests for short-span bridges.

In fact, the strain signal conversion from time domain to truck-position domain can be considered as a sampling process. The time domain signal is the target signal and the truck-position domain signal is the sampled signal. The resolution of WVPI is relative to the sampling frequency. Although the WVPI provides much higher resolution of truck position than other methods and devices, some details of the strain signal still can not be properly presented by using the proposed "Peaks \& Valleys" method. As shown in Figure 6.34, actually there are two peaks near the maximum strain value, which were caused by passes of the two rear axles. It can be seen that the original "Peaks \& Valleys" method with a resolution of $W C / 4$ may not be able to acquire all of the details because the resolution is not high enough in this case. 


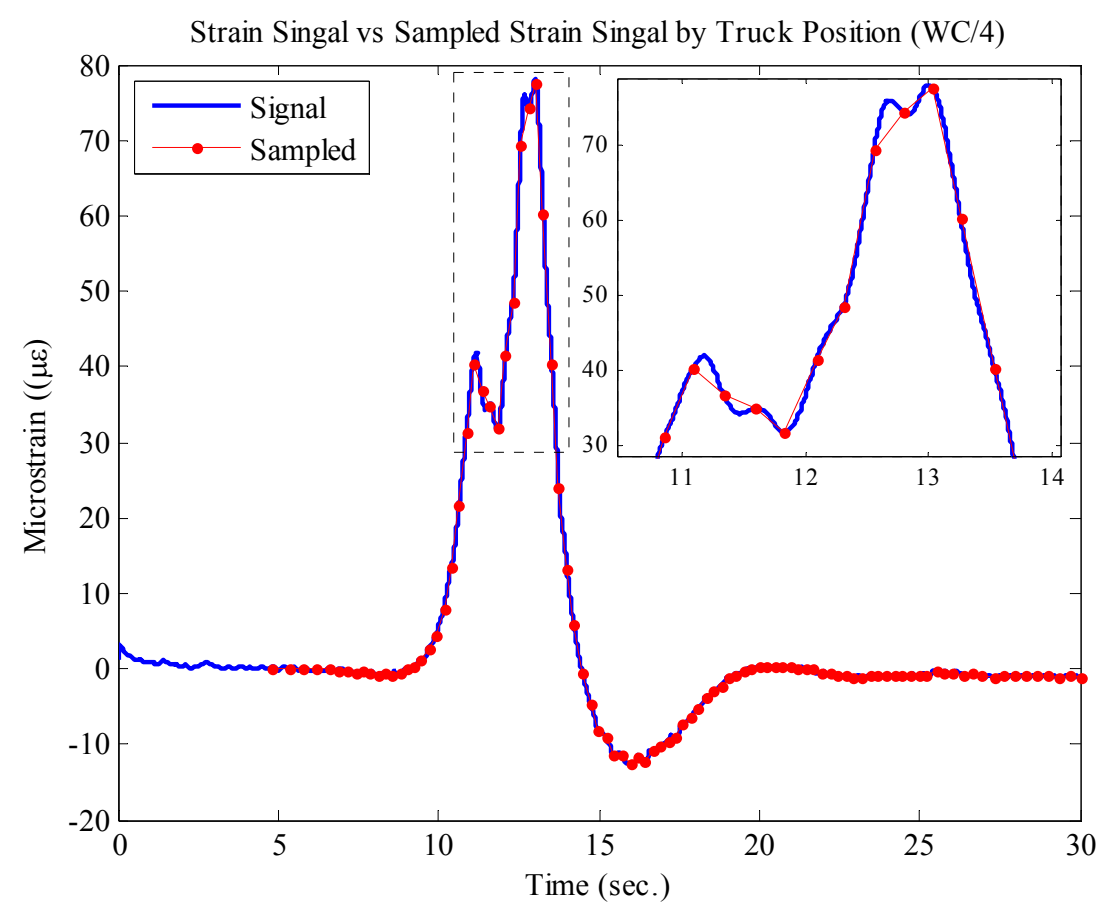

Figure 6.34 Sampling with the original "Peaks \& Valleys" method

In Section 3.5.4, two ways to improve measurement resolution of WVPI haven been discussed. One approach is to deploy more wireless G-Link ${ }^{\circledR}$ nodes and use the same algorithm to locate the peaks and valleys. The other one is to interpolate the rotation angle in a small range of $90^{\circ}$ rotation with the assumption of sinusoidal characteristic in the range. The latter approach will be evaluated because it needs only some modifications in the algorithm without any other installation and cost.

Respectively, Figure 6.35 and Figure 6.36 display the results of sampling strain signal by interpolation at rotation angles of $30^{\circ}$ and $10^{\circ}$, which lead corresponding improved resolutions of $W C / 12$ and $W C / 36(0.275 \mathrm{~m}$ and $0.092 \mathrm{~m}$ for the case). As we can see, the modified method provides an even higher resolution than the original approach and is able to present details of the strain signal very well. 


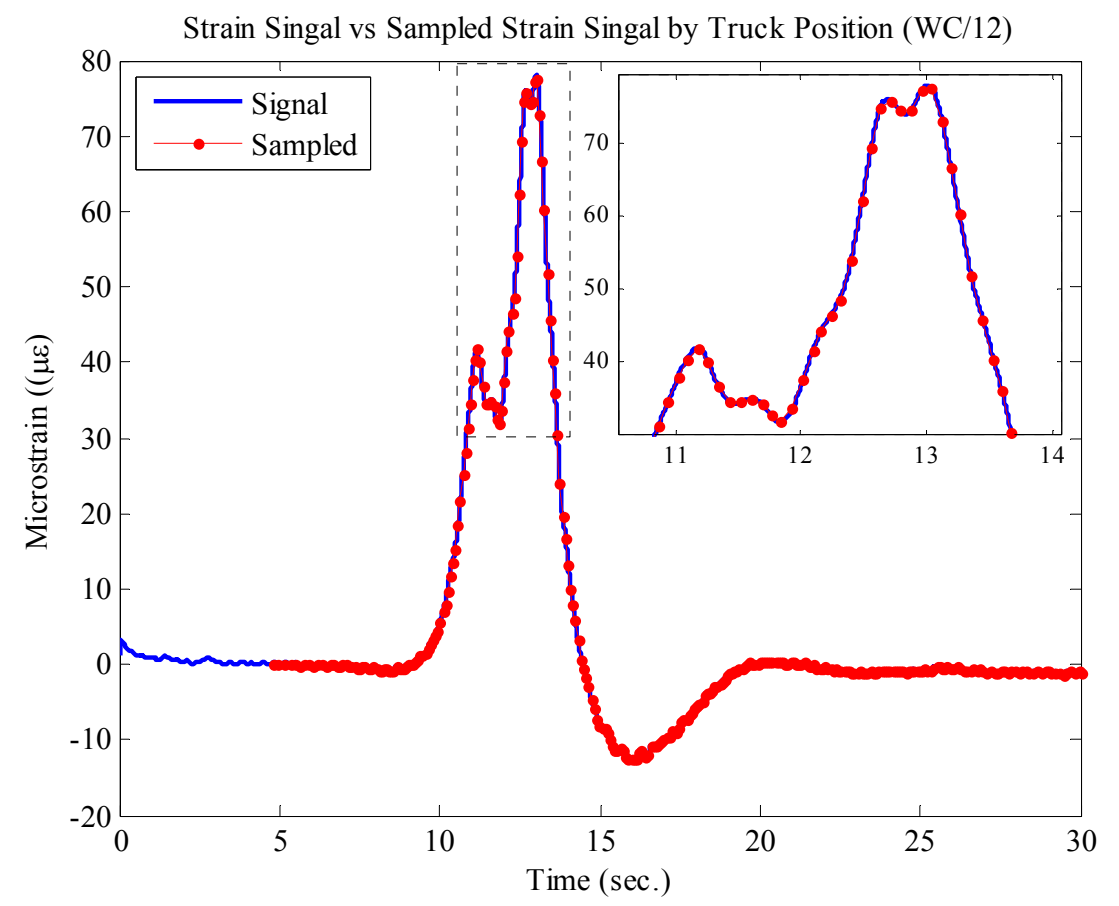

Figure 6.35 Sampling with modified method (interpolation at $30^{\circ}$ )

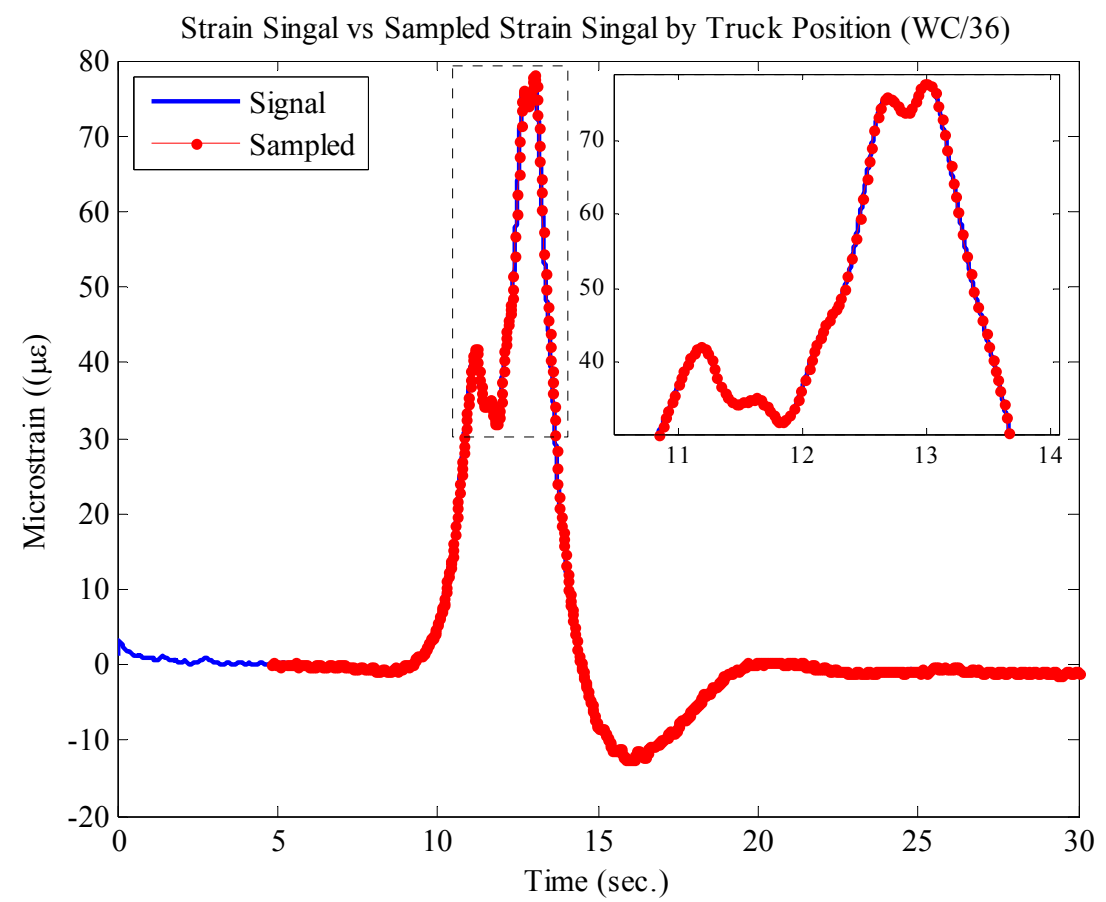

Figure 6.36 Sampling with modified method (interpolation at $10^{\circ}$ )

Figure 6.37 shows the strain signals in truck position domain with original "Peaks $\&$ Valleys" method and modified interpolation method (interpolation at a $10^{\circ}$ resulting a resolution of $W C / 36)$. The detail information of the strain peaks is got with the modified method. Actually, these peaks are corresponding to the passes of axles of the test truck. Distances between the peaks are approximately the distances between the axles. From the records, the distances between peaks are obtained as $5.14 \mathrm{~m}$ and 1.10 $\mathrm{m}$, which are close to the measured axle distances of $5.36 \mathrm{~m}$ and $1.40 \mathrm{~m}$. 


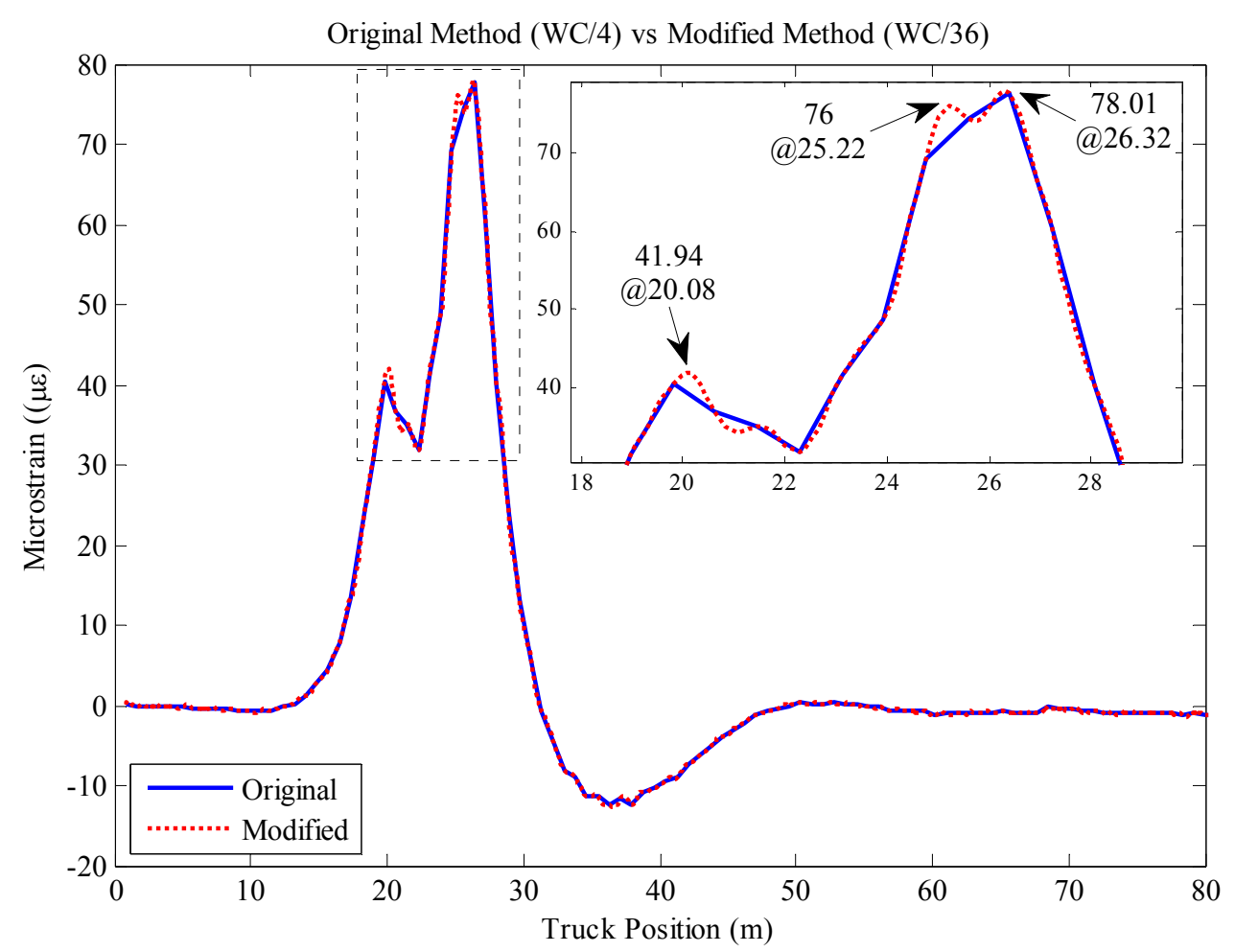

Figure 6.37 Strain signals in truck position domain with different methods

\subsection{Confirmation Test}

In order to validate the repeatability of the load test, a validation test was carried out on the same bridge on April 14, 2010.

A dump truck loaded with gravel from the J.F. Allen Company was used in the test. The actual gross weight of the test truck was $300 \mathrm{KN}$. Respectively, weights of three axles are: front $80 \mathrm{KN}$, rear one $110 \mathrm{KN}$ and rear two $110 \mathrm{KN}$. Distances between axles are $5.33 \mathrm{~m}, 1.52 \mathrm{~m}$. Front wheel distance is $2.13 \mathrm{~m}$ and rear wheel distance is $1.83 \mathrm{~m}$.

Same instrumentation plan and test procedures were followed as previous experiment. The truck path is different, as shown in Figure 6.38. Different truck path also causes different vehicle loads in finite element analysis. 


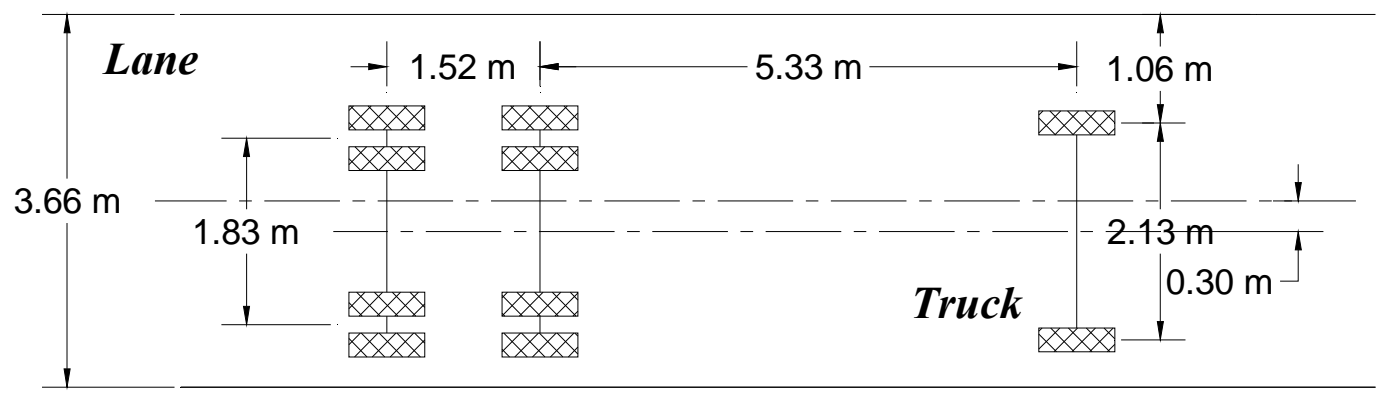

Figure 6.38 Truck path of the load test

Figure 6.39 shows the strain records at $1 / 2$ span of girder 4 . At this location, same as that in the previous experiment, two strain gages (strain pair) were installed respectively on the top and bottom flanges, one BDI strain transducer was clamped beside the strain gage on the bottom flange.
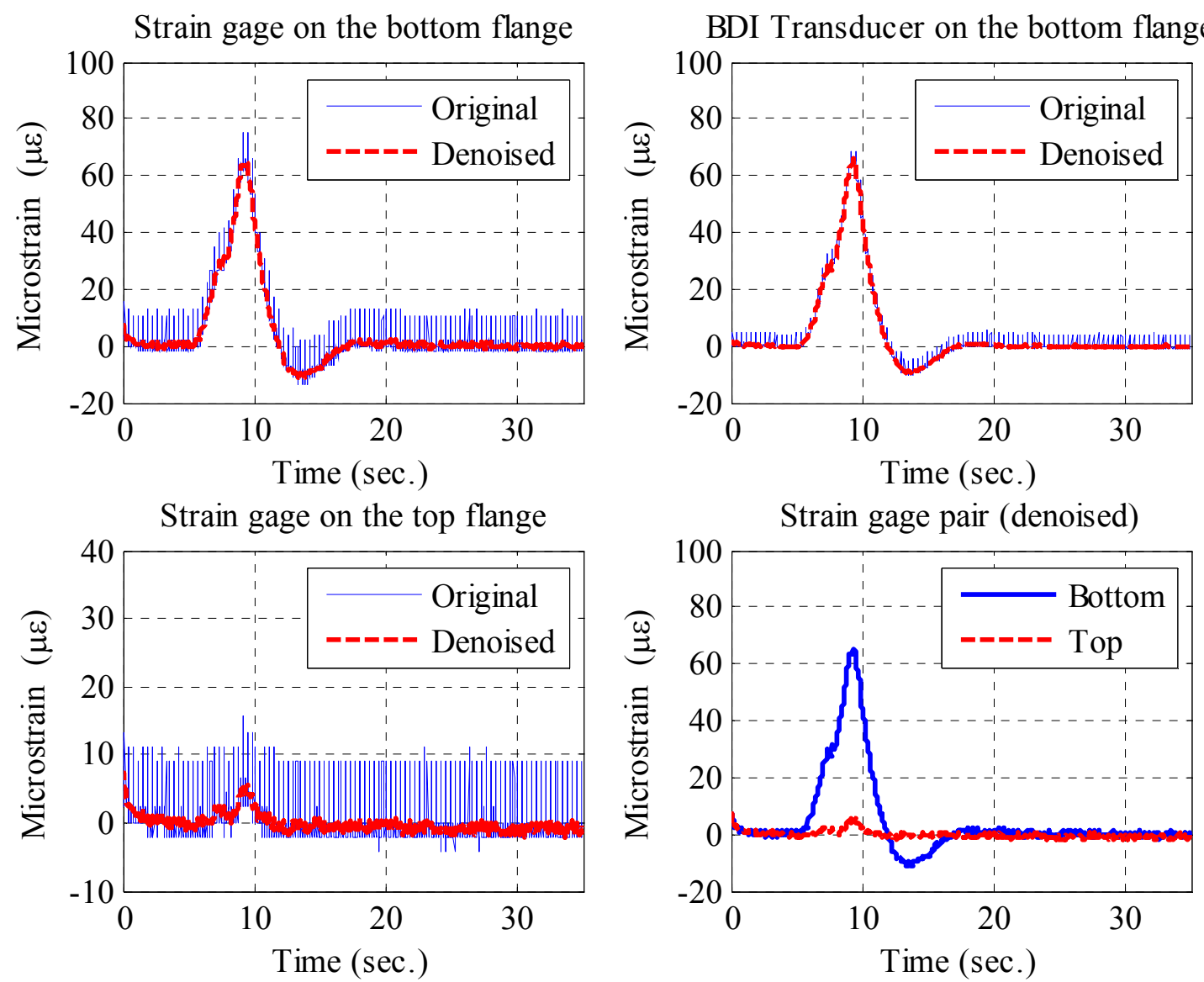

Figure 6.39 Strain records at $1 / 2$ span of girder 4 


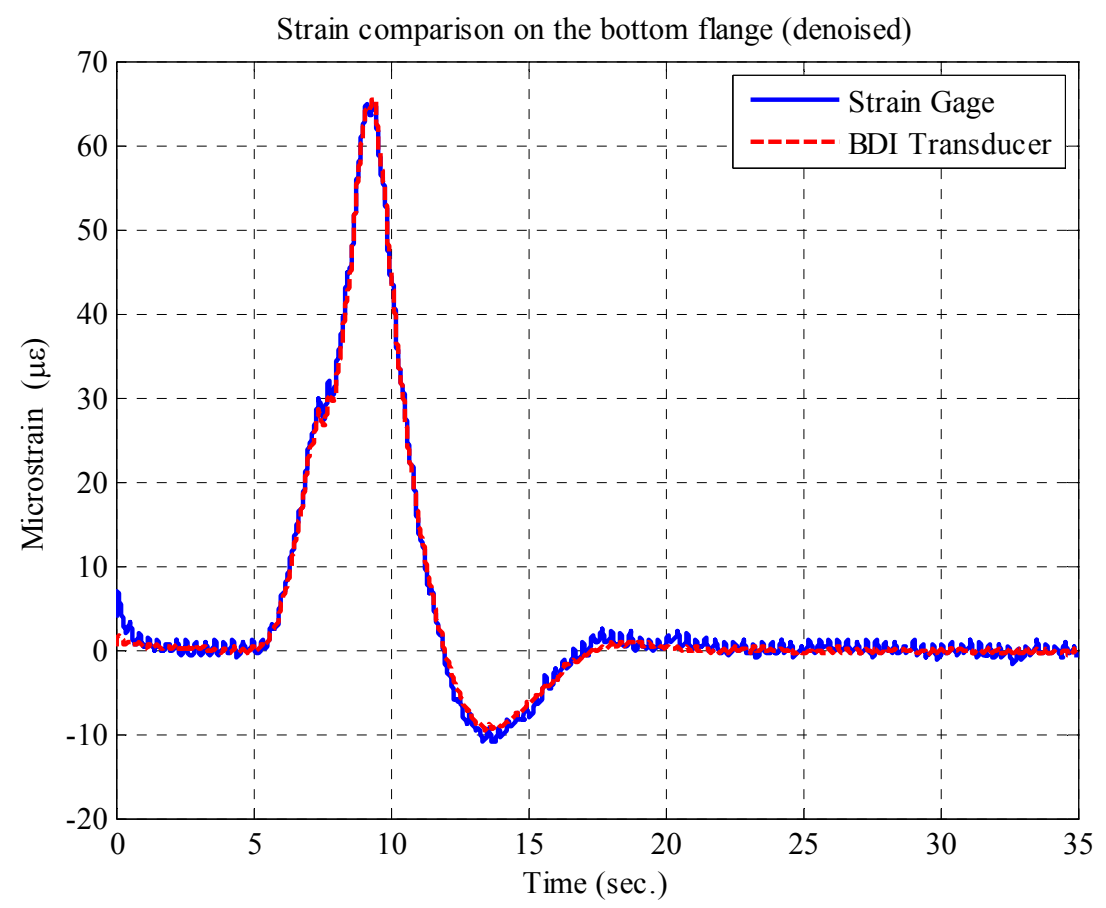

Figure 6.40 Bottom strain comparison at $1 / 2$ span of girder 4

From the strain comparison (Figure 6.40) between strain gage and BDI transducer, which were installed in parallel, it can be seen that the two denoised outputs matched with each other pretty well.

FE model was updated with new truck dimension, weights and path. New load distribution factors were calculated from the new model, as shown in Table 6.6.

Table 6.5 Test truck distribution factors

\begin{tabular}{c|c|c|c}
\hline Girder No. & Lane 1 Dist. (\%) & Lane 2 Dist. (\%) & Total Dist. (\%) \\
\hline G1 & 11.5 & 0.3 & 11.8 \\
\hline G2 & 18.8 & 4.5 & 23.3 \\
\hline G3 & 28.5 & 11.7 & 40.2 \\
\hline G4 & 24.7 & 24.7 & $\mathbf{4 9 . 4}$ \\
\hline G5 & 11.7 & 28.5 & 40.2 \\
\hline G6 & 4.5 & 18.8 & 23.3 \\
\hline G7 & 0.3 & 11.5 & 11.8 \\
\hline Total & 100 & 100 & 200 \\
\hline
\end{tabular}

The average maximum strain recorded in girder 4 is $66.8 \mu \varepsilon$. When both of lanes are loaded, the adjusted strain through testing $\varepsilon_{T}=66.8 \mu \varepsilon(49.4 \% / 24.7 \%)=133.6 \mu \varepsilon$. Combing the distribution factor in Table 6.6, the theoretical bottom-flange maximum strain $\varepsilon_{C}$ is calculated with the same method discussed in section $6.9, \varepsilon_{C}=280.9 \mu \varepsilon$. Then, the adjustment factor $K$ can be calculated: $K=1.69$.

Setups of the two load tests are compared in Table 6.6. 
Table 6.6 Comparison of test trucks and path

\begin{tabular}{c|c|c|c|c}
\hline \multicolumn{2}{c|}{ Properties } & Test 1 & Test 2 & Difference (\%) \\
\hline $\begin{array}{c}\text { Truck Weight } \\
(\mathbf{K N})\end{array}$ & Gross & $304 \mathrm{KN}$ & $300 \mathrm{KN}$ & $1.3 \%$ \\
\cline { 2 - 5 } & Axle & $92,106,106 \mathrm{KN}$ & $80,110,110 \mathrm{KN}$ & $13 \%, 3.8 \%, 3.8 \%$ \\
\hline \multicolumn{2}{c|}{ Path (centerline to wheel) (m) } & $0.5 \mathrm{~m}$ & $1.0 \mathrm{~m}$ & $100 \%$ \\
\hline \multicolumn{2}{c}{ Test Date } & $11 / 19 / 2009$ & $04 / 14 / 2010$ & \\
\hline
\end{tabular}

Strain measurements of two tests are listed in Table 6.7. Average strain variation is about $10 \%$. Considering the change of wheel positions in the two tests, the variation is acceptable. Table 6.8 presents the comparison of distribution factors calculated from finite element model.

Table 6.7 Comparison of strain measurements

\begin{tabular}{c|c|c|c|c|c|c|c|c|c}
\hline \multicolumn{2}{c|}{ Run NO. } & Run 1 & Run 2 & Run 3 & Run 4 & Run 5 & Mean & $\begin{array}{c}\text { Standard } \\
\text { Deviation }\end{array}$ & $\begin{array}{c}\text { Mean } \\
\text { Diff. }\end{array}$ \\
\hline \multirow{2}{*}{$\begin{array}{c}\text { Strain } \\
(\mu \varepsilon)\end{array}$} & Test 1 & 79.7 & 74.4 & 75.7 & 69.6 & 74.1 & 74.7 & 3.6 & \multirow{10.6\%}{nyyyyyyyn}{} \\
\cline { 2 - 10 } & Test 2 & 64.8 & 70.9 & 65.1 & 66.5 & $/$ & 66.8 & 2.8 & \\
\hline
\end{tabular}

Table 6.8 Comparison of distribution factors

\begin{tabular}{c|c|c|c|c|c|c|c|c|c}
\hline \multicolumn{2}{c|}{ Girder } & $\# \mathbf{1}$ & $\mathbf{\# 2}$ & $\mathbf{\# 3}$ & $\mathbf{\# 4}$ & $\mathbf{\# 5}$ & $\mathbf{\# 6}$ & $\mathbf{\# 7}$ & Total \\
\hline $\begin{array}{c}\text { Dis. (\%) } \\
\text { (2 lane load) }\end{array}$ & Test $\mathbf{1}$ & 7.9 & 22.0 & 43.5 & $\mathbf{5 3 . 2}$ & 43.5 & 22.0 & 7.9 & 200 \\
\cline { 2 - 10 } & Test 2 & 11.8 & 23.3 & 40.2 & $\mathbf{4 9 . 4}$ & 40.2 & 23.3 & 11.8 & 200 \\
\hline
\end{tabular}

Table 6.9 Comparison of calculated adjustment factor $K$

\begin{tabular}{c|c|c|c}
\hline & Test 1 & Test 2 & Difference (\%) \\
\hline $\begin{array}{c}\text { Adjustment Factor } K \\
\text { (Calculated from Test data) }\end{array}$ & 1.64 & 1.69 & $3 \%$ \\
\hline
\end{tabular}

From table 6.9, it can be seen that the values of calculated adjustment factor $K$ are very close with a difference of $3 \%$. The fact validates the effectiveness and correctness of this wireless bridge testing and rating system. 


\section{Chapter 7}

\section{Conclusions and Recommendations}

\subsection{Conclusions}

The following conclusions can be drawn from this study based upon the theoretical and experimental analyses:

1. Compared to traditional wired DAQ systems, wireless DAQ systems have significant advantages: a) they can remedy the recurring cabling problem. b) they reduce installation cost with less time consumption and less manpower needed.

2. The wireless bridge load testing \& rating system developed in this study provides a reliable and low-cost technology for structural evaluation of highway bridges using LRFR procedures.

3. Field placement of the system demonstrates its efficiency: no cable, fast installation, and less testing time.

4. The placement of the system on Evansville Bridge required two people working for 3 hours. Ten rounds of tests were performed in 1 hour with no traffic control and using four workers including the truck driver.

5. The wireless vehicle position indicator (WVPI) features merits of wireless, low cost, lightweight, fast installation, and high resolution.

6. The wireless bridge load testing system developed in this study produced satisfactory repeatability of calculated LRFR factors. For test 1, measured maximum strain value is $\varepsilon_{1}=74.7 \pm 3.6 \mu \varepsilon$. For validation test $2, \varepsilon_{2}=66.8 \pm 2.8$ $\mu \varepsilon$. The calculated adjustments factors for rating are respectively 1.64 and 1.69, with a $3 \%$ difference.

7. Comparison between field test results and theoretical rating results for Evansville Bridge indicates that LRFR theoretical rating procedures produce lower rating factors than those obtained through load testing. 
8. Because of its merits, the low-cost wireless bridge load testing \& rating system is an effective means to evaluate the real capacity of bridge.

9. Finite element model of Evansville Bridge provides a prediction of the bridge responses under moving loads with 5\% difference between FE results and field test results.

10.Both OMEGA pre-wired strain gages and BDI strain transducers can accurately measure the strain responses of the bridge. OMEGA pre-wired strain gages need more time for surface preparation and installation, and BDI strain transducers only need rough surface cleaning and can be easily fixed by C-clamps. However, the price of the BDI strain transducer is much higher.

11.Result comparison between external and internal quarter-bridge completion for strain gages shows that internal completion may cause the strain record to shift and the external completion produces stable strain output. 


\subsection{Future Work}

1. The reliability of LRFR bridge load testing \& rating system should be further evaluated for different types and spans of bridges. If allowed, more path routes should be prepared for the load tests.

2. The system developed in this work should be expanded to include sensors and wireless nodes mounted on all spans of a bridge and on all girders. The LRFR software should then be modified accordingly.

3. Smaller signal conditioners for strain gages and accelerometers with low power consumption should be developed.

4. The wireless data acquisition software can be integrated with the data processing and reduction software.

5. In order to minimize installation time, strain transducers can be used to replace strain gages. Meanwhile, the transducers can be reused on other bridges.

6. If possible, LVDTs or other devices can be installed to measure the deflection at the mid-span. Then the measured deflection can be used to compare with the deflection obtained from double-integration of acceleration in order to validate the reliability and accuracy of this approach. 


\section{References}

[1] AASHTO Guide Manual for Condition Evaluation and Load and Resistance Factor Rating (LRFR) of Highway Bridges (2003). American Association of State Highway and Transportation Officials, Washington, D.C.

[2] Abu-Hilal M. and Mohsen M., "Vibration of Beams with General Boundary Conditions Due to A Moving Harmonic Load", Journal of Sound and Vibration, 232 (4), pp. 703-717.

[3] ADXL202/210 data sheet, Analog Devices, Inc., 1999.

[4] Agile-Link ${ }^{T M} 2.4 \mathrm{GHz}$ Wireless Nodes: Maximizing Wireless Communication Range (2007). MicroStrain ${ }^{\circledR}$ Technical Note.

[5] Agile-Link ${ }^{T M} 2.4 \mathrm{GHz}$ Wireless Nodes: Wireless Synchronization (2007). MicroStrain ${ }^{\circledR}$ Application Note.

[6] Aktan, A.E., Turer, A. and Levi, A. (1998). Instrumentation, Proof-Testing and Monitoring of Three Reinforced Concrete Deck-on-Steel Girder Bridges To, During and After Superload, Final Report, Ohio Department of Transportation.

[7] Akyildiz, I.F., Weilian, S., Sankarasubramaniam, Y. and Cayirci, E. (2002). "A survey on sensor networks," Communications Magazine, IEEE, 40(8): 102-114.

[8] Allen, D.W. (2004). "Software for Manipulating and Embedding Data Interrogation Algorithms into Integrated Systems," M.S. Thesis, Department of Mechanical Engineering, Virginia Polytechnic Institute and State University, Blacksburg, VA.

[9] Cunha, A. and Caetano, E. (2006). "Experimental Modal Analysis of Civil Engineering Structures," Journal of Sound and Vibration, 12-20, June 2006.

[10] Aoki, S., Fujino, Y., and Abe, M. (2003). "Intelligent Bridge Maintenance System Using MEMS and Network Technology," in Smart Systems and NDE for Civil Infrastructures, San Diego, CA, March 3-6, Proceedings of the SPIE, Vol. 5057, 37-42.

[11] Arms, S.W., Townsend, C.P. (2003). "Wireless Strain Measurement Systems, Applications \& Solutions," Presented at NSF-ESF Joint Conference on Structural Health Monitoring, Strasbourg, France.

[12] Arms, S.W., Townsend, C.P., Churchill, D.L., Hamel, M.J., Galbreath, J.H., and Mundell, S.W. (2004). "Frequency Agile Wireless Sensor Networks," in Smart Electronics, MEMS, BioMEMS, and Nanotechnology, San Diego, CA, March 15-18, Proceedings of the SPIE, Vol. 5389, 468-475. 
[13] Arms, S.W., Newhard, A.T., Galbreath, J.H. and Townsend, C.P. (2004). "Remotely Reprogrammable Wireless Sensor Networks for Structural Health Monitoring Applications," Presented at ICCES International Conference on Computational and Experimental Engineering and Sciences, Medeira, Portugal, July 2004.

[14] Arms, S.W., Townsend, C.P., Galbreath, J.H. and Newhard, A.T. (2004). "Wireless Strain Sensing Networks," $2^{\text {nd }}$ European Workshop on Structural Health Monitoring, Munich, Germany, July 2004.

[15] Arms, S.W., Galbreath, J.H., Newhard, A.T. and Townsend, C.P. (2004). "Remotely Reprogrammable Sensors for Structural Health Monitoring," Structural Materials Technology (SMT): NDE/NDT for Highways and Bridges, Buffalo, NY, September 2004.

[16] Arms, S.W., Townsend, C.P., Churchill, D.L., Galbreath, J.H. and Mundell S.W. (2005). "Power Management for Energy Harvesting Wireless Sensors," SPIE's Annual International Symposium on Smart Structures and Smart Materials, San Diego, CA.

[17] Barker, M.G. (1999). "Steel Girder Bridge Field Test Procedures", Construction and Building Materials, Volume 13, Issue 4, 229-239.

[18] Basheer, M. R., Rao, V., and Derriso, M. (2003). "Self-organizing Wireless Sensor Networks for Structural Health Monitoring," in Proceedings of the 4th International Workshop on Structural Health Monitoring, Stanford, CA, September 15-17, 1193-1206.

[19] Bathe, K.J. and Wilson, E.L. (1976), Numerical Methods in Finite Element Analysis. Englewood Cliffs, NJ: Prentice-Hall.

[20] Bennett, R., Hayes-Gill, B., Crowe, J.A., Armitage, R., Rodgers, D., and Hendroff, A. (1999). "Wireless Monitoring of Highways," in Smart Systems for Bridges, Structures, and Highways, Newport Beach, CA, March 1-2, Proceedings of the SPIE, Vol. 3671, 173-182.

[21] Biggs, R.M, Barton, F.W., Gomez, J.P., Masserelli, P.J. and McKeel, W.T. (2000). Finite element modeling and analysis of reinforced-concrete bridge decks, Report No. VTRC 01-R4, Virginia Transportation Research Council, Charlottesville, VA, 29 pps.

[22] Binns, J. (2004). "Bridge Sensor System Delivers Results Quickly," Civil Engineering, Vol. 74, No. 9, 30-31.

[23] Casciati, F. and Rossi, R. (2003). "Fuzzy Chip Controllers and Wireless Links in Smart Structures," in Proceedings of the AMAS/ECCOMAS/STC Workshop on Smart Materials and Structures (SMART'03), Warsaw, Poland, September 2-5.

[24] Casciati, F., Faravelli, L. and Borghetti, F. (2003). "Wireless Links Between Sensor-device Control Stations in Long Span Bridges," in Smart Structures and Materials: Smart Systems and Nondestructive Evaluation. San Diego, CA, March 3-6, Proceedings of SPIE, Vol. 5057, 1-7. 
[25] Casciati, F., Casciati, S., Faravelli, L., and Rossi, R. (2004). "Hybrid Wireless Sensor Network," in Smart Structures and Materials: Sensors and Smart Structures Technologies for Civil, Mechanical, and Aerospace Systems, San Diego, CA, March 15-18, Proceedings of the SPIE, Vol. 5391, 308-313.

[26] Casciati, F. and Rossi, R. (2007). "A Power Harvester for Wireless Sensing Applications," Structural Control and Health Monitoring, Vol. 14, 649-659.

[27] Celebi, M. (2002). Seismic Instrumentation of Buildings (with Emphasis on Federal Buildings), Report No. 0-7460-68170 United States Geological Survey (USGS), Menlo Park, CA.

[28] Chajes, M.J., Mertz, D.R. and Commander B. (1997). "Experimental Load Rating of a Posted Bridge", Journal of Bridge Engineering, Vol. 2, No. 1, 1997, pp. 1-10.

[29] Chan, T.H.T., Law, S.S., Yung, T.H. and Yuan X.R. (1999). “An Interpretive Method for Moving Force Identification", Journal of Sound and Vibration, 219 (3), pp. 503-524.

[30] Chan, T.H.T., Yu, L., Law, S.S. and Yung, T.H. (2001). "Moving Force Identification Studies, I: Theory", Journal of Sound and Vibration, 247 (1), pp. 59-76.

[31] Chan, T.H.T. and Ashebo, D.B. (2004). "Experimental Study of Moving Force Identification on a Continuous Bridge", $17^{\text {th }}$ ASCE Engineering Mechanics Conference, Newark, DE, June 13-16, 2004.

[32] Chan, T.H.T. and Ashebo, D.B. (2006). "Theoretical study of moving force identification on continuous bridge", Journal of Sound and Vibration, 295 (3), pp. $870-883$.

[33] Chan, T.H.T and Ashebo, D.B. (2006). "Moving Axle Load From Multi-Span Continuous Bridge: Laboratory Study", Journal of Vibration and Acoustics, Vol. 128, pp. 521-526.

[34] Chang, P.C., Flatau, A. and Liu, S.C. (2003). "Review paper: health monitoring of civil infrastructure," Structural Health Monitoring, 2(3): 257-267.

[35] Chang, J.B.J. and Robertson, I.N. (2003). Computer Modeling of the Proposed Kealakaha Stream Bridge, Research Report UHM/CEE/03-03.

[36] Chase, S. (2001). The Role of Smart Structures in Managing an Aging Highway Infrastructure, Keynote Presentation in SPIE $8^{\text {th }}$ Annual International Symposium on Smart Structures and Materials, Newport Beach, CA, USA, March 4-8, 2001.

[37] Chong, C.Y. and Kumar, S.P. (2003), "Sensor networks: evolution, opportunities, and challenges," Proc. IEE, vol.91, no.8, pp.1247-1256, 2003.

[38] Chung, H.C., Enomoto, T., Shinozuka, M., Chou, P., Park, C., Yokoi, I., and Morishita, S. (2004a). "Real-time Visualization of Structural Response with 
Wireless MEMS Sensors," in Proceedings of the $13^{\text {th }}$ World Conference on Earthquake Engineering, Vancouver, BC, Canada, August 2-6.

[39] Chung, H.C., Enotomo, T., Loh, K., and Shinozuka, M. (2004b). "Real-time Visualization of Bridge Structural Response Through Wireless MEMS Sensors," in Testing, Reliability, and Application of Microand Nano-Material Systems II, San Diego, CA, March 15-17, Proceedings of SPIE, Vol. 5392, 239-246.

[40] Commander, B., Varela-Ortiz, W., Stanton, T.R., and Diaz-Alvarez, H. (2009), "Field Testing and Load Rating Report, Bridge FSBR-514, Fort Shafter, Hawaii", Final Report, Geotechnical and Structure Laboratory, U.S. Army Engineer Research and Development Center, May 2009.

[41] Doebling, S.W., Farrar, C.R. and Prime, M.B. (1998). "A summary review of vibration-based damage identification methods," The Shock and Vibration Digest, 30(2): 91-105.

[42] Dugush, Y.A., Eisenberger, M. (2002). "Vibrations of Non-uniform Continuous Beams under Moving Loads", Journal of Sound and Vibration, 254 (5), pp. 911-926.

[43] Fafard, M., Laflamme, M., Savard, M., and Bennur M. (1998). "Dynamic Analysis of Existing Continuous Bridge”, Journal of Bridge Engineering, 3(1), pp. 28-37.

[44] Farhey, D. N. (2003). "Rapid-response Diagnostics and Smart Structure Monitoring in Bridge Testing," in Proceedings of the County Engineers Association of Ohio Bridge Conference, Columbus, $\mathrm{OH}$.

[45] Farrar, C.R. (2001). "Historical Overview of Structural Health Monitoring," Lecture Notes on Structural Health Monitoring Using Statistical Pattern Recognition, Los Alamos Dynamics, Los Alamos, NM.

[46] Farrar, C. R., Allen, D. W., Ball, S., Masquelier, M. P. and Park, G. (2005). "Coupling Sensing Hardware with Data Interrogation Software for Structural Health Monitoring," in Proceedings of the 6th International Symposium on Dynamic Problems of Mechanics (DINAME), Ouro Preto, Brazil, February 29-March 4.

[47] Galbreath, J.H., Townsend, C.P., Mundell, S.W., Hamel, M.J., Esser, B., Huston, D., and Arms, S.W. (2003). "Civil Structure Strain Monitoring with Power-efficient, High-speed Wireless Sensor Networks," in Proceedings of the 4th International Workshop on Structural Health Monitoring, Stanford, CA, September 15-17, 1215-1222.

[48] Glaser, S.D. (2004). "Some real-world applications of wireless sensor nodes," Proceedings of SPIE 11th Annual International Symposium on Smart Structures and Materials, 5391: 344-355, San Diego, CA, March 14-18, 2004.

[49] Gorman, D.J. (1975). Free Vibration Analysis of Beam and Shafts, Wiley, 1975. 
[50] Henchi, K., Fafard, M., Dhatt G. and Talbot, M (1997). "Dynamic Behavior of Multi-span Beams under Moving Loads”, Journal of Sound and Vibration, 199 (1), pp.33-50.

[51] Hill, J.L. (2003). System Architecture for Wireless Sensor Networks. PhD Thesis, Department of Electrical Engineering and Computer Science, University of California, Berkeley, Berkeley, CA.

[52] Huang, D. (2008). "Full-Scale Test and Analysis of a Curved Steel-Box Girder Bridge”, Journal of Bridge Engineering, Vol. 13, No. 5, September 1, 2008.

[53] Huria, V., Lee, K.L. and Aktan, A.E. (1993). "Nonlinear finite element analysis of RC slab bridge", Journal of Structural Engineering, vol. 119, no. 1, pp. 89-107.

[54] Ichikawa, M., Miyakawa, Y. and Matsuda, A. (2000). "Vibration Analysis of the Continuous Beam Subjected to A Moving Mass", Journal of Sound and Vibration, 230 (3), pp. 493-506.

[55] Ingersoll, J.S., Wipf, T.J. and Klaiber, F.W. (2003). "Experimental Evaluation of Precast Channel Bridges", Proceedings of the 2003 Mid-Continent Transportation Research Symposium, Ames, Iowa, August 2003.

[56] Jackson, J.D., Callahan, D.W. and Wang, P.F. (2006). "Location Tracking of Test Vehicles Using Accelerometers", Proceedings of the $5^{\text {th }}$ WSEAS International Conference on Circuits, Systems, Electronics, Control \& Signal Processing, Dallas, Texas, pp.333-336.

[57] Jackson, J.D. Callahan, D.W. and Wang, P.F. (2007). "Economical Methods for Accurate Vehicle Tracking”, IEEE Transactions, Portable Technologies, May 2007.

[58] Jaramilla, B. and Huo, S. (2005). "Looking to load and resistance factor rating", Public Roads, Vol. 69, No. 1, July/August, 2005.

[59] Jauregui, D.V. and Barr, P.J. (2004). "Nondestructive evaluation of the i-40 bridge over the Rio Grande River", Journal of Performance of Constructed Facilities, 18(4), pp. 195-204.

[60] Kappes, T. and Hauser, P.C. (1999), "A simple supplementary offset device for data acquisition systems", Journal of Chemical Education, Vol. 76, No. 10, October, 1999.

[61] Khemapech, I., Duncan, I. and Miller, A. (2005), "A survey of wireless sensor networks technology," in PGNET, Proceedings of the 6th Annual PostGraduate Symposium on the Convergence of Telecommunications, Networking \& Broadcasting (M.Merabti and R.Pereira, eds.), (Liverpool, UK), EPSRC, June 2005.

[62] Kim, S., Pakzad, S., Culler, D., Demmel, J., Fenves, G., Glaser, S. and Turon, M. (2007), "Health monitoring of civil infrastructures using wireless sensor networks", In IPSN '07: Proceedings of the 6th international conference on 
Information processing in sensor networks, pages 254 - 263, New York, NY, USA, 2007.

[63] Kong, J., Cheung, Y.K. (1996). "Vibration of Continuous Beams Using Modified Beam Vibration Functions", Communications in Numerical Methods in Engineering, Vol. 12, 107-114.

[64] Kottapalli, V.A., Kiremidjian, A.S., Lynch, J.P., Carryer, E., Kenny, T.W., Law, K.H., and Lei, Y. (2003). "Two-tiered Wireless Sensor Network Architecture for Structural Health Monitoring," in Smart Structures and Materials, San Diego, CA, March 3-6, Proceedings of the SPIE, Vol. 5057, 8-19.

[65] Kou, J.W. and DeWolf, J.T. (1997). "Vibrational Behavior of Continuous Span Highway Bridge - Influencing Variables", Journal of Structural Engineering, Vol. 123, No. 3, March 1997.

[66] Lee, H.P. (1994). "Dynamic Response of a Beam with Intermediate Point Constraints Subjected to a Moving Load", Journal of Sound and Vibration, 171, pp. 361-368.

[67] Lee, H.P. (1995). "Dynamic Response of a Multi-Span Beam on One-Sided Point Constraints Subjected to a Moving Load", Computers \& Structures, Vol. 55, No. 4, pp. 615-623.

[68] Lenett, M.S., Hunt V.J., Helmicki, A.J. and Turer, A. (2001). "Health Monitoring of Ironton-Russell Bridge for Rating Purposes", Transportation Research Board Journal, Vol. 1770, pp. 67-75.

[69] Leon, R.T., Galambos, T.V., Schmit, J.J. and Teng, A.L. (1993). Field Instrumentation of Steel Highway Bridges, Final Report to the Minnesota Department of Transportation.

[70] Lichtenstein, A.G. (1993). "The silver bridge collapse recounted", Journal of Performance of Constructed Facilities, Vol. 7, No. 4, November, 1993.

[71] Lichtenstein, A.G. (1998). "Manual for Bridge Rating through Load Testing." Research Results Digest, No. 234, National Cooperative Highway Research Program, Washington, D.C.

[72] Lin, J., Shen, W. and Williams, F.W. (1995). "A High Precision Direct Integration Scheme for Structures Subjected to Transient Dynamic Loading", Computer \& Structures, Vol. 56, No. 1, pp. 113-120.

[73] Liu, S.C., and Tomizuka, M. (2003). "Vision and Strategy for Sensors and Smart Structures Technology Research," Proceedings of the 4th International Workshop on Structural Health Monitoring, Stanford, CA, pp. 42-52.

[74] Livingston, R.A., Jin, S. and Marzougui, D. (2001a). "Stochastic modeling of ambient traffic loading in LS-DYNA nonlinear FE analysis", Proceedings of SPIE - the International Society of Optical Engineering, vol. 4337, pp. 422-431. 
[75] Livingston, R.A., Jin, S. and Marzougui, D. (2001b). “Application of nonlinear dynamics analysis to damage detection and health monitoring of highway structures", Proceedings of SPIE - the International Society of Optical Engineering, vol. 4337, pp. 402-410.

[76] Loh, K., Enotomo, T., Chung, H.C., and Shinozuka, M. (2003). "Real-time Visualization of Structural Bridge Response through Wireless Sensors," Proceedings of the 2003 Earthquake Engineering Symposium for Young Researchers: Sunriver Resort, Bend, Oregon, August 7-10, 2003.

[77] Lynch, J.P., Law, K.H., Kiremidjian, A.S., Kenny, T.W., Carryer, E., and Partridge, A. (2001). "The Design of a Wireless Sensing Unit for Structural Health Monitoring," in Proceedings of the $3^{\text {rd }}$ International Workshop on Structural Health Monitoring, Stanford, CA, September 12-14.

[78] Lynch, J.P., Law, K.H., Kiremidjian, A.S., Kenny, T., and Carryer, E. (2002). "A Wireless Modular Monitoring System for Civil Structures," Proceedings of the $20^{\text {th }}$ International Modal Analysis Conference (IMAC XX), Los Angeles, CA, USA, February 4-7, 2002.

[79] Lynch, J.P. (2002). "Decentralization of Wireless Monitoring and Control Technologies for Smart Civil Structures," Ph.D. Thesis, Department of Civil and Environmental Engineering, Stanford University, Stanford, CA.

[80] Lynch, J.P. (2002). "Decentralization of wireless monitoring and control technologies for smart civil structures," Technical Report No. 140, John A. Blume Earthquake Engineering Center, Stanford, CA: Stanford University.

[81] Lynch, J.P., Law, K.H., Kiremidjian, A.S., Kenny, T.W., and Carryer, E. (2002a). "A Wireless Modular Monitoring System for Civil Structures," in Proceedings of the 20th International Modal Analysis Conference (IMAC XX), Los Angeles, CA, February 4-7, 1-6.

[82] Lynch, J.P., Law, K.H., Kiremidjian, A.S., Carryer, E., Kenny, T.W., Partridge, A., and Sundararajan, A. (2002b). "Validation of a Wireless Modular Monitoring System for Structures," in Smart Structures and Materials: Smart Systems for Bridges, Structures, and Highways, San Diego, CA, March 17-21, Proceedings of the SPIE, Vol. 4696, No. 2, 17-21.

[83] Lynch, J.P., Sundararajan, A., Law, K.H., Kiremidjian, A.S., Carryer, E., Sohn, H., and Farrar, C.R. (2003a). "Field Validation of a Wireless Structural Health Monitoring System on the Alamosa Canyon Bridge," in Smart Structures and Materials: Smart Systems and Nondestructive Evaluation for Civil Infrastructures, San Diego, CA, March 3-6, Proceedings of the SPIE, Vol. 5057, 267-278.

[84] Lynch, J.P., Sundararajan, A., Law, K.H., Kiremidjian, A.S., and Carryer, E. (2003b). "Power-efficient Wireless Structural Monitoring with Local Data Processing," in Proceedings of the International Conference on Structural Health Monitoring and Intelligent Infrastructure,Tokyo, Japan, November 13-15, Vol. 1, 331-338. 
[85] Lynch, J.P., Sundararajan, A., Law, K.H., Kiremidjian, A.S., Kenny, T., and Carryer, E. (2003d). "Embedment of Structural Monitoring Algorithms in a Wireless Sensing Unit," Journal of Structural Engineering and Mechanics, Vol. 15, No. 3, 285-297.

[86] Lynch, J.P., Sundararajan, A., Law, K.H., Kiremidjian, A.S. and Carryer, E. (2003e). "Power-efficient Data Management for a Wireless Structural Monitoring System," in Proceedings of the 4th International Workshop on Structural Health Monitoring, Stanford, CA, September 15-17, 1177-1184.

[87] Lynch, J.P., Sundararajan, A., Law, K.H., Sohn, H., and Farrar, C.R. (2003f). "Design and Performance Validation of a Wireless Active Sensing Unit," in Proceedings of the International Workshop on Advanced Sensors, Structural Health Monitoring, and Smart Structures, Tokyo, Japan, November 10-11.

[88] Lynch, J.P., Sundararajan, A., Law, K.H., Carryer, E., Farrar, C.R., Sohn, H., Allen, D.W., Nadler, B., and Wait, J.R. (2004a). "Design and Performance Validation of a Wireless Sensing Unit for Structural Health Monitoring Applications," Structural Engineering and Mechanics, Vol. 17, No. 3, 393-408.

[89] Lynch, J.P., Sundararajan, A., Sohn, H., Park, G., Farrar, C., and Law, K. (2004b). "Embedding Actuation Functionalities in a Wireless Structural Health Monitoring System," in Proceedings of the International Workshop on Smart Materials and Structures Technology, Honolulu, HI, January 12-14.

[90] Lynch, J.P., Sundararajan, A., Law, K.H., Sohn, H., and Farrar, C.R. (2004c). "Design of a Wireless Active Sensing Unit for Structural Health Monitoring," in Proceedings of the 11th Annual International Symposium on Smart Structures and Materials, San Diego, CA, March 14-18, Proceedings of the SPIE, Vol. 5394, 157-169.

[91] Lynch, J.P., Sundararajan, A., Law, K.H., Kiremidjian, A.S., and Carryer, E. (2004d). "Embedding Damage Detection Algorithms in a Wireless Sensing Unit for Operational Power Efficiency," Smart Materials and Structures, Vol. 13, No. 4, 800-810.

[92] Lynch, J.P., Parra-Montesinos, G., Canbolat, B.A., and Hou, T.C. (2004e). "Real-time Damage Prognosis of High-performance Fiber Reinforced Cementitious Composite Structures," in Proceedings of Advances in Structural Engineering and Mechanics (ASEM'04), Seoul, Korea, September 2-4.

[93] Lynch, J.P. (2004). "Overview of Wireless Sensors for Real-time Health Monitoring of Civil Structures," in Proceedings of the 4th International Workshop on Structural Control, New York, NY, June 10-11, 189-194.

[94] Lynch, J.P., Wang, Y., Law, K.H., Yi, J.H., Lee, C.G., and Yun, C.B. (2005). "Validation of a Large-scale Wireless Structural Monitoring System on the Geumdang Bridge," in Proceedings of the International Conference on Safety and Structural Reliability (ICOSSAR), Rome, Italy, June 19-23. 
[95] Lynch, J.P. (2005). "Design of a Wireless Active Sensing Unit for Localized Structural Health Monitoring," Journal of Structural Control and Health Monitoring, Vol. 12, No. 3-4, 405-423.

[96] Lynch, J.P., Loh, K.J., Hou, T.C., Wang, Y., Yi, J., Yun, C.B., Lu, K.C. and Loh, C.H. (2005), "Validation Case Studies of Wireless Monitoring Systems in Civil Structures," Proceedings of the 2nd International Conference on Structural Health Monitoring of Intelligent Infrastructure (SHMII-2), Shenzhen, China, November 16-18, 2005.

[97] Lynch, J.P. and Loh, K.J. (2006). "A summary review of wireless sensors and sensor networks for structural health monitoring," The Shock and Vibration Digest, 38(2): 91-128.

[98] Mabsout, M.E., Tarhini, K.M., Frederick, G.R. and Tayar, C. (1997). "Finite-element analysis of steel girder highway bridges", Journal of Bridge Engineering, ASCE, 2(3), 83-87.

[99] Mabsout, M.E., Tarhini, K.M. and Frederick, G.R. and Kesserwan, A. (1998). "Effect of continuity on wheel load distribution in steel girder bridges", Journal of Bridge Engineering, vol. 3, no. 3, pp. 103-110.

[100] Mabsout, M.E., Jabakhanji, R., Tarhini, K.M. and Frederick, G.R. (2000). "Finite element analysis of concrete slab bridges", Computing in Civil and Building Engineering, vol. 2, pp. 1045-1050.

[101] Marchesiello, S., Fasana, A., Garibaldi, L. and Piombo, B.A.D. (1999), "Dynamics of Multi-Span Continuous Straight Bridges Subjected to Multi-Degrees of Freedom Moving Vehicle Excitation", Journal of Sound and Vibration, 224 (3), pp. 541-561.

[102] Marzougui, D., Jin, S. and Livingston, R.A. (2001). "Development of an LS-DYNA nonlinear finite element model for use in damage and health monitoring of highway bridges", Proceedings of SPIE - the International Society for Optical Engineering, vol. 4337, pp. 432-440.

[103] Mascarenas, D., Flynn, E., Todd, M., Park, G. and Farrar, C. (2008). "Wireless sensor technologies for monitoring civil structures", Sound and Vibration, April 2008, pp. 16-20.

[104] McBride, K.C. (2005). Thermal Stresses in the Superstructure of Integral Abutment Bridges. Master Thesis, Department of Mechanical and Aerospace Engineering, West Virginia University, Morgantown, WV.

[105] Memmott, J. (2007), "Highway bridges in the United States - an overview", BTS Special Report, September 19, 2007.

[106] Mitchell, K, Dang, N., Liu, P., Rao, V.S., and Pottinger, H.J. (2001). "Web-controlled Wireless Network Sensors for Structural Health Monitoring," in Smart Structures and Materials - Smart Electronics and MEMS, Newport Beach, CA, March 5-7, Proceedings of the SPIE, Vol. 4334, 234-243. 
[107] Mitchell, K., Rao, V.S., and Pottinger, H.J. ( 2002). "Lessons Learned About Wireless Technologies for Data Acquisition," in Smart Structures and Materials 2002: Smart Electronics, MEMS, and Nanotechnology, San Diego, CA, March 18-21, Proceedings of the SPIE, Vol. 4700, 331-341.

[108] Moore, M., Phares, B., Graybeal, B., Rolander, D. and Washer, G. (2001). Reliability of Visual Inspection for Highway Bridges, Technical Report No.FHWA-RD-01-020, v.1, U.S. Department of Transportation - Federal Highway Administration, McLean, VA, USA, June, 2001.

[109] Mufti, A.A., Jaeger, L.G., Bakht, B. and Wegner, L.D. (1993). "Experimental Investigation of Fiber-Reinforced Concrete Deck Slabs without Internal Steel Reinforcement", Canadian Journal of Civil Engineering, vol. 20, pp. 398-406.

[110] Murphy, J.F. (1997). "Transverse Vibration of a Simply Supported Beam with Symmetric Overhang of Arbitrary Length", Journal of Testing and Evaluation, 25(5), pp. 522-524.

[111] Nassif, H.H., Liu, M. and Ertekin, O. (2003). "Model Validation for Bridge-Road-Vehicle Dynamic Interaction System", Journal of Bridge Engineering, 8(2), pp.112-120.

[112] Nowak, A.S., Nassif, H., and DeFrain, L. (1993). "Effect of truck loads on bridges", Journal of Transportation Engineering, 119(6), pp. 853-867.

[113] Ou, J.P. and Li, H.W. (2003) "Wireless Sensors Information Fusion for Structural Health Monitoring," in Multisensor, Multisource Information Fusion: Architectures, Algorithms, and Applications, Orlando, FL, April 23-25, Proceedings of the SPIE, Vol. 5099, 356-362.

[114] Ou, J.P., Li, H.W., and Yu, Y. (2004). "Development and Performance of Wireless Sensor Network for Structural Health Monitoring," in Smart Structures and Materials, San Diego, CA, March 15-18, Proceedings of the SPIE, Vol. 5391, 765-773.

[115] Ou, J.P., Li, H.W., Xiao, Y.Q., and Li, Q.S. (2005). "Health Dynamic Measurement of Tall Building Using Wireless Sensor Network," in Smart Structures and Materials, San Diego, CA, March 6-10, Proceedings of the SPIE, Vol. 5765, No. 1, 205-215.

[116] Park, C., Chou, P.H. and Shinozuka, M. (2005). "Duranode: Wireless networked sensor for structural health monitoring". In IEEE International Conference on Sensors. Irvine, CA.

[117] Park, K.T., Kim, S.H., Park, H.S., and Lee, K.W. (2005). "The determination of bridge displacement using measured acceleration", Engineering Structures, Vol. 27, Issue 3, February 2005.

[118] Paultre, P., Proulx, J. and Talbot, M. (1995). "Dynamic Testing Procedures for Highway Bridges Using Traffic Loads", Journal of Structural Engineering, 121(2), pp. 362-376. 
[119] Pei, J.S., Kapoor, C., Graves-Abe, T.L., Sugeng, Y. and Lynch, J.P. (2005) "Critical design parameters and operating conditions of wireless sensor units for structural health monitoring", In Proceedings of the 23rd International Modal Analysis Conference (IMAC XXIII), Orlando, FL, Jan. 31 - Feb. 3, 2005.

[120] Schonwetter, P. (1999). "Field Testing and Load Rating of a Steel-Girder Highway Bridge", Master Thesis, University of Texas at Austin, May 1999.

[121] Phares B. M., Wipf, Terry J., Klaber, F. Wayne, Abu-Hawash, Ahmad (2003). "Bridge Load Rating Using Physical Testing", Proceedings of the 2003 Mid-Continent Transportation Research Symposium, Ames, Iowa, August 2003.

[122] Phares B. M., Wipf, Terry J., Klaber, F. Wayne, Abu-Hawash, Ahmad, Neubauer, Scott (2005). "Implementation of Physical Testing for Typical Bridge Load and Superload Rating", Transportation Research Record: Journal of the Transportation Research Board (CD-11S): pp. 159-167.

[123] Salem, A.H. El-Aghoury, M.A., Sayed-Ahmed, E.Y. and Moustafa, T.S. (2002). "Composite steel free deck bridges: numerical modeling and pilot parametric study", Canadian Journal of Civil Engineering, vol. 29, p.p. 662-678.

[124] Schiff, S.D., Piccirilli, J.J., Iser, C.M., and Anderson, K.J. (2006). "Load Testing for Assessment and Rating of Highway Bridges - Phase III: Technology Transfer to the SCDOT", Research Project No. 655, South Carolina Department of Transportation, January 2006.

[125] Shahawy, M.A. (1995). "Nondestructive Strength Evaluation of Florida Bridges." Proceedings of SPIE - The International Society of Optical Engineering (Nondestructive Evaluation of Aging Bridges and Highways), Society of Photo-Optical Instrumentation Engineers, Vol. 2456, pp. 101-123.

[126] Shahrooz, B.M., Ho, I.K., Aktan, A.E. de Borst, R., Blaauwendraad, J., van der Veen, C., Idine, R.H. and Miller, R.A. (1994). "Nonlinear finite element analysis of deteriorated RC slab bridge", Journal of Structural Engineering, vol. 120 , no. 2, pp. 423-441.

[127] Shinozuka, M., Feng, M.Q., Chou, P., Chen, Y. and Park, C. (2004). "MEMS-based wireless real-time health monitoring of bridges," Proceedings of $3^{\text {rd }}$ International Conference on Earthquake Engineering, Nanjing, China, October 19-21, 2004.

[128] Shinozuka, M. and Lee, J.J. (2006). "Real-Time Displacement Measurement of a Flexible Bridge Using Digital Image Processing Techniques," Experimental Mechanics, Vol. 46, No. 1, 105-114.

[129] Shoukry, S.N., William, G.W. and Riad, M.Y. (2005). Early age cracks in concrete bridge deck, Final Report, WVDOT Report No. T646-76-4.56, West Virginia Department of Highways Charleston, WV.

[130] Sohn, H., Farrar, C.R., Hemez, F.M., Shunk, D.D., Stinemates, D.W. and Nadler, B.R. (2003). A Review of Structural Health Monitoring Literature: 1996-2001, Los Alamos National Laboratory Report, LA-13976-MS. 
[131] Spencer, B.F., Ruiz-Sandoval, M.E., and Kurata, N. (2004). "Smart Sensing Technology: Opportunities and Challenges," Journal of Structural Control and Health Monitoring, Vol. 11, No. 4, 349-368.

[132] Stallings, J.M., Tedesco, J.W., El-Mihilmy, M., McCauley, M. (2000). "Field Performance of FRP Bridge Repairs," Journal of Bridge Engineering, Vol. 5, No. 2, pp. 107-113.

[133] Straser, E.G. and Kiremidjian, A.S. (1998). A Modular, Wireless Damage Monitoring System for Structures. Report No. 128, John A. Blume Earthquake Eng. Ctr., Stanford University, Stanford, CA.

[134] Tarhini, K.M. and G.R. Frederick (1992), "Wheel load distribution on I-girder highway bridges", Journal of Structural Engineering, Vol. 118, No. 5, pp. 1285-1294.

[135] Thomson, W.T. and Dahleh, M.D. (1998). "Theory of Vibration with Applications," $5^{\text {th }}$ Edition, Prentice-Hall, Inc., Upper Saddle River, New Jersey, 1998.

[136] Tilley, M.R., Barton, F.W. and Gomez, J.P. (2006). Dynamic Analysis and Testing of A Curved Girder Bridge, Final Report to Virginia Transportation Research Council, Charlottesville, Virginia.

[137] Wang, M. L., Gu, H., Lloyd, G. M., and Zhao, Y. (2003). "A Multichannel Wireless PVDF Displacement Sensor for Structural Monitoring," in Proceedings of the International Workshop on Advanced Sensors, Structural Health Monitoring and Smart Structures, Tokyo, Japan, November 10-11.

[138] Wang, X., Wang, M.L., Zhao, Y., Chen, H., and Zhou, L.L. (2004). "Smart Health Monitoring System for a Prestressed Concrete Bridge," in Smart Structures and Materials: Sensors and Smart Structures Technologies for Civil, Mechanical, and Aerospace System, San Diego, CA, March 15-18, Proceedings of the SPIE, Vol. 5391, 597-608.

[139] Wang, Y., Lynch, J.P. and Law, K.H. (2005). "Wireless structural sensors using reliable communication protocols for data acquisition and interrogation," Proceedings of the $23^{\text {rd }}$ International Modal Analysis Conference (IMAC XXIII), Orlando, FL, January 31-February 3, 2005.

[140] Wang Y. (2007). "Wireless Sensing and Decentralized Control for Civil Structures: Theory and Implementation," Ph.D. Thesis, Department of Civil and Environmental Engineering, Stanford University, Stanford, CA, September 2007.

[141] Warneke, B.A. and Pister, K.S.J. (2002). "MEMS for distributed wireless sensor networks," Proceedings of 9th International Conference on Electronics, Circuits and Systems, 1: 291-294, Dubrovnik, Croatia, September 15 - 18, 2002.

[142] Washer, G. and Fuchs, P. (1998). "Better load ratings through nondestructive evaluation", Public Roads, Vol. 62, No. 3, 1998. 
[143] Webb, J. (2007). "Bring on the sensors - we can no longer rely solely on inspecting bridges by eye", NewScientist, August 11, 2007.

[144] Whelan, M.J., Fuchs, M.P., Gangone, M.V., and Janoyan, K.D. (2007). "Development of a Wireless Bridge Monitoring System for Condition Assessment using Hybrid Techniques." SPIE Smart Structures Symposium, San Diego, California, March 19-22.

[145] Whelan, M.J., Gangone, M.V., Janoyan, K.D., Cross, K., Jha, R. (2007). "Reliable high-rate bridge monitoring using dense wireless sensors arrays." 6th International Workshop on Structural Health Monitoring, Stanford, California, Sept. 11-13.

[146] William, G.W., Shoukry, S.N. and Riad, M.Y. (2005). "Thermal stress in steel girder bridge with integral abutments." Bridge Structures, Vol. 1, No. 2, June 2005, 103-119.

[147] Womack, K., Halling, M. and Bott, S. (2001). Static and Dynamic Testing of a Curved, Steel Girder Bridge in Salt Lake City, Utah, Final Report to the Utah Department of Transportation.

[148] Wu, J.S. and Dai, C.W. (1987). "Dynamic responses of multi-span non-uniform due to moving loads", Journal of Structural Engineering, ASCE, Vol. 113, No. 3 , pp. 458-474.

[149] Yang, Y.B., Liao S.S., and Lin, B.H. (1995). "Impact Formulas for Vehicles Moving over Simple and Continuous Beams", Journal of Structural Engineering, 121(11), pp. 1644-1650.

[150] Yang, Y.B., and Lin, B.H. (1995). "Vehicle-Bridge Interaction Analysis by Dynamic Condensation Method", Journal of Structural Engineering, 121(11), pp. 1636-1643.

[151] Yu, Y. and Ou, J.P. (2004). "Design of wireless intelligent sensor for structural health monitoring," Proceedings of IEEE, International Conference on Intelligent Sensors, Sensor Networks and Information Processing, p.p.1-6.

[152] Zheng, D.Y., Cheung, Y.K., Au, F.T. K., and Cheng, Y.S. (1998). "Vibration of multi-span non-uniform beams under moving loads by using modified beam vibration functions", Journal of Sound and Vibration 212 (3), pp. 455-467.

[153] Zhong, W.X. and Williams, F.W. (1994). “A Precise Time Step Integration Method”, Journal of Mechanical Engineering Science, Vol. 208, pp. 427-430.

[154] Zhu, X.Q. and Law, S.S. (1999). "Moving Forces Identification on a Multi-span Continuous Bridge", Journal of Sound and Vibration, 228 (2), pp. 377-396.

[155] Zhu, X.Q. and Law, S.S. (2001). "Precise Time-Step Integration for the Dynamic Response of a Continuous Beam under Moving Loads", Journal of Sound and Vibration, 240 (5), pp. 962-970. 


\section{Appendix A1}

\section{MicroStrain ${ }^{\circledR}$ Wireless Nodes}

\section{Architecture}

The MicrosStrain ${ }^{\circledR}$ wireless node platform was developed from off-the-shelf components, relying on IC's (integrated circuits) for miniaturization and cost reduction. The original platform has 8 channels of analog input. Channels one through four feature amplified full-differential input, with software programmable gain and offset, with optional bridge excitation and completion for interfacing full, half, or quarter bridge sensors, such as strain gages and load cells. Channels five through seven provide non-amplified pseudo-differential input, accepting analog voltages between 0 and 3 volts. The last channel is reserved for an onboard solid-state temperature sensor (TC1046, MicroChip Technologies, Chandler AZ). The platform also features three 12-bit digital to analog converters that enable wireless bi-directional control applications (Galbreath, et al. 2003).

At the heart of the wireless sensor is a low power 8-bit micro-controller (PIC16F877, MicroChip Technologies) that collects sensor data via an 8-channel, 12-bit successive approximation A/D converter (MCP3208, MicroChip Technologies). This data can then be stored locally to an onboard $2 \mathrm{MB}$ flash memory chip (AT45DB41, Atmel Corporation, San Jose CA), or streamed wirelessly. If the latter collection method is chosen, a half-duplex, narrowed ASK transceiver (DR-3000-1, RF Monolithics, Dallas TX) sends the sensor data at $75 \mathrm{Kbps}$, over a $2.4 \mathrm{GHz}$ carrier. On the user/controller-end, a base-station with the same telemetry hardware receives the incoming data stream, and forwards the data to a PC via a standard RS-232 serial port. Since the telemetry hardware is bi-directional, the base station can also send commands and data to the remote nodes. This allows the user to reconfigure the operational parameters of the nodes wirelessly, and trigger data collection sessions (Galbreath, et al. 2003). The functional block diagram is shown in Figure 1. 


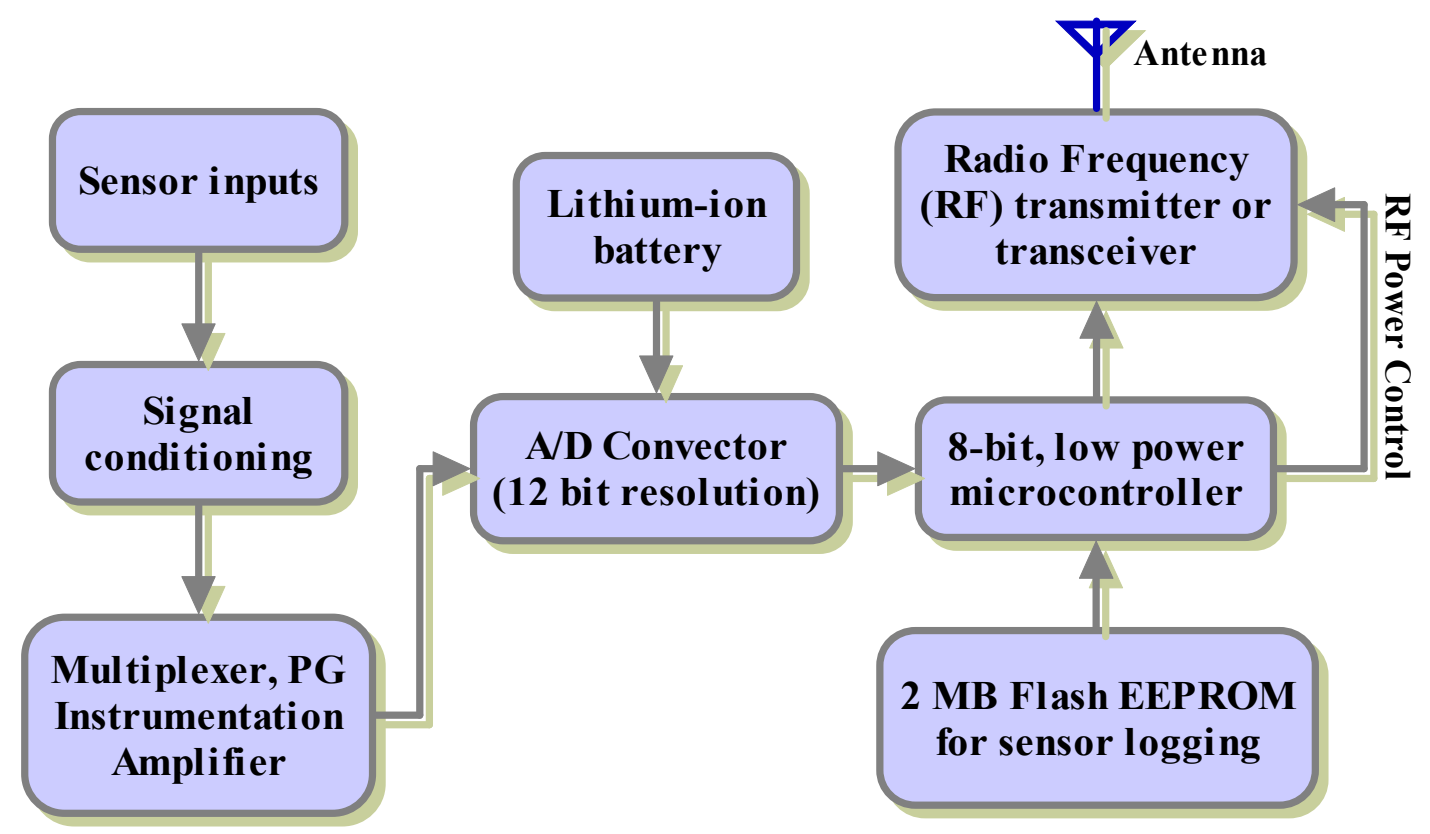

Figure 1. MicroStrain wireless node block diagram (Galbreath, et al. 2003)

The network topology was implemented as a single-hop, hierarchical model, capable of supporting hundreds of nodes per base-station. Combined with the well-defined behavior of the narrowband RF transceiver, the topology enabled a minimal and deterministic sensor streaming latency. The system latency was measured to be less than $2 \mathrm{~ms}$ by measuring the time between and A/D sample on the remote node, and reception of this data on the serial port of a PC (Galbreath, et al. 2003).

The communication range of the wireless nodes can be up to $70 \mathrm{~m}$ line-of-sight with the standard $2.2 \mathrm{dBi}$ antenna. Furthermore, three optional range extending antennas (5.5 $\mathrm{dBi}$ omni antenna, $8 \mathrm{dBi}$ patch antenna, $14 \mathrm{dBi}$ patch antenna) are available, which are capable of providing a $150 \%$ to $400 \%$ (up to $300 \mathrm{~m}$ ) range improvement, illustrated in Figure 2 (MicroStrain ${ }^{\circledR}$ Technical Note, 2007). Attention must be paid to the difference between the omni-directional antenna behavior and the unidirectional behavior of the patch antennas. 




Figure 2. Wireless communication range with different antennas (MicroStrain)

Wireless sensor streaming occurs at a fixed rate of $75 \mathrm{Kbps}$, which allows for approximately 1700 data points per second, depending on the number of active channels. Datalogging occurs at one of seven user-selected sample rates between 32 $\mathrm{Hz}$ and $2048 \mathrm{~Hz}(32 \mathrm{~Hz}, 64 \mathrm{~Hz}, 128 \mathrm{~Hz}, 256 \mathrm{~Hz}, 512 \mathrm{~Hz}, 1024 \mathrm{~Hz}, 2048 \mathrm{~Hz})$. This is a sweep rate, covering all active channels, with a maximum aggregate bandwidth of 16,384 data points per seconds (when all eight channels are selected). This information is stored on a 2 megabyte, non-volatile flash memory chip (Galbreath, et al. 2003).

As for multi-node data logging, data from remotely located nodes can be precisely synchronized if the broadcast triggering mode is used. The technical note claims that the device synchronization is better than 100 microseconds over a 10 second data collection period (MicroStrain ${ }^{\circledR}$ Application Note, 2007).

For strain sensing applications, the ability to wirelessly program sensor offsets and gains has been an important feature of the signal conditioning, because strain gages typically exhibit significant offset due to changes in resistance induced during installation. Furthermore, gain programmability is important because in many applications the full scale strain output is not known, and therefore the system gain is required (Arms, et al. 2003).

Since access to civil structures can be limited, battery life is one of the most important design considerations for the Datalogging transceiver. RF communications often dominate energy consumption in wireless sensing applications, so it is important to develop a communications protocol that minimizes radio usage on the remote node. It is also important to implement intelligent sleep states, since the nodes may remain on civil structures for a long time without user-interaction. The microcontroller on the remote node features a low power sleep mode that can be excited via a watchdog 
timer, or an external interrupt. This enables two low-power monitoring modes. In the first mode, the microcontroller periodically awakes via a watchdog timer interrupt, turns on the telemetry hardware, and listens for a wake command from the base station. If it does not detect a wake command within $50 \mathrm{msec}$, it returns to the same sleep mode. In the second mode, the microcontroller remains in the low power sleep mode until a rising external analog voltage triggers hardware interrupt. Comparison of the power required for three distinct modes of operation is: 1) transmission of RF data: 45 milliwatts; 2) processing/logging of sensed data: 5.0 milliwatts; and sleep mode: 0.02 milliwatts (Arms, et al. 2003).

\section{Hardware Configuration}

MicroStrain ${ }^{\circledR}$ mainly has 4 types of $2.4 \mathrm{GHz}$ wireless nodes with different configurations and purposes: V-Link ${ }^{\circledR}$, SG-Link ${ }^{\circledR}$, G-Link ${ }^{\circledR}$ and TC-Link ${ }^{\circledR}$, shown in Table 3.1. Only G-Link ${ }^{\circledR}, V-\operatorname{Link}{ }^{\circledR}$ and $S G-L i n k ®$ nodes were used in this research. Pin-out of the SG-Link ${ }^{\circledR}$ and V-Link ${ }^{\circledR}$ are shown in Figure 3 and Figure 4 respectively. G-Link ${ }^{\circledR}$ node doesn't have pin-out.

Both of SG-Link ${ }^{\circledR}$ and V-Link ${ }^{\circledR}$ nodes have versatile programmable hardware that allows the system to read data from practically and conventional sensor that produces a voltage output from 0-3.0 volts. The node includes programmable functions such as amplifier gain and offset that make it especially easy to deal with sensors, including $\mathrm{mV}$ output sensors such as accelerometers, strain gages, and load cells. The V-Link ${ }^{\circledR}$ node provides four channels that support milli-volt level sensors and three channels are provided that support higher voltage (0-3.0 V) sensor inputs. For the SG-Link ${ }^{\circledR}$ node, there are one channel for milli-volt level input and one channel for higher voltage input. The differential input channels allow for direct connections of a full Wheatstone bridge. Half and quarter bridges are supported if the optional internal bridge completion was ordered or using external bridge completion. The 0-3.0 volt inputs allow direct input of analog sensors that have a high-level voltage output. Higher input voltages will require a voltage divider to avoid damaging the unit. The system uses a 12 bit $A / D$ converter, to convert the output of the $A / D$ converter to volts using the following transfer function:

$$
\text { OutputVolts }=\text { OutputBits } \times\left(\frac{3.00 \text { Volts }}{4096 \text { Bits }}\right)
$$


Additionally the G-Link ${ }^{\circledR}, \mathrm{V}$-Link ${ }^{\circledR}$ and SG-Link ${ }^{\circledR}$ nodes have an internal temperature sensor and an internal connection to the battery that allows the user to measure the battery output voltage. The temperature sensor outputs $6.25 \mathrm{mV} /{ }^{\circ} \mathrm{C}$, and it can be calculated based on Equation (2).

$$
\operatorname{Temp}\left[{ }^{\circ} \mathrm{C}\right]=\frac{\left\{\text { BitsOut } \times\left(\frac{3000[\mathrm{mV}]}{4096[\text { Bits }]}\right)-424[\mathrm{mV}]\right\}}{6.25\left[\frac{\mathrm{mV}}{{ }^{\circ} \mathrm{C}}\right]}
$$

Most of the hardware functions are programmable. This includes:

- Channels sampled

- Programmable amplifier gain

- Offset on amplifier chains (useful for sensors with large initial offsets)

- Duration of sampling time in datalogging mode

- Sampling rate of system in datalogging mode (fixed in streaming mode)

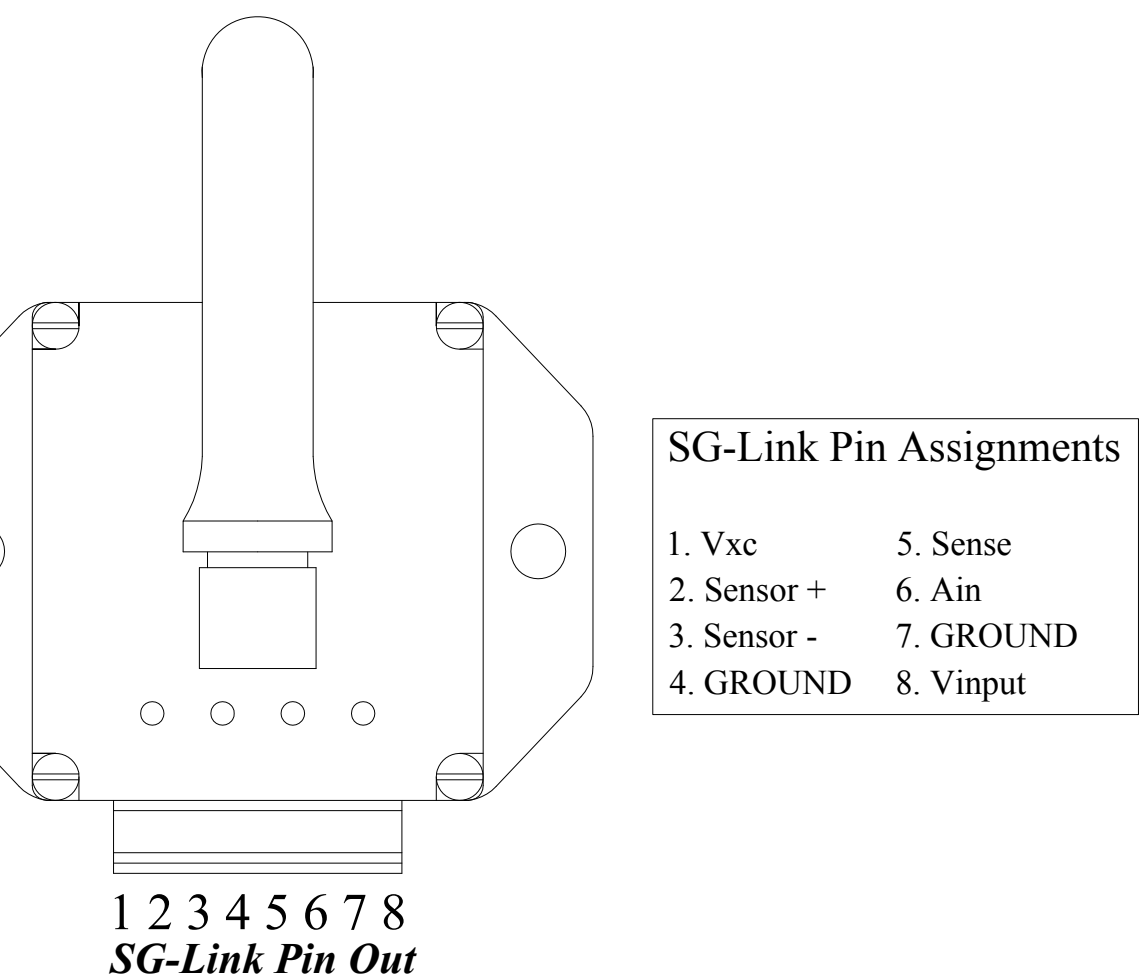

Figure 3. Connector for the SG-Link® node (MicroStrain) 




Figure 4. Connector for the V-Link ${ }^{\circledR}$ node (MicroStrain)

\section{Power Consideration}

The MicroStrain ${ }^{\circledR}$ node is normally powered by its internal rechargeable Lithium Ion battery and may also be powered by an external source. The node has a 2 position on-and-off toggle switch on its sidewall next to the antenna post. With the node placed flat with the label up, $\mathbf{O F F}$ is down and $\mathbf{O N}$ is up.

The MicroStrain ${ }^{\circledR}$ node contains an internal rechargeable Ultralife ${ }^{\circledR}$ brand 3.7 volt Lithium Ion battery. Properties of the internal batteries for different wireless nodes are listed in Table 1. The internal battery should only be charged with specified external power supply which outputs +9 Volts DC. Charging may take up several hours depending on battery depletion.

Table 1. Properties of internal batteries (MicroStrain)

\begin{tabular}{|c|c|c|c|}
\hline Node Type & Battery Model & $\begin{array}{l}\text { Nominal Capacity } \\
\text { a C/5 Rate @ } 23^{\circ} \mathrm{C}\end{array}$ & $\begin{array}{c}\text { Recharge Cycle Life } \\
\text { (a) C/5 to } 80 \%\end{array}$ \\
\hline V-Link ${ }^{\circledR}$ & UBPC003 & $600 \mathrm{mAh}$ & $>500$ \\
\hline SG-Link ${ }^{\circledR}$ & UBPC005 & $200 \mathrm{mAh}$ & $>300$ \\
\hline G-Link ${ }^{\circledR}$ & UBPC005 & $200 \mathrm{mAh}$ & $>300$ \\
\hline TC-Link ${ }^{\circledR}$ & UBPC003 & $600 \mathrm{mAh}$ & $>500$ \\
\hline
\end{tabular}


The MicroStrain ${ }^{\circledR}$ node may be directly powered by external batteries, external regulated power supply or other external source. The source should deliver stable voltage, must range between 3.2 to 9.0 volts DC, and must be capable of sourcing at least $50 \mathrm{~mA}$. The power may be applied through the external power supply barrel connector on the side of wall of the node. Polarity must be observed: the center post is + (positive) and the outside barrel is ground. Alternatively, external power may be applied through pin 1 (GND) and pin 2 (Vin) on the terminal block connectors.

There is an internal 2-position power switch on the top of the node circuit board assembly. The "default" position allows the node to only operate on the internal battery power and at the same time allows the battery to be recharged through the recharge/power connector. Additionally, the "default" position allows the node to be charged through the terminal block. The "bypass" position allows the node to only operate on power supplied through the recharge/power connector. Additionally, in "bypass" position allows the node to operate on power supplied through the terminal block. The recharging circuit is not operational in the bypass position.

Power consumption on the wireless node is influenced by a wide range of variables including operating mode, sampling rate and number of active channels. A power profile which outlines power consumption for the matrix of operating states is demonstrated below. 
Table 2. V-Link® power profile (MicroStrain)

\begin{tabular}{|c|c|c|c|c|c|c|c|c|c|c|c|c|c|c|c|c|}
\hline \multicolumn{17}{|c|}{ Sleep Mode } \\
\hline Sleep Interval (s) & 1 & 2 & \multicolumn{2}{|c|}{3} & \multicolumn{2}{|r|}{5} & 6 & 7 & 8 & 9 & \multicolumn{2}{|c|}{10} & 11 & 12 & 13 & 14 \\
\hline $\begin{array}{c}\text { Average Current } \\
(\mathrm{mA})\end{array}$ & 0.81 & 0.50 & \multicolumn{2}{|c|}{0.34} & .27 & 0.26 & 0.24 & 0.23 & 0.22 & 0.21 & \multicolumn{2}{|c|}{0.22} & 0.21 & 0.21 & 0.21 & 0.20 \\
\hline \multicolumn{17}{|c|}{ Idle Mode } \\
\hline $\begin{array}{c}\text { Average Current } \\
(\mathrm{mA})\end{array}$ & \multicolumn{16}{|c|}{29} \\
\hline \multicolumn{17}{|c|}{ Streaming Mode } \\
\hline $\begin{array}{l}\text { Num. of Active } \\
\text { Channels }\end{array}$ & \multicolumn{2}{|c|}{1} & \multicolumn{2}{|c|}{2} & \multicolumn{2}{|c|}{3} & \multicolumn{2}{|c|}{4} & \multicolumn{2}{|c|}{5} & \multicolumn{2}{|c|}{6} & \multicolumn{2}{|c|}{7} & \multicolumn{2}{|r|}{8} \\
\hline Sample Rate $(\mathrm{Hz})$ & \multicolumn{2}{|c|}{736} & \multicolumn{2}{|c|}{679} & \multicolumn{2}{|c|}{617} & \multicolumn{2}{|c|}{565} & \multicolumn{2}{|c|}{520} & \multicolumn{2}{|c|}{485} & \multicolumn{2}{|c|}{452} & \multicolumn{2}{|c|}{424} \\
\hline $\begin{array}{c}\text { Average Current } \\
(\mathrm{mA}), 4 \times 1 \mathrm{Kohm} \\
\text { load }\end{array}$ & \multicolumn{2}{|c|}{30.10} & \multicolumn{2}{|c|}{30.06} & \multicolumn{2}{|c|}{30.06} & \multicolumn{2}{|c|}{30.09} & 30. & & & 95 & & .11 & & 9.92 \\
\hline & & & & & & Data & Loggin & Mode & & & & & & & & \\
\hline $\begin{array}{c}\text { Num. of Active } \\
\text { Channels }\end{array}$ & 1 & 1 & 2 & 2 & 3 & 3 & 4 & 4 & 5 & 5 & 6 & 6 & 7 & 7 & 8 & 8 \\
\hline Sample Rate (Hz) & 32 & 2048 & 32 & 2048 & 32 & 2048 & 32 & 2048 & 32 & 2048 & 32 & 2048 & 32 & 2048 & 32 & 2048 \\
\hline $\begin{array}{c}\text { Average Current } \\
(\mathrm{mA}), 4 \times 1 \mathrm{Kohm} \\
\text { load }\end{array}$ & 14.55 & 17.98 & 14.61 & 20.24 & 14.65 & 22.54 & 14.70 & 24.83 & 14.70 & 27.47 & 14.80 & 30.17 & 14.86 & 31.61 & 14.86 & 32.34 \\
\hline & & & & & & ow Duty & Cycle ( & (DC) $N$ & & & & & & & & \\
\hline Sample Rate (Hz) & 0.1 & 0 . & & 0.5 & 1 & & 2 & 5 & 10 & 2 & & 50 & 100 & & 50 & 500 \\
\hline $\begin{array}{c}\text { Average Current } \\
(\mathrm{mA}), 4 \times 1 \mathrm{Kohm} \\
\text { load }\end{array}$ & 0.19 & 0.2 & & 0.26 & 0.34 & & 39 & 1.67 & 2.28 & 4. & & 6.85 & 7.24 & & .96 & 24.57 \\
\hline
\end{tabular}


Table 3. SG-Link ${ }^{\circledR}$ power profile (MicroStrain)

\begin{tabular}{|c|c|c|c|c|c|c|c|c|c|c|c|c|c|c|}
\hline \multicolumn{15}{|c|}{ Sleep Mode } \\
\hline Sleep Interval (s) & 1 & 2 & 3 & 4 & 5 & 6 & 7 & 8 & 9 & 10 & 11 & 12 & 13 & 14 \\
\hline Average Current (mA) & 0.40 & 0.22 & 0.19 & 0.16 & 0.15 & 0.12 & 0.11 & 0.10 & 0.10 & 0.10 & 0.09 & 0.09 & 0.09 & 0.09 \\
\hline \multicolumn{15}{|c|}{ Idle Mode } \\
\hline Average Current (mA) & \multicolumn{14}{|c|}{27} \\
\hline \multicolumn{15}{|c|}{ Streaming Mode } \\
\hline $\begin{array}{c}\text { Num. of Active } \\
\text { Channels }\end{array}$ & \multicolumn{3}{|c|}{1} & \multicolumn{4}{|c|}{2} & \multicolumn{3}{|c|}{3} & \multicolumn{4}{|c|}{4} \\
\hline Sample Rate $(\mathrm{Hz})$ & \multicolumn{3}{|c|}{736} & \multicolumn{4}{|c|}{679} & \multicolumn{3}{|c|}{617} & \multicolumn{4}{|c|}{565} \\
\hline $\begin{array}{c}\text { Average Current } \\
(\mathrm{mA}), 4 \times 1 \mathrm{Kohm} \text { load }\end{array}$ & \multicolumn{3}{|c|}{31.39} & \multicolumn{4}{|c|}{31.61} & \multicolumn{3}{|c|}{31.90} & \multicolumn{4}{|c|}{32.16} \\
\hline \multicolumn{15}{|c|}{ Data Logging Mode } \\
\hline $\begin{array}{c}\text { Num. of Active } \\
\text { Channels }\end{array}$ & \multicolumn{2}{|l|}{1} & \multicolumn{2}{|l|}{1} & 2 & \multicolumn{2}{|c|}{2} & \multicolumn{2}{|l|}{3} & \multicolumn{2}{|l|}{3} & \multicolumn{2}{|l|}{4} & 4 \\
\hline Sample Rate $(\mathrm{Hz})$ & \multicolumn{2}{|l|}{32} & \multicolumn{2}{|l|}{2048} & 32 & \multicolumn{2}{|c|}{2048} & \multicolumn{2}{|l|}{32} & \multicolumn{2}{|l|}{2048} & 32 & \multicolumn{2}{|c|}{2048} \\
\hline $\begin{array}{c}\text { Average Current } \\
(\mathrm{mA}), 4 \times 1 \mathrm{Kohm} \text { load }\end{array}$ & \multicolumn{2}{|l|}{16.53} & 20.71 & & 16.61 & \multicolumn{2}{|c|}{24.37} & \multicolumn{2}{|l|}{16.61} & 27.66 & & 16.71 & & 0.81 \\
\hline & & & & & ow Du & Cycle & DC) $\mathrm{M}$ & & & & & & & \\
\hline Sample Rate (Hz) & 0.1 & 0.2 & 0.5 & & 1 & 2 & 5 & 10 & 25 & 50 & & 00 & 250 & 500 \\
\hline $\begin{array}{c}\text { Average Current } \\
(\mathrm{mA}), 4 \times 1 \mathrm{Kohm} \text { load }\end{array}$ & 0.07 & 0.08 & 0.12 & & 17 & 1.17 & 1.40 & 1.88 & 3.28 & 5.60 & & .83 & 11.86 & 28.90 \\
\hline
\end{tabular}


Table 4. G-Link ${ }^{\circledR}$ power profile (MicroStrain)

\begin{tabular}{|c|c|c|c|c|c|c|c|c|c|c|c|c|c|c|}
\hline \multicolumn{15}{|c|}{ Sleep Mode } \\
\hline Sleep Interval (s) & 1 & 2 & 3 & 4 & 5 & 6 & 7 & 8 & 9 & 10 & 11 & 12 & 13 & 14 \\
\hline Average Current (mA) & 0.75 & 0.45 & 0.33 & 0.26 & 0.23 & 0.22 & 0.20 & 0.19 & 0.18 & 0.18 & 0.17 & 0.16 & 0.16 & 0.16 \\
\hline \multicolumn{15}{|c|}{ Idle Mode } \\
\hline Average Current (mA) & \multicolumn{14}{|c|}{29} \\
\hline \multicolumn{15}{|c|}{ Streaming Mode } \\
\hline $\begin{array}{c}\text { Num. of Active } \\
\text { Channels }\end{array}$ & \multicolumn{4}{|c|}{1} & \multicolumn{3}{|c|}{2} & \multicolumn{4}{|c|}{3} & \multicolumn{3}{|c|}{4} \\
\hline Sample Rate (Hz) & \multicolumn{4}{|c|}{736} & \multicolumn{3}{|c|}{679} & \multicolumn{4}{|c|}{617} & \multicolumn{3}{|c|}{565} \\
\hline $\begin{array}{c}\text { Average Current } \\
(\mathrm{mA}), 4 \times 1 \mathrm{Kohm} \text { load } \\
\end{array}$ & \multicolumn{3}{|c|}{25.97} & & \multicolumn{3}{|c|}{25.96} & \multicolumn{3}{|c|}{26.47} & & \multicolumn{3}{|c|}{26.47} \\
\hline \multicolumn{15}{|c|}{ Data Logging Mode } \\
\hline $\begin{array}{c}\text { Num. of Active } \\
\text { Channels }\end{array}$ & \multicolumn{2}{|l|}{1} & \multicolumn{2}{|l|}{1} & 2 & \multicolumn{2}{|c|}{2} & \multicolumn{2}{|l|}{3} & \multicolumn{2}{|l|}{3} & \multicolumn{2}{|l|}{4} & 4 \\
\hline Sample Rate (Hz) & \multicolumn{2}{|l|}{32} & \multicolumn{2}{|l|}{2048} & 32 & \multicolumn{2}{|c|}{2048} & \multicolumn{2}{|l|}{32} & \multicolumn{2}{|l|}{2048} & \multicolumn{2}{|l|}{32} & 2048 \\
\hline $\begin{array}{c}\text { Average Current } \\
(\mathrm{mA}), 4 \times 1 \mathrm{Kohm} \text { load } \\
\end{array}$ & \multicolumn{2}{|c|}{11.54} & \multicolumn{2}{|l|}{16.05} & 11.60 & \multicolumn{2}{|c|}{19.61} & 11.65 & & 22.97 & & 11.71 & & 26.56 \\
\hline & & & & & Low Du & Cycle & C) $\mathrm{M}$ & & & & & & & \\
\hline Sample Rate (Hz) & 0.1 & 0.2 & 0.5 & & 1 & 2 & 5 & 10 & 25 & 50 & & 100 & 250 & 500 \\
\hline $\begin{array}{c}\text { Average Current } \\
(\mathrm{mA}), 4 \times 1 \mathrm{Kohm} \text { load }\end{array}$ & 0.12 & 0.12 & 0.15 & & .17 & 1.15 & 1.28 & 1.53 & 2.26 & 3.45 & & 6.51 & 13.29 & 23.42 \\
\hline
\end{tabular}




\section{Configuration for Strain Sensors}

The V-Link ${ }^{\circledR}$ and SG-Link ${ }^{\circledR}$ nodes can be used with quarter, half and full bridge strain gages. However, for the quarter and half bridge strain gages, the nodes should be ordered with optional on-board bridge resistors. Otherwise, the completion of the bridge must be completed externally. The configuration and connection between strain gages and wireless nodes are shown in Table 5 and Figure 5. As for the full bridge sensor, such as strain transducers, it can be connected directly with the node with the configuration as shown in Table 6 and Figure 6. An example of V-Link® node connections is shown in Figure 7.

Table 5. Connection of MicroStrain ${ }^{\circledR}$ for quarter bridge strain gauges

\begin{tabular}{c|c|c|c}
\hline \multirow{3}{*}{ Node } & $\begin{array}{c}\text { Sense } \\
\text { Pin\# } \\
\text { (Signal) }\end{array}$ & $\begin{array}{c}\text { S- } \\
\text { Pin\# } \\
\text { (Signal) }\end{array}$ & $\begin{array}{c}\text { Ground } \\
\text { Pin\# }\end{array}$ \\
\hline \multirow{2}{*}{ SG-Link } & 5 & 3 & 4 \\
\hline \multirow{3}{*}{ V-Link } & 14 & 15 & 17 \\
\cline { 2 - 4 } & 19 & 18 & 8 \\
\cline { 2 - 4 } & 11 & 10 & 8 \\
\hline
\end{tabular}

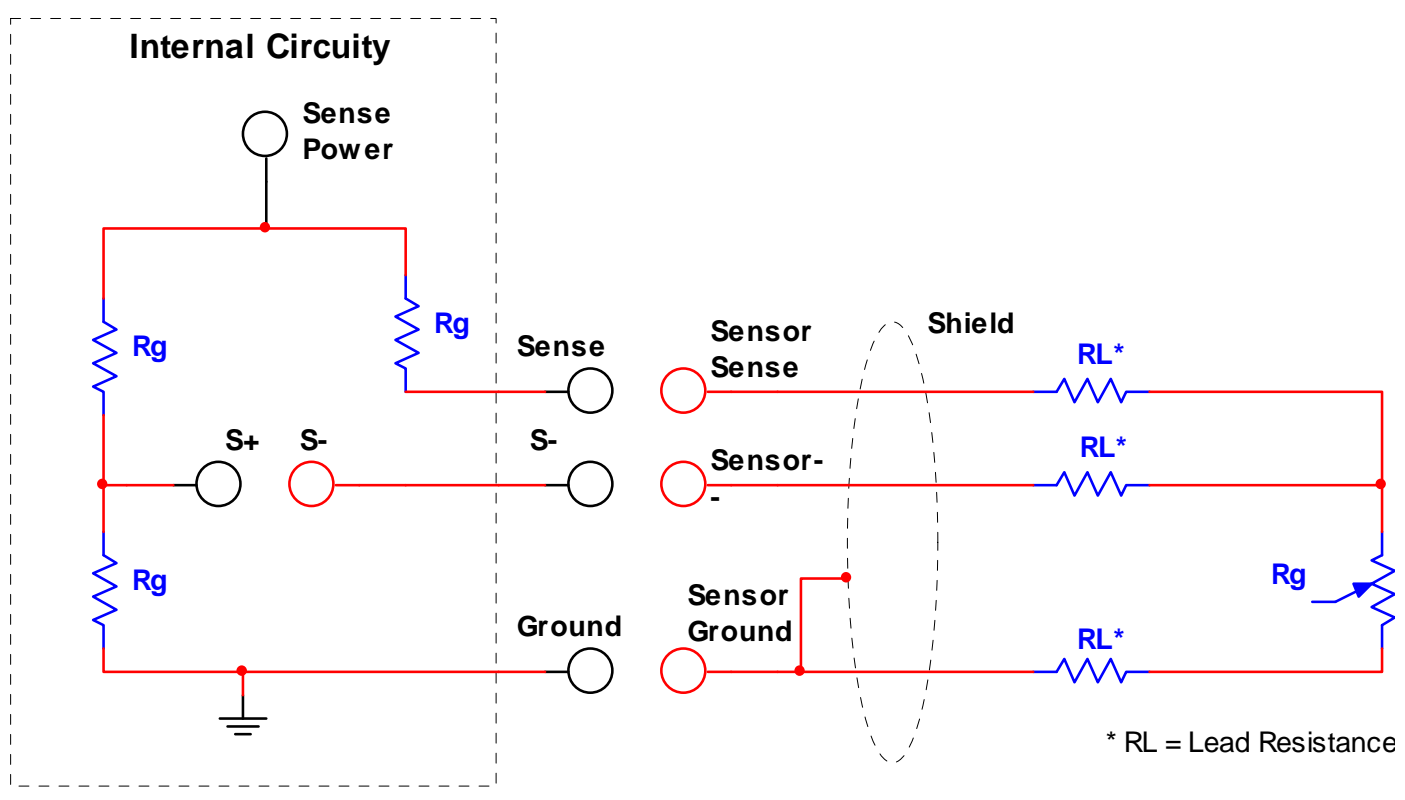

Figure 5. MicroStrain ${ }^{\circledR}$ node internal quarter bridge completion diagram 
Table 6. Connection of MicroStrain ${ }^{\circledR}$ for full bridge strain gauges

\begin{tabular}{c|c|c|c|c|c}
\hline \multirow{2}{*}{ Node } & $\begin{array}{c}\text { Sensor } \\
\text { Channel\# }\end{array}$ & $\begin{array}{c}\text { P+ } \\
\text { Pin\# } \\
\text { (Signal Power) }\end{array}$ & $\begin{array}{c}\text { S+ } \\
\text { Pin\# } \\
\text { (Signal+) }\end{array}$ & $\begin{array}{c}\text { S- } \\
\text { Pin\# } \\
\text { (Signal-) }\end{array}$ & $\begin{array}{c}\text { Ground } \\
\text { Pin\# }\end{array}$ \\
\hline SG-Link & 1 & 1 & 2 & 3 & 4 \\
\hline \hline \multirow{3}{*}{ V-Link } & 1 & 16 & 13 & 15 & 17 \\
\cline { 2 - 6 } & 2 & 16 & 20 & 10 & 17 \\
\cline { 2 - 6 } & 3 & 9 & 12 & 10 & 8 \\
\hline
\end{tabular}



Figure 6. MicroStrain ${ }^{\circledR}$ node full bridge completion diagram 


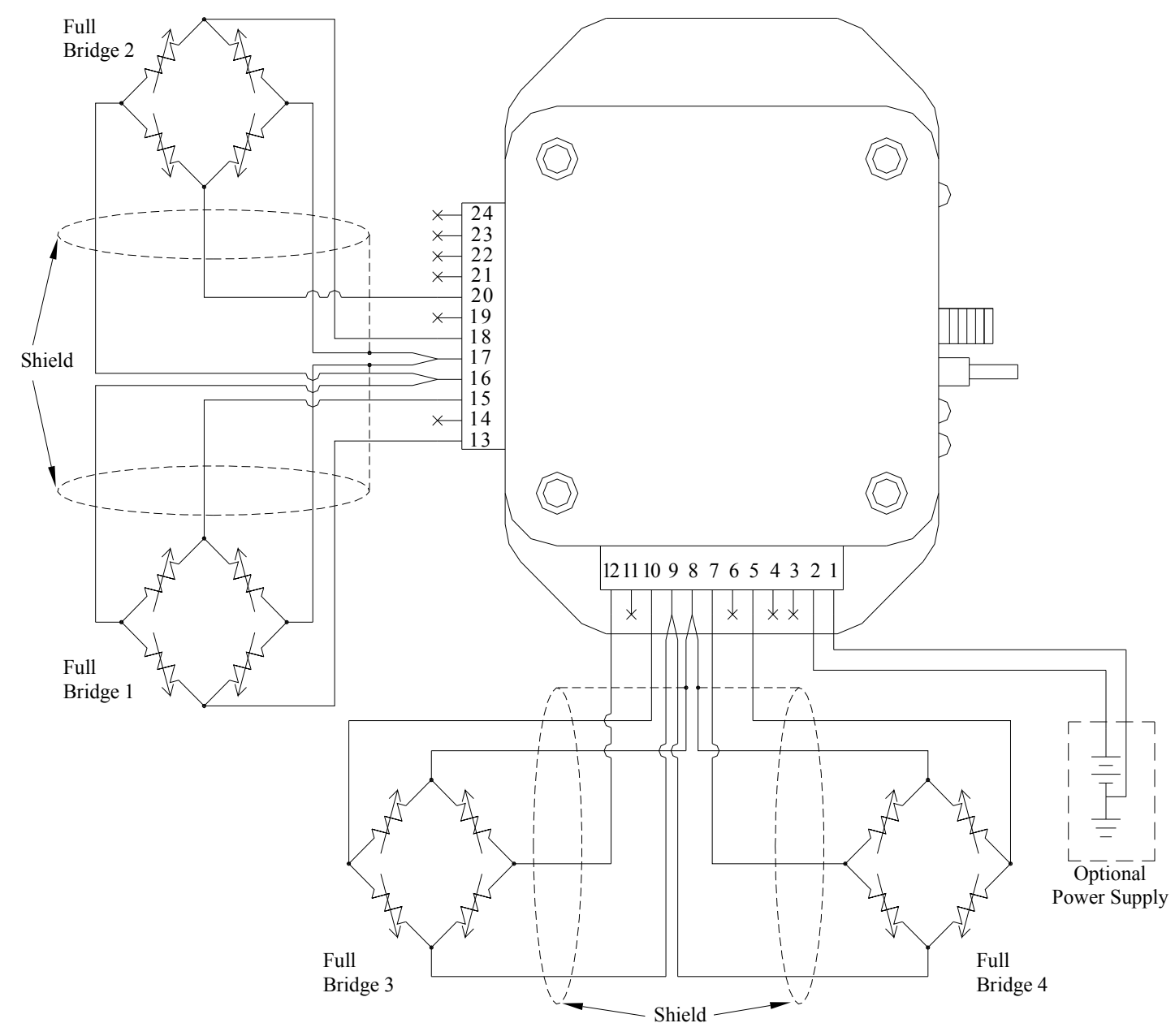

Figure 7. V-Link ${ }^{\circledR}$ connections for full bridge strain gauges (MicroStrain ${ }^{\circledR}$ ) 


\section{Appendix A2}

\section{Load and Resistance Factor Rating of Evansville Bridge}

\section{Three Span Composite Steel Stringer Bridge}

Evaluation of Interior and Exterior Stringers

\section{Given:}

Spans:

$48.5 \mathrm{ft}, 50 \mathrm{ft}, 48.5 \mathrm{ft}$

Year Built:

2003

Materials:

A36 Steel

$F_{y}=50 \mathrm{ksi}$

$f_{c}^{\prime}=3 \mathrm{ksi}$

Condition: No deterioration

Riding Surface: Minor surface deviations

ADDT (one direction): 1000

Skew:

55 degrees

\section{Section Properties:}

Noncomposite: $\quad W 27 \times 84$

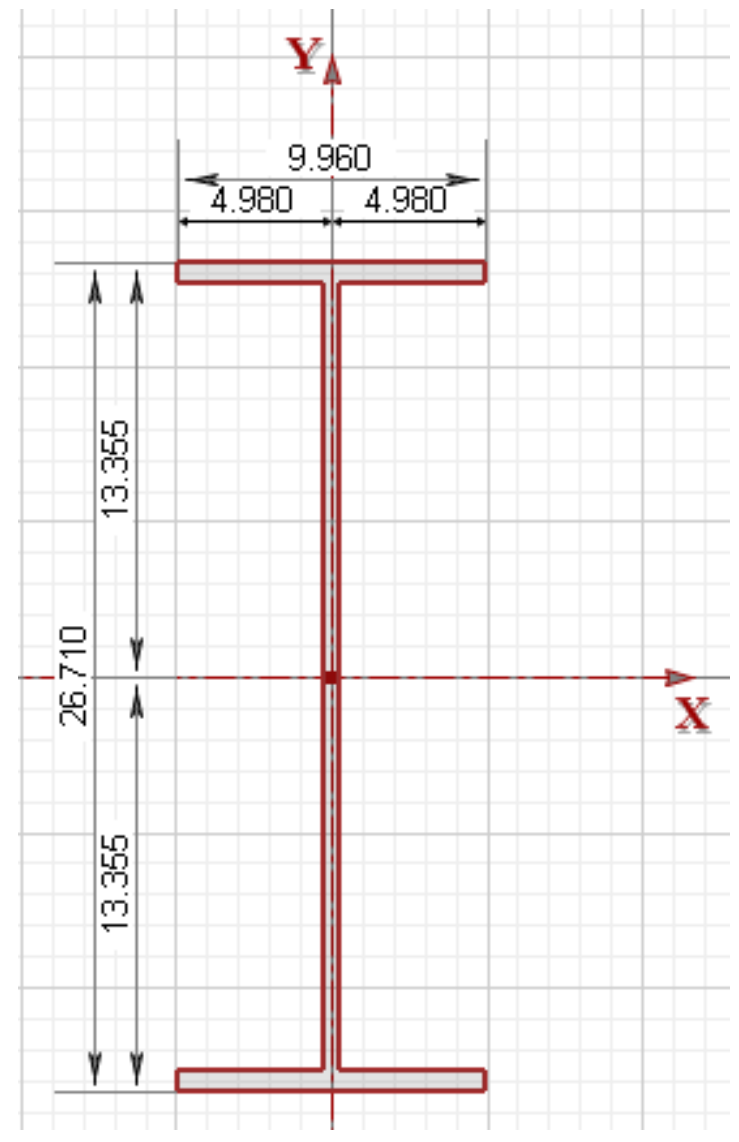

$\bar{y}=13.355 \mathrm{in}$

$I_{x}=2850.0 \mathrm{in}^{4}$

Section Modulus:

(The ratio of the moment of inertia of the cross section of a beam undergoing flexure to the greatest distance of an element of the beam from the neural axis.)

Section Modulus at top of steel

$$
S_{t}=213.4 \mathrm{in}^{3}
$$

Section Modulus at bottom of steel

$$
S_{b}=213.4 \mathrm{in}^{3}
$$




\section{Composite Section Properties:}

Effective Flange Width $b_{\text {eff }}$

Minimum of:

1) One-quarter of the effective span length:

$L_{\text {eff }} / 4=(0.7 \times 48.5 \times 12) / 4=101.85$ in

2) 12.0 times the average depth of the slab, plus the greater of web thickness or one-half the width of the top flange of the girder:

$$
12.0 t_{s}+\text { greater }\left(t_{w}, 1 / 2 b_{\text {ftop }}\right)=100.98 \text { in }
$$

3) The average spacing of adjacent beams: $S=81$ in controls

$$
b_{\text {eff }}=81 \mathrm{in}
$$

Modular Ration: $(n)$ :

for $2.9<f_{c}^{\prime}=3<3.6, n=9$

Typical Interior Stringer:

\section{Short-Term Composite $(n): \quad W 27 \times 84$ \& Conc. 8 in. $\times 81$ in.}

\section{$81 / n=9$ in}

Transformed Slab

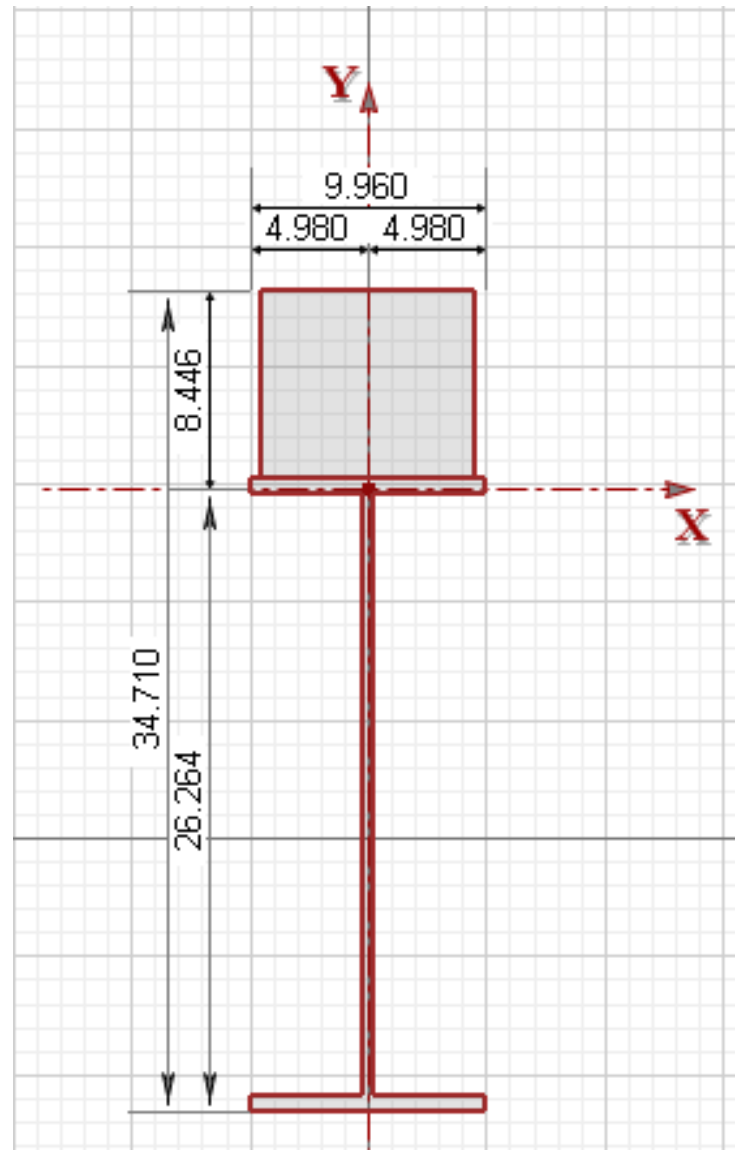

$\bar{y}=26.264$ in

$I_{x}=8789.95 \mathrm{in}^{4}$

Section Modulus:

Section Modulus at top of steel

$$
S_{t}=19694.17 \mathrm{in}^{3}
$$

Section Modulus at bottom of steel

$$
S_{b}=334.68 \text { in }^{3}
$$


Long-Term Composite $(3 n): \quad$ W27 $\times 84$ \& Conc. 8 in. $\times 81$ in. $81 /(3 n)=3$ in.

Transformed Slab

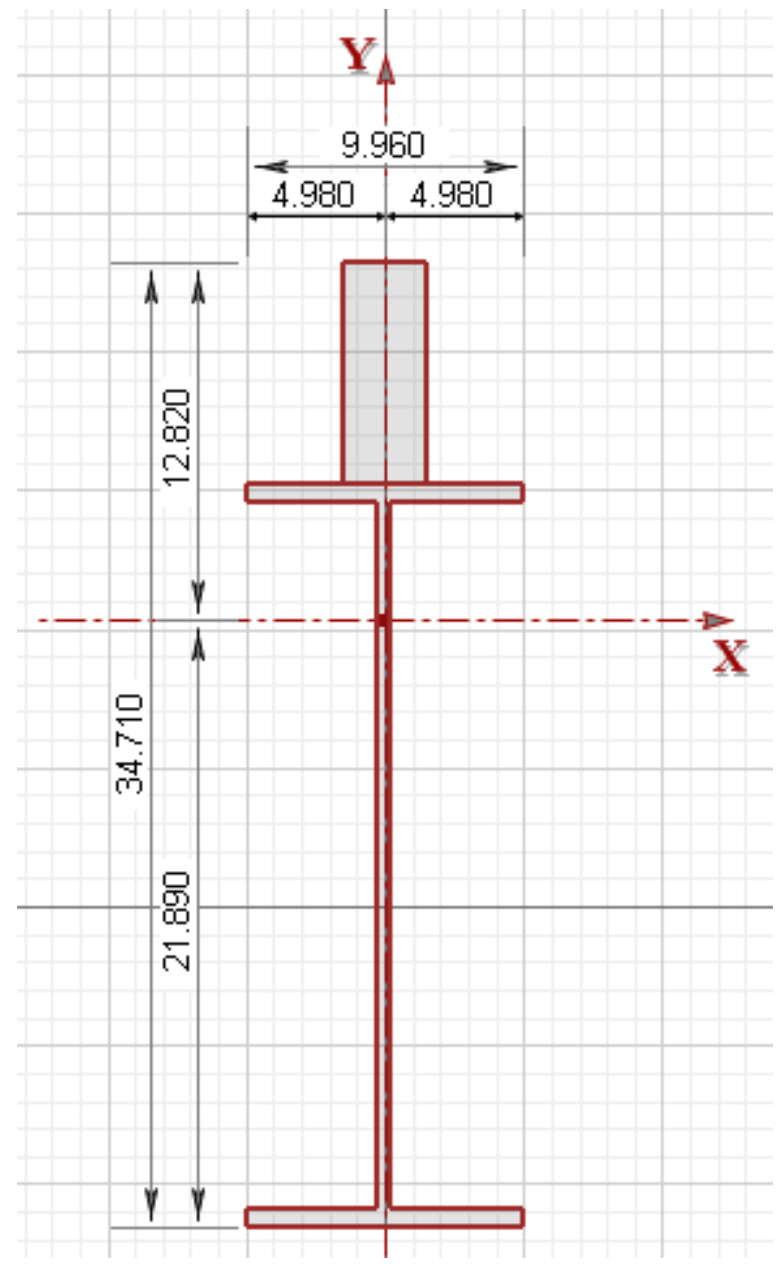

$\bar{y}=21.890 \mathrm{in}$

$I_{x}=6651.60 \mathrm{in}^{4}$

Section Modulus:

Section Modulus at top of steel $S_{t}=1380.07$ in $^{3}$

Section Modulus at bottom of steel $S_{b}=303.86 \mathrm{in}^{3}$

SUMMARY OF SECTION PROPERTIES AT MIDSPAN

\begin{tabular}{c|c|c|c}
\hline & Steel Section Only & $\begin{array}{c}\text { Composite Section - } \\
\text { Short Term }\end{array}$ & $\begin{array}{c}\text { Composite Section - } \\
\text { Long Term }\end{array}$ \\
\hline$S_{\text {TOP steel }}$ & 213.4 & 19694.17 & 1380.07 \\
\hline$S_{B O T}$ & 213.4 & 334.68 & 303.86 \\
\hline
\end{tabular}




\section{DEAD LOAD ANALYSIS - INTERIOR STRINGER}

\subsection{Components and Attachments}

a) Non-Composite Dead Load: $D C_{1}$
Deck:
$0.675 \mathrm{kip} / \mathrm{ft}$
Stringer:
$0.084 \mathrm{kip} / \mathrm{ft}$
SIP forms:
$0.169 \mathrm{kip} / \mathrm{ft}$
Diaphragms:
$0.037 \mathrm{kip} / \mathrm{ft}$
Total per stringer:
$0.981 \mathrm{kip} / \mathrm{ft}$

Moment

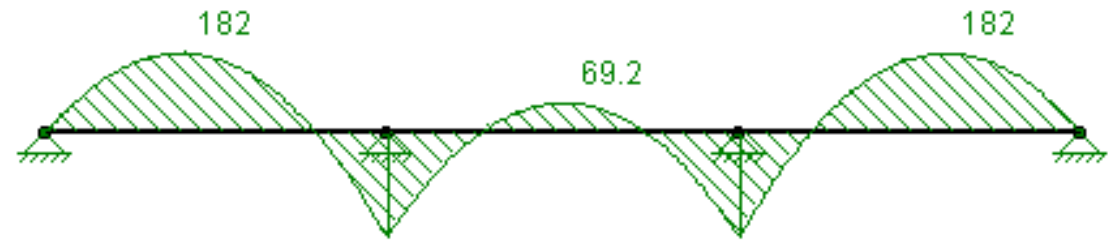

$-237.4$

Shear

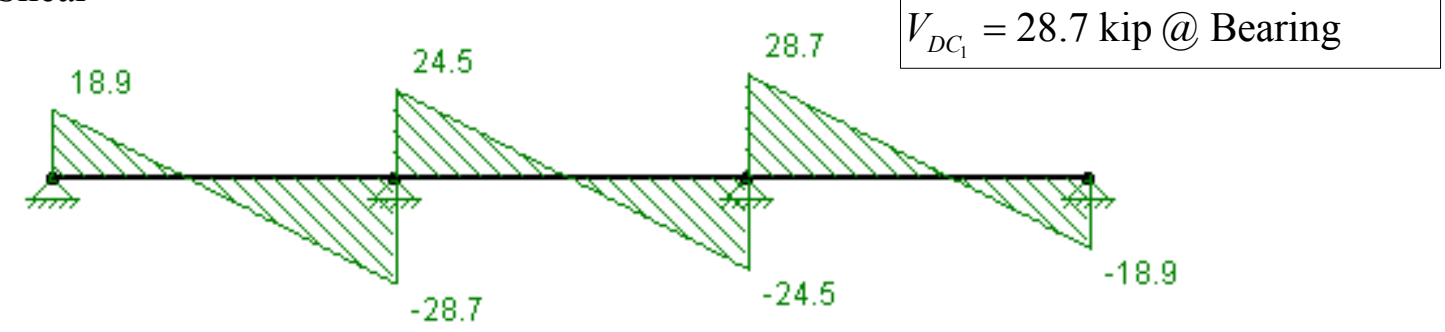

b) Composite Dead Load: $\quad \mathrm{DC}_{2}$
Curb:
$0.0 \mathrm{kip} / \mathrm{ft}$
Parapet:
$0.082 \mathrm{kip} / \mathrm{ft}$
Railing:
$0.0 \mathrm{kip} / \mathrm{ft}$
Total per stringer:
$0.082 \mathrm{kip} / \mathrm{ft}$

Moment


\subsection{Wearing Surface $\quad D W=0$}




\section{LIVE LOAD ANALYSIS - INTERIOR STRINGER}

\section{Compute Live-Load Distribution Factors (Type (a) cross section).}

Longitudinal Stiffness Parameters $K_{g}$

$$
\begin{gathered}
K_{g}=\frac{E_{B}}{E_{D}}\left(I+A e_{g}{ }^{2}\right) \quad(4.6 .2 .2 .1-1) \quad\left(=94828.062 \mathrm{in}^{4}\right) \\
E_{B}=\text { modulus of elasticity of beam material }(=29000 \mathrm{ksi}) \\
E_{D}=\text { modulus of elasticity of deck material }(\mathrm{ksi}) \\
I=\text { moment of inertia of beam }\left(=2850.0 \mathrm{in}^{4}\right) \\
e_{g}=\text { distance between the centers of gravity of the } \\
\text { basic beam and deck }(=17.355 \mathrm{in}) \\
E_{D}=33,000 w_{c}^{1.5} \sqrt{f_{c}{ }^{\prime}} \quad(5.4 .2 .4-1) \quad(=3155.924 \mathrm{ksi}) \\
w_{c}=\text { unit weight of concrete }(=0.145 \mathrm{kcf}) \\
f_{c}{ }^{\prime}=\text { specified strength of concrete }(=3 \mathrm{ksi})
\end{gathered}
$$

\section{a) Distribution Factor for Moment $\quad g_{m}$}

One Design Lane Loaded:

$$
g_{m 1}=0.06+\left(\frac{S}{14}\right)^{0.4}\left(\frac{S}{L}\right)^{0.3}\left(\frac{K_{g}}{12.0 L t_{s}^{3}}\right)^{0.1}
$$

Two or More Design Lanes Loaded:

$$
\begin{aligned}
& g_{m 2}=0.075+\left(\frac{S}{9.5}\right)^{0.6}\left(\frac{S}{L}\right)^{0.2}\left(\frac{K_{g}}{12.0 L t_{s}^{3}}\right)^{0.1} \\
& S=\text { spacing of supporting components }(=6.75 \mathrm{ft} .) \\
& L=\text { span length of deck }(=48.5 \mathrm{ft} .) \\
& t_{s}=\text { depth of concrete slab }(=8 \mathrm{in} .) \\
& g_{m 1}=0.429<g_{m 2}=0.565 \quad \Rightarrow \quad g_{m}=0.565
\end{aligned}
$$

\section{b) Distribution Factor for Shear $\quad g_{V}$}

One Design Lane Loaded:

$$
0.36+\frac{S}{25.0}
$$

Two or More Design Lanes Loaded:

$$
0.2+\frac{S}{12}-\left(\frac{S}{35}\right)^{2.0}
$$

$S=$ spacing of supporting components $(=6.75 \mathrm{ft}$. $)$

$$
g_{V 1}=0.630<g_{V 2}=0.725 \quad \Rightarrow \quad g_{V}=0.725
$$


II. Compute Maximum Live Load Effects (Using RISA-2D)

LRFD design live load (HL-93) (LRFD 3.6.1)

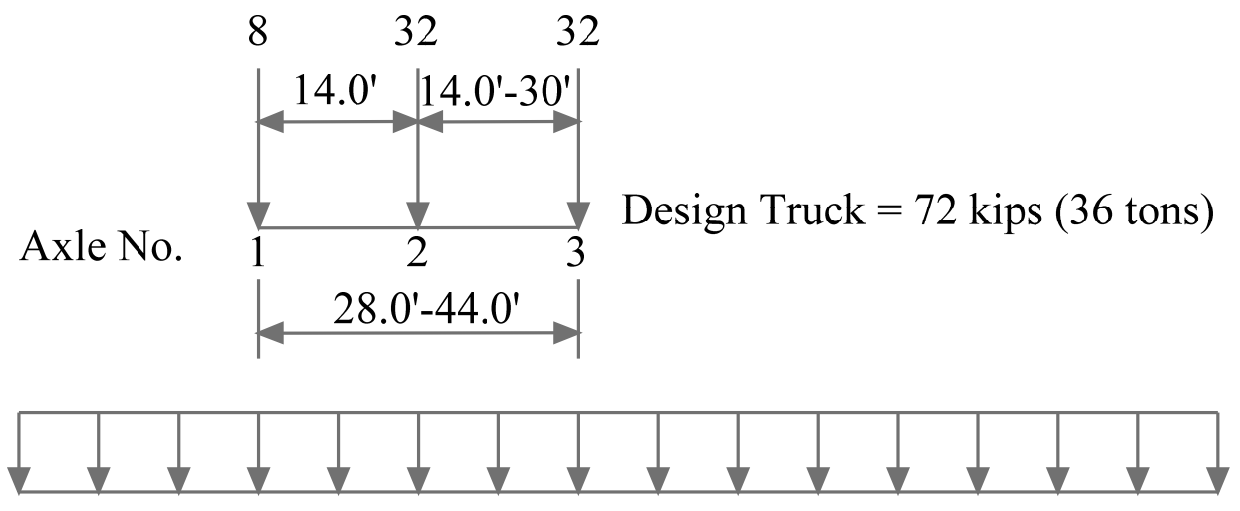

Design Lane Load $=0.64 \mathrm{klf}$

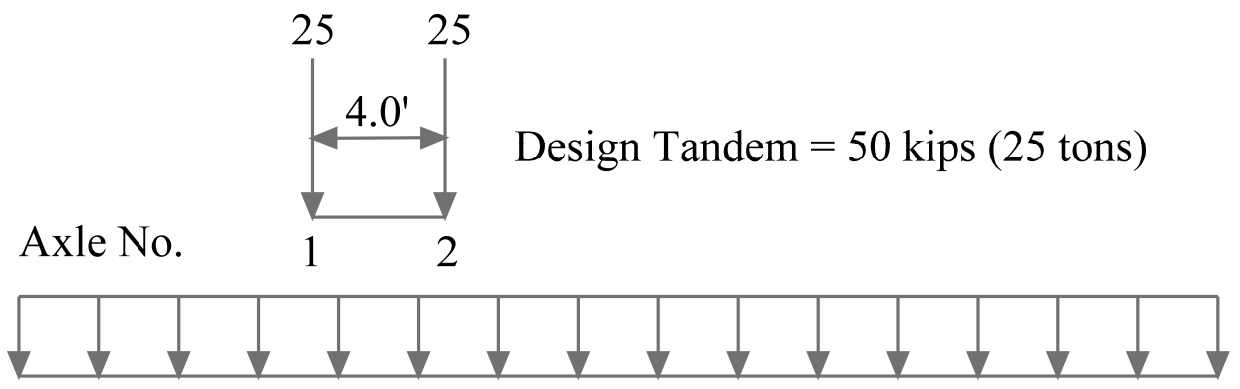

Design Lane Load $=0.64 \mathrm{klf}$

a) Maxima Design Live Load (HL-93) Moment at midspan

Design Lane Load Moment $=118.71 \mathrm{kip}-\mathrm{ft}$

Design Truck Moment $\quad=459.55 \mathrm{kip}-\mathrm{ft} \quad \underline{\text { Governs }}$

Tandem Axles Moment $\quad=\quad 441.29 \mathrm{kip}-\mathrm{ft}$

$I M=33 \%$

$$
M_{L L+I M}=118.71+459.55 \times 1.33=729.91 \mathrm{kip}-\mathrm{ft}
$$

b) Maxima Design Live Load Shear at beam ends

Design Lane Load Shear $=18.71 \mathrm{kip}$

Design Truck Shear $\quad=58.26 \mathrm{kip}$

Tandem Axles Shear $=48.84 \mathrm{kip}$

$\underline{\text { Governs }}$

$$
V_{L L+I M}=18.71+58.26 \times 1.33=96.2 \mathrm{kip}
$$

Distributed Live-Load Moments and Shears

Design Live-Load HL-93:

$$
\begin{aligned}
& M_{L L+I M}=730.18 \times g_{m}=412.19 \text { kip-ft } \\
& V_{L L+I M}=100.79 \times g_{V}=69.77 \mathrm{kip}
\end{aligned}
$$


$\underline{\text { Compute Nominal Resistance of Section at Midspan }}$

Locate Plastic Neutral Axis PNA:

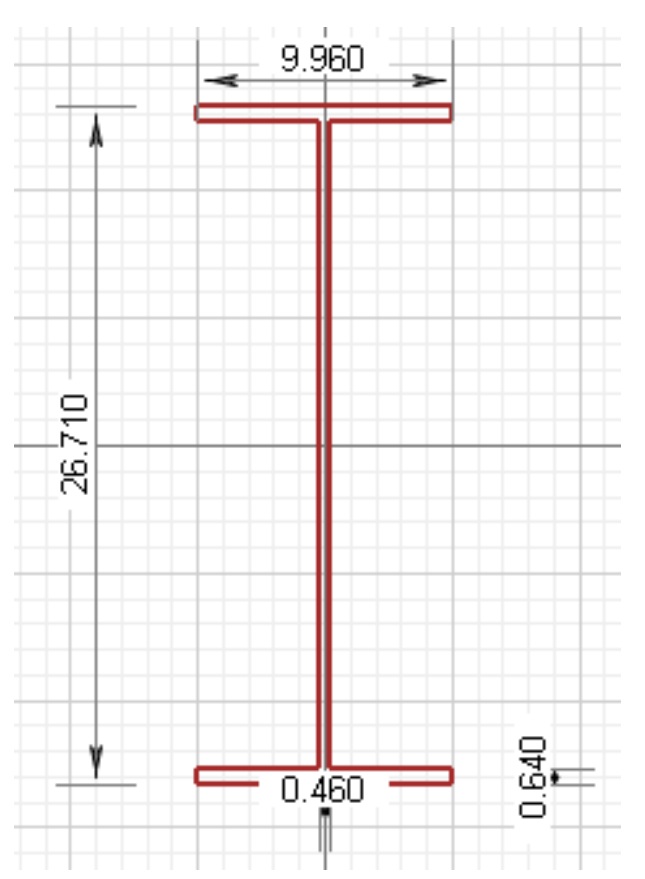

$t_{f}=0.64 \mathrm{in}$

$t_{w}=0.46 \mathrm{in}$

$b_{f}=9.96 \mathrm{in}$

$d=26.71$ in

Web Depth: $D=d-2 \times t_{f}=25.43$ in

$A_{t}=b_{f} \times t_{f}=6.3744 \mathrm{in}^{2}$

$y=t_{f} / 2=0.32$ in

$\left(\begin{array}{l}\text { from top of tension flange } \\ \text { to centriod of flange }\end{array}\right)$ 


\section{$\underline{\text { Plastic Forces }}$}

$P_{s}=$ plastic compressive force in the concrete deck used

to compute the plastic moment (kip) (D6.1)

$P_{c}=$ plastic force in the compression flange used to

compute the plastic moment (kip) (D6.1)

$P_{w}=$ plastic force in the web used to compute the plastic

moment (kip) (D6.1)

$P_{t}=$ plastic force in the tension flange used to compute

the plastic moment (kip) (D6.1)

$$
\begin{aligned}
& P_{s}=0.85 f_{c}^{\prime} b_{\text {eff }} t_{s}=1652.4 \mathrm{kip} \\
& P_{c}=F_{y} b_{f} t_{f} \quad=318.72 \mathrm{kip} \\
& P_{w}=F_{y} D t_{w} \quad=584.89 \mathrm{kip} \\
& P_{t}=F_{y} b_{f} t_{f} \quad=318.72 \mathrm{kip} \\
& D=\text { web depth }(=25.43 \text { in. }) \\
& b_{\text {eff }}=\text { effective width of the concrete deck ( }=81 \text { in.) } \\
& P_{c}+P_{w}+P_{t}=1222.33 \mathrm{kip}<P_{s}=1652.4 \mathrm{kip}
\end{aligned}
$$

The PNA lies in the slab; only a portion of the slab $($ depth $=\bar{y})$ is required to balance the plastic forces in the steel beam.

$$
\begin{aligned}
& \frac{\bar{y}}{t_{s}} \times P_{s}=P_{c}+P_{w}+P_{t} \\
& \bar{y}=5.918 \mathrm{in}
\end{aligned}
$$

\section{$\underline{\text { Classify Section }}$}

a) Check web slenderness:

Since PNA is in the slab, the web slenderness requirement is automatically satisfied.

b) Check Ductility Requirement.

$$
\frac{D_{p}}{D^{\prime}}=\frac{5.918}{3.2396}=1.827<5
$$

The section has adquate ductility.

$D_{P}=$ distance from the top of the concrete deck

to the neutral axis of the composite section

at the plastic moment $(=\bar{y}=5.918 \mathrm{in}$.)

$D^{\prime}=$ depth at which a composite section reaches its theoretical plastic moment capacity when the maximum strain in the concrete deck is at its theoretical crushing strain (in.) C6.10.7.3 


$$
\begin{aligned}
D^{\prime}= & \beta\left(\frac{d+t_{s}+t_{h}}{7.5}\right)=0.7\left(\frac{26.71+8.0}{7.5}\right)=3.2396 \\
t_{h}= & \text { thickness of the flange of the member to be stiffened } \\
& \text { in a rigid-frame connection (in.) } \\
\beta= & 0.7 \text { for } F_{y}=50 \text { and } 70 \mathrm{ksi} \\
\beta= & 0.9 \text { for } F_{y}=36 \mathrm{ksi} \quad(\mathrm{C} 6.10 .7 .1 .2(2007))
\end{aligned}
$$

\section{$\underline{\text { Plastic Moment } M_{p}}$}

Moment arms about the PNA:

Slab:

$$
d_{s}=\frac{\bar{y}}{2}=2.959 \mathrm{in}
$$

Compression Flange: $\quad d_{c}=\left(t_{s}-\bar{y}\right)+\frac{t_{f}}{2}=2.402$ in

Web:

$$
d_{w}=\left(t_{s}-\bar{y}\right)+t_{f}+\frac{D}{2}=15.437 \text { in }
$$

Tension Flange:

$$
d_{t}=\left(t_{s}-\bar{y}\right)+t_{f}+D+\frac{t_{f}}{2}=28.472 \text { in }
$$

The plastic moment $M_{p}$ is the sum of the moments of the plastic forces about the PNA.



$$
M_{p}=\frac{\bar{y}}{t_{s}} P_{s} d_{s}+P_{c} d_{c}+P_{w} d_{w}+P_{t} d_{t}=1873.84 \text { kip-ft }
$$


Nominal Flexural Resistance Moment $M_{n}$

$D_{t}=34.71$ in (total depth of the composite section)

as $D_{p}>0.1 \times D_{t} \quad M_{n}=M_{p} \times\left(1.07-1.07 \times D_{p} / D_{t}\right) \quad($ LRFD: $6.10 .7 .1 .2-2)$

otherwise, $M_{n}=M_{p}$

$$
M_{n}=1781.374 \text { kip-ft }
$$

Nominal Shear Resistance $V_{\underline{n}}$

$$
\begin{aligned}
& 2.46 \sqrt{\frac{E}{F_{y w}}}>\frac{D}{t_{w}} \text {, then } V_{n}=0.58 F_{y w} D t_{w} \\
& D(\text { web depth clear of fillet })=25.43-2 \times 0.75=23.93 \mathrm{in} \\
& \quad V_{n}=319.226 \mathrm{kips}
\end{aligned}
$$




\section{GENERAL LOAD-RATING EQUATION}

$$
R F=\frac{C-\left(\gamma_{D C}\right)(D C)-\left(\gamma_{D W}\right)(D W) \pm\left(\gamma_{P}\right)(P)}{\left(\gamma_{L}\right)(L L+I M)}
$$

\section{EVALUATION FACTORS (for Strength Limit States)}

a) Resistance Factor $\varphi$

$\varphi=1.0 \quad$ for flexure and shear

b) Condition Factor $\varphi_{c}$

$\varphi_{c}=1.0$

No member condition informatioin avaliable. NBI Item 59=7.

c) System Factor $\varphi_{s}$

$\varphi_{s}=1.0 \quad$ Mulit-girder bridge (for flexure and shear)

Table 6-1 Limit States and Load Factors for Load Rating (Steel Bridge)

\begin{tabular}{|c|c|c|c|c|c|c|c|}
\hline \multirow{3}{*}{$\begin{array}{c}\text { Bridge } \\
\text { Type }\end{array}$} & \multirow{3}{*}{$\begin{array}{l}\text { Limit } \\
\text { State* }\end{array}$} & \multirow{3}{*}{$\begin{array}{c}\text { Dead } \\
\text { Load } \\
D C\end{array}$} & \multirow{3}{*}{$\begin{array}{c}\text { Dead } \\
\text { Load } \\
D W\end{array}$} & \multicolumn{2}{|c|}{ Design Load 6.4.3.2.1 } & \multirow{2}{*}{$\begin{array}{c}\text { Legal } \\
\text { Load } \\
\text { 6.4.4.21 }\end{array}$} & \multirow{2}{*}{$\begin{array}{c}\text { Permit } \\
\text { Load } \\
\text { 6.4.5.4.1 }\end{array}$} \\
\hline & & & & Inventory & Operating & & \\
\hline & & & & $L L$ & $L L$ & $L L$ & $L L$ \\
\hline \multirow{4}{*}{ Steel } & Strength I & 1.25 & 1.50 & 1.75 & 1.35 & Table 6-5 & - \\
\hline & Strength II & 1.25 & 1.50 & - & - & - & Table 6-6 \\
\hline & Service II & 1.00 & 1.00 & 1.30 & 1.00 & 1.30 & 1.00 \\
\hline & Fatigue & 0.00 & 0.00 & 0.75 & - & - & - \\
\hline
\end{tabular}

* Defined in the AASHTO LRFD Bridge Design Specifications

Notes:

- Shaded cells of the table indicate optional checks

- Service I is used to check the $0.9 F_{y}$ stress limit in reinforcing steel

- Load factor for $D W$ at the strength limit state may be taken as 1.25 when thickness has been field measured

- Fatigue limit state is checked using the LRFD fatigue truck (see Article 6.6.4.1)

Table 6-5 Generalized Live-Load Factors for Legal Loads:

\begin{tabular}{c|c}
\hline Traffic Volume (one direction) & Load Factor \\
\hline Unknown & 1.80 \\
\hline$A D T T \geq 5000$ & 1.80 \\
\hline$A D T T=1000$ & 1.65 \\
\hline$A D T T \leq 100$ & 1.40 \\
\hline
\end{tabular}




\section{Design Load Rating}

A) Strength I Limit State

$R F=\frac{\left(\varphi_{c}\right)\left(\varphi_{s}\right)(\varphi) R_{n}-\left(\gamma_{D C}\right)(D C)-\left(\gamma_{D W}\right)(D W)}{\left(\gamma_{L}\right)(L L+I M)}$

a) Inventory Level

\begin{tabular}{c|c}
\hline Load & Load Factor \\
\hline$\gamma_{D C}$ & 1.25 \\
\hline$\gamma_{L}$ & 1.75 \\
\hline
\end{tabular}

Flexure: $\quad R F=\frac{(1.0)(1.0)(1.0)\left(M_{n}\right)-(1.25)\left(M_{D C 1}+M_{D C 2}\right)}{(1.75)\left(M_{L L+I M}\right)}=2.13$

Shear: $\quad R F=\frac{(1.0)(1.0)(1.0)\left(V_{n}\right)-(1.25)\left(V_{D C 1}+V_{D C 2}\right)}{(1.75)\left(V_{L L+I M}\right)}=2.30$

b) Operating Level

\begin{tabular}{c|c}
\hline Load & Load Factor \\
\hline$\gamma_{D C}$ & 1.25 \\
\hline$\gamma_{L}$ & 1.35 \\
\hline
\end{tabular}

Flexure: $R F=2.16 \times \frac{1.75}{1.35}=2.80$

Shear: $\quad R F=2.21 \times \frac{1.75}{1.35}=2.86$

\section{B) Service II Limit State}

$$
R F=\frac{f_{R}-\left(\gamma_{D C}\right)\left(f_{D}\right)}{\left(\gamma_{L}\right)\left(f_{L L+I M}\right)}
$$

\section{a) Inventory Level}

Allowable Flange Stress $f_{R}=0.95 R_{b} R_{h} F_{y f}$

Checking the tension flange as compression flanges typically do not govern for composite section..

$$
\begin{aligned}
& R_{b}=1.0 \text { for tension flanges } \\
& R_{h}=1.0 \text { for non-hybrid sections } \\
& f_{R}=0.95 \times 1.0 \times 1.0 \times 50.0=47.5 \mathrm{ksi} \\
& f_{D}=f_{D C 1}+f_{D C 2}=\frac{M_{D C 1}}{S_{N C}}+\frac{M_{D C 2}}{S_{L T}}=9.99 \mathrm{ksi} \\
& f_{L L+I M}=\frac{M_{L L+I M}}{S_{S T}}=14.78 \mathrm{ksi}
\end{aligned}
$$




\begin{tabular}{c|c}
\hline Load & Load Factor \\
\hline$\gamma_{D C}$ & 1.00 \\
\hline$\gamma_{L}$ & 1.30 \\
\hline
\end{tabular}

$R F=1.91$

b) Operating Level

\begin{tabular}{c|c}
\hline Load & Load Factor \\
\hline$\gamma_{D C}$ & 1.00 \\
\hline$\gamma_{L}$ & 1.00 \\
\hline
\end{tabular}

$R F=2.48$

\section{Legal Load Rating}

Note: The Inventory Design Load Rating Produced rating factors greater than 1.0. This indicates that the bridge has adequate load capacity to carry all legal loads within the LRFD exclusion limits and need not be subject to Legal Load Rating. The load rating computations that follow have been done for illustration purposes.

Live Load: AASHTO Legal Loads - Type 3, 3S2, 3-3 (Rate for all 3)



Type 3 Unit Weight $=50$ kip (25 tons)

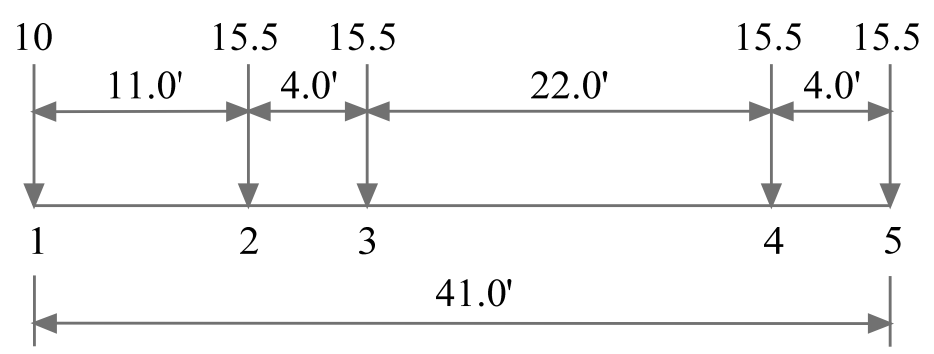

Type 3S2 Unit Weight $=72$ kip (36 tons)

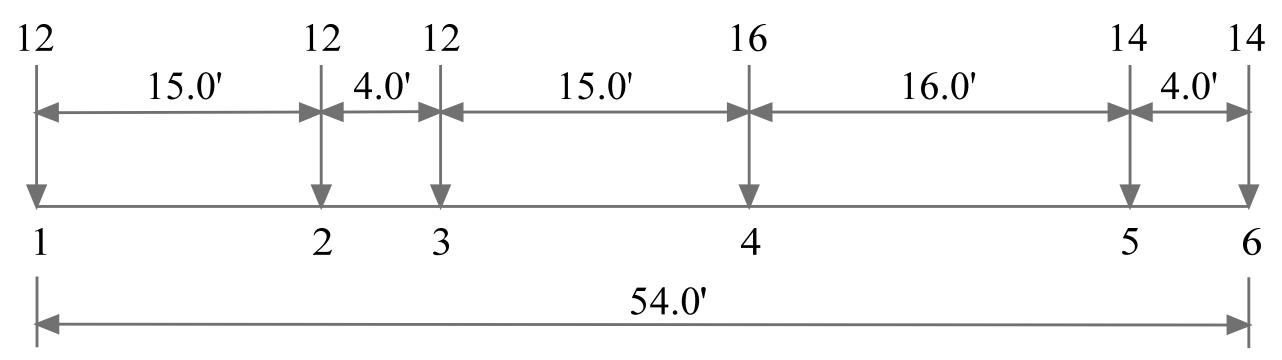

Type 3-3 Unit Weight $=80$ kip (40 tons) 
$g_{m}=0.565, \quad g_{v}=0.725$

$I M=20 \%$

The standard dynamic load allowance of 33 percent is decreased based on a field evaluation verifying that the approach and bridge riding surfaces have only minor surface deviations or depressions.

\begin{tabular}{c|c|c|c|c}
\hline & Type 3 & Type 3S2 & Type 3-3 & \\
\hline$M_{L L}$ & 351.2 & 318.2 & 298.2 & kip-ft \\
\hline$g_{m} M_{L L+M M}$ & 238.0 & 215.6 & 202.1 & kip-ft \\
\hline \hline$V_{L L}$ & 44.56 & 48.10 & 45.43 & kip \\
\hline$g_{v} M_{L L+I M}$ & 38.8 & 41.9 & 39.5 & kip \\
\hline
\end{tabular}

* The values above are calculated by using RISA-2D (moving loads were applied), based on the geometric parameters of the bridge and configuration of the loads.

\section{1) Strength I Limit State}

Dead Load DC: $\quad \gamma_{D C}=1.25$

$A D T T=1000$

Generalized Live-Load Factor for Legal Loads, $\gamma_{L}=1.65$

\begin{tabular}{c|c|c|c}
\hline Rating Factor & Type3 & Type 3S2 & Type 3-3 \\
\hline Flexure & 3.91 & 4.31 & 4.60 \\
\hline Shear & 4.38 & 4.06 & 4.30
\end{tabular}

2) Service II Limit State

$$
\gamma_{D C}=1.00, \gamma_{L}=1.30 \quad \text { Table 6-1 }
$$

$$
R F=\frac{f_{R}-\left(\gamma_{D C}\right)\left(f_{D}\right)}{\left(\gamma_{L}\right)\left(f_{L L+I M}\right)} \quad \text { No posting required as } R F>1.0
$$

\begin{tabular}{c|c|c|c}
\hline Truck & Type3 & Type 3S2 & Type 3-3 \\
\hline Weight (tons) & 25 & 36 & 40 \\
\hline$R F$ & 3.31 & 3.65 & 3.89 \\
\hline Safe Load Capacity (tons) & 82.6 & 131.4 & 155.7 \\
\hline
\end{tabular}

\section{Permit Load Rating}

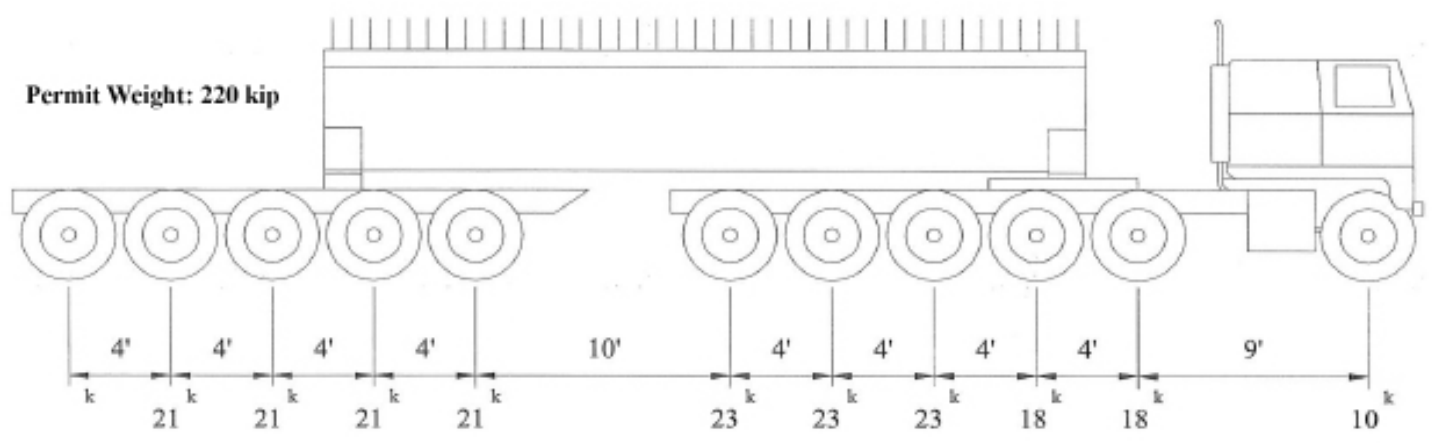


Permit Type: $\quad$ Special (Single-Trip, Escorted)

Permit Weight: 220 kip

The permit vehicle is shown above

ADTT (one direction): 1000

Using RISA-2D:

Undistributed Maximum $M_{L L}=913.61 \mathrm{kip}-\mathrm{ft}$

Undistributed Maximum $V_{L L}=133.35 \mathrm{kip}$

1) Strength II Limit State

$$
\gamma_{D C}=1.25, \gamma_{L}=1.15 \quad \text { (Single-Trip, Escorted) }
$$

Use One-Lane Distribution Factor and divide out the 1.2 multiple presence factor.

$g_{m 1}=g_{m} / 1.2=0.357$

$g_{V 1}=g_{V} / 1.2=0.525$

$I M=20 \%$ (non speed control, minor surface deviations)

Distributed Maximum $\quad M_{L L+I M}=M_{L L} g_{m 1}(1+I M)=391.62 \mathrm{kip}-\mathrm{ft}$

Distributed Maximum $\quad V_{L L+I M}=V_{L L} g_{V 1}(1+I M)=84.01 \mathrm{kip}$

Flexure: $R F=3.41>1 \quad O K$

Shear: $R F=2.90>1 \quad O K$

2) Service II Limit State

$$
\begin{aligned}
& \gamma_{D C}=1.0, \quad \gamma_{L}=1.0 \quad R F=\frac{f_{R}-\left(\gamma_{D C}\right)\left(f_{D}\right)}{\left(\gamma_{L}\right)\left(f_{L L+I M}\right)} \\
& R F=2.61
\end{aligned}
$$

\begin{tabular}{|c|c|c|c|c|c|c|c|}
\hline \multirow{2}{*}{\multicolumn{2}{|c|}{ Limit State }} & \multicolumn{2}{|c|}{ Design Load Rating } & \multicolumn{3}{|c|}{ Legal Load Rating } & \multirow{2}{*}{$\begin{array}{l}\text { Permit Load } \\
\text { Rating }\end{array}$} \\
\hline & & Inventory & Operating & T3 & T3S2 & T3-3 & \\
\hline \multirow{2}{*}{ Strength I } & Flexure & 2.13 & 2.76 & 3.91 & 4.31 & 4.60 & \\
\hline & Shear & 2.30 & 2.98 & 4.38 & 4.06 & 4.30 & \\
\hline \multirow{2}{*}{$\begin{array}{c}\text { Strength } \\
\text { II }\end{array}$} & Flexure & & & & & & 3.41 \\
\hline & Shear & & & & & & 2.90 \\
\hline Service II & & 1.91 & 2.48 & 3.31 & 3.65 & 3.89 & 2.61 \\
\hline \multicolumn{2}{|c|}{ Safe Load Capacity (ton) } & & & 82.6 & 131.4 & 155.7 & \\
\hline
\end{tabular}

Rating Factors for Interior Girder 


\section{For exterior stringer, similar procedures were involved.}

\section{Section Properties (exterior stringer):}

\section{Noncomposite: $\quad W 27 \times 84$}

Section Modulus at top of steel

$$
S_{t}=213.4 \mathrm{in}^{3}
$$

Section Modulus at bottom of steel

$$
S_{b}=213.4 \text { in }^{3}
$$

\section{Composite Section Properties:}

Effective Flange Width $b_{\text {eff }}$

$1 / 2$ Interior $b_{\text {eff }}+$ minimum of:

1) $1 / 8$ of the effective span length: $L_{\text {eff }} / 8=(0.7 \times 48.5 \times 12) / 8=50.93$ in

2) 6.0 times the average depth of the slab, plus the greater of one-half of web thickness or one-quarter the width of the top flange of the girder: $6.0 t_{s}+\operatorname{greater}\left(t_{w} / 2,1 / 4 b_{\text {ftop }}\right)=50.49$ in

3) Overhang: $=21$ in controls

$$
b_{\text {eff }}=1 / 2 \times 81+21=61.5 \text { in }
$$

Modular Ration: $(n)$ :

$$
\text { for } 2.9<f_{c}^{\prime}=3<3.6, n=9
$$

Short-Term Composite $(n): \quad W 27 \times 84 \&$ Conc. 8 in. $\times 61.5$ in.

$$
\begin{aligned}
& 61.5 / n=6.833 \mathrm{in} . \\
& \bar{y}=25.29 \mathrm{in} \\
& I_{x}=8280.08 \mathrm{in}^{4}
\end{aligned}
$$

Section Modulus:

Section Modulus at top of steel

$$
S_{t}=5846.87 \mathrm{in}^{3}
$$

Section Modulus at bottom of steel

$$
S_{b}=327.36 \mathrm{in}^{3}
$$

Short-Term Composite $(n): \quad W 27 \times 84 \&$ Conc. 8 in. $\times 61.5$ in.

$61.5 /(3 n)=2.278$ in.

$$
\begin{aligned}
& \bar{y}=20.706 \mathrm{in} \\
& I_{x}=6110.988 \mathrm{in}^{4}
\end{aligned}
$$


Section Modulus:

Section Modulus at top of steel

$$
S_{t}=1017.78 \mathrm{in}^{3}
$$

Section Modulus at bottom of steel

$$
S_{b}=295.13 \mathrm{in}^{3}
$$

\section{SUMMARY OF SECTION PROPERTIES AT MIDSPAN}

\begin{tabular}{c|c|c|c}
\hline & Steel Section Only & $\begin{array}{c}\text { Composite Section - } \\
\text { Short Term }\end{array}$ & $\begin{array}{c}\text { Composite Section - } \\
\text { Long Term }\end{array}$ \\
\hline$S_{\text {TOP steel }}$ & 213.4 & 5846.87 & 1017.78 \\
\hline$S_{B O T}$ & 213.4 & 327.36 & 295.13 \\
\hline
\end{tabular}

\section{DEAD LOAD ANALYSIS - EXTERIOR STRINGER}

\subsection{Components and Attachments}

a) Non-Composite Dead Load: $D C_{1}$

Deck:

Stringer:

SIP forms:

Diaphragms:

Total per stringer:
$0.675 \mathrm{kip} / \mathrm{ft}$

$0.084 \mathrm{kip} / \mathrm{ft}$

$0.169 \mathrm{kip} / \mathrm{ft}$

$0.019 \mathrm{kip} / \mathrm{ft}$

$0.725 \mathrm{kip} / \mathrm{ft}$
$M_{D C_{1}}=134.4$ kip-ft @ Midspan

$V_{D C_{1}}=21.2$ kip@ Bearing

b) Composite Dead Load: $\quad \mathrm{DC}_{2}$
Curb:
$0.0 \mathrm{kip} / \mathrm{ft}$
Parapet:
$0.082 \mathrm{kip} / \mathrm{ft}$
Railing:
$0.0 \mathrm{kip} / \mathrm{ft}$
Total per stringer:
$0.082 \mathrm{kip} / \mathrm{ft}$
$M_{D C_{1}}=15.2$ kip-ft @ Midspan
$V_{D C_{1}}=2.4$ kip @ Bearing

\subsection{Wearing Surface $\quad D W=0$}

\section{LIVE LOAD ANALYSIS - EXTERIOR STRINGER}

\section{Compute Live-Load Distribution Factors.}

a) Distribution Factor for Moment

$g_{m}$

One Design Lane Loaded:

(Table 4.6.2.2.2d-1)

Lever Rule

For one lane loaded, the multiple presence factor, $m=1.20$

(Table 3.6.1.1.2-1)

For $S+d_{e}=6.75 \mathrm{ft} .+0.5 \mathrm{ft} .<8 \mathrm{ft}$. one wheel is acting upon the girder

$$
g_{m 1}=m\left(\frac{S+d_{e}-2 \mathrm{ft}}{2 S}\right)=1.20 \times\left(\frac{6.75+0.5-2}{2 \times 6.75}\right)=0.467
$$


$S=$ spacing of supporting components $(=6.75 \mathrm{ft}$. $)$

$d_{e}=$ distance from the exterior beam to the interior edge of curb or taffic barrier ( $=0.5 \mathrm{ft}$.)

Two or More Design Lanes Loaded:

$$
\begin{aligned}
& \text { if }-1.0 \leq d_{e} \leq 5.5 \\
& g_{m 2}=e g_{\text {int erior }}, \quad e=0.77+\frac{d_{e}}{9.1} \\
& g_{m 2}=0.466<g_{m 1}=0.467 \quad \Rightarrow \quad
\end{aligned}
$$

\section{b) Distribution Factor for Shear $\quad g_{V}$}

One Design Lane Loaded:

Lever Rule: $\quad g_{V 1}=g_{m 1}=0.467$

Two or More Design Lanes Loaded:

$$
\begin{gathered}
\text { if }-1.0 \leq d_{e} \leq 5.5 \\
g_{m 2}=e g_{\text {int erior }}, \quad e=0.6+\frac{d_{e}}{10} \\
g_{V 2}=0.471>g_{V 1}=0.467 \quad \Rightarrow \quad \underline{g_{V}=0.471}
\end{gathered}
$$

c) Special Analysis for Exterior Girders with Diaphragms or Cross-Frames Roadway Layout: Two 12-ft wide lanes

$$
\begin{aligned}
& R=\frac{N_{L}}{N_{b}}+\frac{X_{\text {ext }} \sum^{N_{L}} e}{\sum_{b} x^{2}} \\
& g_{\text {special }}=(m)(R) \\
& \text { where: } \\
& R=\text { reaction on exterior beam in terms of lanes } \\
& N_{L}=\text { number of loaded lanes under consideration } \\
& e=\text { eccentricity of a design truck or a design lane } \\
& \quad \text { load from the center of gravity of the pattern of } \\
& \quad \text { girders (ft.) } \\
& x=\text { horizontal distance from the center of gravity of } \\
& \quad \text { the pattern of girders to each girder (ft.) } \\
& X_{\text {ext }}=\text { horizontal distance from the center of gravity of } \\
& \quad \text { the pattern of girders to the exterior girder (ft.) } \\
& N_{b}=\text { number of beams or girders }
\end{aligned}
$$




\begin{tabular}{c|c|c|c|c|c|c|c|c|c|c|c|c}
\hline$X_{\text {ext }}$ & $N_{L 1}$ & $N_{L 2}$ & $e_{1}$ & $e_{2}$ & $N_{b}$ & $x_{1}$ & $x_{2}$ & $x_{3}$ & $x_{4}$ & $x_{5}$ & $x_{6}$ & $x_{7}$ \\
\hline $\mathrm{ft}$ & lanes & lanes & $\mathrm{ft}$ & $\mathrm{ft}$ & beams & $\mathrm{ft}$ & $\mathrm{ft}$ & $\mathrm{ft}$ & $\mathrm{ft}$ & $\mathrm{ft}$ & $\mathrm{ft}$ & $\mathrm{ft}$ \\
\hline 20.25 & 1 & 2 & 6 & -6 & 7 & 0 & 6.75 & -6.75 & 13.5 & -13.5 & 20.25 & -20.25 \\
\hline
\end{tabular}

One Lane Loaded:

$$
\begin{aligned}
& R=0.238, \quad m=1.20 \\
& g_{\text {special } 1}=1.20 \times 0.238=0.286
\end{aligned}
$$

Two Lanes Loaded:

$$
\begin{aligned}
& R=0.286, \quad m=1.00 \\
& g_{\text {special } 1}=1.00 \times 0.286=0.286
\end{aligned}
$$

\section{SUMMARY OF DISTRIBUTION FACTORS FOR THE EXTERIOR GIRDERS}

$\begin{array}{llll}\text { Moment } g_{m} & \text { 1 Lane } & =\mathbf{0 . 4 6 7} & \text { Governs } \\ & \text { 2 or More lanes } & =0.466 & \\ & \text { Special Analysis (1 Lane) } & =0.286 & \\ & \text { Special Analysis (2 Lanes) } & =0.286 & \\ & \quad g_{m}=0.467 & & \\ \text { Shear } g_{V} & & =0.467 & \\ & \text { 1 Lane } & =\mathbf{0 . 4 7 1} & \text { Governs } \\ & \text { 2 or More lanes } & & \\ & \text { Special Analysis (1 Lane) } & =0.286 & \\ & \text { Special Analysis (2 Lanes) } & =0.286 & \\ & & \end{array}$

\section{Compute Maximum Live Load Effects}

Same as for interior girder

Midspan:

$$
\begin{aligned}
& M_{L L+I M}=729.91 \mathrm{kip}-\mathrm{ft} \\
& V_{L L+I M}=96.2 \mathrm{kip}
\end{aligned}
$$

Bearing:

Distributed Live-Load Moments and Shears

Design Live-Load HL-93:

$$
\begin{aligned}
& M_{L L+I M}=730.18 \times g_{m}=340.63 \mathrm{kip}-\mathrm{ft} \\
& V_{L L+I M}=100.79 \times g_{V}=45.35 \mathrm{kip}
\end{aligned}
$$




\section{$\underline{\text { Compute Nominal Resistance of Section at Midspan }}$}

Locate Plastic Neutral Axis PNA:

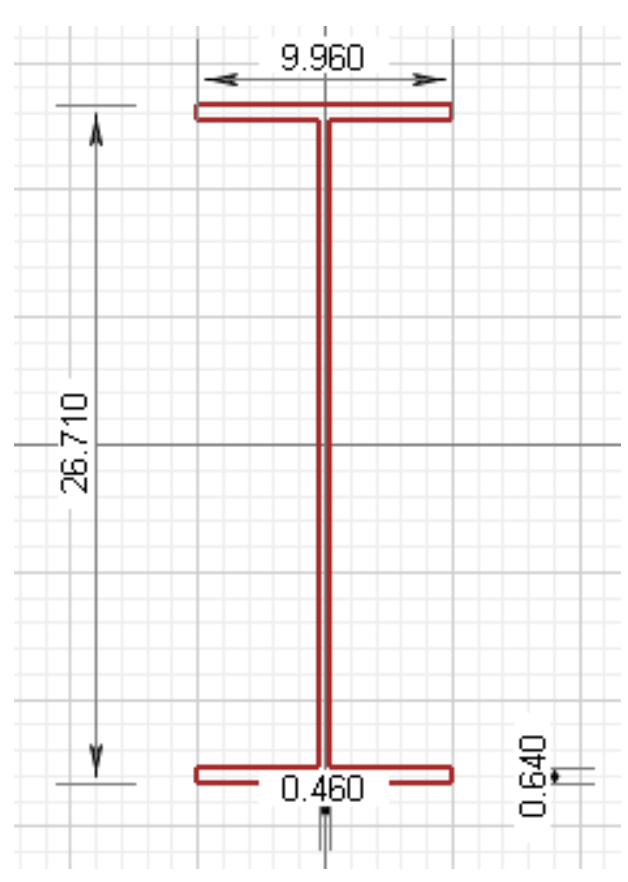

$$
\begin{aligned}
& t_{f}=0.64 \mathrm{in} \\
& t_{w}=0.46 \mathrm{in} \\
& b_{f}=9.96 \mathrm{in} \\
& d=26.71 \mathrm{in}
\end{aligned}
$$

Web Depth: $D=d-2 \times t_{f}=25.43$ in

$$
\begin{aligned}
& A_{t}=b_{f} \times t_{f}=6.3744 \mathrm{in}^{2} \\
& y=t_{f} / 2=0.32 \mathrm{in} \\
& \left(\begin{array}{l}
\text { from top of tension flange } \\
\text { to centriod of flange }
\end{array}\right)
\end{aligned}
$$

\section{$\underline{\text { Plastic Forces }}$}

$$
\begin{aligned}
& P_{s}=0.85 f_{c}{ }^{\prime} b_{e f f} t_{s}=1254.60 \mathrm{kip} \\
& P_{c}=F_{y} b_{f} t_{f} \quad=318.72 \mathrm{kip} \\
& P_{w}=F_{y} D t_{w} \quad=584.89 \mathrm{kip} \\
& P_{t}=F_{y} b_{f} t_{f} \quad=318.72 \mathrm{kip} \\
& D=\text { web depth (=25.43 in.) } \\
& b_{\text {eff }}=\text { effective width of the concrete deck ( }=61.5 \text { in.) } \\
& P_{c}+P_{w}+P_{t}=1222.33 \mathrm{kip}<P_{s}=1254.60 \mathrm{kip}
\end{aligned}
$$

The PNA lies in the slab; only a portion of the slab $($ depth $=\bar{y})$ is required to balance the plastic forces in the steel beam.

$$
\begin{aligned}
& \frac{\bar{y}}{t_{s}} \times P_{s}=P_{c}+P_{w}+P_{t} \\
& \bar{y}=7.794 \mathrm{in}
\end{aligned}
$$

\section{Classify Section}

c) Check web slenderness:

Since PNA is in the slab, the web slenderness requirement is automatically satisfied.

d) Check Ductility Requirement. 


$$
\frac{D_{p}}{D^{\prime}}=\frac{7.794}{3.2396}=2.406<5
$$

The section has adquate ductility.

$D_{P}=$ distance from the top of the concrete deck to the neutral axis of the composite section at the plastic moment $(=\bar{y}=7.794$ in.)

$D^{\prime}=$ depth at which a composite section reaches its theoretical plastic moment capacity when the maximum strain in the concrete deck is at its theoretical crushing strain (in.) C6.10.7.3

$$
D^{\prime}=\beta\left(\frac{d+t_{s}+t_{h}}{7.5}\right)=0.7\left(\frac{26.71+8.0}{7.5}\right)=3.2396
$$

$t_{h}=$ thickness of the flange of the member to be stiffened in a rigid-frame connection (in.)

$\beta=0.7$ for $F_{y}=50$ and $70 \mathrm{ksi}$

$\beta=0.9$ for $F_{y}=36 \mathrm{ksi} \quad$ (C6.10.7.1.2 (2007))

\section{$\underline{\text { Plastic Moment } M_{p}}$}

Moment arms about the PNA:

Slab:

$$
d_{s}=\frac{\bar{y}}{2}=3.8971 \mathrm{in}
$$

Compression Flange: $\quad d_{c}=\left(t_{s}-\bar{y}\right)+\frac{t_{f}}{2}=0.5258$ in

Web:

$$
d_{w}=\left(t_{s}-\bar{y}\right)+t_{f}+\frac{D}{2}=13.5608 \text { in }
$$

Tension Flange:

$$
d_{t}=\left(t_{s}-\bar{y}\right)+t_{f}+D+\frac{t_{f}}{2}=26.5958 \text { in }
$$

The plastic moment $M_{p}$ is the sum of the moments of the plastic forces about the PNA. 


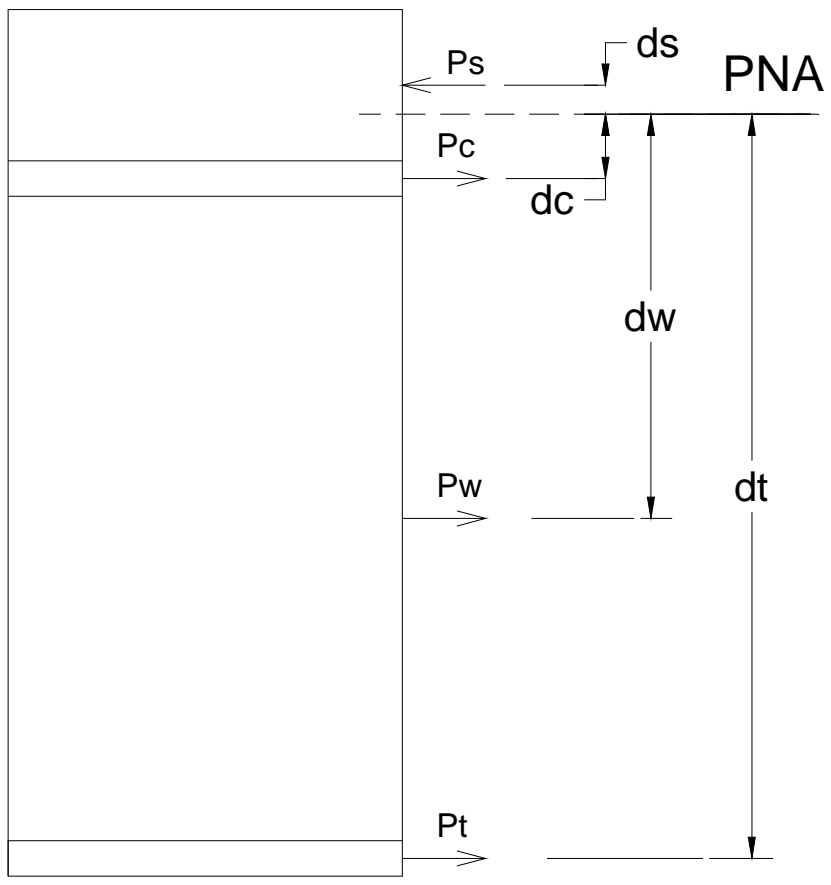

$M_{p}=\frac{\bar{y}}{t_{s}} P_{s} d_{s}+P_{c} d_{c}+P_{w} d_{w}+P_{t} d_{t}=1778.27 \mathrm{kip}-\mathrm{ft}$

Nominal Flexural Resistance Moment $M_{n}$

$D_{t}=34.71$ in (total depth of the composite section)

as $D_{p}>0.1 \times D_{t} \quad M_{n}=M_{p} \times\left(1.07-0.7 \times D_{p} / D_{t}\right)$

(LRFD: 6.10.7.1.2-2)

otherwise, $M_{n}=M_{p}$

$$
M_{n}=1623.23 \mathrm{kip}-\mathrm{ft}
$$

$\underline{\text { Nominal Shear Resistance } V_{\underline{n}}}$

Classification and Resistance same as for interior.

$$
V_{n}=319.226 \mathrm{kips}
$$




\section{GENERAL LOAD-RATING EQUATION}

$$
R F=\frac{C-\left(\gamma_{D C}\right)(D C)-\left(\gamma_{D W}\right)(D W) \pm\left(\gamma_{P}\right)(P)}{\left(\gamma_{L}\right)(L L+I M)}
$$

\section{EVALUATION FACTORS (for Strength Limit States)}

a) Resistance Factor $\varphi$

$\varphi=1.0 \quad$ for flexure and shear

b) Condition Factor $\varphi_{c}$

$\varphi_{c}=1.0$

No member condition informatioin avaliable. NBI Item 59=7.

c) System Factor $\varphi_{s}$

$\varphi_{s}=1.0 \quad$ Mulit-girder bridge (for flexure and shear)

\section{Design Load Rating}

\section{A) Strength I Limit State}

$R F=\frac{\left(\varphi_{c}\right)\left(\varphi_{s}\right)(\varphi) R_{n}-\left(\gamma_{D C}\right)(D C)-\left(\gamma_{D W}\right)(D W)}{\left(\gamma_{L}\right)(L L+I M)}$

a) Inventory Level

\begin{tabular}{c|c}
\hline Load & Load Factor \\
\hline$\gamma_{D C}$ & 1.25 \\
\hline$\gamma_{L}$ & 1.75 \\
\hline Flexure: $R F=\frac{(1.0)(1.0)(1.0)\left(M_{n}\right)-(1.25)\left(M_{D C 1}+M_{D C 2}\right)}{(1.75)\left(M_{L L+I M}\right)}=2.41$
\end{tabular}

Shear: $\quad R F=\frac{(1.0)(1.0)(1.0)\left(V_{n}\right)-(1.25)\left(V_{D C 1}+V_{D C 2}\right)}{(1.75)\left(V_{L L+I M}\right)}=3.65$

b) Operating Level

\begin{tabular}{c|c}
\hline Load & Load Factor \\
\hline$\gamma_{D C}$ & 1.25 \\
\hline$\gamma_{L}$ & 1.35 \\
\hline
\end{tabular}

Flexure: $R F=2.41 \times \frac{1.75}{1.35}=3.12$

Shear: $\quad R F=3.65 \times \frac{1.75}{1.35}=4.73$

B) Service II Limit State

$$
R F=\frac{f_{R}-\left(\gamma_{D C}\right)\left(f_{D}\right)}{\left(\gamma_{L}\right)\left(f_{L L+I M}\right)}
$$

\section{a) Inventory Level}

Allowable Flange Stress $f_{R}=0.95 R_{b} R_{h} F_{y f}$

Checking the tension flange as compression flanges typically do not govern 
for composite section..

$R_{b}=1.0$ for tension flanges

$R_{h}=1.0$ for non-hybrid sections

$f_{R}=0.95 \times 1.0 \times 1.0 \times 50.0=47.5 \mathrm{ksi}$

$f_{D}=f_{D C 1}+f_{D C 2}=\frac{M_{D C 1}}{S_{N C}}+\frac{M_{D C 2}}{S_{L T}}=8.17 \mathrm{ksi}$

$f_{L L+I M}=\frac{M_{L L+I M}}{S_{S T}}=12.49 \mathrm{ksi}$

\begin{tabular}{c|c}
\hline Load & Load Factor \\
\hline$\gamma_{D C}$ & 1.00 \\
\hline$\gamma_{L}$ & 1.30 \\
\hline
\end{tabular}

$R F=2.42$

b) Operating Level

\begin{tabular}{c|c}
\hline Load & Load Factor \\
\hline$\gamma_{D C}$ & 1.00 \\
\hline$\gamma_{L}$ & 1.00 \\
\hline
\end{tabular}

$R F=3.15$

\section{Legal Load Rating}

$g_{m}=0.467, \quad g_{v}=0.471$

$I M=20 \%$

The standard dynamic load allowance of 33 percent is decreased based on a field evaluation verifying that the approach and bridge riding surfaces have only minor surface deviations or depressions.

\begin{tabular}{c|c|c|c|c}
\hline & Type 3 & Type 3S2 & Type 3-3 & \\
\hline$M_{L L}$ & 351.2 & 318.2 & 298.2 & kip-ft \\
\hline$g_{m} M_{L L+I M}$ & 196.7 & 178.2 & 167.0 & kip-ft \\
\hline \hline$V_{L L}$ & 44.56 & 48.10 & 45.43 & kip \\
\hline$g_{v} M_{L L+I M}$ & 21.0 & 22.7 & 21.4 & kip \\
\hline
\end{tabular}

1) Strength I Limit State

Dead Load DC: $\quad \gamma_{D C}=1.25 \quad A D T T=1000$

Generalized Live-Load Factor for Legal Loads, $\gamma_{L}=1.65$

\begin{tabular}{c|c|c|c}
\hline Rating Factor & Type3 & Type 3S2 & Type 3-3 \\
\hline Flexure & 4.56 & 5.04 & 5.38 \\
\hline
\end{tabular}

2) Service II Limit State

$\gamma_{D C}=1.00, \gamma_{L}=1.30 \quad$ Table 6-1 


$$
R F=\frac{f_{R}-\left(\gamma_{D C}\right)\left(f_{D}\right)}{\left(\gamma_{L}\right)\left(f_{L L+I M}\right)} \quad \text { No posting required as } R F>1.0
$$

\begin{tabular}{c|c|c|c}
\hline Truck & Type3 & Type 3S2 & Type 3-3 \\
\hline Weight (tons) & 25 & 36 & 40 \\
\hline$R F$ & 4.20 & 4.63 & 4.94 \\
\hline Safe Load Capacity (tons) & 104.9 & 166.7 & 197.7 \\
\hline
\end{tabular}

\section{Permit Load Rating}

Undistributed Maximum $M_{L L}=913.61 \mathrm{kip}-\mathrm{ft}$

Undistributed Maximum $V_{L L}=133.35 \mathrm{kip}$

\section{1) Strength II Limit State}

$$
\gamma_{D C}=1.25, \gamma_{L}=1.15 \quad \text { (Single-Trip, Escorted) }
$$

Use One-Lane Distribution Factor and divide out the 1.2 multiple presence factor.

$g_{m 1}=g_{m} / 1.2=0.389$

$g_{V 1}=g_{V} / 1.2=0.393$

$I M=20 \%$ (non speed control, minor surface deviations)

Distributed Maximum $\quad M_{L L+I M}=M_{L L} g_{m 1}(1+I M)=426.35 \mathrm{kip}-\mathrm{ft}$

Distributed Maximum $\quad V_{L L+I M}=V_{L L} g_{V 1}(1+I M)=62.87 \mathrm{kip}$

Flexure: $R F=2.93>1 \quad O K$

Shear: $R F=4.01>1 \quad O K$

\section{2) Service II Limit State}

$$
\begin{aligned}
& \gamma_{D C}=1.0, \quad \gamma_{L}=1.0 \quad R F=\frac{f_{R}-\left(\gamma_{D C}\right)\left(f_{D}\right)}{\left(\gamma_{L}\right)\left(f_{L L+I M}\right)} \\
& R F=2.52
\end{aligned}
$$

\section{Rating Factors for Exterior Girder}

\begin{tabular}{l}
\hline \multirow{2}{*}{ Limit State } \\
\cline { 2 - 9 }
\end{tabular}




\section{Appendix A3}

\section{Bridge Load Testing with Wireless Data Acquisition System}

1) Work out the instrumentation plan. Decide the locations of sensors and how many sensors \& wireless nodes are needed.

2) Before field tests, make sure that all of the wireless nodes are fully charged and the batteries of the accelerometer conditioners are brand new.

3) Install sensors based on the instrumentation plan. Connect sensors with wireless nodes.

4) Setup traffic signs for traffic control.

5) Measure and record the dimension \& configuration of the test truck, such as gross weight, axle weights, wheel weights, axle distance, wheel distance, etc.

6) Mark the start line, normally 30 feet away from the origin $(0,0$ point $)$, and mark the wheel line based on the plan.

7) Position the test truck so that the front wheel is located over the start line.

8) Install the Wireless Vehicle Position Indicator (WVPI) on the test truck (refer to Appendix A4).

9) Turn on all wireless nodes. Setup the antennas. Check the communication between the antennas and the nodes. Make sure they are communicating well.

10) Configure the settings of each wireless node. Set the sampling frequency and number of samples to proper values.

11) Position the truck on the appropriate wheel line at the starting end of the bridge.

12) Trigger all of the wireless nodes, and let the test truck pass at crawl speed.

13) After one run, download data to computer and check the records. Make sure wireless nodes are working properly and results are reasonable. If necessary, change the configuration of the wireless nodes, such as sampling frequency, 
number of samples, etc.

14) Repeat steps 9-11 three times.

15) After finishing static test, reconfigure the settings of nodes according to plan.

16) For dynamic test, let the test truck cross at normal speed three times, and records the corresponding data.

17) For each test, write down the starting time for post data processing.

18) Take pictures of settings and truck and others. 


\section{Appendix A4}

\section{How to Use the Wireless Vehicle Position Indicator (WVPI)}

Procedures of installation and usage of the Wireless Vehicle Position Indicator (WVPI, namely G-Link ${ }^{\circledR}$ node) have been list below. Following each step will help to ensure that the WVPI will function properly and produce quality data.

1) Clean the bottom surface of the WVPI and the front wheel hub of the loading vehicle. Ensure that the application surface is clean and dry without oil or residue. If necessary, wipe it clean with isopropanol (rubbing alcohol) or degreaser.

2) Carefully press two hook-and-loop Superlock ${ }^{\mathrm{TM}}$ Fasteners into the clean surface of the front wheel hub. Attach other Superlock ${ }^{\mathrm{TM}}$ Fasteners on the bottom of the WVPI.

3) Measure the circumference of the front wheel of the loading vehicle by first marking the side of the tire and the pavement directly below the center of the front axle. Then, roll the truck forward exactly ten wheel revolutions, and place another mark on the pavement that lines up with the mark on the tire. Measure the distance between the two marks on the roadway and divide this number by ten. This method of measuring will produce a good "averaged" value for the circumference of the wheel.

4) Mount the WVPI on the wheel hub. With proper mounting, the connection strength can reach $4 \mathrm{lb} / \mathrm{in}^{2}$ in tensile and sheer at $72^{\circ} \mathrm{F}\left(22^{\circ} \mathrm{C}\right)$. When mounting, make sure the sensitive $\mathrm{x}$-axis of WVPI is horizontal and the $\mathrm{y}$-axis is vertical.

5) Turn on the WVPI, and check the wireless communication.

6) Locate the start line for the tests. This should be approximately 30 feet before the origin $(0,0$ point $)$ on the bridge and extend perpendicular across the roadway.

7) Position the truck so that the front wheel is located over the start line and the WVPI is at the highest position. 
8) The truck is now ready for the test. Wirelessly trigger the WVPI and all other wireless nodes.

9) The truck can now cross the bridge at crawl speed.

10) The WVPI is only designed for slow speed tests. Be sure to remove the WVPI unit before any high-speed passes are made. 


\section{Appendix A5}

\section{User Manual of Bridge Load Testing \& Rating Software}

For the purpose of simplifying LRFR and processing of test data, the Bridge Load Testing \& Rating software was developed using MATLAB (version: R2009b). Running the software requires MATLAB environment, and the latest MATLAB version is recommended.

\section{Main Window}

In order to run the software, users need to change the working directory to where the programs are. For example: "C:LLRFR Matlab". Then type "MainWindow" in the MATLAB command area, which will active the main window of the software, as shown in Figure 1. Follow the sequence of the instruction.

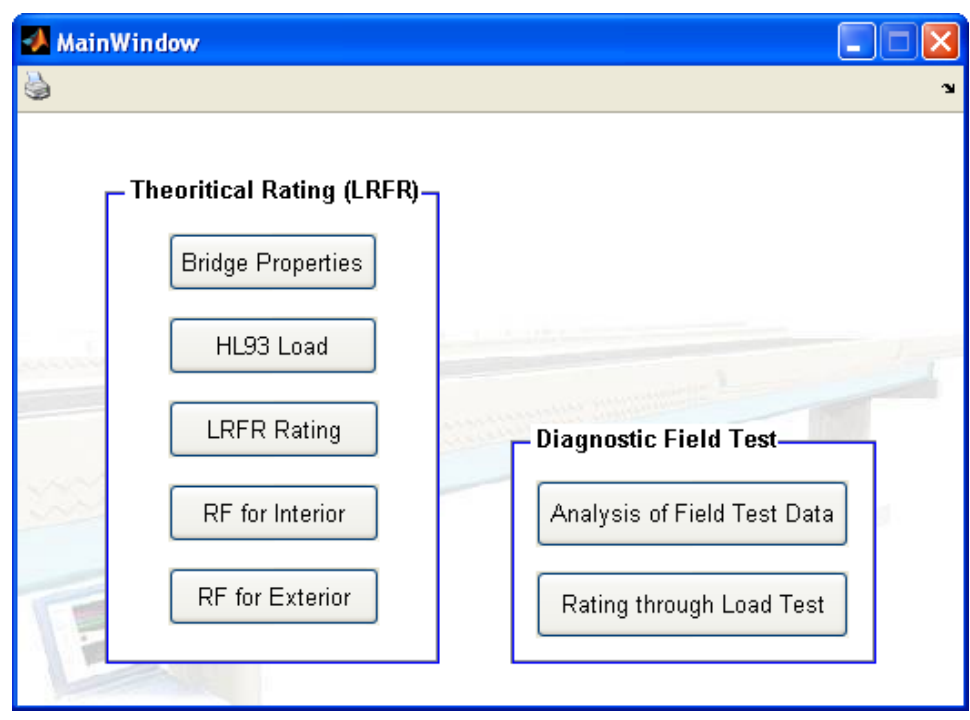

Figure 1. Main window of bridge load testing \& rating software

There are two major function groups in the interface. One is for theoretical rating (LRFR). The other is for diagnostic field test. LRFR should be carried out before field data processing. In fact, the sequence of buttons is following the order to operate the software. 


\section{Theoretical Rating (LRFR)}

Pressing "Bridge Properties" button Bridge Properties will call a window for users to input the properties of the bridge, such as geometrical properties, material properties, visual inspection and so on. The interface is shown in Figure 2.

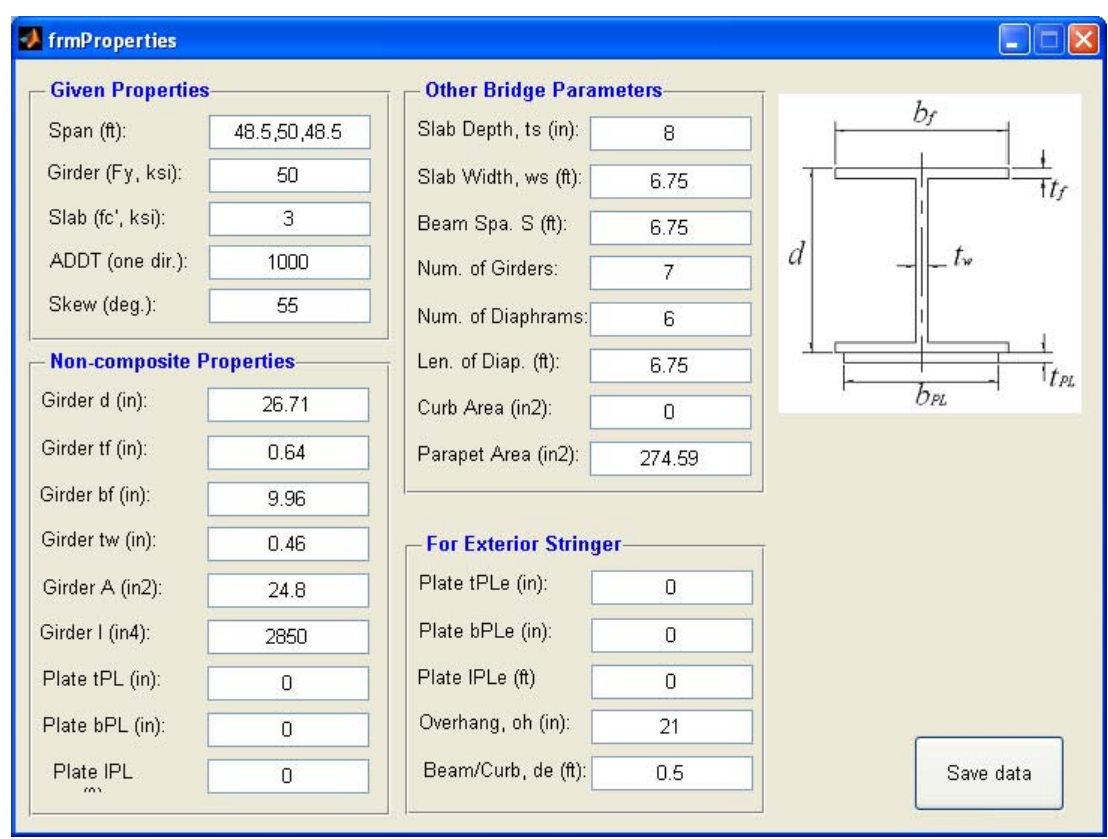

Figure 2. Interface of inputting bridge properties

Pressing "HL93 Load" button HL93 Load will calculate the moments and shears on the bridge under HL93 Load. Depending on the computer, it may take a few minutes for calculation. Results are saved for later rating.

"LRFR Rating" button will do the bridge rating based on the bridge properties, loads and others. The rating factors for interior girders and exterior girders will be obtained.

Pressing the two buttons $R F$ for Interior and RF for Exterior will display rating factors for interior/exterior girders respectively, as shown in Figure 3 and Figure 4. 


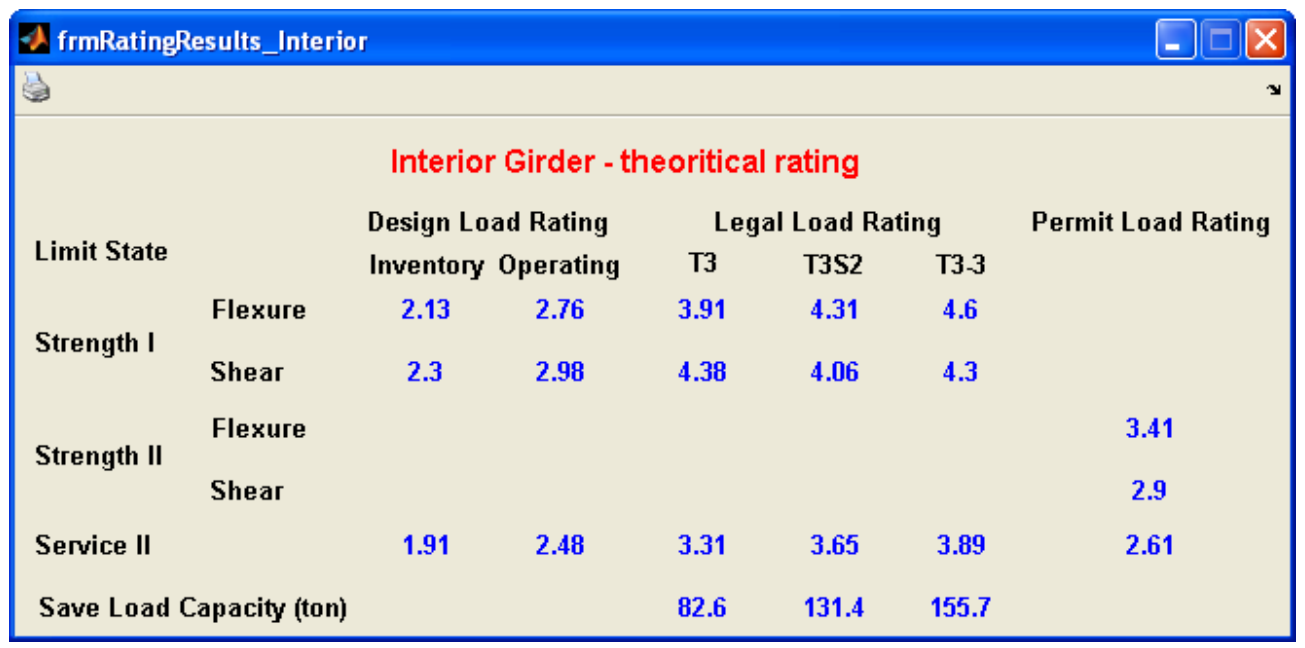

Figure 3. Rating factors for interior girders

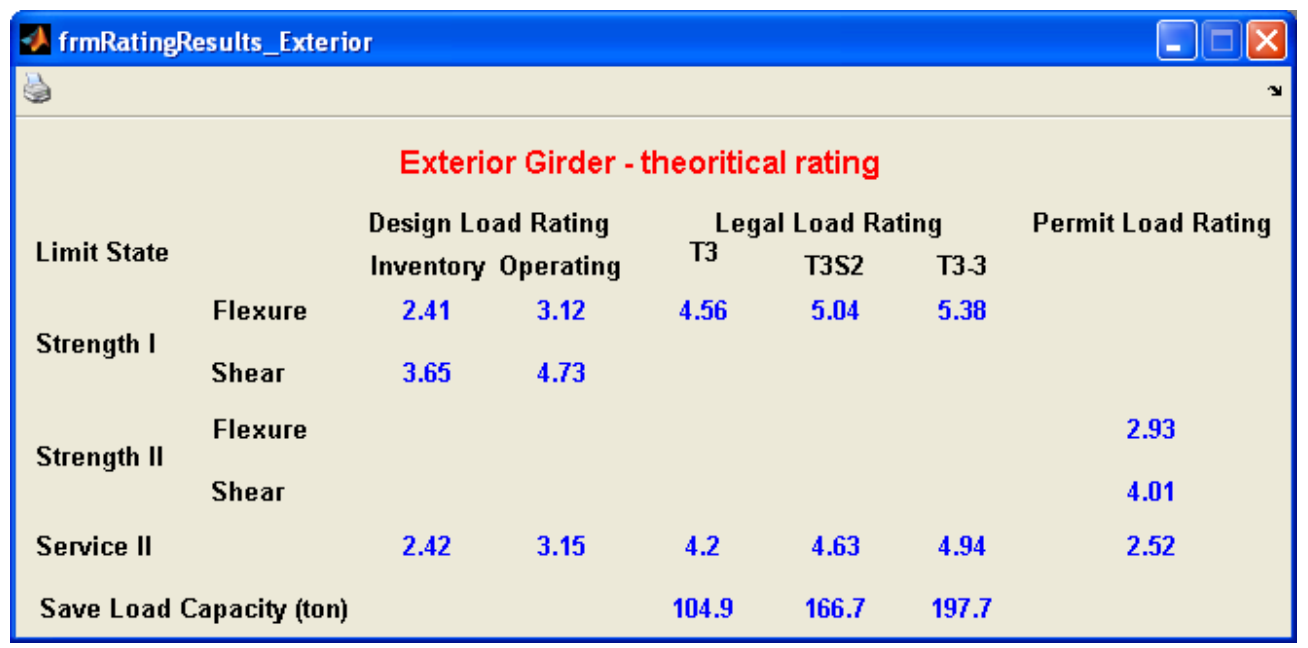

Figure 4. Rating factors for exterior girders

\section{Data Process of Diagnostic Load Test}

By pressing the button "Analysis of Field Test Data"

Analysis of Field Test Data

the interface for processing of field test data will appear, as shown in Figure 5. 


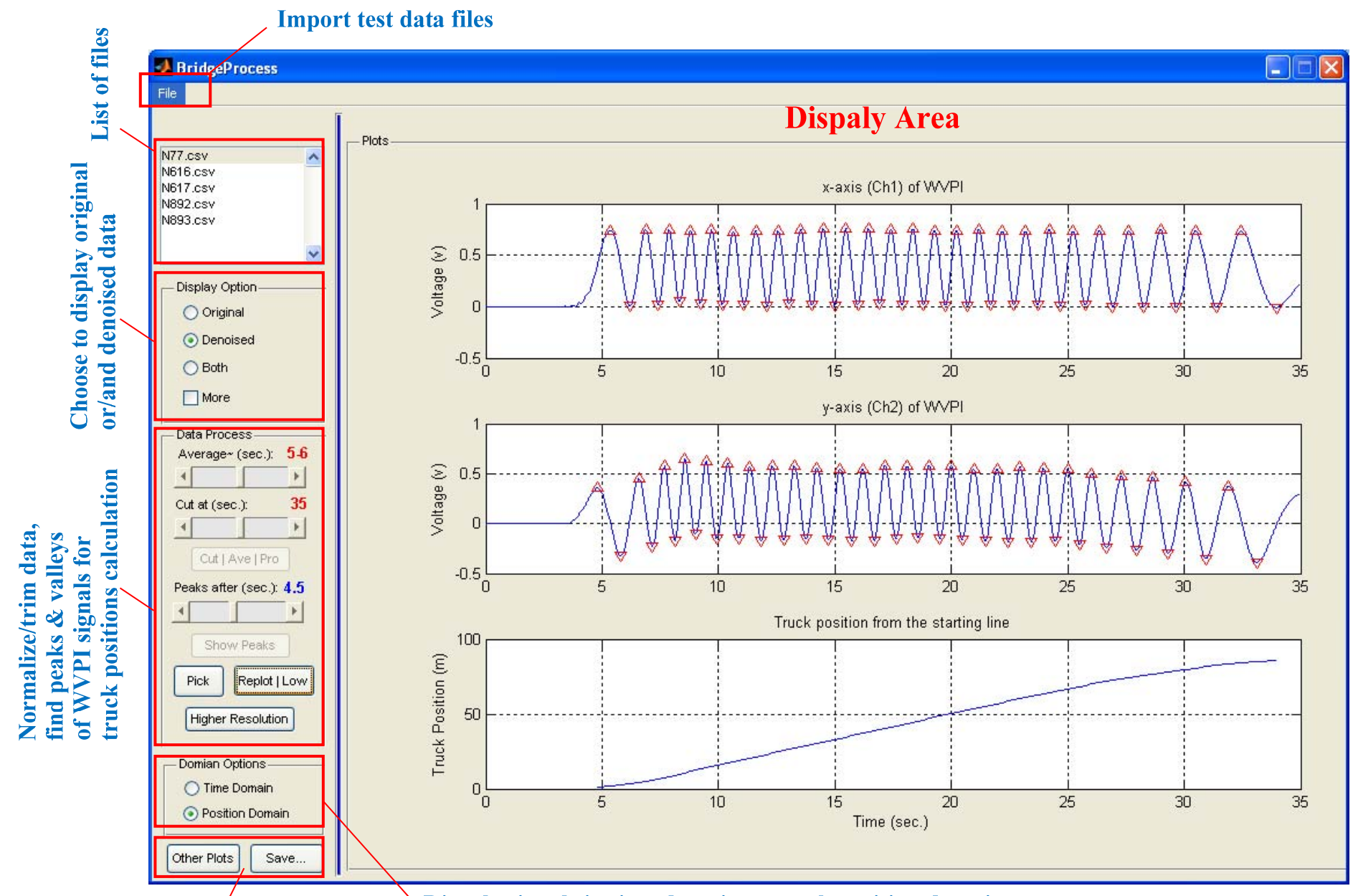

Dispaly signals in time domain or truck position domain

Other plots \& save useful strain data for bridge load rating

Figure 5. Interface for processing of field test data 
First, import test data files through the "File" menu downloaded from the wireless nodes in .csv format, which can be opened by Excel. Signals are denoised after they are imported into MATLAB.

Different display options are provided for users to view the original signals, denoised signals or both.

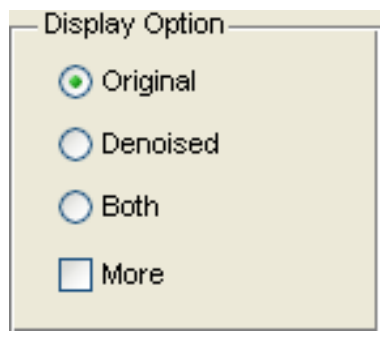

Then, data need to be normalized and trimmed. Users are allowed to define the average range and cutting point after observation of test signals. These settings are effective to all signals.

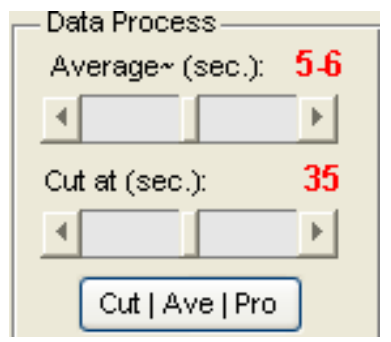

For calculation of truck positions, peaks \& valleys of WVPI signals can be automatically located. In order to avoid calculation errors caused by "fake" peaks \& valleys, users are allowed to manually choose and eliminate these defects.

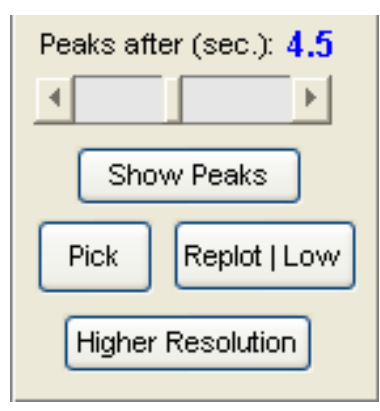

After the truck positions are obtained, strain records in truck position domain can be displayed. 




For each test run, the corresponding processed data should be saved in different name. For example, Run1.mat, Run2.mat, Run3.mat. Stain data are saved for later bridge rating through load testing.

\section{Bridge Rating through Load Testing}

After finishing processing of field test data, more accurate rating factors can be calculated based on the test results. The interface for bridge rating through load testing is illustrated in Figure 6. 


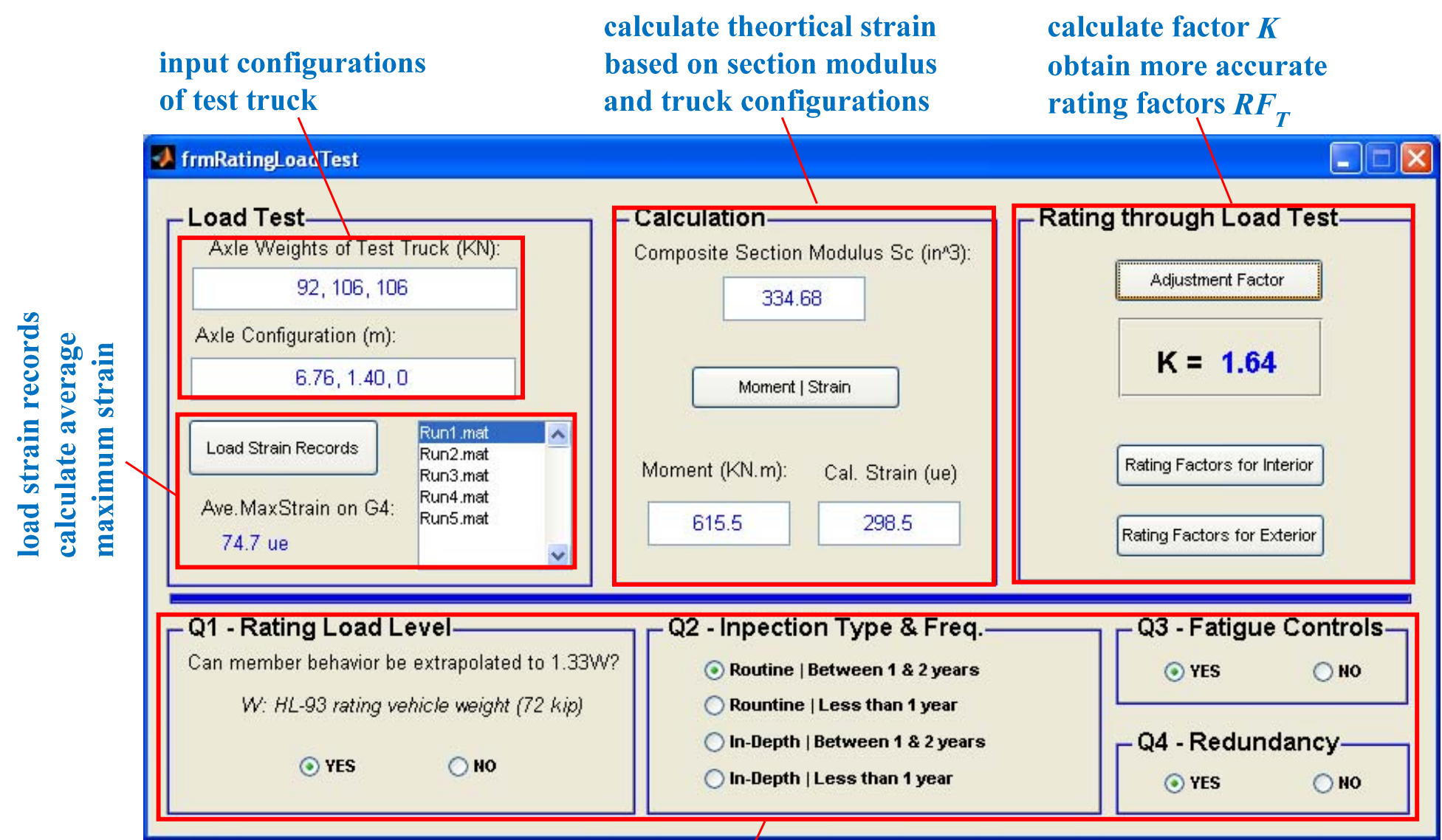

answer questions for rating

Figure 6. Interface for bridge rating through load testing 
Users need to input configurations of test truck (axle weights, axle distances) for calculation of theoretical moments on the bridge.

\begin{tabular}{l} 
Axle Weights of Test Truck (KN): \\
\hline $92,106,106$ \\
Axle Configuration $(\mathrm{m})$ : \\
\hline $6.76,1.40,0$ \\
\hline
\end{tabular}

Meanwhile, average maximum strain on critical girder will be calculated after loading strain records of all test runs.

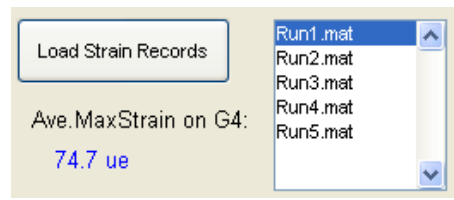

These values, plus section modulus of the bridge, are used to calculate theoretical strain value at the same location.

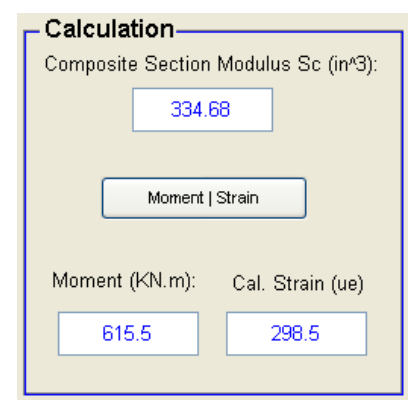

Users need to answer some questions about rating load level, inspection type \& frequency, and fatigue controls.
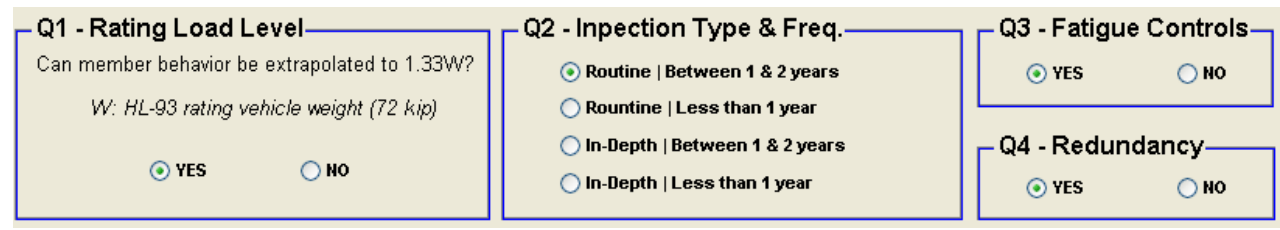

Then the adjustment factor $\mathrm{K}$ will automatically be calculated. Therefore, more accurate rating factors RFT are obtained.

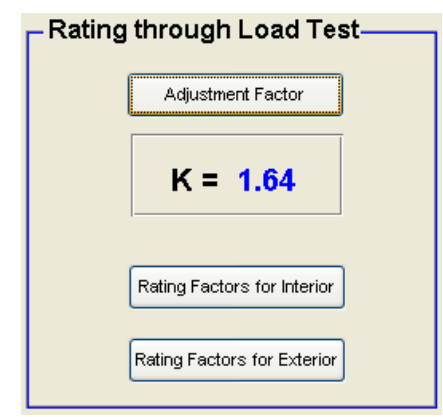

